NAT'L INST. OF STAND \& TECH

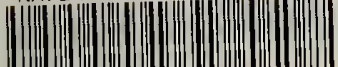

All106 979003

PUBLICATIONS

NBSIR 82-1670

\title{
APPLIED J-INTEGRAL IN HY130 TENSILE PANELS AND IMPLICATIONS FOR FITNESS FOR SERVICE ASSESSMENT
}

D. T. Read

National Bureau of Standards

U.S. Department of Commerce

Boulder, CO 80303

July 1982

100

.456

$32-1670$

1982

c. 2 

D. T. Read

Fracture and Deformation Division National Measurement Laboratory

National Bureau of Standards

U.S. Department of Commerce

Boulder, CO 80303

Sponsored by:

Naval Sea Systems Command

David Taylor Naval Ship R\&D Center

Annapolis, MD

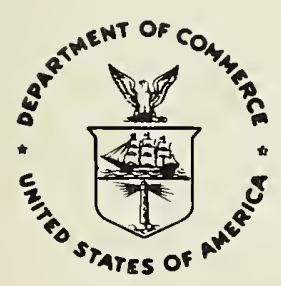

U.S. DEPARTMENT OF COMMERCE, Malcolm Baldrige, Secretary

NATIONAL BUREAU OF STANDARDS, Ernest Ambler, Director 



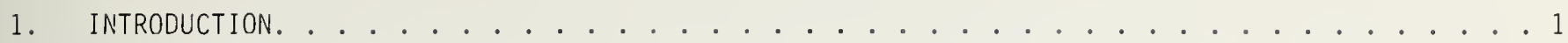

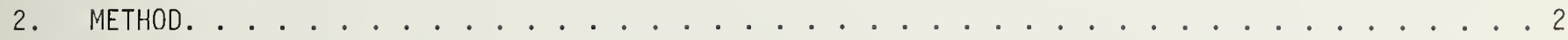

2.1 Arlalytical approach. . . . . . . . . . . . . . . . . . . 2

2.2 Experimental procedure . . . . . . . . . . . . . . . . 4 4

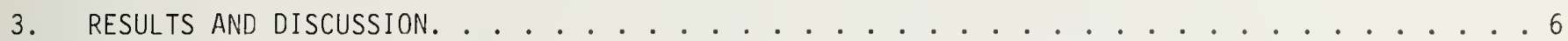

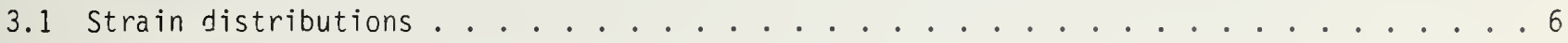

3.2 Strain dependence of J-integral, stress, and crack

mouth opening displacement . . . . . . . . . . . . . . . . . . 8

3.3 Gross section yielding results . . . . . . . . . . . . . . 10

3.4 Implications of present results for fitness-for-

service assessment . . . . . . . . . . . . . . . . . . 12

3.5 surface flaws. . . . . . . . . . . . . . . . . . . . . 14

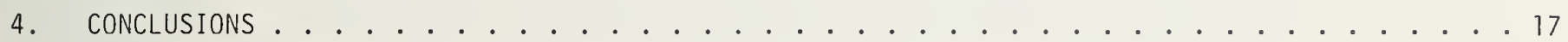

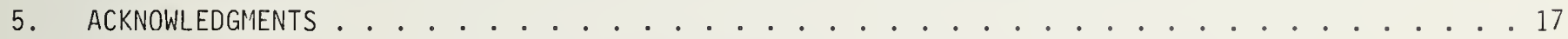

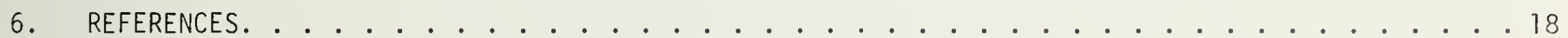

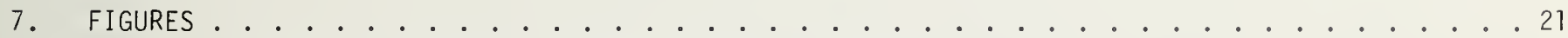

8. APPENDIX. APPLIED J-INTEGRAL VAlUeS IN TENSILE PANELS . . . . . . . . . . . . . 102 


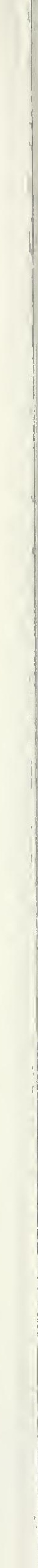




\section{T. Read}

An experimental technique for direct evaluation of the $\mathrm{J}$ contour integral is described. Results are reported and discussed. Some fifteen cracked HY130 tensile panels were tested, including center-cracked, single-edge-cracked, double-edge-cracked, face-cracked, and part-through-cracked configurations. As crack size increased, the post-yield deformation pattern changed from gross section yielding, for very small cracks, to net section yielding, for larger cracks. Net section yielding was associated with much larger J-integral values than gross section yielding. The product of crack mouth opening displacement and yield strength was approximately equal to the J-integral for all cases in the tensile panel geometry used here. The implications of these results for fitness-for-service assessment of practical components and structures containing crack-like defects are discussed. Net section yielding behavior is intolerable in high-performance applications. Gross section yielding behavior can be treated using a J-integral estimation curve derived from the present experimental results. The scatter in the normalized gross section yielding contribution to $\mathrm{J}$ was high, approximately a factor of 2 . This scatter was attributed to specimen imperfections and experimerital problems. The experimentally derived J-integral estimation curve of the present study feli at the top of the range of previously reported curves. Applications of this estimation curve to cases of residual stresses, stress concentrations, and surface cracks are briefly described.

Key words: crack; defect; fitness-for-service; fracture mechanics; gross section yielding; J-integral; net section yielding; surface crack; through crack.

\section{INTRODUCTION}

This report describes experimental evaluation of the J-integral as a function of stress or strairifor through and part-through cracks in tensile panels. The principle of the present method is to measure the integrand terms of $\mathrm{J}$ at suitable intervals along an appropriate contour and then evaluate the integral. Because the resulting $J$ value is based directly on the definition of $J$, no assuniptions about the crack size or the behavior of stress-strain fields produced by the action of the crack tip are necessary. This advantage is crucial in cases of very short cracks, which are of special interest for structural applications. The present method extends previous direct experimental evaluations of the J-integral in metals and composites in the elastic range [1-3] and in rubber [4] to the case of metals in the plastic strain range.

The 3 contour integral has been applied widely in characterizing the fracture toughness of metals [5-7]. But its application to evaluation of structural durability requires knowledge of the material "c value needed in a cracked, structural element subject to stress and strain. The material ${ }^{J} \mathrm{c}$ value needed is the same as the applied J-integral value addressed experimentally in this study. The present study, therefore, is complementary to current work advancing the use of the l-integral for materials characterization; it also extends current knowledge of applied i-integral values beyond

*Contribution of U.S. National Bureau of Standards, not subject to copyright.

This report was prepared as part of the Fracture Control Technology Program under the sponsorship of Dr. H. H. Vanderveldt, Naval Sea Systems Command (SEA 05R15). The effort was directed by Mir. John P. Gudas, David Taylor Maval Ship Ri̊D Center, under Program Element 62761N, Task Area SF-61-544-504. 
the linear-elastic case where well-kriown and widely used handbook solutions [8] for the stress intensity $K$ can be used to calculate the applied J-integral.

\section{METHOD}

The principle of the present method is to obtain the $J$ integral by measuring its integrand terms at suitable intervals along an appropriate contour and then evaluating the integral. The analytical and experimental aspects of the present method for direct experimental evaluation of the $J$ contour integral are discussed separately below.

\subsection{Analytical approach}

The definition of the J-integral as given by Rice [9] is:

$$
J=\int_{\Gamma} \| ! d y-\vec{T} \cdot \partial \vec{u} / \partial x d s \quad,
$$

where $W$ is the strain work density, $\vec{\dagger}$ is the traction vector, $\vec{u}$ is the displacement vector, $x$ and $y$ are Cartesian position coordinates, and $s$ is arc length along the contour. The contour chosen for direct measurement of the J-integral is indicated in Fig. 1 for single-edge-cracked specimens. Because of symmetry about the plane of the crack, only half of each specimen was instrumented. The contour follows specimen free surfaces along the y-direction and traverses the tensile axis at a location away from the crack. For some specimeris, one y-direction contour segment was along the specimen centerline.

Plane stress behavior was assumed all along the contour because no through-thickness applied stresses were present and because the specimen thickness was small compared with its length and width [3].

Evaluation of the two terms of Eq. 1, the work density term, Wdy, and the traction-bending term, $\vec{\dagger} \cdot \partial \vec{u} / \partial x$ ds, for contour segments DC, CGA, and AB (Fig. 2) is now discussed in detail.

The strain work density $W$, given as

$$
W=\int \sigma_{i j} \mathrm{~d} \varepsilon_{i j},
$$

where $\sigma_{i j}$ is the stress tensor and $\varepsilon_{i j}$ is the strain tensor, reduces simply to

$$
W=\int \sigma_{y y} d \varepsilon_{y y}
$$

along $D C$ arid $A B$ because all stress components except $\sigma_{y y}$ are zero for these contour segments along free surfaces in plane stress. Below yield, $\sigma_{y y}$ is given simply by $\varepsilon_{y y} / E$ (where $E$ is Young's moduius) agair because all stresses except $\sigma_{y y}$ are zero. For the same reason, the yield criterion becomes, $\operatorname{simply}, \varepsilon_{y y} \cdot E>\sigma_{y}$, where $\sigma_{y}$ is the yield strength, and the stress $\sigma_{y y}$ depends on the strain $\varepsilon_{y y}$ just as the longitudinal stress depends on the longitudinal strain in a simple tensile bar. A stress-strain curve from a smooth-bar tensile test of the specimen material was found to be wel.1 approximated by an elastic-perfectly-plastic stress strain law. This bilinear stress-strain relation, in the form 


$$
\begin{array}{ll}
\sigma_{y y}=\varepsilon_{y y} E, & \text { for } \varepsilon_{y y}<\sigma_{y} / E \\
\sigma_{y y}=\sigma_{y}, & \text { for } \varepsilon_{y y}>\sigma_{y} / E
\end{array}
$$

was substituted into Eq. 3. The resulting expressions for $W$, $W=E \varepsilon_{y y}^{2} / 2$, for $\varepsilon_{y y}<\sigma_{y} / E$ $W=\sigma_{y}^{2} / 2 E+\sigma_{y}\left(\varepsilon_{y y}-\sigma_{y} E\right) \quad$ for $\varepsilon_{y y}<\sigma_{y} / E$,

were used in the evaluation of the integrand of Eq. 1 along contour segments $D C$ and $A B$. The traction vector, $\neq$, is zero along contour segments $D C$ and $A B$ because they are on free surfaces, so the second term of the integrand of Eq. 1 is zero for these segments.

Along segment CGA, dy is zero because this segment is parallel to the $x$-axis. Therefore the first term of the integrand of Eq. 1 does not contribute. The traction $\vec{f}$ at the contour can be expressed as $T_{j}=\sigma_{i j} n_{j}$, where $n_{j}$ is the unit vector outward normal to the contour. Along segment CGA, $n_{j}$ is the unit vector outward normal to the contour. Along segment CGA, $n_{y}=1$ and $n_{x}=0$ so $T_{y}=\sigma_{y y}$ and $T_{x}=\sigma_{x y}$. The shear stress, $\sigma_{x y}$, was assumed to be negligible for this contour segment chosen to be away from the crack. The $x$-component of $\vec{u}$ along CGA, $u_{x}$, was assumed to be negligible because no source for such a displacement component was present. Therefore, the integrand in Eq. 1 reduces to $T_{y} \cdot \partial u_{y} / \partial x$ for contour segment CGA. The traction, $T_{y}$, was calculated from strains measured by strain gages between $C$ and $G$ and $G$ and $A$ (Fig. 2) using the stress-strain relation of Eq. 4 above, which applied because all stress components except $\sigma_{y y}$ were insignificant along CGA. The traction, $T_{y}$, all along $C G$ was assumed to be the value calculated from the strain gage between $C$ and $G$. The bending term, $\partial u_{y} / \partial x, a l l$ along $C G$ was approximated by

$$
\partial u_{y} / \partial x=\left[u_{y}(G)-u_{y}(C)\right] /[x(G)-x(C)] \quad .
$$

The value of $u_{y}(G)$ was obtained as half the displacement measured by the linear variable differential transducer (LVDT) mounted between points $G$ and $H$. In similar fashion, $u_{y}(C)$ was obtained from the LVDT mounted between points $C$ and $E$. The quantities $x(G)$ and $x(C)$ were simply the $x$ coordinates of points $C$ and $G$. The traction-bending term, $T_{x} \cdot \partial u_{y} / \partial x$, along segment $C G$ was calculated using $T_{y}$ and $\partial u_{y} / \partial x$ obtained as described, and the traction-bending term along segment GA was calculated similarly.

Strain values needed for calculation of the work density, $W$, were available at only a limited number of locations along contour segments $D C$ and AE. Therefore the integral of Eq. 1 could only be evaluated approximately. Two different approximation methods were tried. The first method was direct numerical integration (no-fit procedure). Segments $D C$ and $A B$ were divided into increments each containing one strain gage. The contribution of each increment to the integral was taken to be the product of the strain energy density, calculated from the measured strain value using Eq. 5, multiplied by the increment length. Because of the sense of the contour integration, increment lengths along $D C$ were taken to be positive, and those along $A B$, negative. The second method for evaluating the integral of Eq. 1 was to fit the measured strain values along segment $D C$ or $A B$ to $a$ polynomial or selected nonlinear function of distance $y$ from the crack plane; the strain values given by the fitting functions were then used to calculate work density values, using Eq. 5, at 
many locations a long segments $D C$ or $A B$ so that conventional numerical integration could be used to evaluate Eq. 1 along these segments. Functions were selected and evaluated according to how well they reproduced the observed dependence of strain on position. Strain values from strain gages were available at approximately eight locations along both segments $C D$ and $A B$. In addition, qualitative indicatiors of the dependence of strain on position were obtained from brittle lacquer coatings on the specimen surfaces. Third-and-fourth order polynominals expressing strain $\varepsilon_{y y}$ as a function of distance, $y$, from the crack plane achieved a compromise between fitting the measured strain values and modeling the qualitative dependence of strain or position. Fifth- and sixth order polynominals fit the measured values more closely, but introduced spurious maxima and minima into the position dependence of the strain. The nonlinear functions were chosen to provide a better fit to the measured strain values without introducing spurious maxima and mirima. The functional forms used were: on segments $D C$,

$$
\varepsilon_{y y}=a_{1} \exp \left(-a_{2} y\right)+a_{3}+a_{4} y+a_{5} y^{2} \quad ;
$$

and on segments $A B$,

$$
\varepsilon_{y y}=a_{1} \exp \left(-z^{2} / 2\right)+a_{4}+a_{5} y+a_{6} y^{2}
$$

The $a_{j}$ were coefficients to be fitted and $z=\left(y-a_{2}\right) / a_{3}$. These functions allowed modeling of the low strain region near the crack mouth on contour segment $A B$ and the peak in strain on segment $D C$ where a deformation band emanating from the crack intersected the specimen surface.

The analytical strategy just discussed was applied to experimental data obtained as described below.

\subsection{Experimental procedure}

The specimen material used in the present study was HYl30 steel; the plate used had a yield strength of $933 \mathrm{MPa}$ and a tensile strength of $964 \mathrm{MPa}$. The chemical composition of the plate used is listed in Table 1. Engineering stress-strain curves obtained using round bar tensile specimens with gage section $6 \mathrm{~mm}$ in diameter by $25 \mathrm{~mm}$ long, Fig. 3, showed that the specimen material was nearly elastic-perfectly-plastic. The stress rose only 2 percent between 1 and 5 percent strain. i-integral resistance curves ( $3-R$ curves) obtained using the unloading compliance technique on side-grooved compact tensile specimens $25 \mathrm{~cm}$ thick are shown in Fig. 4. Also shown for comparison is a J-R curve obtained from a face-cracked tensile panel $25 \mathrm{~mm}$ thick by $90 \mathrm{~mm}$ wide by $300 \mathrm{~mm}$ 1ong, with initial crack length $4 \mathrm{~mm}$. The difference between J-R curves from the two specimen types is caused by differences in crack tip constraint, as discussed in a later section. Fin-loaded tensile panels with gage sections $30-\mathrm{cm}$ long by $9-\mathrm{cm}$ wide by $1-\mathrm{cm}$ thick were used for most tests. Larger-scale tests were performed in wedge-gripped center-cracked panels with gage sections $84 \mathrm{~cm}$ 1ong by $56 \mathrm{~cm}$ wide by $2.5 \mathrm{~cm}$ thick. Saw-cut notches were usually used instead of fatigue cracks to postpone tearing (in a 11 but the two cases where fatigue precracks were used). Figure 5 indicates the configurations of the 15 specimens covered in this report. Figures 6 through 12 give details of the instrumentation of seven specimeris representative of each design. Similar instrumentation was used on the other specimens of each design.

As indicated in Figs. 6 through 12, the strain gages were concentrated rear the crack mouths and on the opposite side of the specimen at a location offset from the crack plane by a distance on the 
order of the length of the uncracked ligament. These two locations were the sites of significant features of the strain distribution.

Table 1. Chemical compositions by weight percent and treatment for HY130.

Chemical Composition, weight percent:

$\frac{\mathrm{Ni}}{5.00} \frac{\mathrm{Cr}}{0.42} \frac{\mathrm{Mo}}{0.53} \frac{\mathrm{V}}{0.043} \frac{\mathrm{C}}{0.11} \frac{\mathrm{Mn}}{0.76} \frac{\mathrm{P}}{0.005} \frac{\mathrm{Si}}{0.03}$
$\frac{\mathrm{S}}{0.004} \frac{\mathrm{Cu}}{0.022} \frac{\mathrm{Al}}{0.021} \frac{\mathrm{Co}}{0.02} \frac{\mathrm{Ti}}{0.008} \frac{\mathrm{Fe}}{\mathrm{bal}}$

Treatment: Austenitized, quenched, tempered, quenched.

Very small gages (four or five independent gages on a single backing sheet, active length of about $0.75 \mathrm{~mm}$ each, gage centers about $1.4 \mathrm{~mm}$ apart) were used near the mouth of short cracks. Linear variable differential transducers (LVDTS) were used to measure relative displacements of the ends of the gage sections. A clip-on gage was mourited in the crack mouth to measure crack mouth opening displacement $(C M O D)$. Each specimen was coated with brittle lacquer or photoelastic plastic to reveal strain patterns. The strain patterns produced were suitable for recording by photography.

A servohydraulic testing machine with a load capacity of 1 MN was used. The tests were run in displacement control. An analog-to-digital (A-D) conversion system with a 16-bit resolution was connected to the strain gages, LVDTs, testing-machine load cel1, and CMOD gage. The A-D converter was connected to a minicomputer system. The minicomputer system consisted of a processor, a duai floppy-disk data-storage unit, a digital plotter, and a printer.

The servohydraulic testing machine was controlled manually, but the data acquisition, on-line analysis, storage, printing, and plotting for each data point were controlled by the minicomputer. For each deformation increment, each sensor was polled and its signal was converted from electrical to physical units and stored on floppy disk. Then the J-integral was calculated by direct numerical integration as described above. The J-integral, stress, CMOD, average strain (defined below), measured displacement, and measured strain values were printed. Finally, each strain-gage output was plotted on a bar graph, and the calculated J-integral value was plotted against average strain. (The bar graphs of strain provided real-time indications of proper functioning of individual strain gages and the yielding of different parts of the specimen, but were not used for data analysis.)

Average strain $\bar{\varepsilon}$, also referred to as gage length strain, was calculated as

$$
\bar{\varepsilon}=\left(V_{C E}+V_{G H}+V_{A F}\right) / 3 L=\Delta L / L
$$

where $V_{C E}$ is the displacement measured by the LVDT mounted between points $C$ and $E$ and similarly $V_{G H}$ and $V_{A F}$ are displacements measured by the other two LVDTs. $L$ is the y-direction distance between contour segments CGA and EHF and represents the specimen gage length. The measured displacements, and therefore $\bar{\varepsilon}$, included both contributions from the strain field of the crack and contributions from 
the strain that would have existed in the absence of the crack. A consistency check on this calculation of $\bar{\varepsilon}$ was made by integrating measured strains along y-direction contours. The two methods gave identical values at low strains. At high strains, disagreement occurred, usually indicating strain gage failure.

In the course of a typical test, first the instrumented specimen was mounted in the testing machine, and all of the instrumentation was connected and checked for proper function. When all the apparatus was performing properly, a zero-load data point was taken, and the specimen was extended by a preselected amount. Then the computer was allowed to proceed through the data acquisition-storagecalculation-print-plot procedure described above. The specimen was then extended further and the procedures repeated. The strain patterns revealed by the brittle lacquer coating were photographed periodically throughout the test. Tests were terminated for two reasons: specimen tearing or gage failure. Tearing occurred before strain-gage failure for specimeris with large cracks.

About one hundred data points, each consisting of about twenty-five measured strain values, three displacement values, one CMOD value, and one load value, were obtained during a typical test. The maximum average strain (defined above) attained during a test ranged from around 1.5 times yield for relatively deep cracks to near 9 times for shallow cracks.

\section{P.ESULTS AND DISCUSSION}

The experimental results are presented and discussed in separate sections on: strain distributions; strain dependence of J-integral, crack mouth opening displacement (CMOD), and stress; detailed discussion of gross section yielding (GSY) results; implications of present results for fitness-for-service assessment; and surface flaws. The primary measured quantity in this study was strain as a function of position, obtained from strain gage data. The character of the strain distributions controlled the behavior of the J-integral. Crack length controlled the form of the strain distributions. Two general types of strain distributions occurred, resulting in two general forms of the dependence of J-integral on strain. The quantities measured in this series of experiments allowed study of the strain dependence of J-integral, stress, and CMOD. These data are presented graphically for seven representative specimens. The unifying concept for all these experimental results is that net section yielding (NSY) produces high J-integral values and GSY produces low values. Because only the GSY case is appropriate to an estimation-curve approach to fitness-for-service assessment, the GSY results are discussed separately. Average and upper-bound curves representing the dependence of J-integral on strain and crack length are extracted from the data for the one specimen with GSY and the three specimens with combiried GSY ano NSY. Methods of applying the upper bound of the present results as a fitness-for-service assessment curve for through cracks are discussed. Surface crack behavior is more complex than through-flaw behavior. Yielding of the ligament behind a surface crack produces an intermediate characteristic dependence of J-integral on applied stress between contained plasticity and general (gross or net section) yielding. A three-step procedure for estimating applied J-integral values, which accounts for contained plasticity, ligament yielding (LY), and GSY is described.

\subsection{Strain distributions}

Strain distributions in HY130 tensile panels were obtained both from strain gages (quantitative information) and from brittle lacquer and photoelastic coatings (qualitative information). Strain distributions measured by the strain gages are plotted in Figs. 13 through 19. These figures show the longitudinal strains parallel to the tensile axis plotted against distance from the plane of the 
crack for seven representative specimens. For most specimens, data from three different scans of the strain gages are plotted, one just before yield, one after some yielding, and one after considerable yielding. Specific strain levels are indicated in the plots. Two measures of the strain level are given, gage length strain and remote strain. Gage length strain was defined earlier in Eq. 9 . It is the change in the gage length divided by the original gage length. Remote strain is the strain measured by a strain gage remote from the crack. The difference between gage length strain and remote strain is a measure of the strain concentration introduced by the crack. This strain concentration is significant for plastic strains for specimens with cracks larger than approximately one percent of the cross section.

In the scans before yield (nominal yield strain for HY130 is 0.0045 ), strain distributions along contour segments on the uncracked sides are uniform just as would be the case if no cracks were present. The crack sizes were not large enough to influence the strain distributions away from the crack for the specimens described by Figs. 13 through 19. The face-cracked specimen (Figs. 9 and 16) was an exception to this behavior pattern. This crack was sufficiently deep that bending reduced the strain opposite the crack. On the cracked contour segment "strain shadows" of the cracks can be seen. A crack forms a free surface perpendicular to the tensile direction, so the stress in this direction vanishes at the crack mouth. Therefore the strains near the crack mouth are low. Far away from the crack, the strain has the value it would have had everywhere in the absence of the crack. The strain shadow is localized around the crack mouth. The extent of the strain shadow varies with the size of the crack. The strain shadow occurs both before and after yield, as can be seen in Figs. 13 through 19.

In the strain gage scans after yield, a new feature of the strain distribution appears on the contour segments opposite the crack: a hump or spike of high strain offset from the crack plane by approximately the length of the uncracked ligament (Figs. 13-19). These strain spikes result from deformation bands that emanate from the crack tip and extend to the opposite side of the specimen. The deformation band is a localized region of high strain. In the coordinate system with axes parallel and perpendicular to the specimen axes, the strain in the deformation band is an extensional strain along the tensile axis and a compressional strain perpendicular to the tensile axis. The strain transverse to the axis was not detected by the axial strain gages. Strains transverse to the tensile axis do not contribute to the J-integral along free surfaces because stresses transverse to the tensile axis are zero at free surfaces. (In some specimens contour segments lying parallel to the tensile axis did not fall along free surfaces. Some transverse strain gages were used in such cases. These indicated strains small enough so that corrections to the J-integral were not usually needed. A transverse strain contribution was included in the $\mathrm{J}$-integral for the large, center-cracked panel with $a=5 \mathrm{~mm}$.) The occurrence of deformation bands for postyie 7 d strairis was also clearly shown by the brittle lacquer and photoelastic coatings (Figs. 20-26).

Postyield strain patterns for cracked tensile panels have been divided into two general types: net section yielding (NSY) and gross section yielding (GSY) [10,11]. Panels with liSY have deformation bands, panels with GSY do not. In NSY, the specimen segments outside the deformation bands move as rigid bodies. Displacements applied at the specimen ends are transmitted fully to the crack through the deformation bands. The change in CMOD is Equal to the change in the relative displacment of the specimen ends. The specimen segments cutside the deformation bands remain at or below yield strain, while high strains occur within the deformation bands. This behavior is apparent in most of the strain distribution plots, Figs (13-19).

If the crack is small enough so that plastic strain is distributed uniformly all along the specimen length, no deformation band is formed and GSY occurs. Of the through-cracked specimens 
tested in this program only the single-edge-cracked specimen with a 1-mm crack formed no deformation band. The strain distributions in this specimen are plotted in Fig. 27; brittle-lacquer representations of its strain patterns are shown in Fig. 28. These figures show that in this specimen no NSY occurred and that GSY did occur. Experimental problems with this test were caused by the small crack size and instrumentation malfunctions. But the GSY behavior of this specimen was clear. The singleedge-cracked specimen with a crack length of $2 \mathrm{~mm}$, the double-edge-cracked specimen, and the large center-cracked specimen with a half-crack length of $5 \mathrm{~mm}$ exhibited a combination of NSY and GSY. In these specimens deformation bands were formed, but the strains remote from the crack reached levels well above yield because the cracks were small and the deformation bands strain-hardened enough to compensate for the missing cross-sectional area in the crack plane.

From an examination of data from all tested specimens including those with part-through cracks, it is concluded that crack area must be restricted to 1 percent or less of total specimen crosssectional area to avoid NSY in HY130 tensile panels.

3.2 Strain dependence of J-Integra 1, stress, and crack mouth opening displacement

The strain dependence of the J-integral, stress, and CMOD are presented in Figs. 29 through 35 for seven representative specimens. Each of these figures consists of eleven separate graphs that present relationships between measured quantities. They are:
a. J-integral plotted against gage length strain
b. J-integral plotted against remote strain
c. J-integral plotted against stress
d. Stress intensity factor plotted against stress
e. Stress plotted against gage length strain
f. Stress plotted against remote strain
g. Gage length strain plotted against remote strain
h. Crack mouth opening displacement plotted against gage length strain
i. Crack mouth opening displacement plotted against remote strain
j. Crack mouth opening displacement plotted against stress
k. J-integral plotted against crack mouth opening displacement

These figures, along with Figs. 6 through 28 , provide a very complete and detailed description of the response of cracked HY130 tensile panels to imposed strains. The key theme that unifies all these experimental results is the effect of yielding pattern on $\mathrm{J}$ and on CMOD. Net section yielding produces high "? and CMOD values, gross section yielding produces low values. The plots are discussed individually for the first specimen of the series. The remaining specimens all demonstrated similar behavior.

For each of the seven specimens chosen as typical, a graph of J-integral plotted against gage length strain (for example, Fig. 29a) is shown. The behavior of these curves is parabolic, at strains below yield, and linear, at strains above yield. The parabolic part below yield is accounted for by linear elastic fracture mechanics. The linear part at strains above yield is the region of interest here. This region of the j-integral vs. gage length strain curve is linear for both net and gross section yielding. To distinguish NSY from GSY, the plot of J-integral vs. remote strain (Fig. 29b for the center-cracked panel with crack half-length $4 \mathrm{~mm}$ ) is helpful. Note that in Fig. $27 \mathrm{~b}$ the remote strain remains near yield while the J-integral increases rapidly. "For similar values of $j$, the gage length strain reached twice yield. This behavior difference indicates that displacements imposed at the specimen ends are being transmitted to the crack tip, steadily 
increasing the J-integral. Because these displacements are not absorbed as plastic strain away form the crack, the remote strain does not increase. This is the signature of net section yielding. If NSY were to occur in a structure, increases in J-integral could occur at constant strain because the strain considered in a structure is the remote strain, not the strain at the crack. The imposed displacement needed to increase $\mathrm{J}$ to critical levels is about $1 \mathrm{~mm}$ or less, too small to be noticed $i$ For continuity with linear elastic fracture mechanics, the J-integral can be converted to stress intensity factor in the usual way and plotted against stress, as in Fig. 29d for the first specimen of the series. This particular specimen had high scatter in its stress intensity factor vs. stress plot, as can be seen by reference to the other plots of these quantities, Figs. 30d through $35 \mathrm{~d}$. The results were a linear dependence of stress intensity factor on stress below yield with experimental error superposed. In Fig. 29d, the theoretical linear elastic stress intesnity factor is shown as a solid line. The experimental techniques and crack sizes used here were aimed at behavior in the plastic strain range, not at the we11-known, well understood linear elastic behavior. Some significant experimental errors occurred in the elastic range. These errors were lower in the plastic range, because of the larger and more easily measured strains in the plastic range. These experimental errors are evident in several of the plots of stress intensity factor against strain. They were accepted in order to concentrate the experimental effort on understanding the behavior in the plastic strain range. The plots of stress intensity factor against stress show that as stress approaches yield strength, stress intensity factor increases more rapidly, indicating increasing plastic zone size.

The plots of stress vs. gage length strain (Fig. 29) for the first specimen of the series) clearly show the nearly elastic-perfectly-plastic nature of HY130 in the strain range considered here. The plots of stress vs. remote strain (Fig. $29 \mathrm{f}$ for the first specimen of the series) emphasize again that very little remote yielding occurs in NSY. Perhaps the clearest method of distinguishing GSY from NSY uses a plot of gage length strain against remote strain (Fig. $29 \mathrm{~g}$ for the first specimen of the series). For NSY, the two strains increase together in the elastic strain range; but after yield the gage length strain continues to increase but the remote strain does not, so the data points form a nearly vertical 1ine. If GSY had occurred, the two strains would continue to be nearly equal above yield.

For each set of results plotted, it can be seen that the dependences of CMOD on gage length strain, remote strain, and stress (Figs. $29 \mathrm{~h}-29 \mathrm{j}$ for the first specimen of the series) parallel those of the J-integral. This is not surprising because it is well known that the crack tip opening displacement (CTOD) is closely related to $J$ and is an alternate measure of the driving force for fracture under plastic strain. In the tensile geometries studied here, CMOD and CTOD seem to be increasing at the same rate in the plastic strain range. The J-integral $J$ is plotted against CMOD for the seven typical specimens (Fig. 29k for the first one of the series). For these specimens, it can be seen that the approximation

$$
J \sim \sigma_{y} \cdot C M O D
$$

holds, where $\sigma_{y}$ is the material yield strength. A line showing the locus $J=\sigma_{y}$ CMOD in Figs. $29 \mathrm{k}$ through 35K shows the accuracy of Eq. 10. This finding improves confidence in the J-integral results because CMOD is a much simplier quantity to obtain experimentally.

For the case of the edge-hole-cracked specimen, the J-integral should be correlated with the strain at the hole in the absence of the crack. The presence of the crack prevents measurement of this strain. It can be calculated by application of Neuber's rule [12], given below in Eq. 14 . 
Plots of J-integral and CMOD against Neuber strain ard Neuber stress are given in Fig. 33. The relationship between the behavior of a crack at a stress concentration and a crack in a tensile panel in GSY is discussed later in $\$ 3.4$.

The spectrum of behavior from NSY for long crack lengths to GSY for short cracks is most fully illustrated by the five single-edge-cracked specimens [13]. Their J vs. strain behavior is plotted in Figs. 36 and 37. Note that the increase in crack length from $1 \mathrm{~mm}$ to $20 \mathrm{~mm}$ did nore than simply raise the $]$-integral in the plastic strain range: it actually prevented the specimens with cracks $4 \mathrm{~mm}$ long and longer from reaching remote strains above yield (Fig. 38). For NSY, J increases with imposed displacement at a constant level of remote strain. The specimen with the $1 \mathrm{~mm}$ crack reached remote strain levels well above yield with low J-integral values. A similar effect is shown by the comparison of the large center-cracked panels (Fig. 39). The panel with the $16 \mathrm{~mm}$ crack never reached remote strains above yield. From these results it can be concluded that for a high-performance component which must survive tensile strains above yield, NSY must be avoided.

\subsection{Gross section yielding results}

The experimental results for through-cracked specimens with GSY are crucial for formulating a fitness-for-service assessment method. Net section yielding must be handled separately arid in any case is unacceptable in high performance structures. The single-edge-cracked specimen with a $1-\mathrm{mm}$ crack was the only specimen with GSY without any NSY. The specimens with combined GSY and NSY were the single-edge-cracked specimen with a 2-mm crack and the double-edge-cracked specimen with 2-mm cracks, both $90-\mathrm{mm}$ wide, and the center-cracked-specimen with half-crack-length 5 -mm, width $560 \mathrm{~mm}$, and thickness $25 \mathrm{~mm}$. A fitness-for-service assessment curve was derived from the data from these specimens. Previous J-integral estination curves [14-16] plotted normalized J-integral against normalized strain. The normalization equations used were

and,

$$
\text { Normalized }] \text {-Integral }=j=E J /\left(\pi a \sigma_{y}^{2}\right) \text {, }
$$

$$
\text { Normalized strain }=e=\varepsilon / \varepsilon_{y}
$$

where $E$ is Young's modulus, a is crack length (usual fracture mechanics usage), $\sigma_{y}$ is material yield strength, and $\varepsilon_{y}$ is the nominal yield strain given by $\sigma_{y} / E$. The key normalization operation in Eq. 11a is that J-integral is divided by crack 1ength; all the other parameters are material properties independent of crack length or specimen geometry. The appropriate strain for Eq. 11 is remote strain, $\varepsilon_{r}$ for GSY. For GSY, the J-integral is proportional to the extent of the strain shadow around the crack mouth. Because in HY130 the stress is essentially constant above yield, the strain work density reduces approximately to the product of yield strength and strain for strains well above yield. The J-integral is the difference between cracked and uncracked sides of the strain work density integrated over y position, as indicated in Fig. 40. The yield strength factors out, so that J-integral is proportional to the difference between cracked and uncracked sicies of strain integrated over y position. The strain on the uncracked side is simply the remote strain, for a tensile parel; so the i-integral is approximately proportional to the area of the strain shadow on a plot of strain against position.

For purposes of evaluating the i-integral, the strains near the crack mouth for each specimen were fitted by an exponential function given in Eq. 7 above. To obtain a fitness-for-service curve 
representative of all the experiments with GSY, strain data for these specimens was fitted to the function:

$$
\varepsilon(y) / \varepsilon_{r}=1-\exp (-g y / a)
$$

where $\varepsilon(y)$ is strain at a distance $y$ from the crack mouth, $\varepsilon_{r}$ is remote strain, and $g$ is the fitting parameter. The parameter $g$ was allowed to vary with $\varepsilon_{r}$. Normalization of $\varepsilon_{r}$ was performed according to Eq. 11b. A plot of $\varepsilon(y) / \varepsilon_{r}$ against $y / a$ for the normalized strain interval from 1.5 to 2 for the four specimens with GSY and the fitting function of Eq. 12 is shown as Fig. 4l. J-integral values were calculated from the strain dependence of Eq. 12 using the definition of J in Eq. 1 , with tractionbending terms assumed to be negligible for GSY. The resulting i-integral values were normalized according to Eq. 11 a and plotted against normalized remote strain in Fig. 42 .

As indicated by Figure 41, the normalized J-integral vs. strain curves for the individual experiments exhibited a high degree of scatter. Figure 43 shows the behavior of the individual specimens. The line in Fig. 43 labeled "four-specimen average" is a linear least squares fit to the postyield data of Fig. 42. The scatter amiong the data of Fig. 43 might be a result of variability of specimen material properties and possible experimerital error in measured strain values. This scatter may also be a result of the inadequacy of Eq. 12 to represent the dependence of strain on position for specimens of two sizes with three crack geometries. Neither solid mechanics calculations nor numerical analysis has successfully calculated the specific form and slope of the normalized J-integral vs. strain curve for GSY for any crack geometry or specimen size. The data and analysis of the present study show that a single curve can approximately represent the dependence of applied J-integral on strain for all crack geometries and specimen sizes in HY130, as long as only GSY occurs. Such a curve should be regarded as a good first-order approximation.

The data for the double-edge-cracked specimen in Fig. 43 form the lower bound of the experimentally observed GSY behavior. This specimen had the largest ratio of crack size to specimen width of the four through-cracked specimens with GSY. Large relative crack sizes tend to favor NSY. Therefore, one might suspect that the extraction of the GSY 1-integral behavior was less accurate for this specimen than for the others. This data set is lower than any theoretical predictions. Therefore use of this data set as the basis of a fitness-for-service assessment curve cannot be supported at present.

The nature of GSY behavior may be relevant to the scatter of data in Fig. 43. In GSY, the crack is so small that it does not control the specimen behavior. Other variables such as local variability of flow strength, imperfections in specimen machining, or perturbation of the strain distribution by the gripping apparatus may be capable of producing variability in applied $\mathrm{J}$ values. Such variability would also occur in practical applications. Previous experimental attempts [17] to verify the Burdekin-Dawes [14] crack opening displacement (COD) design curve have been subject to more scatter than the present study; the experimental method used was totally unrelated to that of the present study.

The data of Fig. 43 can be compared with previous fitness-for-service assessment curves[14-16]. The fitness-for-service curve considered representative of the data of Fig. 43 is the experimental upper bound. Figure 44 shows previous J-integral estimation curves. Quantitative comparison can be 
made by expressing the upper-bound curve of Fig. 43 as an equation relating normalized $\mathrm{l}$-integral, $j$, to normalized strain, e:

$$
\begin{aligned}
& j=2 e^{2}, \quad e \leq 1 \\
& j=2+4(e-1), \quad e>1
\end{aligned}
$$

The key element of these equations is the number that multiplies the term (e-1) in Eq. 13b. This number gives the rate of increase of normalized J-integral with normalized strain in the plastic strain range. This rate is the slope of a normalized applied J-integral vs normalized strain plot. The range of previous estimates [14-16] of this quantity is 2 to 4; see Fig. 45 (Turner's [16] value of 5 applies only over a narrow strain range). Therefore, the lower bound of the present results is almost as large as the lower bound of previous estimates, the trend of the present results is within the range of previous estimates, and the upper-bound of the present results is the same as the upper bound of previous estimates.

\subsection{Implications of present results for fitness-for-service assessment}

The present experimental results provide the upper-bound curve of Fig. 43 as an experimentally derived J-integral estimation curve for HY130, Fig. 46. This curve is applicable to contained plasticity and GSY only. Net section yielding cannot be treated using the J-integral estimation curve of Fig. 46. Net section yielding constitutes a separate failure mode. Structures should be checked to ensure that this failure mode will not occur. According to the instructions for application of the COD design curve [18], the need for critical assessment of this failure mode (yielding due to overloading of remaining cross section, in the terminology of Ref. 18) is most likely to arise in small structural sections.

Once NSY has been excluded, the applied J-integral level for any through-thickness flaw or any full-width surface flaw can be estimated for any level of applied strain from Fig. 46. The estimation curve of Fig. 46 clearly overestimates applied J-integral where linear elastic fracture mechanics (LEFM) is adequate and the plastic zone is small compared to the crack size. In such cases LEFM might be used if necessary; the present estimation curve provides for conservative tolerance levels for the large flaws that would be under consideration in such cases. However near yield stress the plastic zone size increases rapidly with stress, so that for such stresses the present estimation is considered to be accurate rather than conservative.

The strain axis should be entered at the applied strain value anticipated in the component in question. The presence of residual stresses or stress concentrations must be accounted for in the applied strain value. Residual stresses of unknown magnitude should be estimated to be at yield level. One yield strain unit should be added to the normalized strain before entering the $J$ estimation curve. Stress concentrations in tension can be conservatively approximated as uniform tensile strain fields for which the strain level is approximated using the Neuber relation [12]

$$
\begin{aligned}
& e=K_{T} S, K_{T} S \leq 1 \\
& \dot{e}=K_{T}{ }^{2} S^{2}, K_{T} S>1, S<1
\end{aligned}
$$


where $S$ is nominal stress divided by yield stress, $\sigma / \sigma_{y}, K_{T}$ is the elastic stress concentration factor, and elastic-perfectly plastic behavior has been assumed. The J-integral estimation curve is then entered at the calculated normalized strain value. The estimated J-integral value is likely to be conservative by a factor of 3 to 10 if the stress concentrater radius is not adeouately large compared with the crack length. For the edge-hole-cracked specimen tested here, the applied J-integral value was approximately one sixth the value estimated from Fig. 46 . For this case the crack length was 0.15 of the stress concentrater radius. Of course, NSY must be avoided for stress concentrations.

The J-integral estimation curve derived here from experimental d measurements provides the value of applied J-integral divided by crack length after the material yield strength and Young's modulus are accounted for. Applied J-integral levels greater than some critical level are predictive of material tearing. If the desired failure criterion is the least detectable tearing at a sharp fatigue crack, very low critical flaw size levels will be predicted at strains of a few times yield. A typical J Ic value for HY130 would be about $230 \mathrm{kN} / \mathrm{m}(1300 \mathrm{lb} / \mathrm{in})$. For a strain of 3 times yield the predicted critical flaw size would be $1.6 \mathrm{~mm}(0.071 \mathrm{in})$. However the HY130 specimens tested here at room temperature, including those with fatigue cracks, showed no tendency to macroscopic tearing at $\mathrm{J}$ levels less than around $900 \mathrm{kN} / \mathrm{m}(5000 \mathrm{lb} / \mathrm{in})$. If a critical J-integral of $900 \mathrm{kN} / \mathrm{m}$ were used instead of $230 \mathrm{kN} / \mathrm{m}$, the predicted critical flaw size would be $7 \mathrm{~mm}(0.28 \mathrm{in})$. This calculation indicates that care must be exercised in adopting an appropriate critical J-integral value.

It is well-established that the degree of crack-tip-constraint in a structure or specimen has a major influence on its fracture behavior [19]. This effect is usually discussed in terms of the dependence of some crack-initiation criteria such as a critical stress intensity factor, $K_{C}$, on specimen thickness. But the constraint effect applies to tearing (R-curve) behavior as we11 [20-22]. The J-R curves shown previously as Fig. 4 demonstrate this effect. The face-cracked tensile panel $1 \mathrm{~cm}$ thick has less constraint than side-grooved compact tensile (CT) specimens $2.5 \mathrm{~cm}$ thick by $5 \mathrm{~cm}$ wide. Accordingly, the J-R curve for the face-cracked tensile panel lies above that for the compact speicmen. The J-R curve of through cracked tensile panels $1 \mathrm{~cm}$ thick used in this study has not been specifically measured, but its qualitative behavior has been observed. In accord with expectation based on consideration of constraint, the J-R-curve for the through-cracked tensile panels $1 \mathrm{~cm}$ thick are even higher than the curve for the face-cracked panel in Fig. 4. This explains why very high J-integrals were obtained in the tensile panel tests before significant tearing.

The variability of J-R behavior with configuration, coupled with the need that structures be demonstrated to be as crack tolerant as possible, may require use of configuration-specific J ${ }_{C}$ values for crack initiation and propagation. The $J_{C}$ value chosen controls the flaw size calculated using the gross-section-yielding J-integral estimation curve. Larger $J_{C}$ vlaues correspond to larger flaw sizes.

Use of configuration-specific ${ }_{C}{ }_{C}$ values instead of conservative values from CT specimens can be classified with use of application-specific applied stress and strain values instead of conservative estimates as refinements to a basic fitness-for-service assessmerit proceudre. such refinements allcw demonstration of larger tolerable crack sizes in specific situations, at a cost of additional information about the application and additional information about the configuration dependence of $\mathrm{J}$ values for crack initiation and propagation.

Qualitative use of this configuration dependence of effective fracture toughness is made in some well-known fracture criteria, including through-thickness-yielding, leak-before-break, and 
ratio-analysis-diagram. Attempts have been made to quantify crack-tip constraint in order to explain the configuration-dependence of fracture toughness, but no generally applicable method is available.

\subsection{Surface flaws}

Three surface-cracked HY130 specimens have been tested. Net section and gross section yielding effects occurred in these specimens. The rule that flaws 1 percent of the cross-sectional area are required for GSY held for surface flaws in HY130 base metal. For the remainder of this section it will be assumed that NSY has been eliminated from consideration.

Three behavior types, each associated with a specific three-dimensional strain pattern, must be accounted for in calculating applied crack driving force for surface cracks: elastic, ligament yielding (LY) and gross section yielding.

\section{Elastic strain}

At low stresses, a tensile panel containing a surface crack behaves in a generally elastic fashion; plastic strains occur only in a very small zone near the crack tip. Applied J-integral can be evaluated in this stress range using equations reported by Newman and Raju [23]:

$$
\begin{aligned}
& J=\frac{\sigma^{2}}{E} \pi \frac{h}{Q} F \\
& Q=1+1.464\left(\frac{h}{c}\right)^{1.65} \\
& F=\left[M_{1}+M_{2}\left(\frac{h}{t}\right)^{2}+M_{3}\left(\frac{h}{t}\right)^{4}\right] f_{W} \\
& M_{1}=1.13-0.09\left(\frac{h}{c}\right) \\
& M_{2}=-0.54+\frac{0.89}{0.2+\frac{h}{c}} \\
& M_{3}=0.5-\frac{1.0}{0.65+\frac{h}{c}}+14\left(1.0-\frac{h}{c}\right)^{24} \\
& f_{W}=\left[\sec \left(\frac{\pi c}{W} \sqrt{\frac{h}{t}}\right)\right]^{\frac{1}{2}}
\end{aligned}
$$

where $\sigma$ is applied stress, $h$ is surface crack depth, $c$ is surface crack half-length, $t$ is plate thickness, and $W$ is plate width.

\section{Ligament yielding}

As stress increases, the crack tip plastic zone extends through the ligament behind the surface flaw toward the back face of the specimen. This ligament plasticity causes the crack driving force, measured by applied J-integral or applied CTOD, to increase with applied stress at a higher rate than before LY. Experimental verification of an analytical model for LY was reported recently by Cheng et a) [24]. According to this study, CTOD resulting from LY is given by

$$
\text { CTOD }=\frac{2\left(2 c+2 r_{y}\right)[\sigma-(1-h / t) \sigma]}{E}
$$

where $c$ is crack half-length, $h$ is crack depth, $t$ is plate thickness, $r_{y}$ is plastic zone size and 
$\bar{\sigma}$ is material flow strength. A previously obtained Dugdale solution for the plastic zone size was given as

$$
\frac{\sin \left(\frac{\pi}{2} \cdot 2 \frac{c}{W}\right)}{\sin \left(\frac{\pi}{2} \cdot 2 \frac{c}{W}\right)}=\cos \left(\frac{\pi}{2} \cdot \frac{\sigma^{\prime}}{\bar{\sigma}^{\prime}}\right)
$$

where $c_{p}=c+2 r_{y}, \sigma^{\prime} / \bar{\sigma}^{\prime}=1-(1-\sigma / \bar{\sigma}) \cdot t / h$, and $W$ is plate width. A somewhat more rigorous analytical model was developed by King using a simplified line-spring approach [25]. The crack driving forces calculated from King's model are practically identical to those from Eq. 16. This agreement allows increased confidence in the reliability of Eq. 16. The simplified line spring model also shows that CTOD values can be converted to J-integral values for tensile panels simply by multiplying CTOD by $\sigma_{y}$. The agreement between the line spring model and experimentally measured J-integral values was found to be good (Fig. 45). Another variation of the LY model was reported by deWit and Smith [26]. Although the mathematical form they reported is slightly different from Eq. 16, their calculated CTOD values agree well with those from the other models. The mathematical form used in Ref. 26 was found to be adaptable for graphical evaluation, as discussed below. Gross section yielding

As the stress is increased, the LY model eventually breaks down because yielding spreads away from the ligament. After yielding spreads throughout the specimen, GSY behavior occurs (assuming the absence of NSY). Data obtained to date in this study and the precedent of the British approach [18] indicate that surface cracks in tensile panels with GSY can be treated in the same general way as through flaws in GSY. That is, the increase in applied J-integral is proportional to the increase in applied strain and the effective crack size $\bar{a}$ :

$$
\Delta \mathrm{J} \sim \overline{\mathrm{a}} \Delta \varepsilon
$$

Here $\bar{a}$ depends on crack depth, $h$, crack half-length, $c$, and plate thickness, $t$. It is independent of plate width and independent of applied strain. The plot of Fig. 46 illustrates the form of the dependence of $\bar{a}$ on $h$ and $c$. This plot was derived by requiring that in cases where the surface crack reduces to a through crack, the effective crack size should reduce to $h$ or $c$, as appropriate, and that $\bar{a}$ should be zero when $c$ or $h$ is zero. Figure 46 is consistent with the available data, but it has not been critically evaluated at values of $\mathrm{c} / \mathrm{t}$ above 0.8 and $\mathrm{h} / \mathrm{t}$ values above 0.12 . The extremely large specimen sizes required for experimental tests of GSY behavior in this range of crack sizes might make such measurements impractical unless a specific need for the data arises.

\section{Evaluation of total J-integral}

The applied J-integral produced by the three mechanisms discussed above can be evaluated as follows. The first step is to determine the stress where LY begins and to obtain an index of the degree of yielding around the surface crack. According to the models presented above, ligament yielding begins at an applied stress level, $\sigma^{\star}$, given as:

$$
\sigma^{*}=\sigma_{y}(1-h / t)
$$

As the stress increases, the degree of LY also increases. The quantity chosen as the surface crack yielding index is zero for stresses below $\sigma^{*}$ and increases linearly with applied stress. When the applied stress reaches the material flow strength, the plane of specimen material 
containing the surface crack has yielded everywhere. The surface crack yielding index is chosen to be one for this stress level. The surface crack yielding index $Y$ is given mathematically as

$$
Y=\frac{\sigma / \bar{\sigma}-(1-h / t)}{h / t}
$$

and can conveniently be evaluated using the graph of Fig. 49. This same graph can also be used to evaluate $\sigma^{*}$, the stress level at which LY begins. The stress $\sigma^{*}$ is the stress where the line for the $h / t$ value under consideration intersects the $x$-axis. Interpolation may be used to locate lines for $h / t$ values not shown in the figure.

The normalized applied J-integral for the elastic stress range is found by entering the $x$-axis of Fig. 50 at either $\sigma^{*}$ or the applied stress, $\sigma$, whichever is lower, and reading off the indicated $y$-axis value. The effective crack size for elastic behavior can be obtained from Fig. 51, allowing calculation of the absolute value of the elastic part of the applied J-integral.

If the applied stress is greater than $\sigma^{*}$, additional contributions to the applied J-integral must be accounted for. The LY contribution to the applied J-integral can be evaluated using Fig. 52, entering the $x$-axis at the surface crack yielding index previously obtained from Fig. 49. For the scaling chosen for the $y$-axis of Fig. 52, the effective crack size is given by

$$
\bar{a}=h c / t \text {, }
$$

as noted on the figure. The absolute value of the applied J-integral from LY is added to the contribution from elastic strain.

The maximum achievable surface crack yielding index occurs at the stress level at which yielding occurs away from the surface crack. This stress level is indicated by a vertical dashed line in Fig. 49. The value used was obtained from the experimental data of the present study. For applied strain levels above yield, the maximum surface crack yielding index for the crack under consideration is used in evaluating the LY contribution to the applied J-integral.

The GSY contribution to the applied J-integral value could be evaluated using the graph of Fig. 53 to obtain normalized J-integral and the effective crack size plot of Fig. 48. As discussed above, Fig. 48 is only hypothetical for $c / t$ values above 0.8 and $h / t$ values between 0.12 and 1 .

\section{Discussion}

The concept of a three-step evaluation procedure for applied J-integral is illustrated by Fig. 54, which may be compared with Fig. 46 for through cracks. Simplification of the evaluation process illustrated by Fig. 54 awaits advances in understanding of surface flaw behavior.

Probably the most problematic aspect of the procedure described above is the use of the material flow strength in the evaluation of the LY contribution to the applied J-integral. The flow strength is based on the idealization of a metal as an elastic-perfectly plastic material. The present specimen material, HY130 steel, is nearly elastic-perfectly plastic. But GSY cannot occur in an ideally elastic-perfectly plastic tensile panel containing a surface flaw, because the crosssectional area of the crack plane is less than the area away from the crack, so that all the strain must occur in the plane of the crack. Strain-hardening and three-dimensional geometrical constraint effects can raise the effective strength of the material surrounding the surface crack to a high enough level that GSY can occur. Another important effect is overmatching weld metal in specimens with welds transverse to the tensile axis. The flow strength of an overmatching weld can easily be higher than the yield strength of the base metal, which would lower the applied J-integral from LY. 
An additional beneficial effect of overmatching may be to limit applied plastic strain during GSY in a transverse weld to values below those in the surrounding base plate. Lower applied strain would mean lower applied J-integral values. The existence of these strengthening effects is demonstrated by Fig. 55, which shows fractured welded and base metal HY130 specimens containing small surface cracks. These specimens fractured away from their cracks. But the magnitude of effective strengthening owing to overmatching, strain hardening, and geometrical constraint must be carefully studied; the ability of surface cracked specimens or structures to achieve gross section yielding should not be taken for granted.

\section{CONCLUSIONS}

As a result of 15 direct experimental measurements of the applied J-integral in HY130 tensile panels several conclusions have been reached:

1. Applied J-integral is controlled qualitatively by deformation pattern. Net section yielding produces large applied J-integral values, whereas gross section yielding produces small applied J-integral values.

2. Fitness-for-service assessment for contained plasticity and gross section yielding can be performed using a J-integral estimation curve to obtain applied J-integral as a function of applied strain and crack size.

3. Net section yielding is intolerable in high performance components. This yielding pattern can be avoided in tensile panels by restricting crack size to 1 percent or less of the load-bearing cross-sectional area.

4. The J-integral estimation curve for gross section yielding can be used to treat cracks at stress and strain concentrations. Neuber's rule may be used to estimate applied strain.

A safe (too large) estimate of applied J-integral will be obtained if the crack under consideration is not sufficiently small compared with the stress concentrator.

5. Estimation of applied J-integral values for surface flaws requires consideration of ligament yielding as well as contained and gross section yielding. Contributions of each of these yielding patterns to applied J-integral can be evaluated using estimation curves specific to each yielding pattern.

\section{ACKNOWLEDGMENTS}

This report was prepared as part of the Fracture Control Technology program under the sponsorship of Dr. H. H. Vanderveldt, Naval Sea Systems Command (SEA 05R15). The effort was directed by Mr. John P. Gudas, David Taylor Naval Ship R\&D Center, under Program Element 62761N, Task Area SF-61-544-504. The contributions of J. D. McColskey as technician on this project are gratefully acknowledged. Helpful discussions with J. P. Gudas, H. I. McHenry, R. B. King, and Y. W. Cheng, assistance in data analysis and plotting by P. Campau and B. Gunther, and manuscript preparation by J. Wilken are appreciated. 


\section{REFERENCES}

[1] J. Tirosh and C. A. Berg, Experimental Stress Intensity Factor Measurements in Orthotropic Composites, Composite Materials: Testing and Design (Third Conference), STP 546, American Society for Testing and Materials, Philadelphia, 1974, pp. 663-673.

[2] G. Herrmann and G. S. Kino, Ulträsonic Measurements of Inhomogeneous Stress Fields, Proceedings of ARPA/AFML Review of Progress in Quantitative NDE, AFML-TR-78-205, Air Force Materials Laboratory, 1979, pp. 447-451.

[3] R. B. King and G. Herrmann, Nondestructive Evaluation of the $J$ and M Integrals, Journal of Applied Mechanics 48, 1981, pp. 83-87.

[4] H. L. Oh, A Simple Method for Measuring Tearing Energy of Nickel Rubber Strips, Mechanics of Crack Growth, STP 590, American Society for Testing and Materials, Philadelphia, 1976, pp. $104-114$.

[5] W. A. Logsdon, Elastic Plastic ( $\mathrm{J}_{\mathrm{C}}$ ) Fracture Toughness Values: Their Experimental Determination and Comparison with Conventional Linear Elastic $\left(\mathrm{K}_{\mathrm{IC}}\right)$ Fracture Toughness Values for Five Materials, Mechanics of Crack Growth, STP 560, American Society for Testing and Materials, Philadelphia, 1976, pp. 43-60.

[6] J. A. Begley and J. D. Landes, The J integral as a Fracture Criterion, Fracture Toughness, STP 514, American Society for Testing and Materials, Philadelphia, 1972, pp. 1-20.

[7] J. D. Landes and J. A. Begley, The Effect of Specimen Geometry on J Ic, Fracture Toughness, STP 514, American Society for Testing and Materials, Philadelphia, 1972, pp. 24-39.

[8] H. Tada, P. Paris, and G. Irwin, The Stress Analys is of Cracks Handbook, Del Research Corporation, Hellertown, Pennsylvania, 1973.

[9] 3. R. Rice, A Path Independent Integral and the Approximate Analysis of Strain Concentration by Notches and Cracks, Journal of Applied Mechanics 35, 1968, pp. 379-386.

L10] C. E. Turner, Methods for Post-Yield Fracture Safety Assessment, Post-Yield Fracture Mechanics, edited by D. G. H. Latzko, Applied Science Publishers, London, 1979, pp. 23-210.

[11] W. Soete and R. Denys, Full and General Yield Behavior of Homogeneous Plates with Cracks, Proceedings of the International Institute of Welding Conference at Bratislava, Doc. X-921-79, 1979 .

[12」 H. Neuber, Theory of Stress Concentration for Shear-strained Prismatica] Bodies with Arbitrary Nonlinear stress strain Law, Journal of Applied Mechanics 28, 1961, pp. 544-550.

[13] D. T. Read, Applied J-Integral Values in Tensile Panels,", Appendix of this report. 
[14] M. G. Dawes, The COD Design Curve, in Advances in Elasto-Plastic Fracture Mechanics, edited by L. H. Larsson, Applied Science Publishers, London, 1980, pp. 279-300.

[15] J. A. Begley, J. D. Landes, and W. K. Wilson, An Estimation Model for the Application of the J-Integral, Fracture Analysis, STP 560, American Society for Testing and Materials, Philadelphia, 1974, pp. 155-169.

[16] C. E. Turner, Elastic-Plastic aspects of fracture stress analysis: methods for other than standardized test conditions, in Fracture Mechanics in Design and Service, Philosophical Transactions of the Royal Society of London A299, 1981, pp. 73-92.

[17] J. D. Harrison, M. G. Dawes, G. L. Archer, and M. S. Kamath, The COD Approach and Its Application to Welded Structures, Elastic-Plastic Fracture, STP 668, American Society for Testing and Materials, Philadelphia, 1979, pp. 606-631.

[18] British Standards Institution, Guidance on Some Methods for the Derivation of Acceptance Levels for Defects in Fusion Welded Joints, PD6493:1980, British Standards Institution, London, 1980.

[19] S. T. Rolfe and J. M. Barsom, Fracture and Fatigue Control in Structures, Prentice-Ha11, New Jersey, 1977, pp. 372-412.

[20] J. R. Rice, W. J. Drugan, and T-L. Sham, Elastic-Plastic Analysis of Growing Cracks, Fracture Mechanics, STP 700, American Society for Testing and Materials, Philadelphia, 1980, pp. $189-221$.

[21] M. G. Vassilaros, J. A. Joyce, and J. P. Gudas, Effects of Specimen Geometry on the J ${ }_{I}-R$ Curve for ASTM A533B Stee1, Fracture Mechanics, STP 700, American Society for Testing and Materials, 1980, pp. 251-270.

[22] S. J. Garwood, Measurement of Crack Growth Resistance of A533B Wide Plate Tests, Fracture Mechanics, STP 700, American Society for Testing and Materials, 1980, pp. 271-295.

123] J. C. Newman, Jr. and I. S. Raju, Analyses of Surface Cracks in Finite Plates under Tension or Bending Loads, NASA Technical Paper 1578, 1979. Available from NTIS, Springfield, Virginia.

[24] Y. W. Cheng, H. I. McHenry, and D. T. Read, Crack-opening Displacement of Surface Cracks in Pipeline Steel Plates, Proceedings of the Fourteenth National Symposium on Fracture Mechanics, June 30-July 2, 1981, Los Angeles, California. 
[25] R. B. King. Y. W. Cheng, D. T. Read, and H. I. McHenry, J-Integral Analysis of Surface Cracks in Pipeline Steel Plates. Proceedings of Second International Symposium on ElasticPlastic Fracture Mechanics, 1981, to be published.

[26] R. deWit and 3. H. Smith, Development of Some Analytical Fracture Mechanics Models for Pipeline Girth Welds, Fracture Mechanics, STP 700, American Society for Testing and Materials, Philadelphia, 1980, pp. 513-528. 


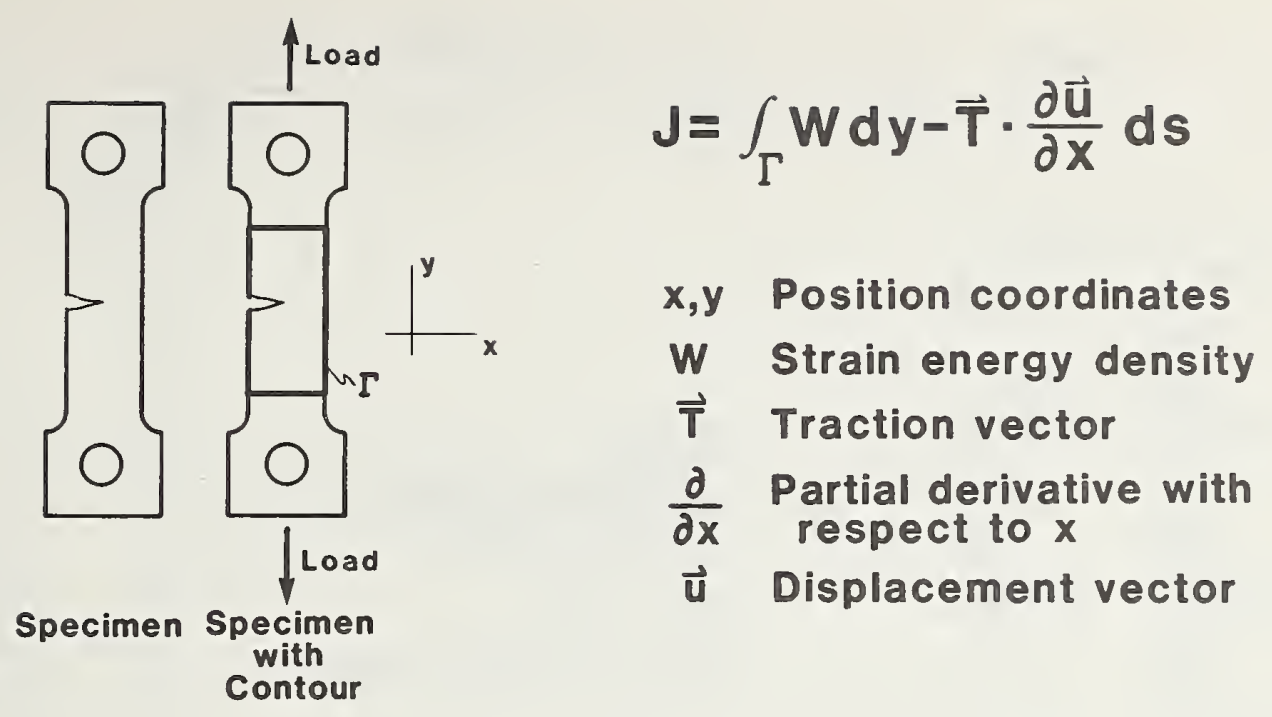

Figure 1. Contour for direct measurement of $\mathrm{J}$-integral in single-edge-cracked specimens.
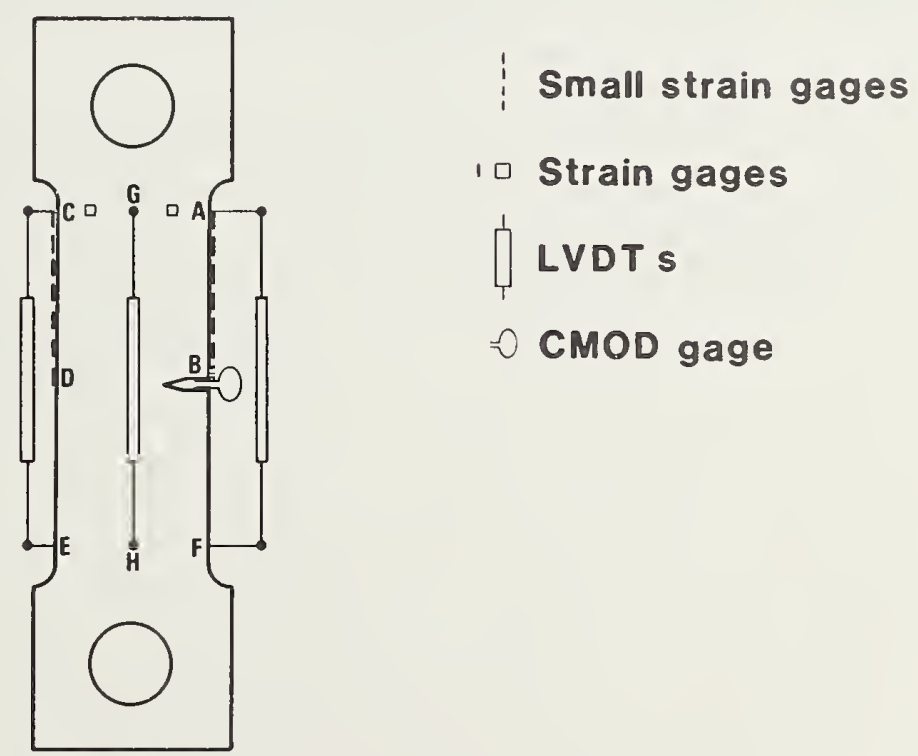

Specimen with Instrumentation

Figure 2. Instrumentation of single-edge-cracked specimen. 


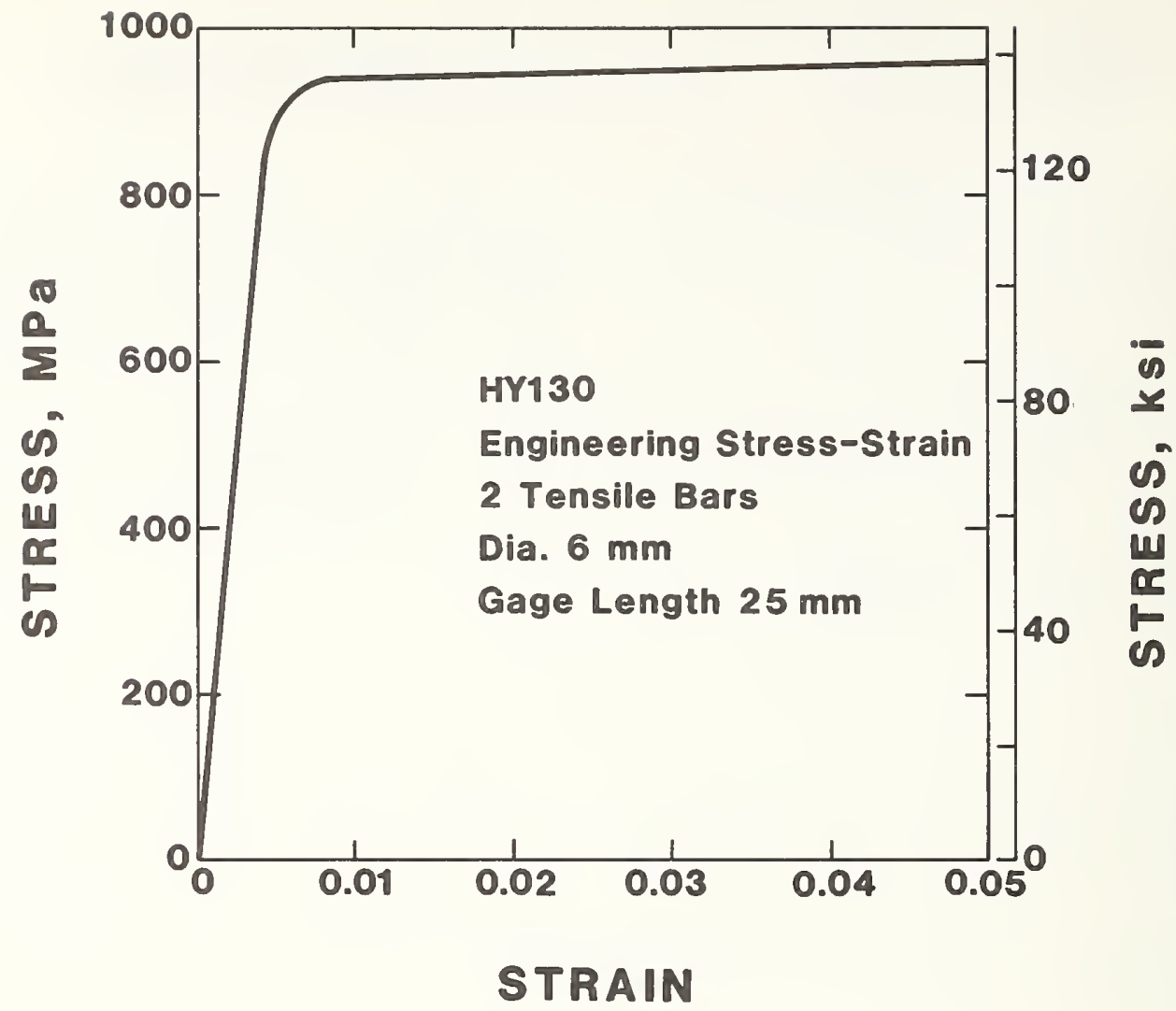

Figure 3. Engineering stress-strain curves for the HY130 specimen material used in the present study. 


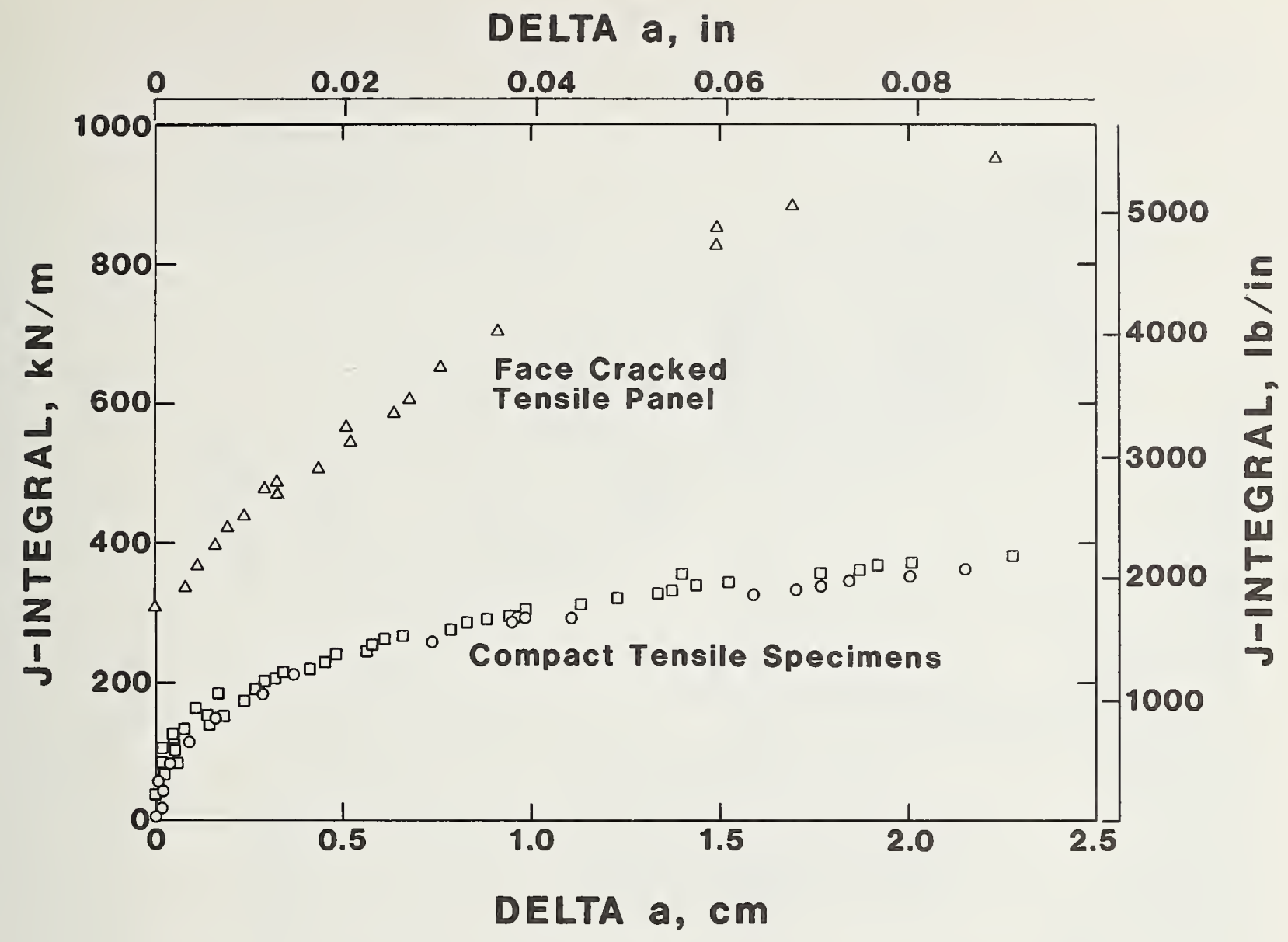

Figure 4. J-integral crack growth resistance curves (J-R-curves) for the HY130 material used in the present study. The lower curves are for standard $2.5 \mathrm{~cm}$ thick compact tensile specimens. The upper curve is for a crack $4 \mathrm{~mm}$ deep in a tensile panel $25 \mathrm{~mm}$ thick by $90 \mathrm{~mm}$ wide by $300 \mathrm{~mm}$ long. 


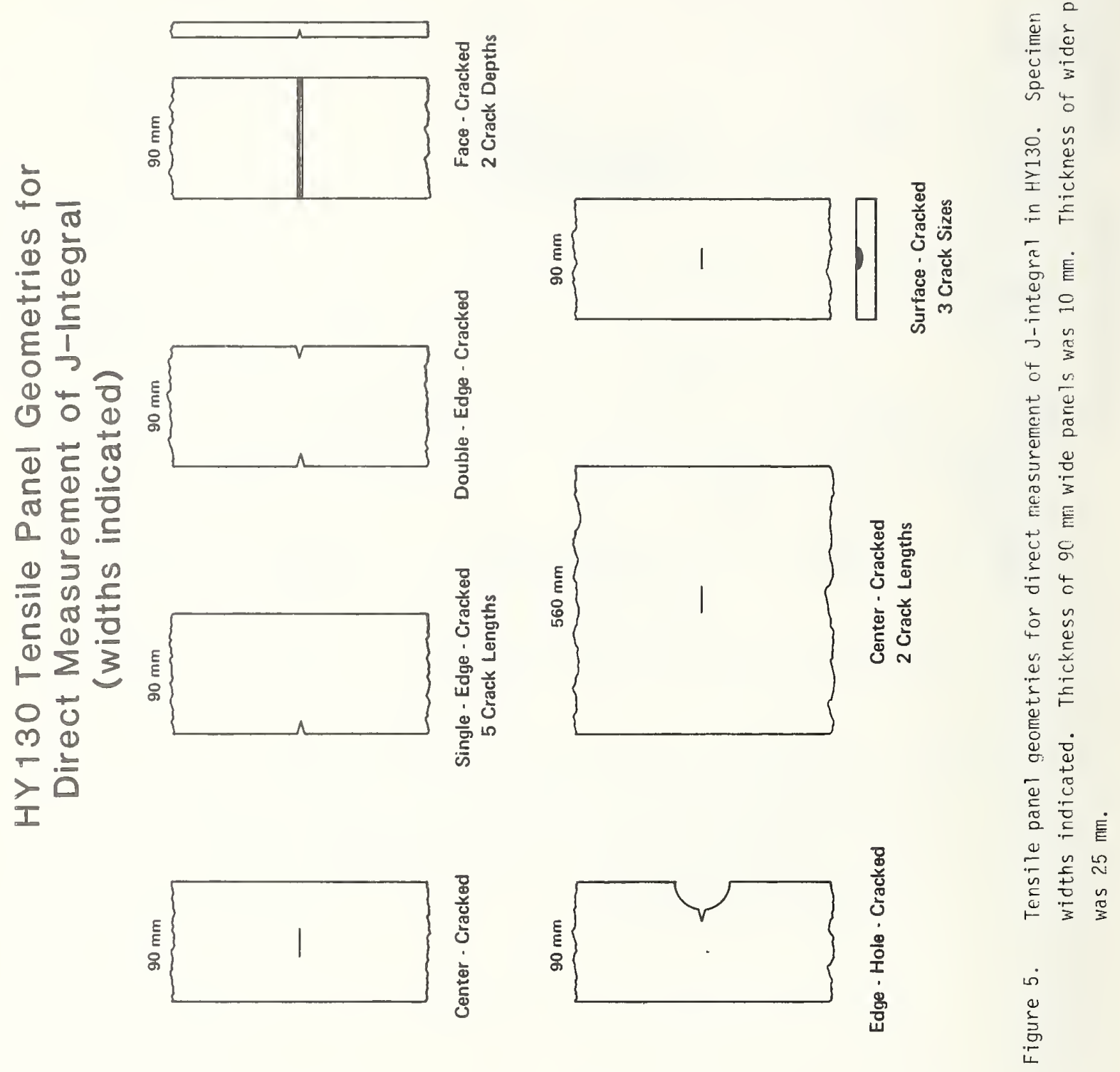




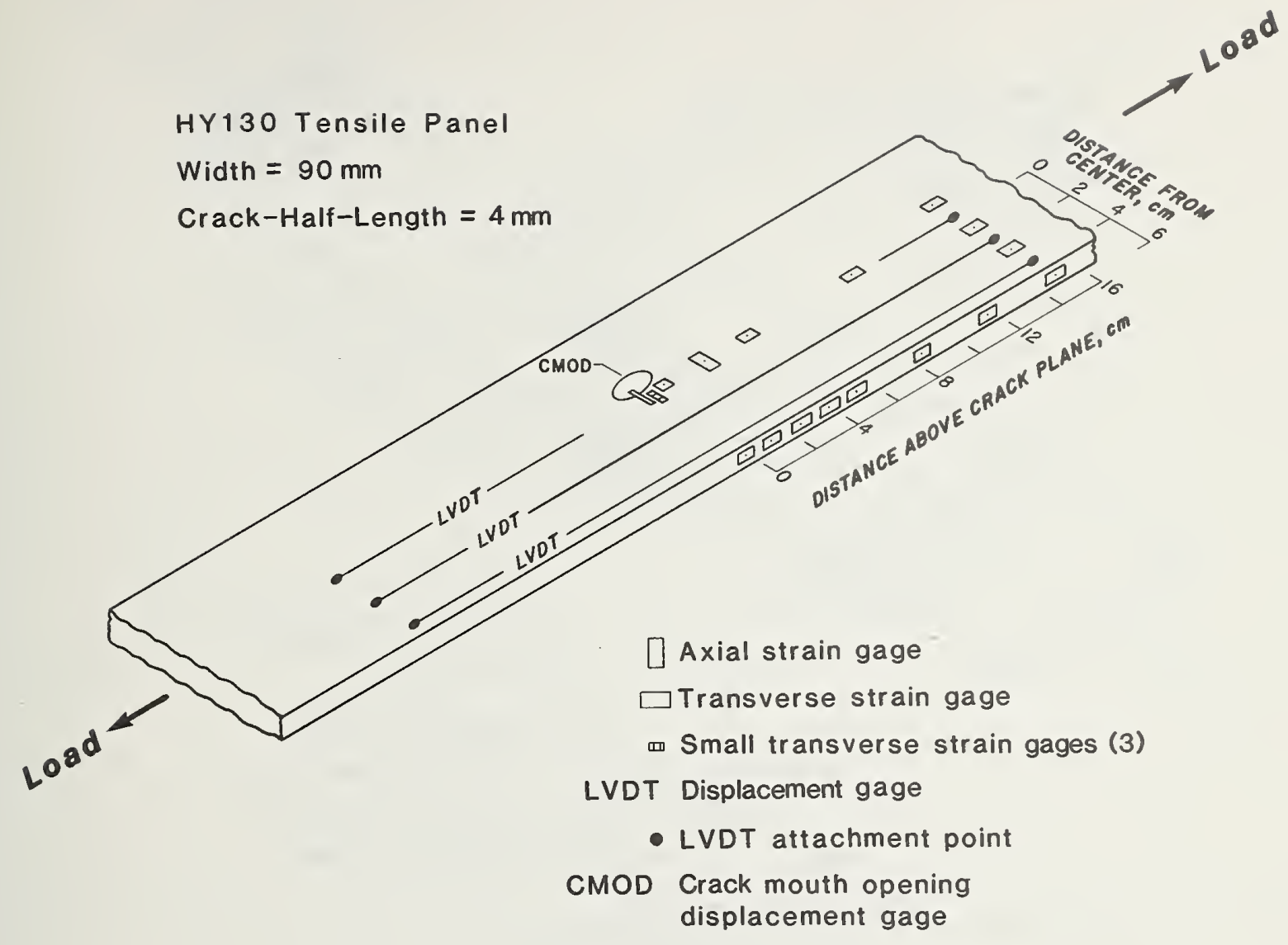

Figure 6. Instrumentation layout for center-cracked tensile panel, crack half-lerigth $4 \mathrm{~mm}$.

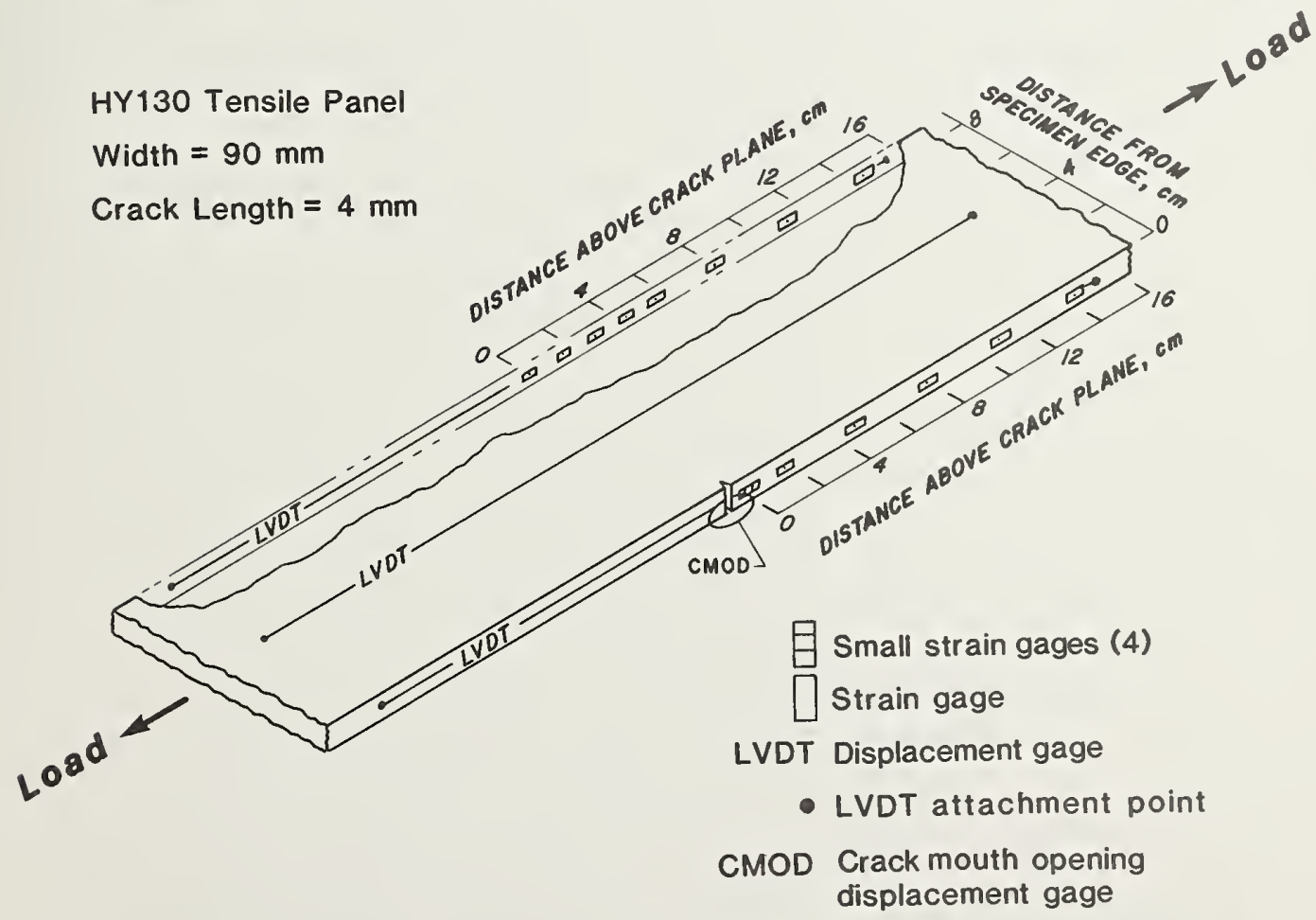

Figure 7. Instrumentation laycut for single-edge-cracked tensile panel, crack length $4 \mathrm{~mm}$. 


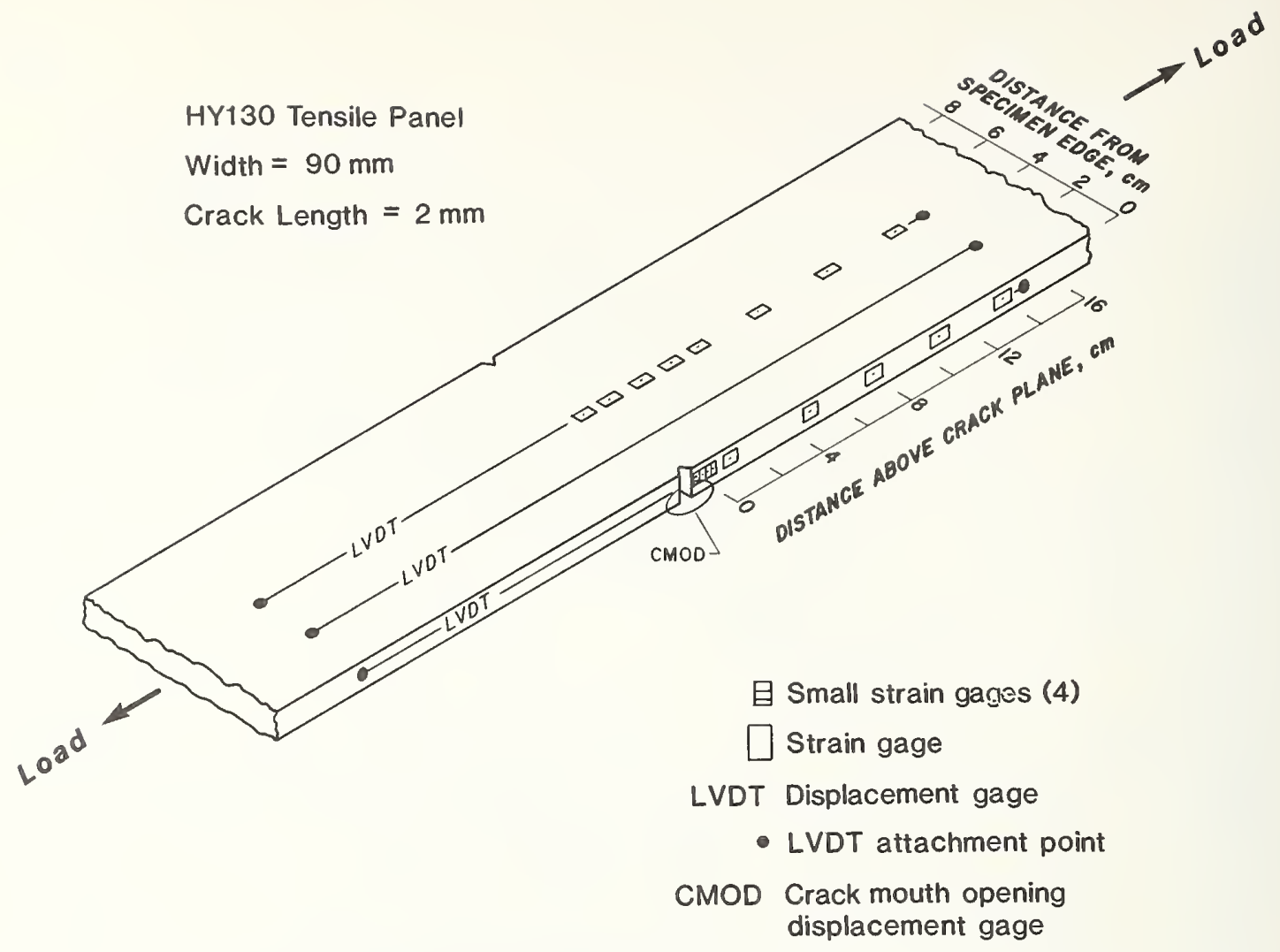

Figure 8. Instrumentation layout for double-edge-cracked tensile panel, crack 1ength $2 \mathrm{~mm}$. 


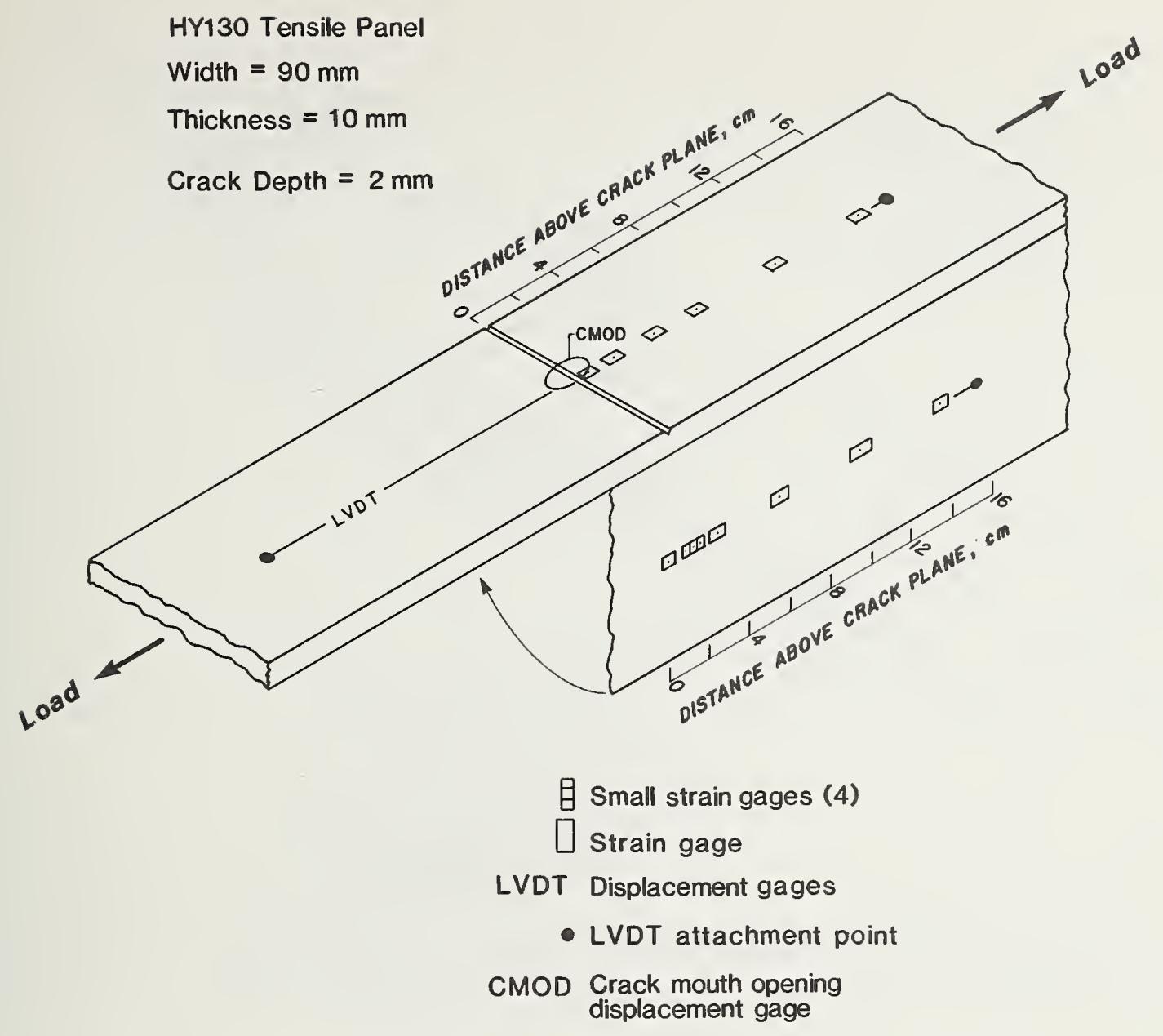

Figure 9. Instrumentation layout for face-cracked tensile panel, crack depth $2 \mathrm{~mm}$. 


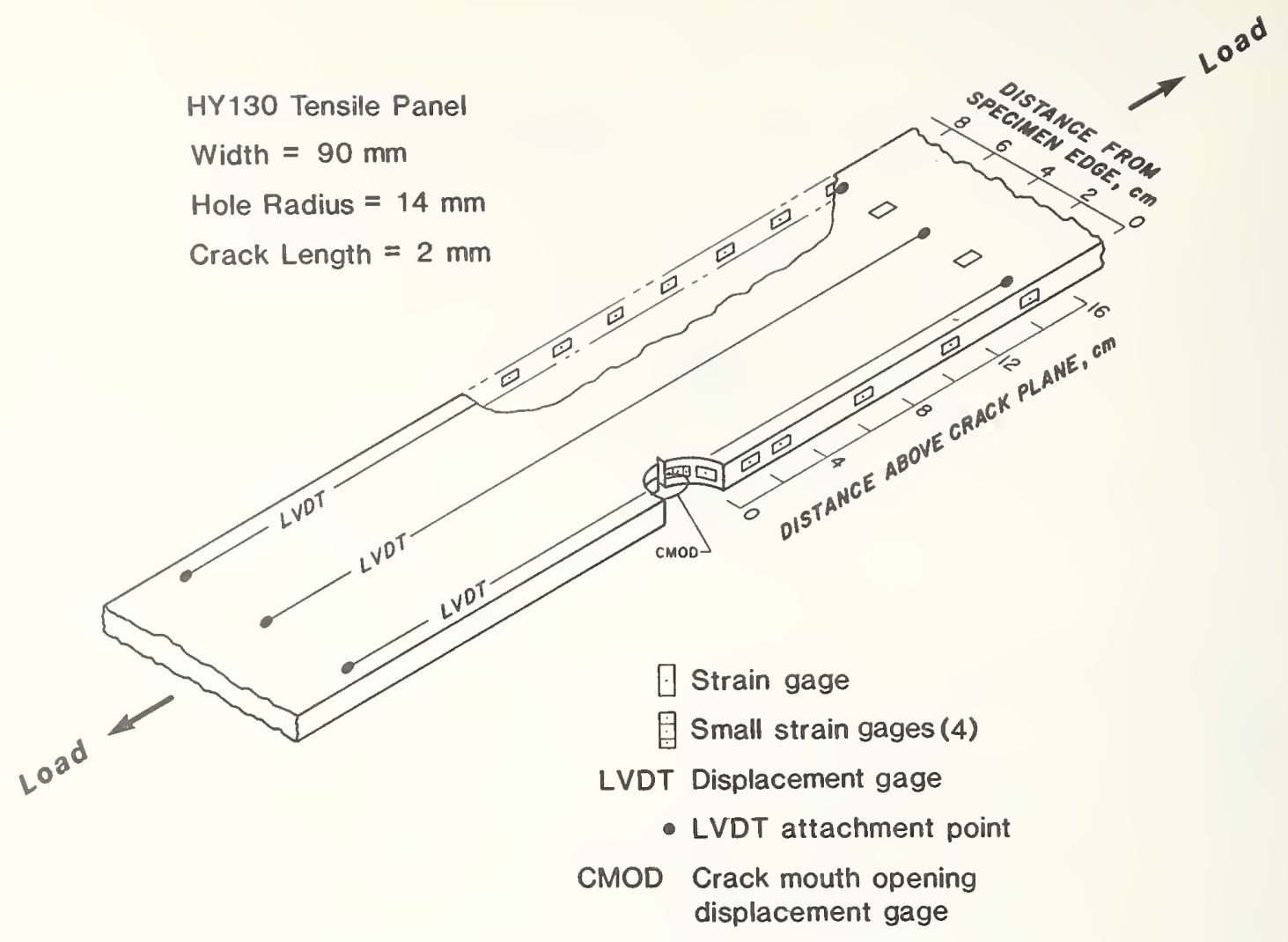

Figure 10. Instrumentation layout for edge-hole-cracked tensile pane1, crack length $2 \mathrm{~mm}$, hole radius $14 \mathrm{~mm}$.

HY130 Tensile Panel

Width $=560 \mathrm{~mm}$
Crack-Half-Length $=16 \mathrm{~mm}$

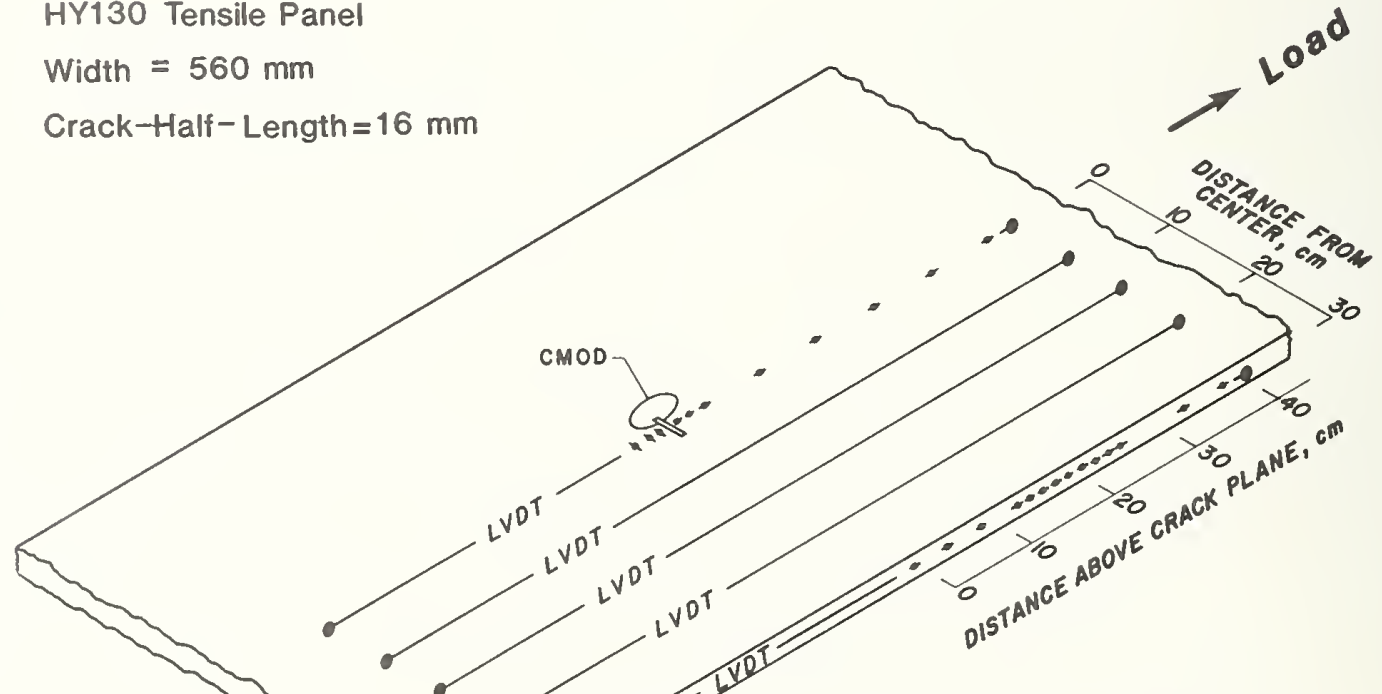
$10^{8 d}$ 2

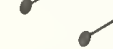

- Axial strain gage

- Transverse strain gage

LVDT Displacement gage

NOTE:

All instrumentation on face side is duplicated on back side
- LVDT attachment point

CMOD Crack mouth opening displacement gage

Figure 11. Instrumentation layout for wide center-cracked tensile panel, crack half-length $16 \mathrm{~mm}$, panel width $560 \mathrm{~mm}$. 


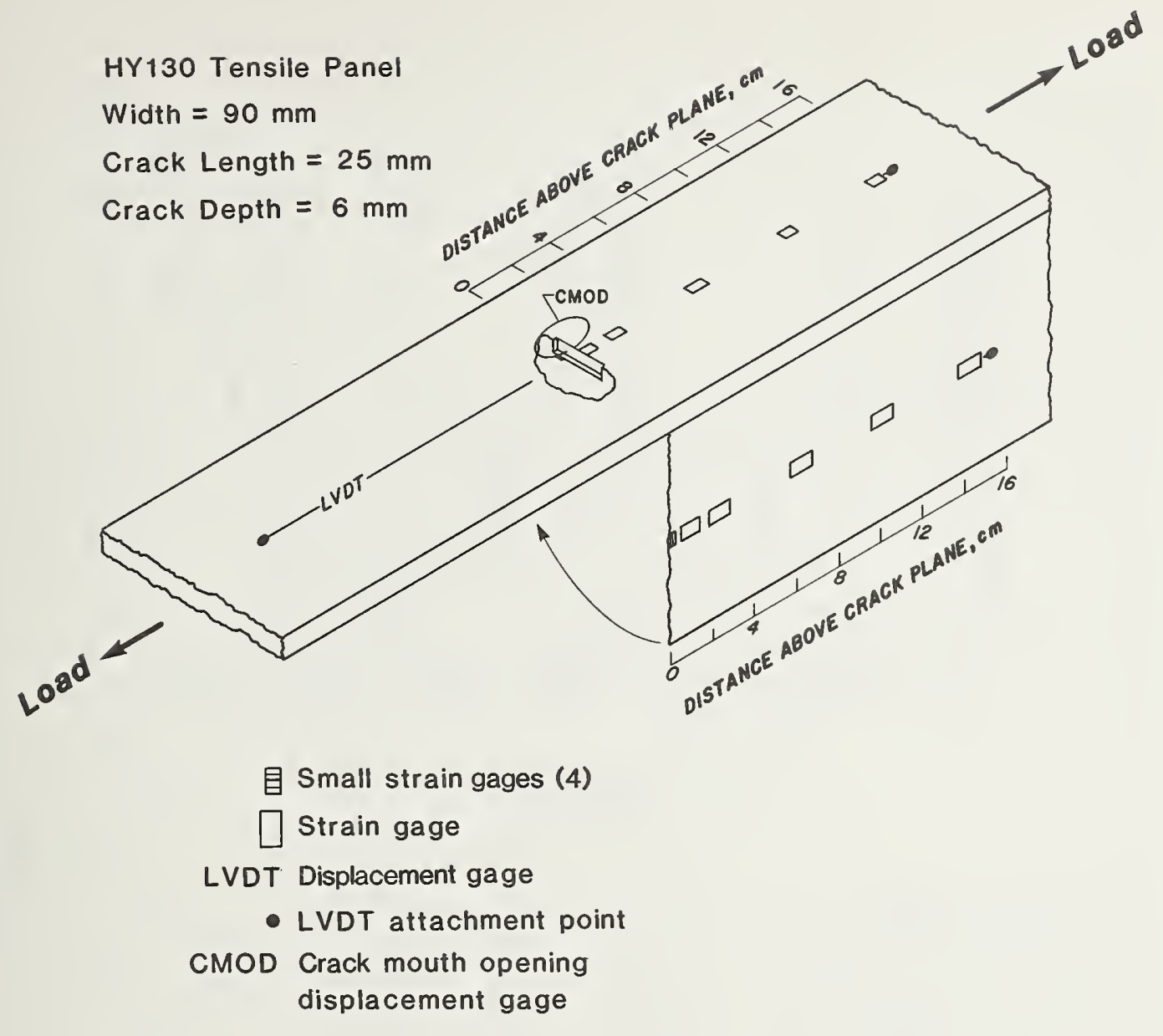

Figure 12. Instrumentation layout for surface-cracked tensile panel, crack depth $6 \mathrm{~mm}$, crack length $25 \mathrm{~mm}$. 


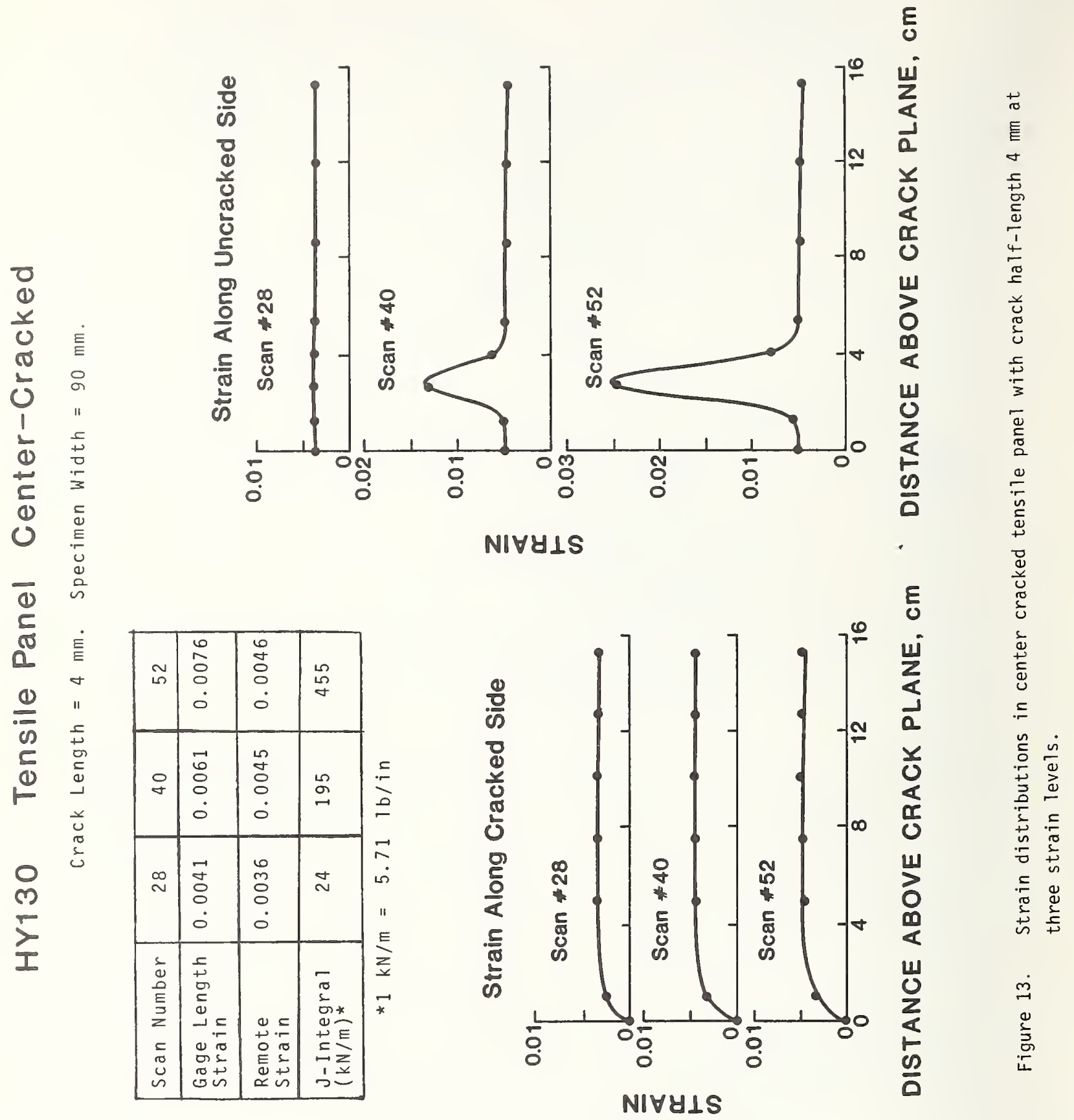




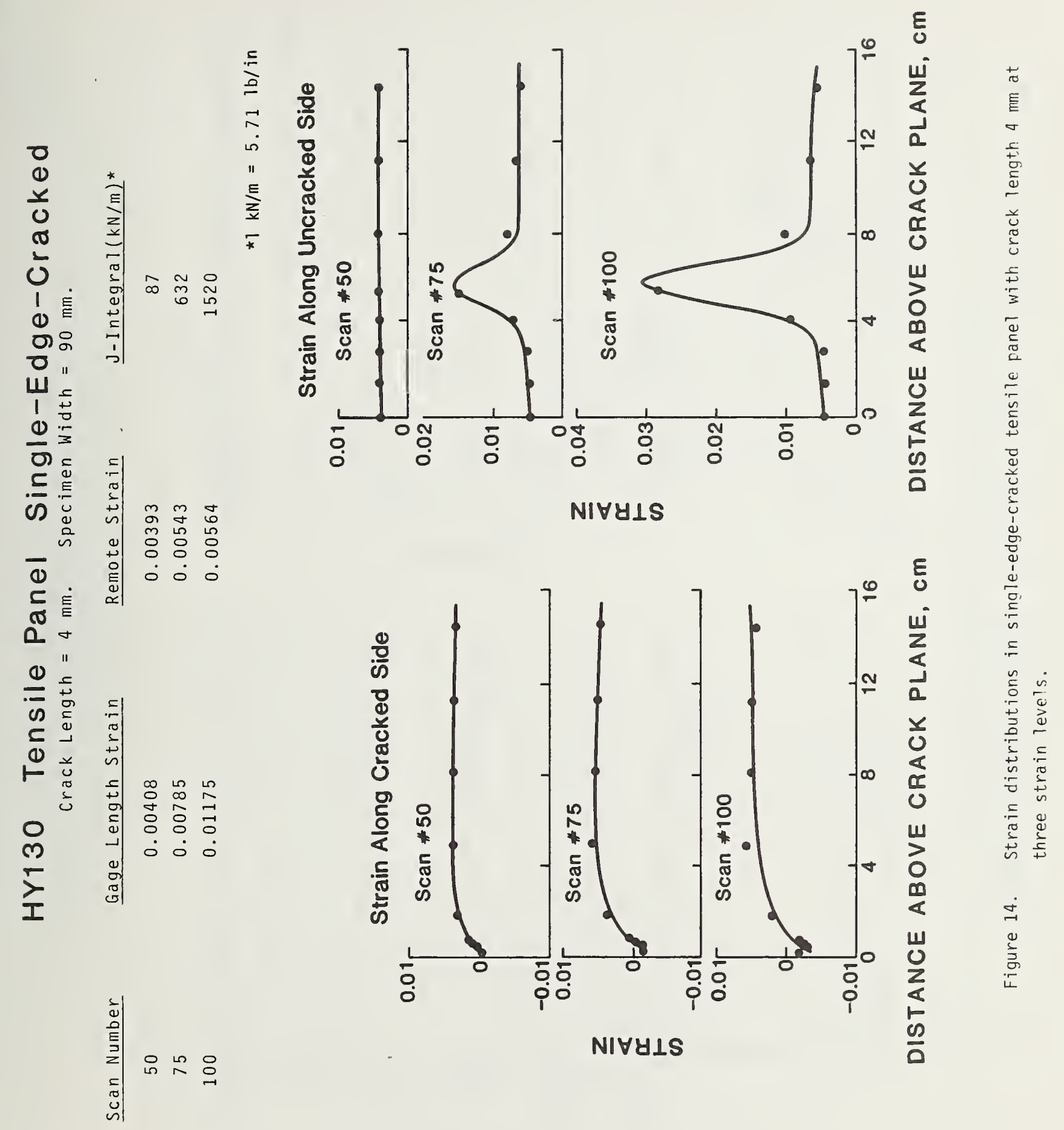



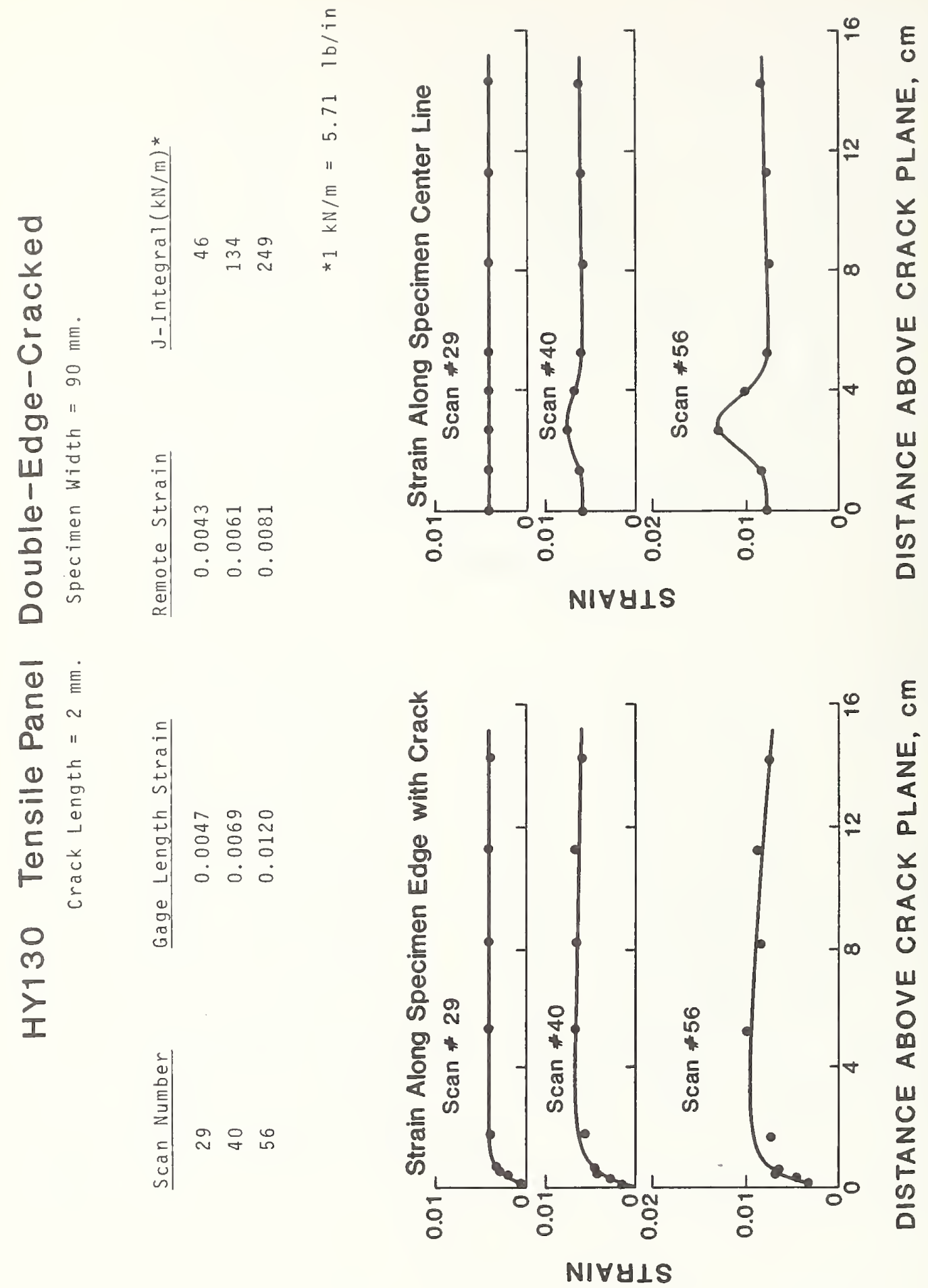

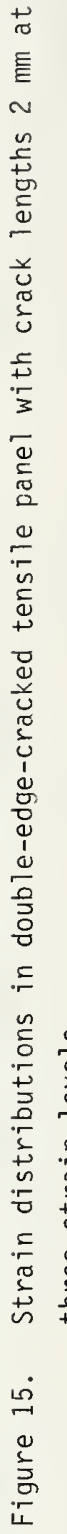




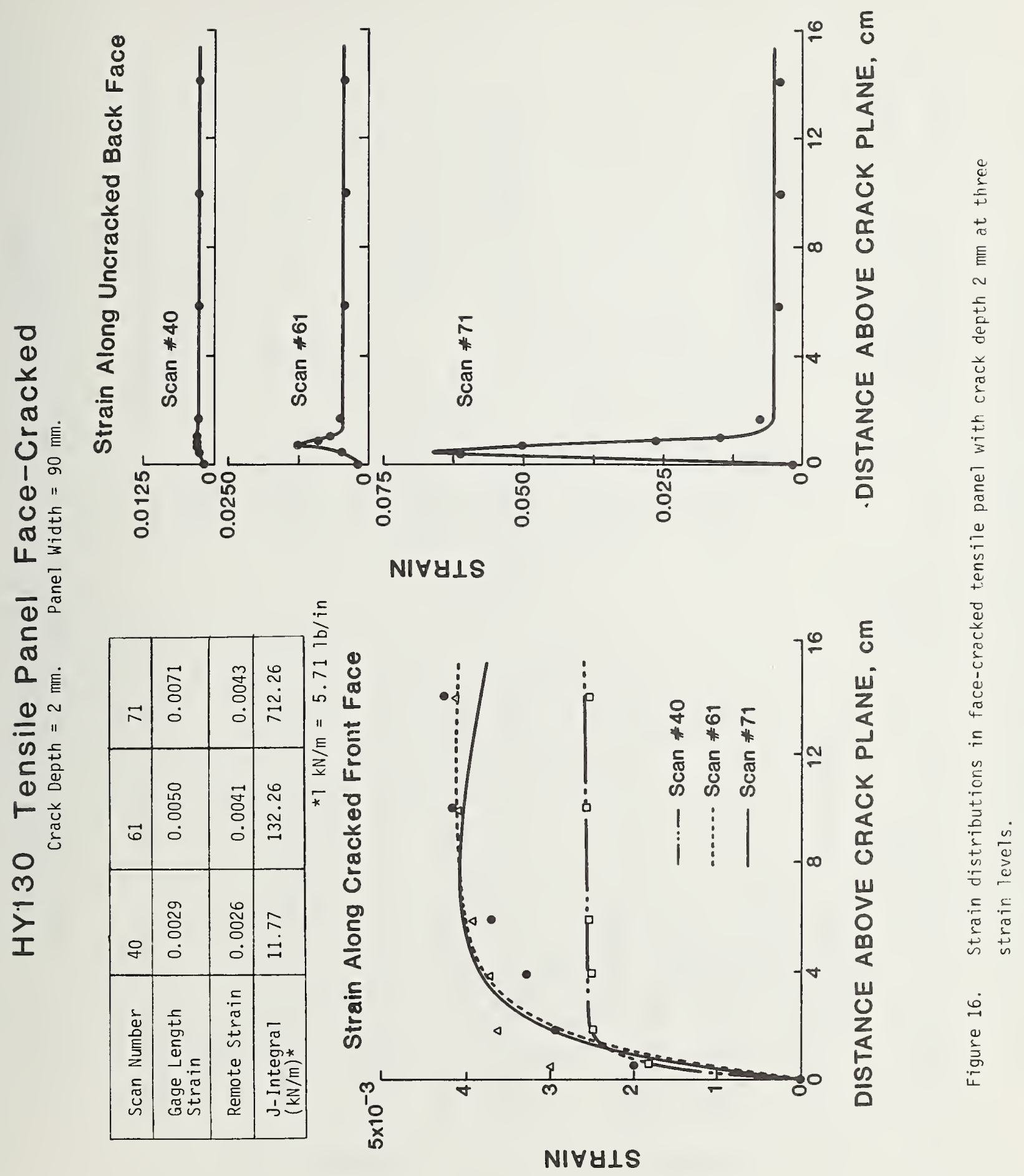




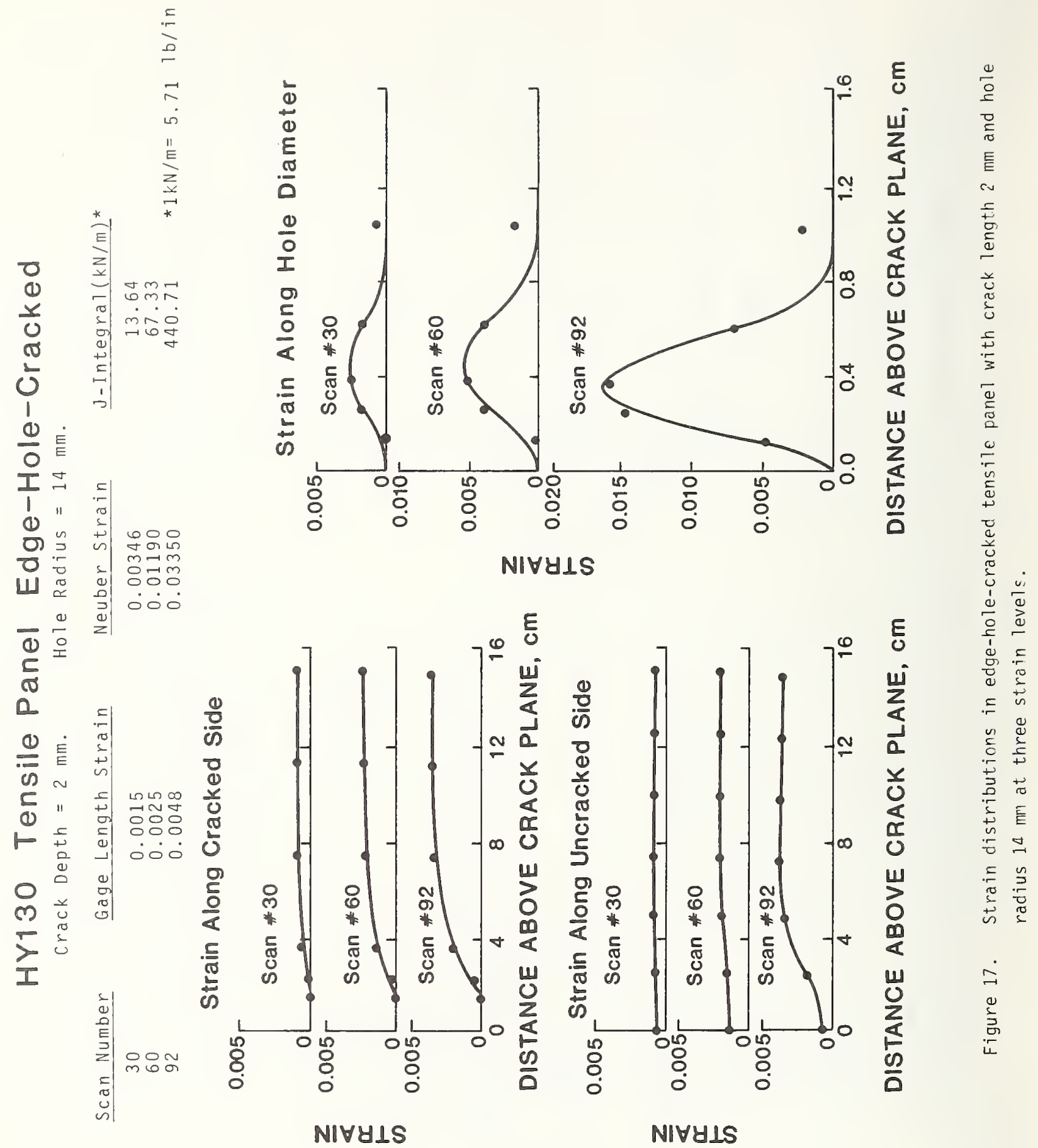




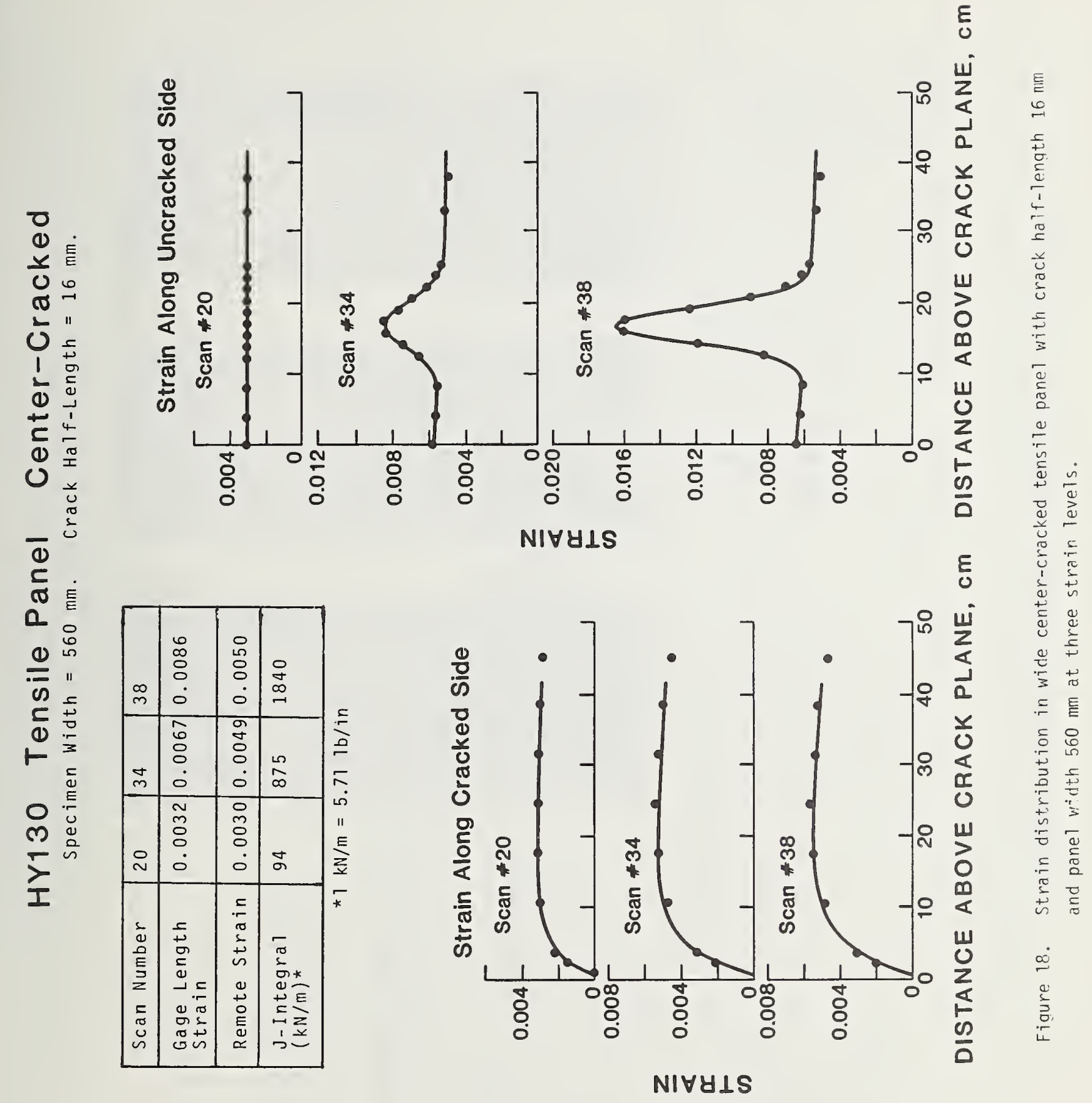




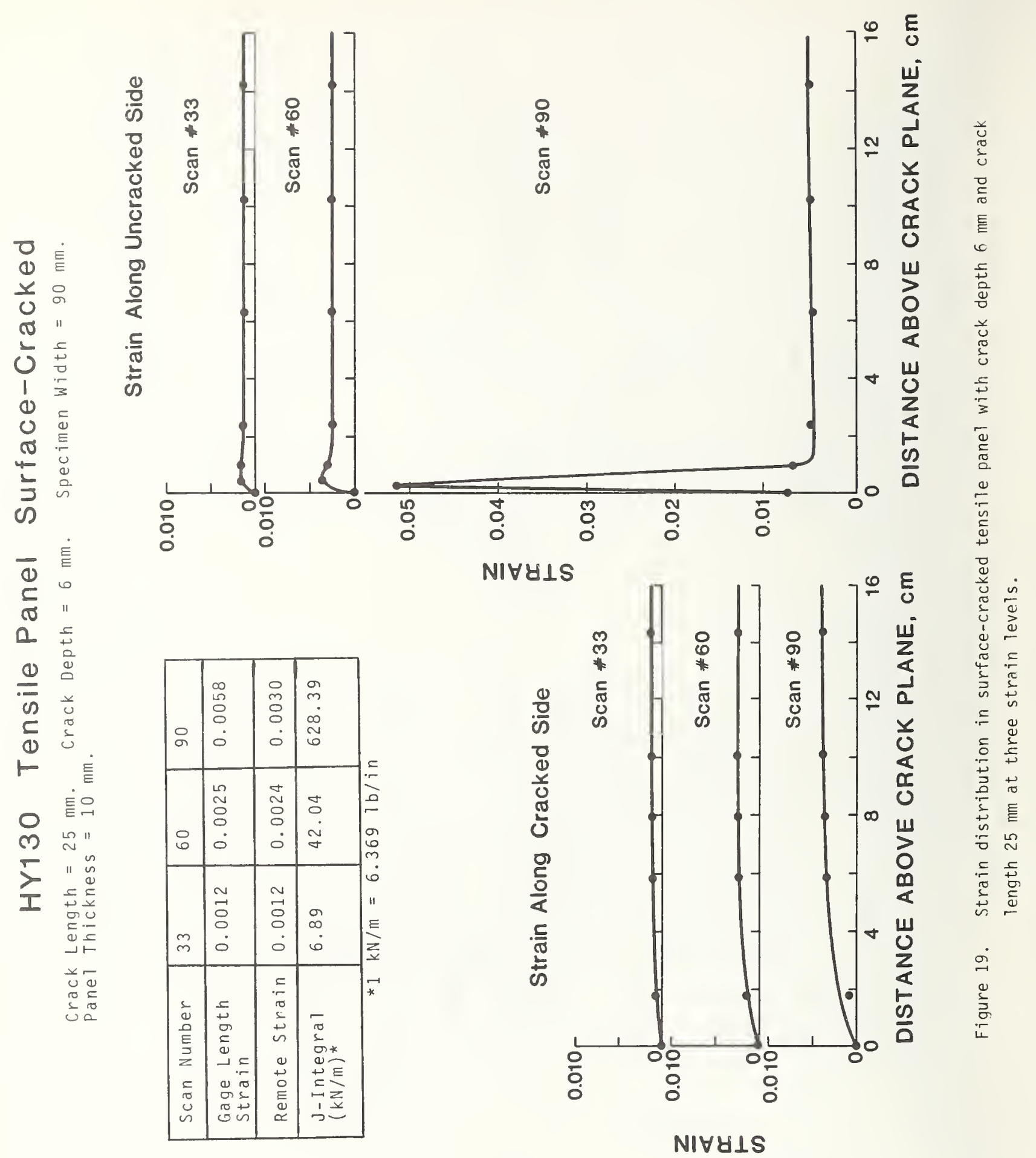



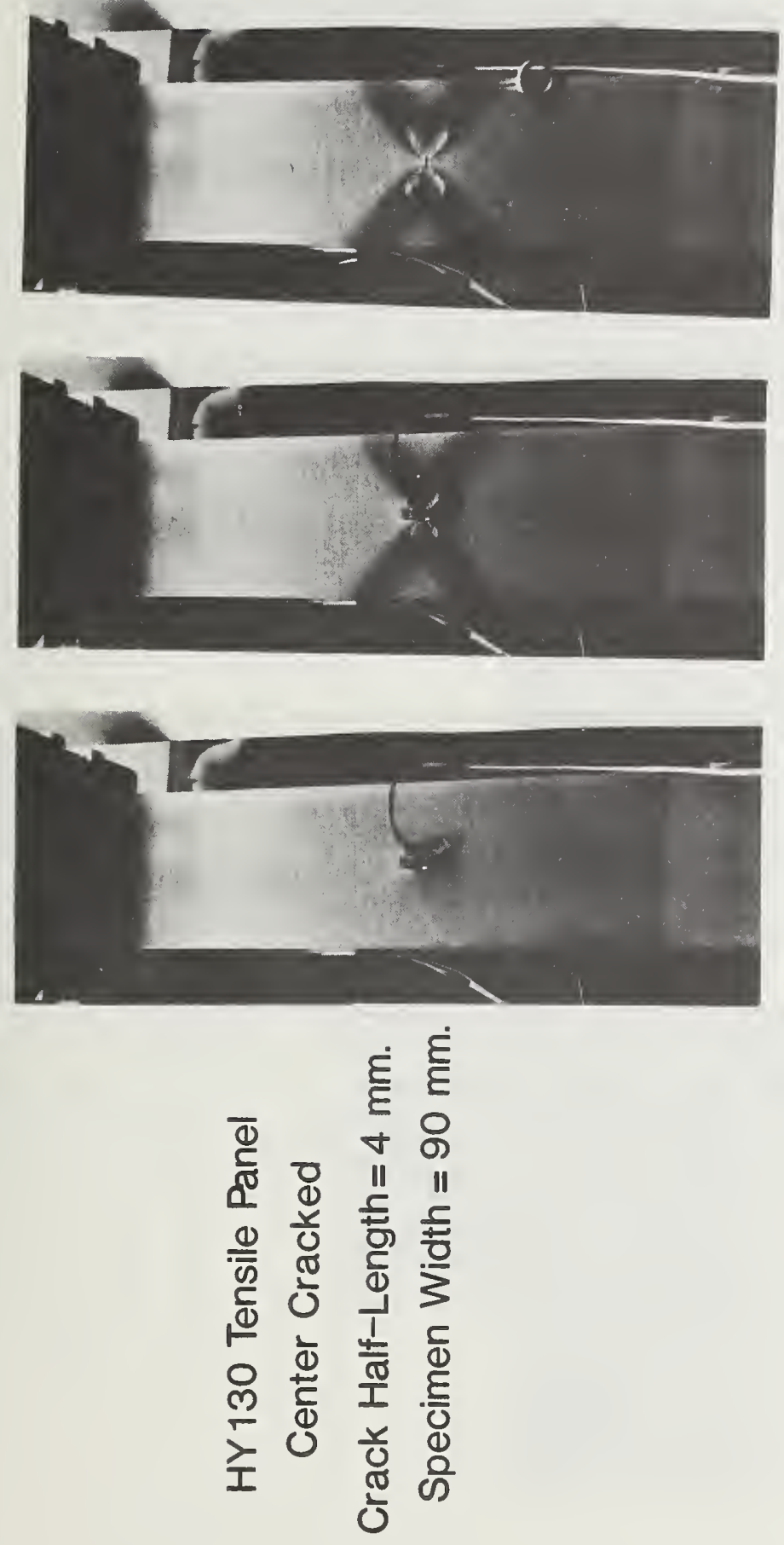

$\frac{3}{v}$

\begin{tabular}{|c|c|c|c|}
\hline $\begin{array}{l}N \\
10\end{array}$ & $\begin{array}{l}0 \\
0 \\
0 \\
0 \\
0\end{array}$ & $\begin{array}{l}0 \\
+ \\
0 \\
0 \\
0\end{array}$ & $\begin{array}{l}0 \\
0 \\
\forall\end{array}$ \\
\hline$\stackrel{\circ}{\forall}$ & $\begin{array}{l}\sigma \\
0 \\
0 \\
0 \\
0\end{array}$ & $\begin{array}{l}n \\
+ \\
0 \\
0 \\
0\end{array}$ & $\begin{array}{l}6 \\
0 \\
0\end{array}$ \\
\hline $\begin{array}{l}\infty \\
\sim\end{array}$ & $\begin{array}{l}\sigma \\
\dot{0} \\
0 \\
0 \\
0\end{array}$ & $\begin{array}{l}0 \\
\text { M } \\
0 \\
0 \\
0 \\
0\end{array}$ & $\underset{v}{+}$ \\
\hline 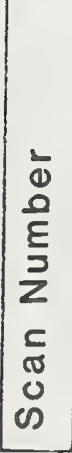 & 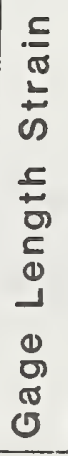 & 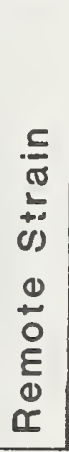 & 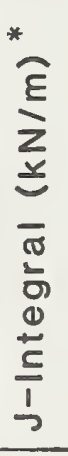 \\
\hline
\end{tabular}



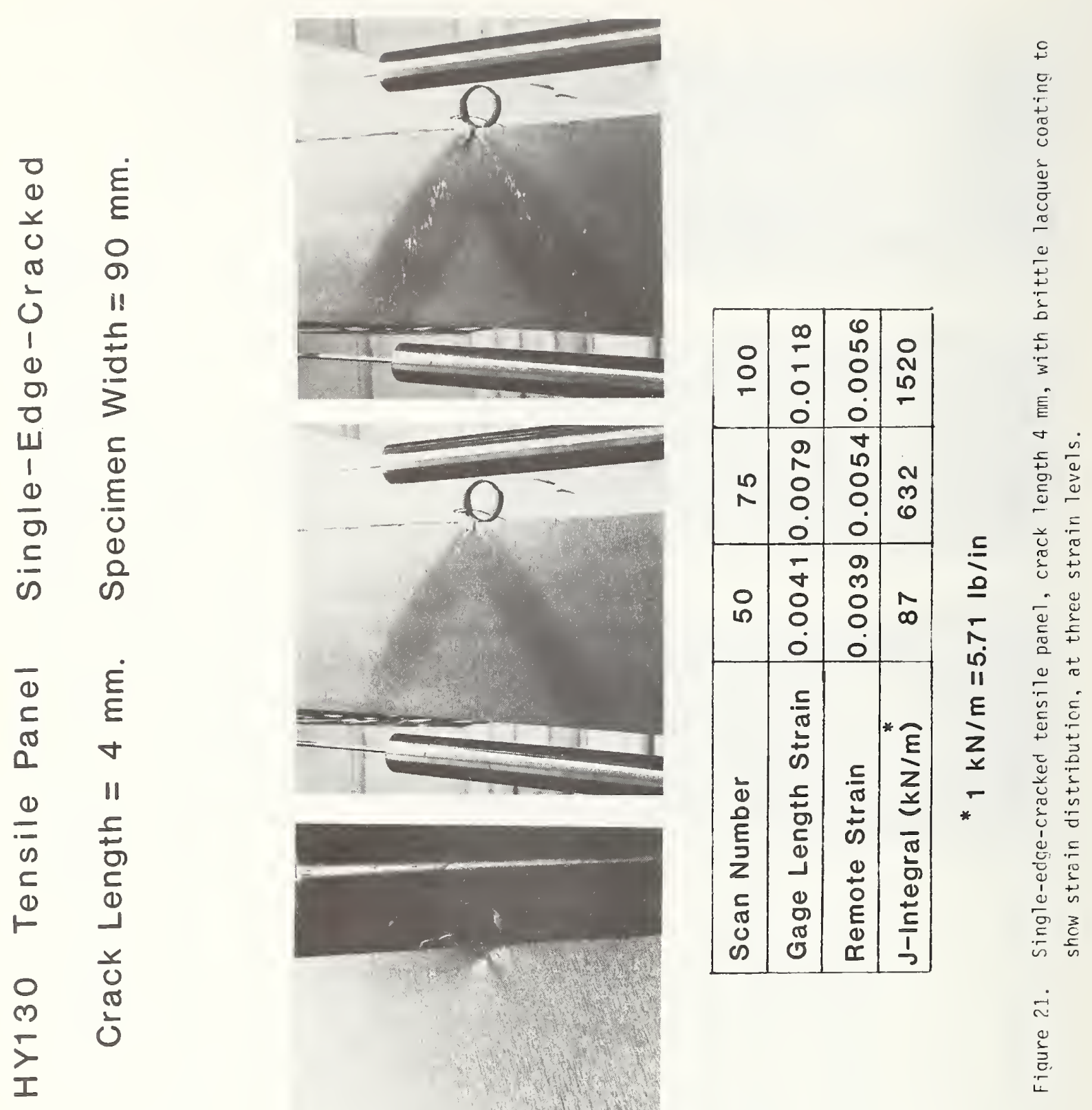

$\dot{\sim}$
0
$\frac{0}{3}$
$\frac{\pi}{4}$ 

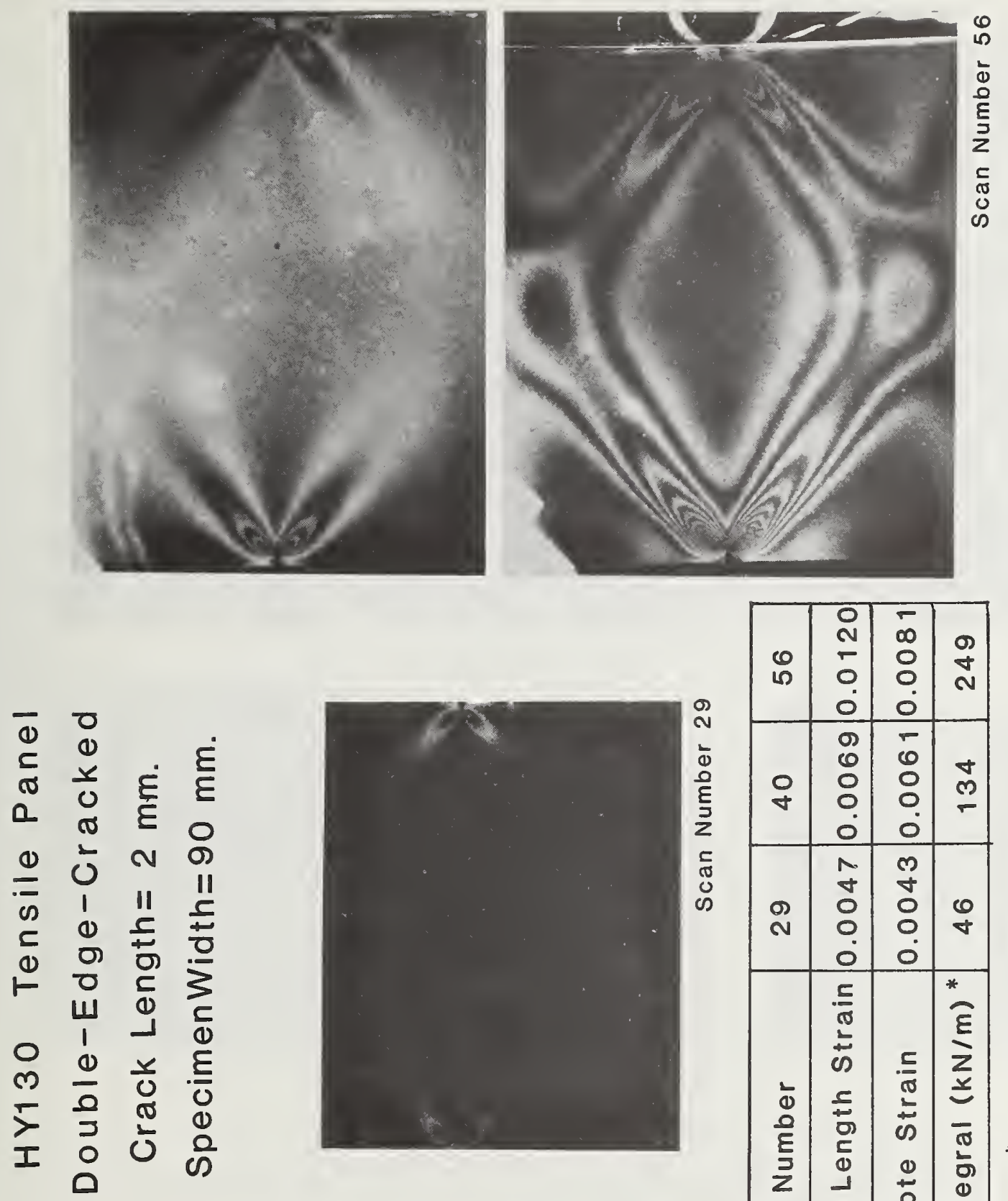

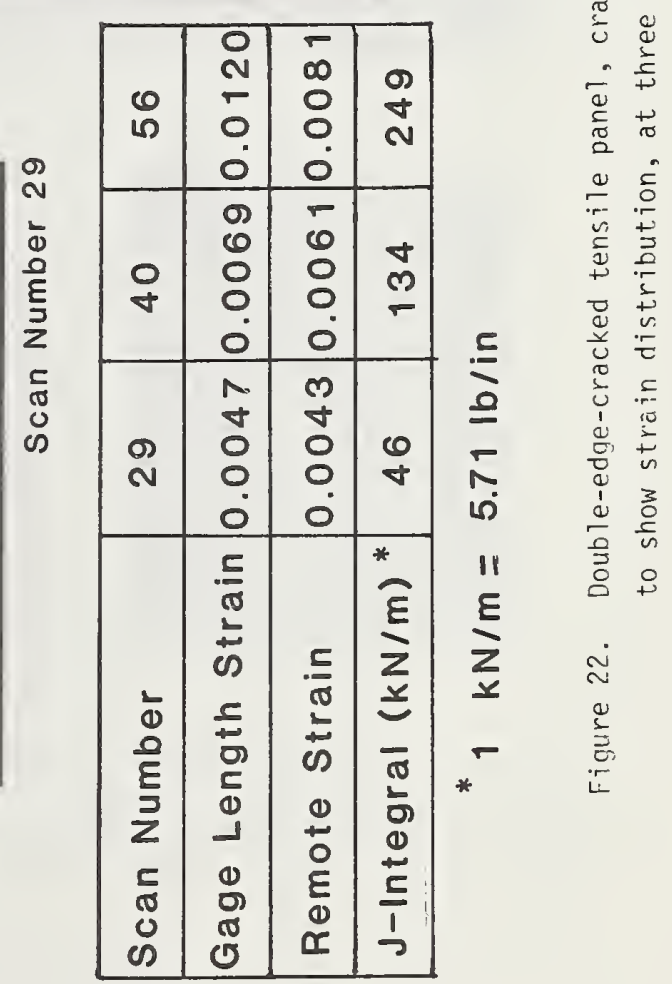


HY130 Tensile Panel

Face-Cracked

Crack Depth $=2 \mathrm{~mm}$.

Panel Width $=90 \mathrm{~mm}$.
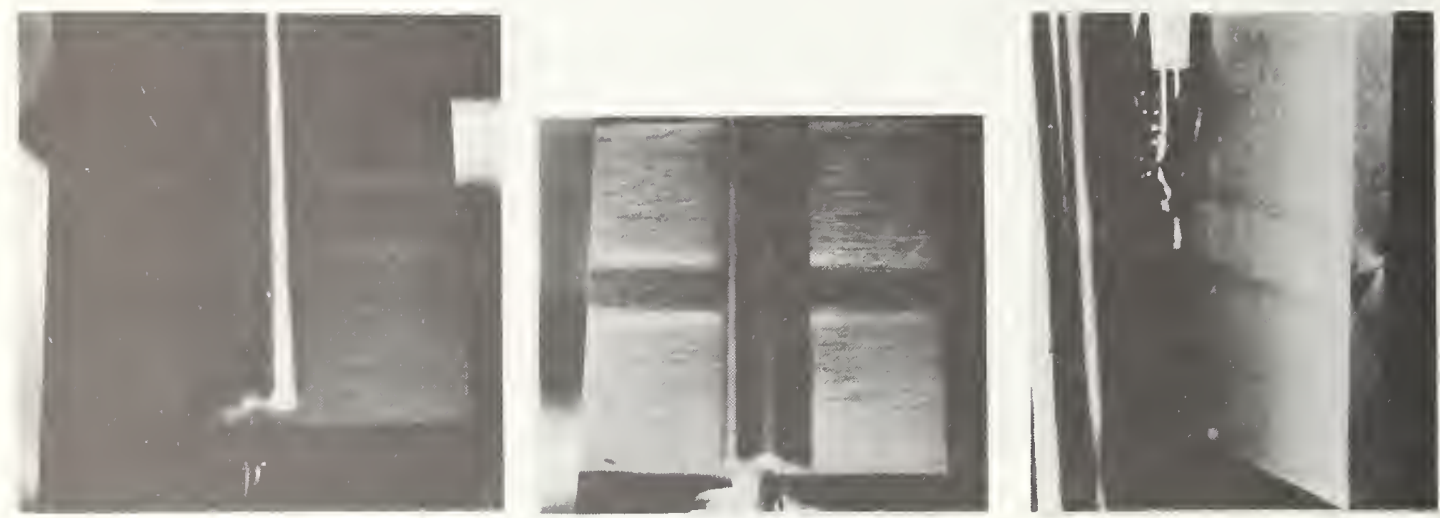

Scan Number 61
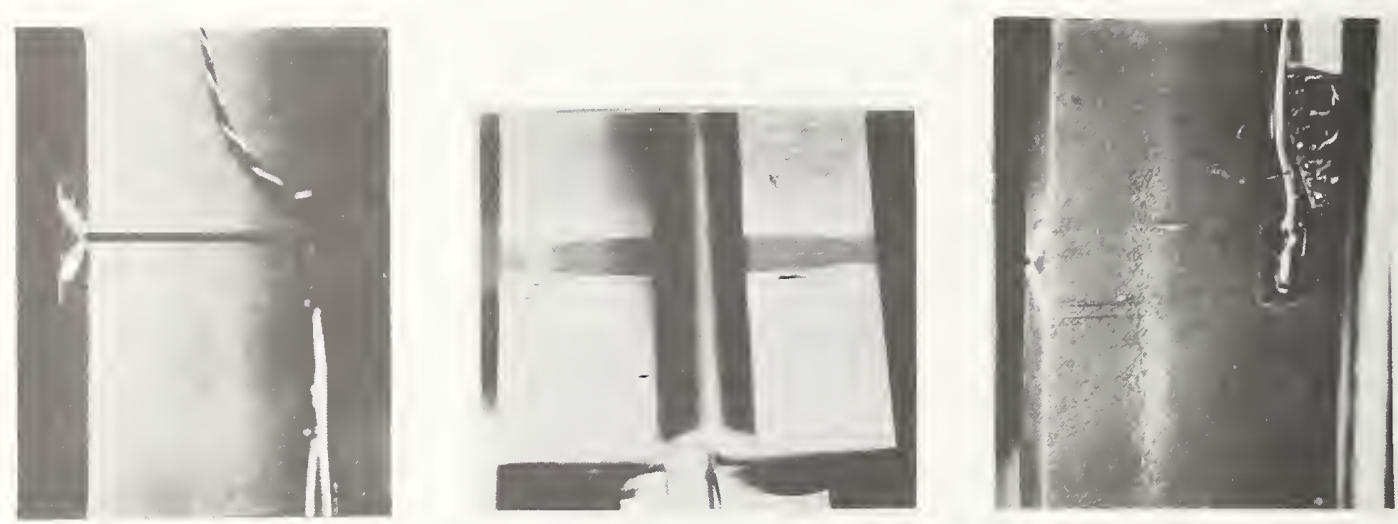

Scan Number 71

\begin{tabular}{|c|c|c|c|}
\hline Scan Number & Gage Length Strain & Remote Strain & J-Integral (kN/m)* \\
\hline 40 & 0.0029 & 0.0026 & 12 \\
\hline 61 & 0.0050 & 0.0041 & 132 \\
\hline 71 & 0.0071 & 0.0043 & 712 \\
\hline
\end{tabular}

Figure 23. Face-cracked tensile pane1, crack depth $2 \mathrm{~mm}$, with brittle laccuer coating to show strain distribution, at three strain levels. 

HY130 Tensile Panel
Edge-Hole-Cracked
Crack Depth $=2 \mathrm{~mm}$. Hole Radius $=14 \mathrm{~mm}$.
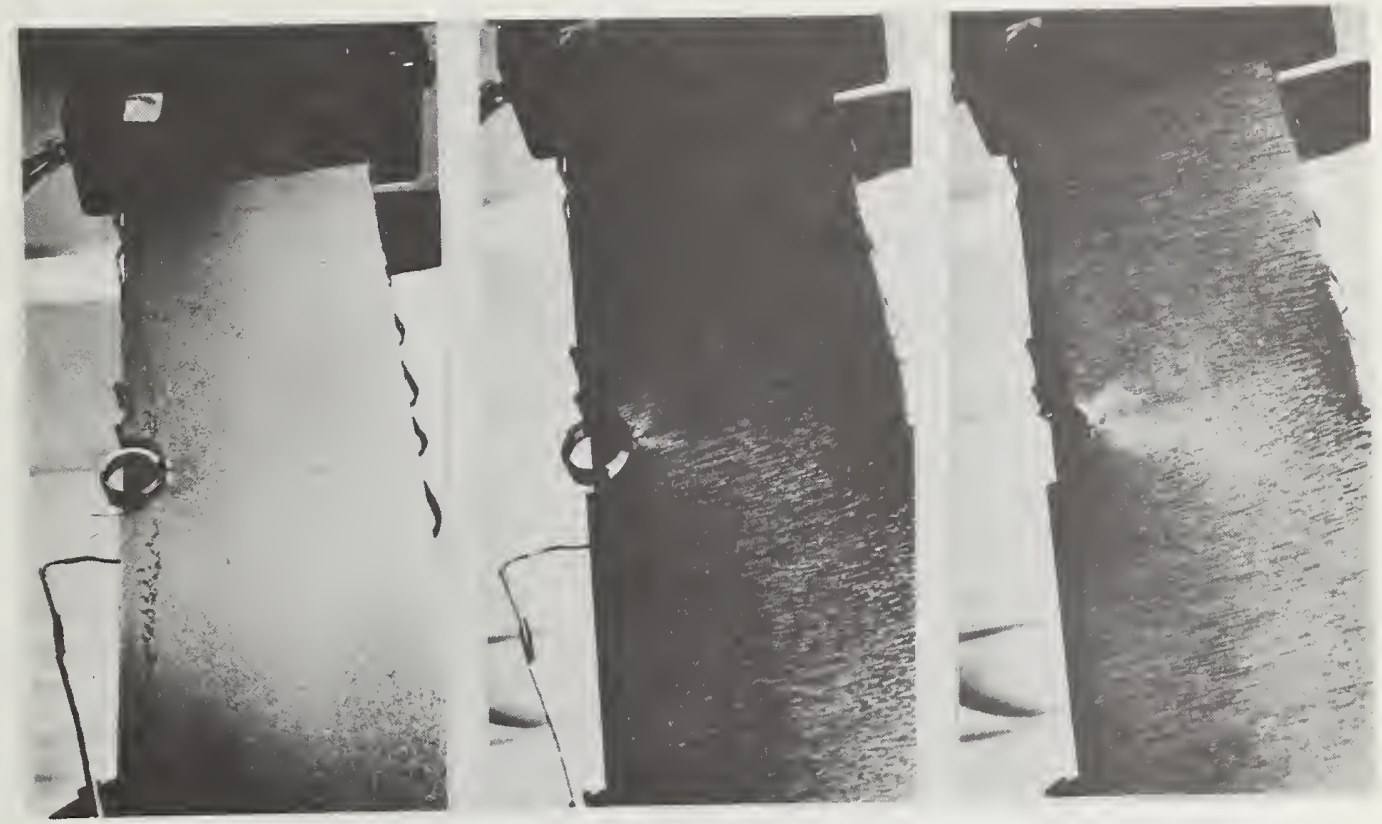

\begin{tabular}{|l|c|c|c|}
\hline Scan Number & 30 & 60 & 92 \\
\hline Gage Length Strain & 0.0015 & 0.0025 & 0.0048 \\
\hline Neuber Strain & 0.0035 & 0.0119 & 0.0335 \\
\hline $\mathrm{J}$-Integral $(\mathrm{kN} / \mathrm{m})^{*}$ & 13 & 67 & 440 \\
\hline
\end{tabular}

$* 1 \mathrm{kN} / \mathrm{m}=5.71 \mathrm{lb} / \mathrm{in}$

Figure 24. Edge-hole-cracked tensile panel, crack length $2 \mathrm{~mm}$, with brittle lacquer coating to show strain distribution, at three strain levels. 

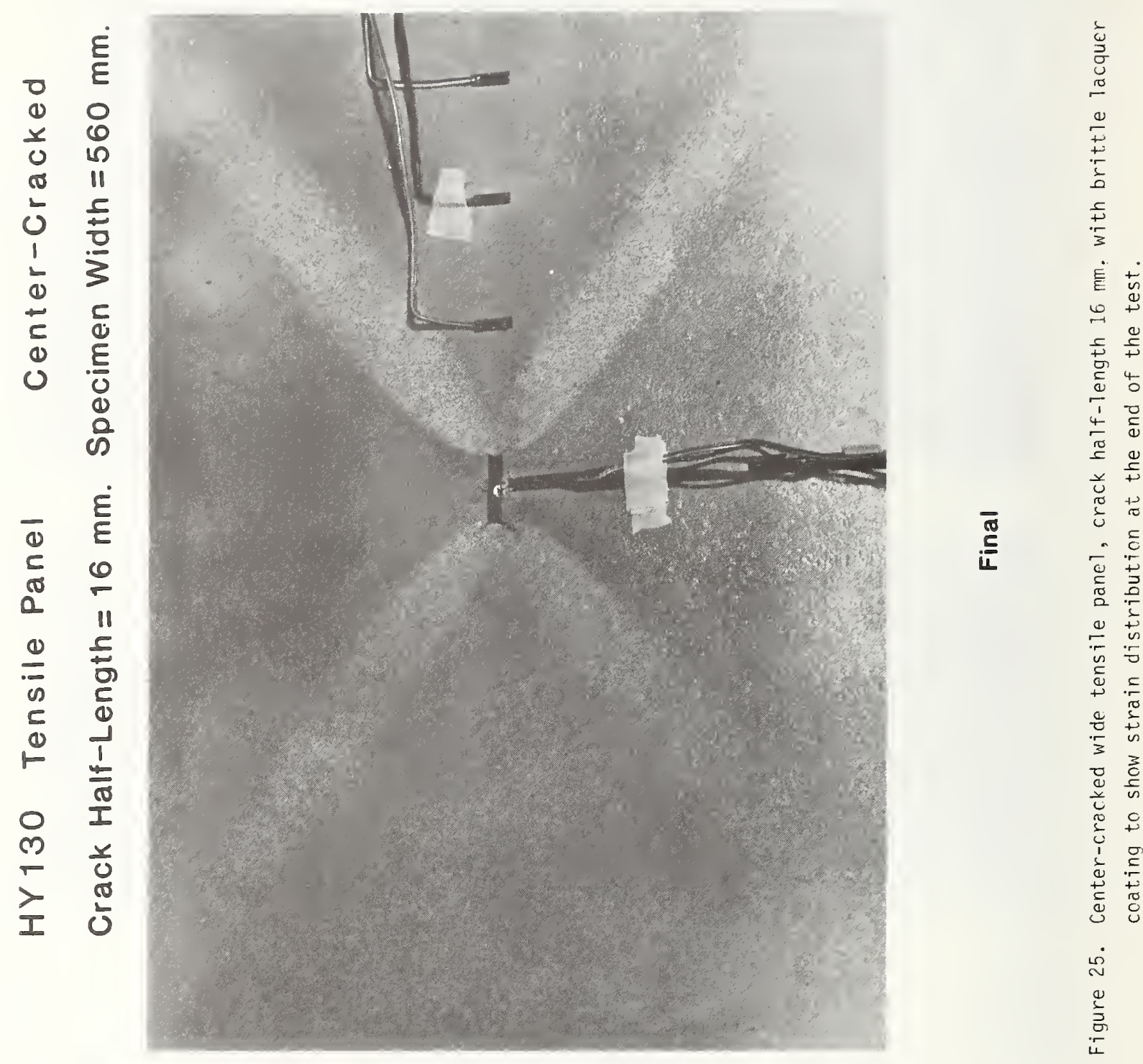

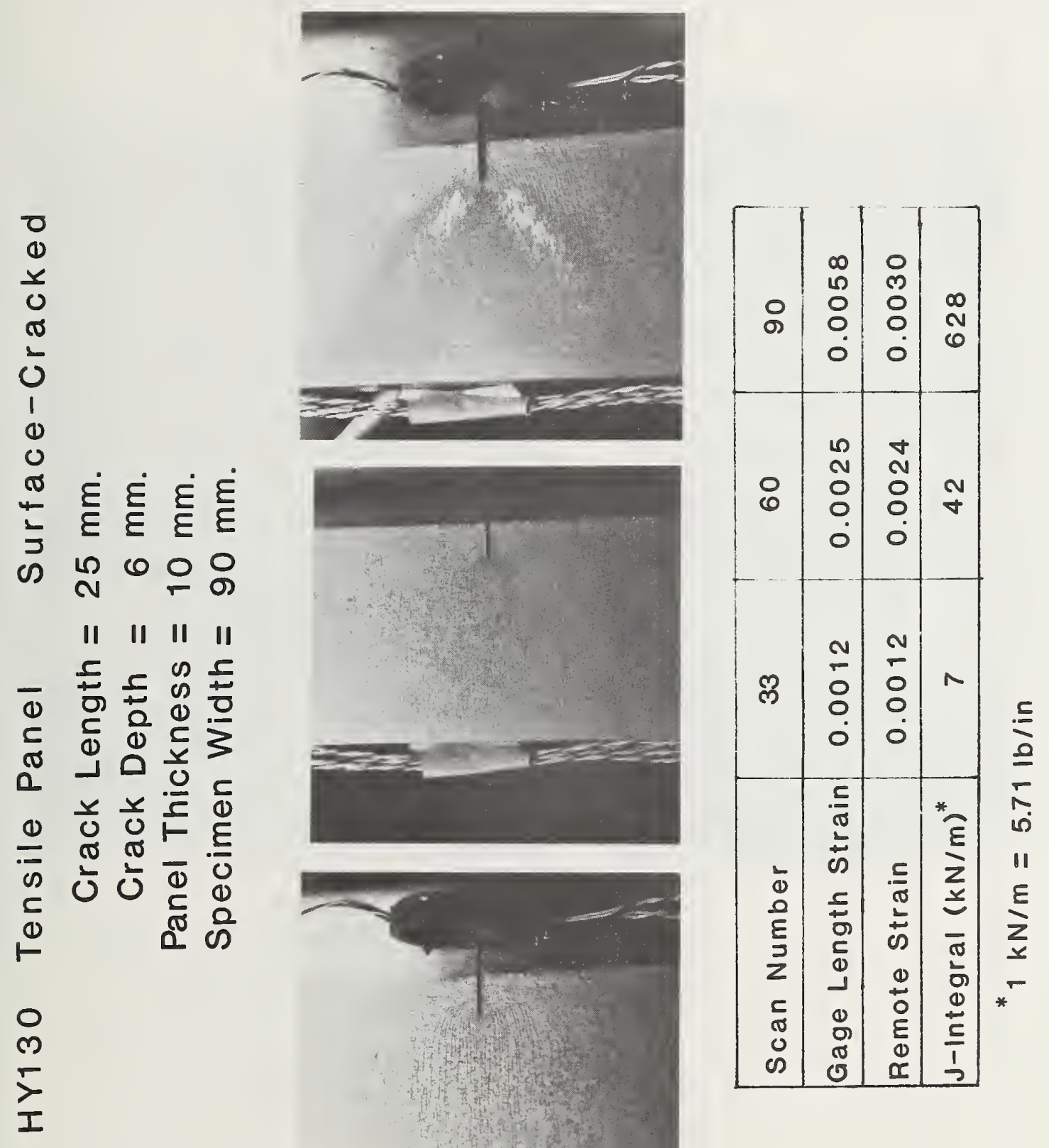

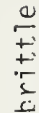




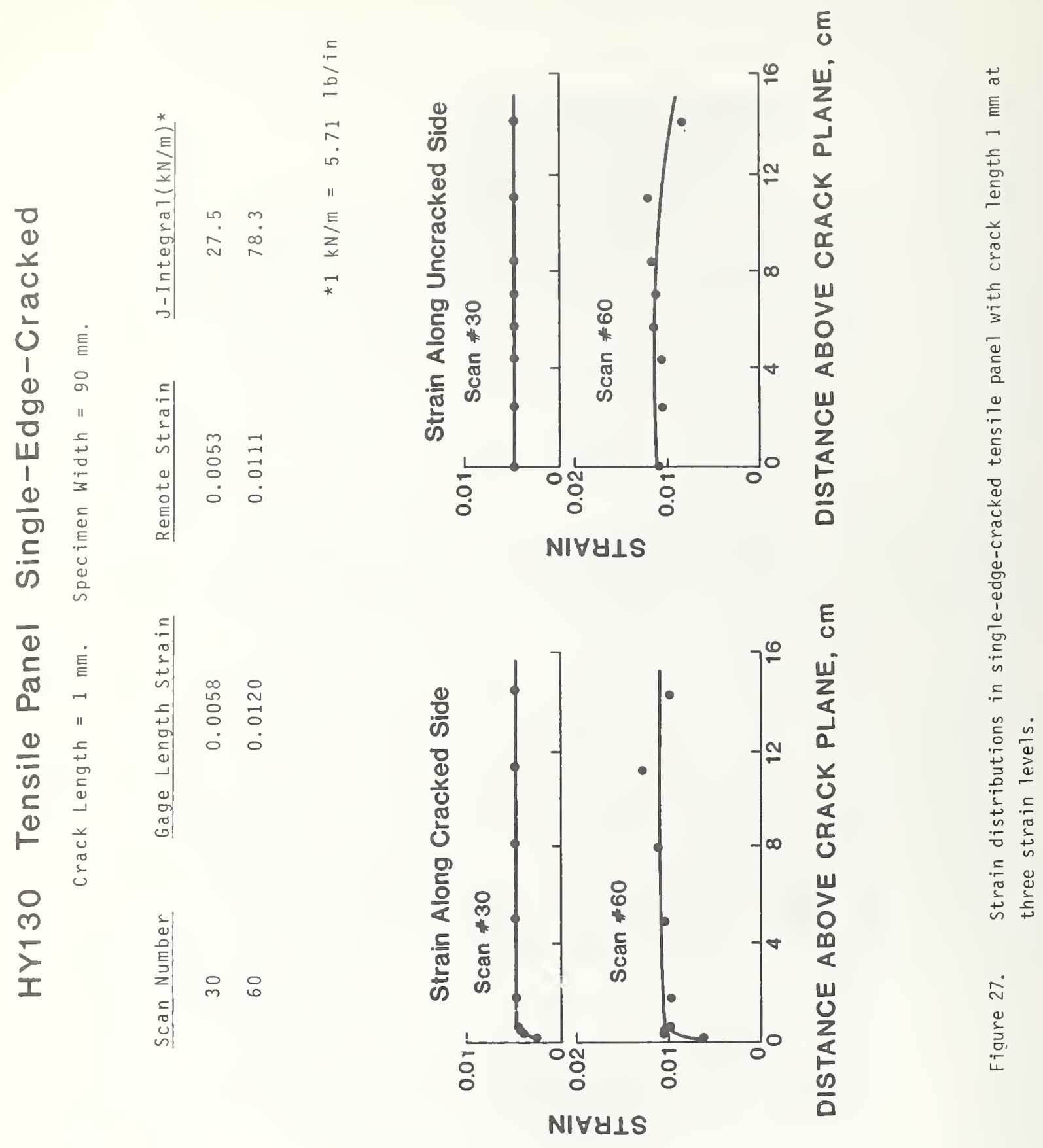


HY130 Tensile Panel

\section{Crack Length $=1 \mathrm{~mm}$.}

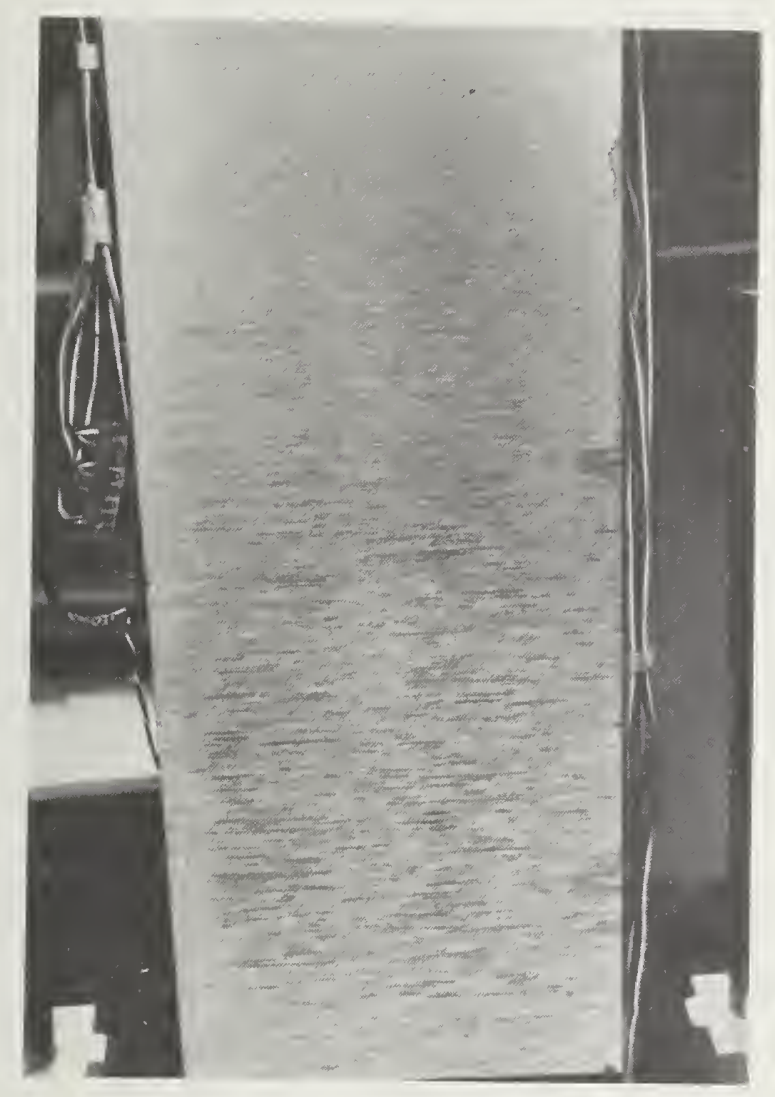

$$
\begin{aligned}
\text { Scan Number } & 30 \\
\text { Gage Length Strain } & =0.0058 \\
\text { Remote Strain } & =0.0053 \\
\mathrm{~J}-\text { Integral }(\mathrm{kN} / \mathrm{m}) & =27.5
\end{aligned}
$$

*1 $\mathrm{kN} / \mathrm{m}=5.71 \mathrm{lb} / \mathrm{in}$
Single-Edge-Cracked

$$
\text { Specimen Width }=90 \mathrm{~mm} \text {. }
$$

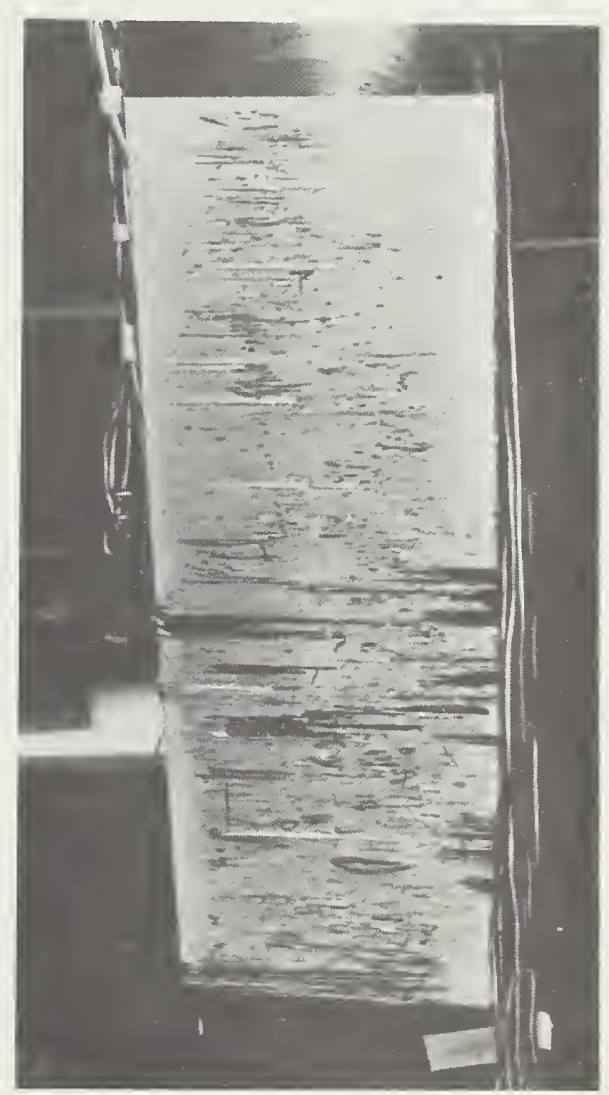

Final

Figure 28. Single-edge-cracked tensile panel, crack length $1 \mathrm{~nm}$, with brittle lacquer coating to show strain distribution near yield and at the end of the test. 


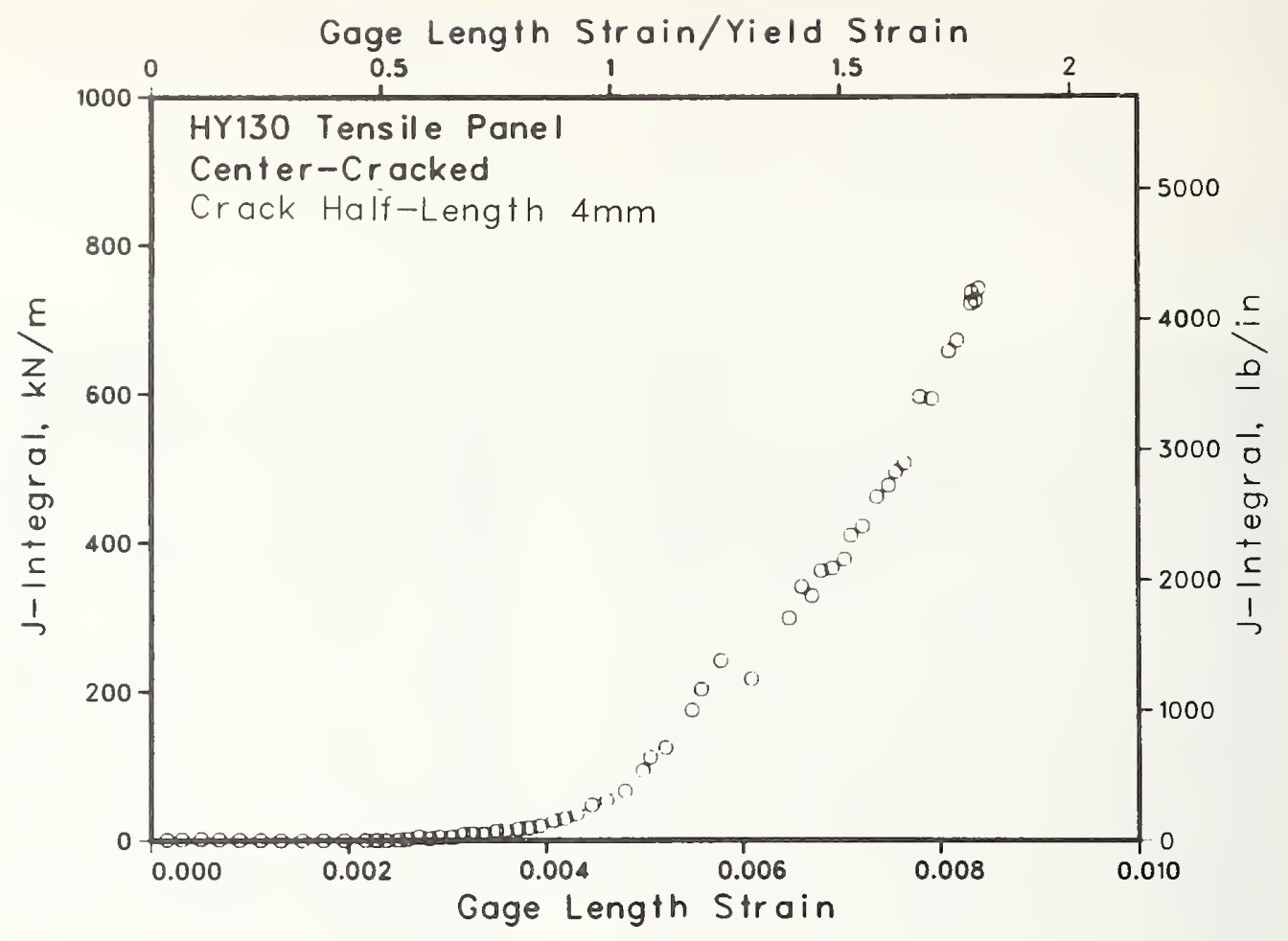

Figure 29a. J-integral plotted against gage length strain for center-cracked tensile panel with crack half-length $4 \mathrm{~mm}$.

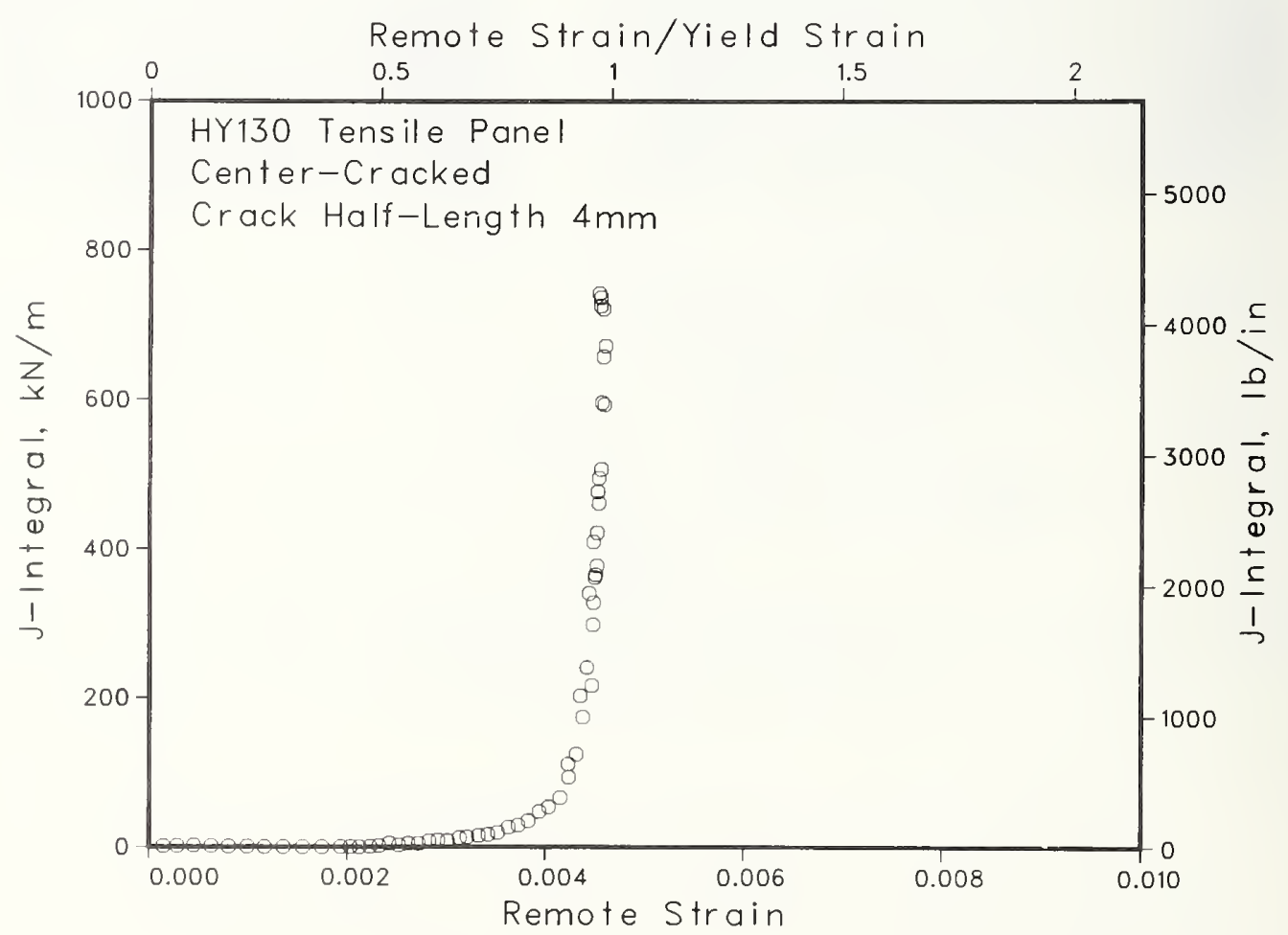

Figure 29b. J-integral plotted against remote strain for center-cracked tensile panel with crack half-length $4 \mathrm{~mm}$. 


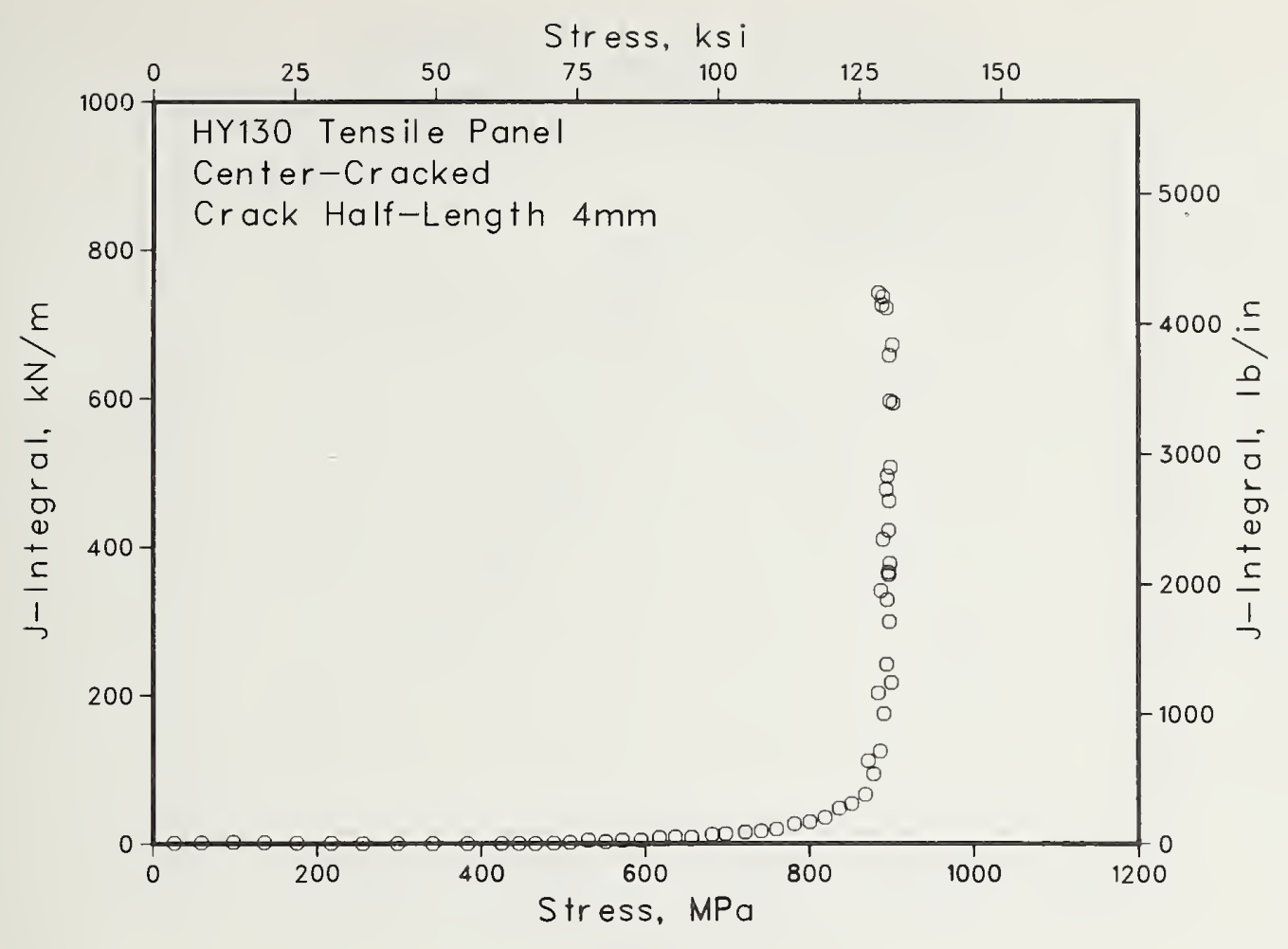

Figure 29c. J-integral plotted against stress for center-cracked tensile panel with crack length 4. $\mathrm{mm}$.

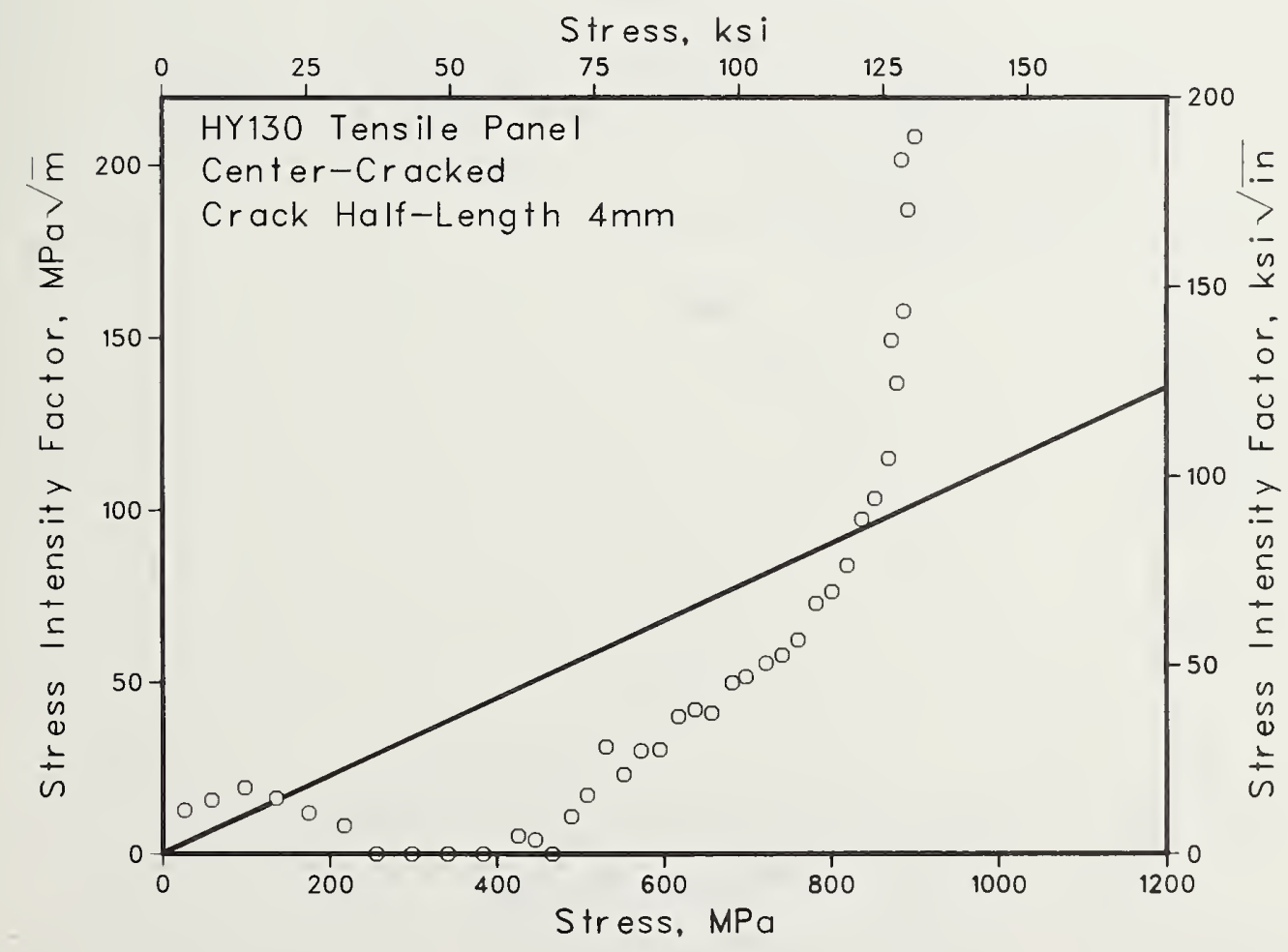

Figure 29d. Stress intensity factor plotted against stress for center-cracked tensile panel with crack half-length $4 \mathrm{~mm}$. 


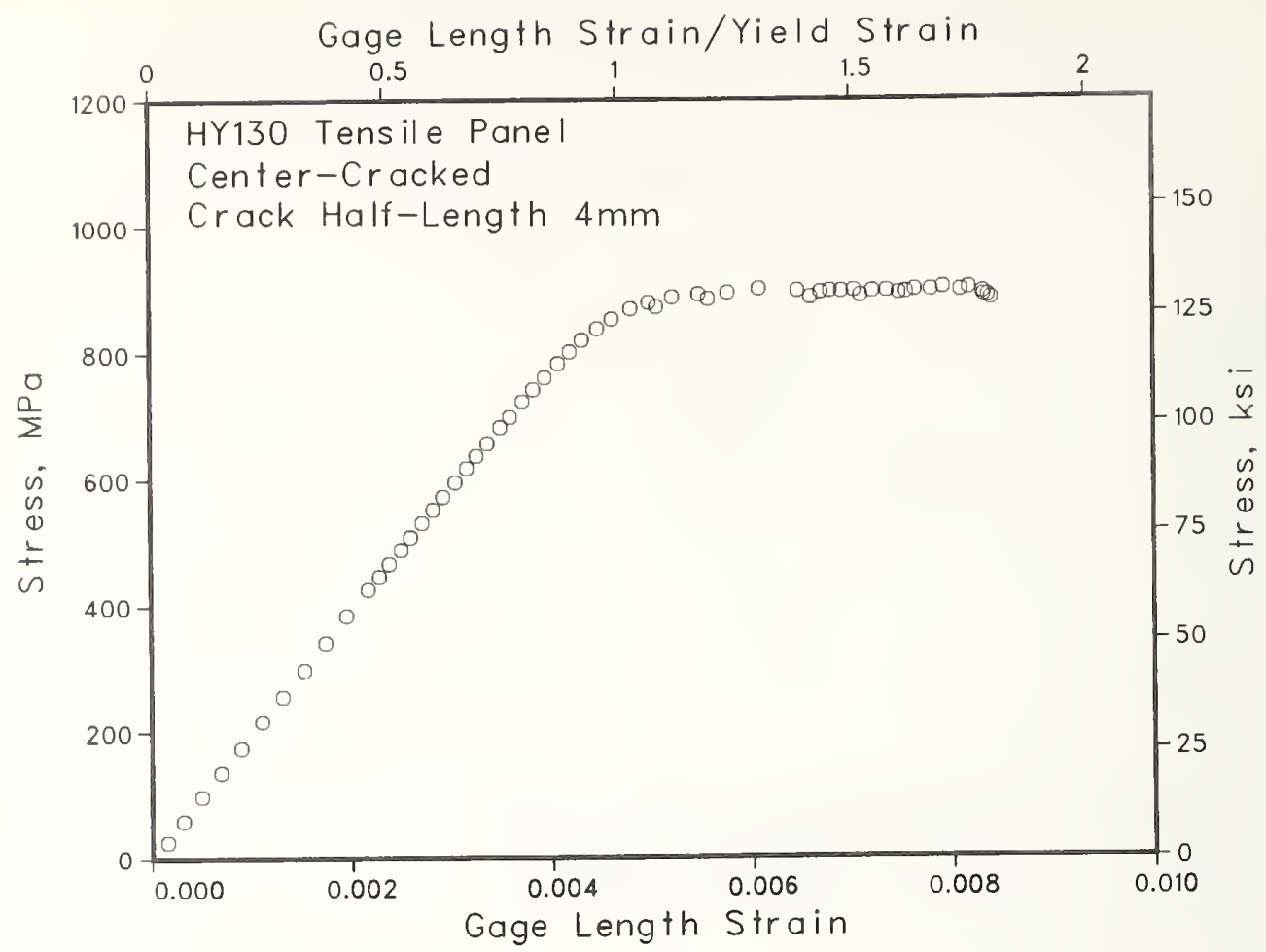

Figure 29e. Stress plotted against gage length strain for center-cracked tensile panel with crack half-length $4 \mathrm{~mm}$.

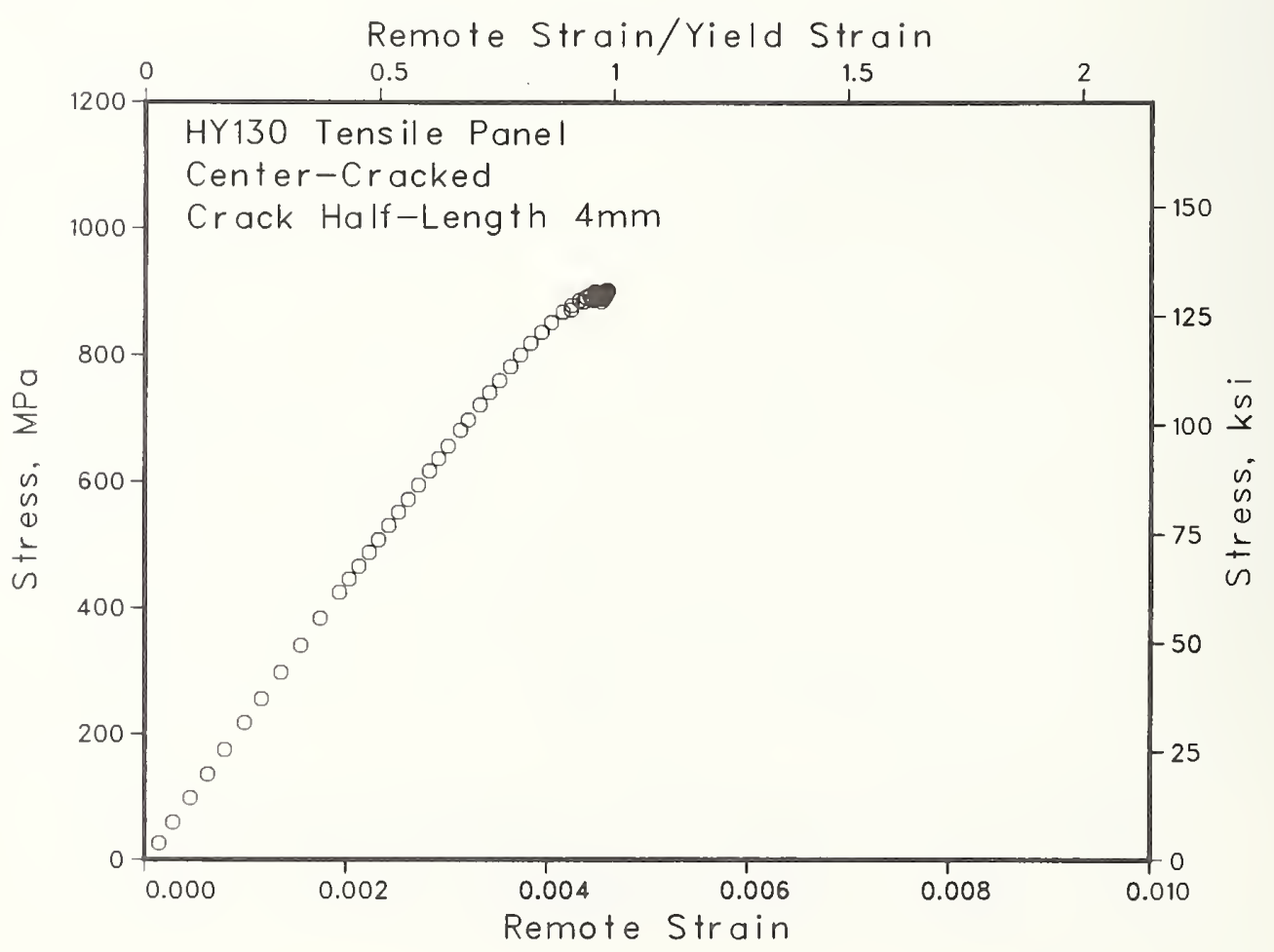

Figure 29f. Stress plotted against remote strain for center-cracked tensile panel with crack length $4 \mathrm{~mm}$. 


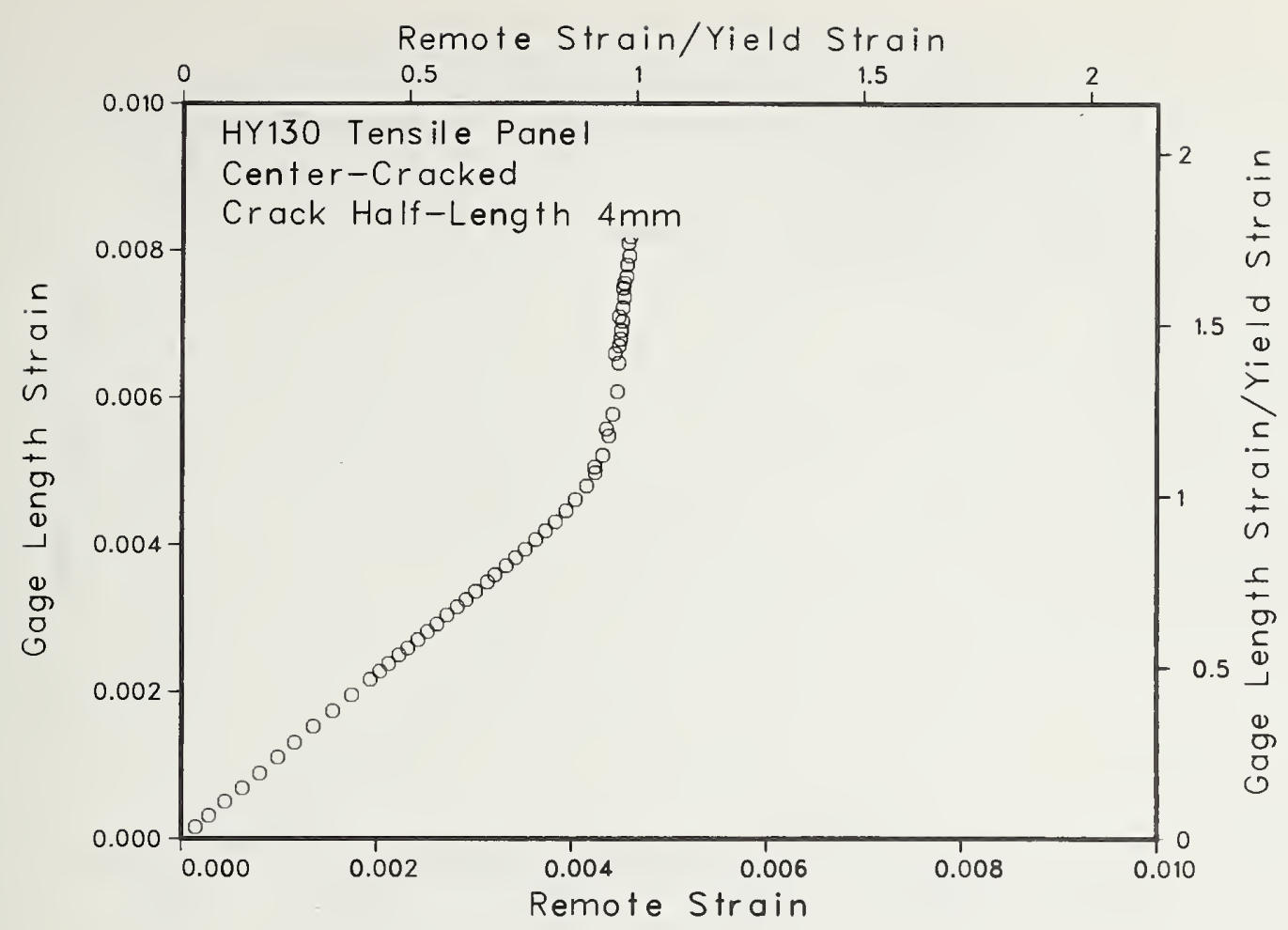

Figure 29g. Gage length strain plotted against remote strain for center-cracked tensile panel with crack half-length $4 \mathrm{~mm}$.

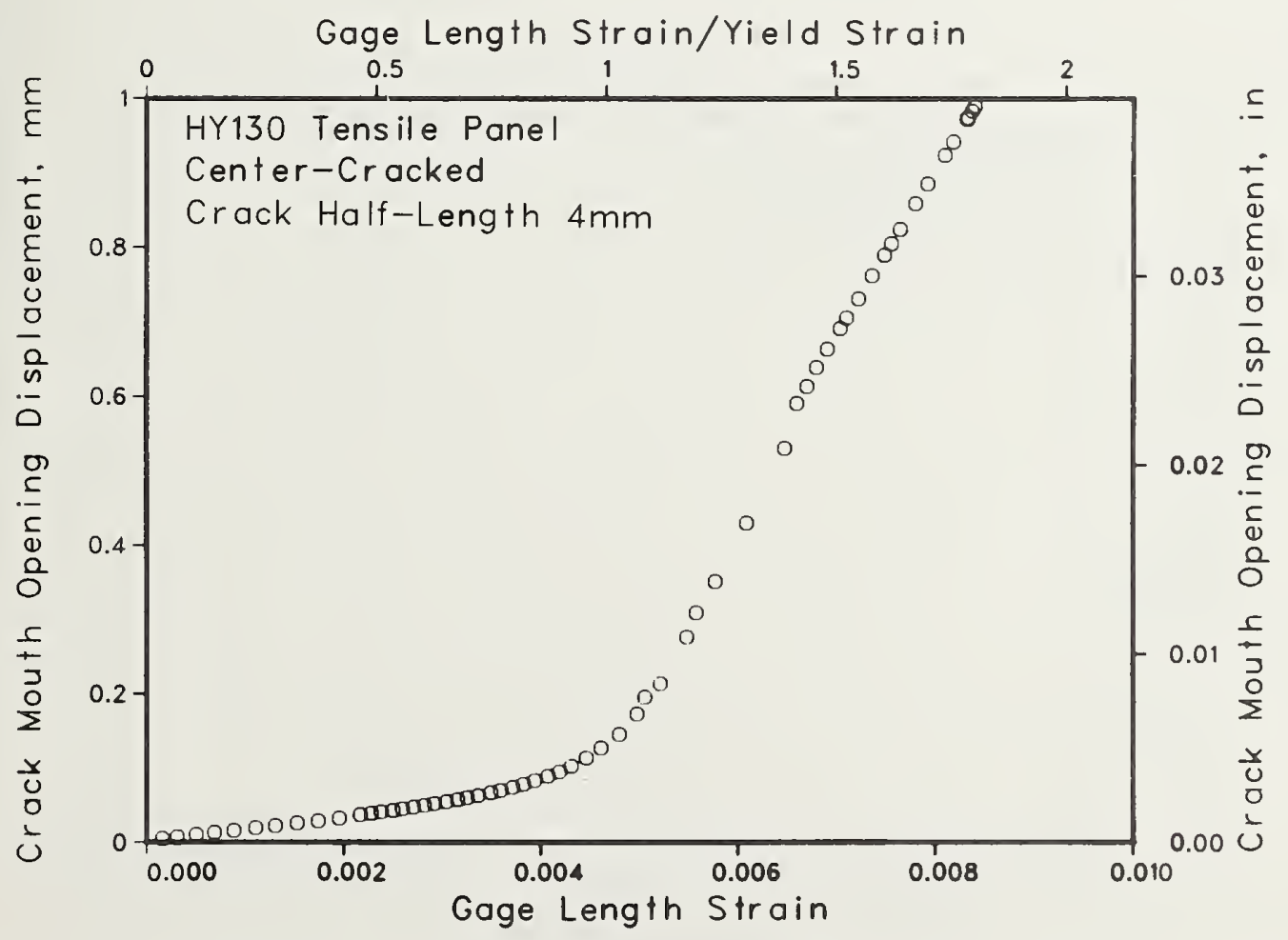

Figure 29h. Crack mouth opening displacement plotted against gage length strain for center-cracked tensile panel with crack half-length $4 \mathrm{~mm}$. 


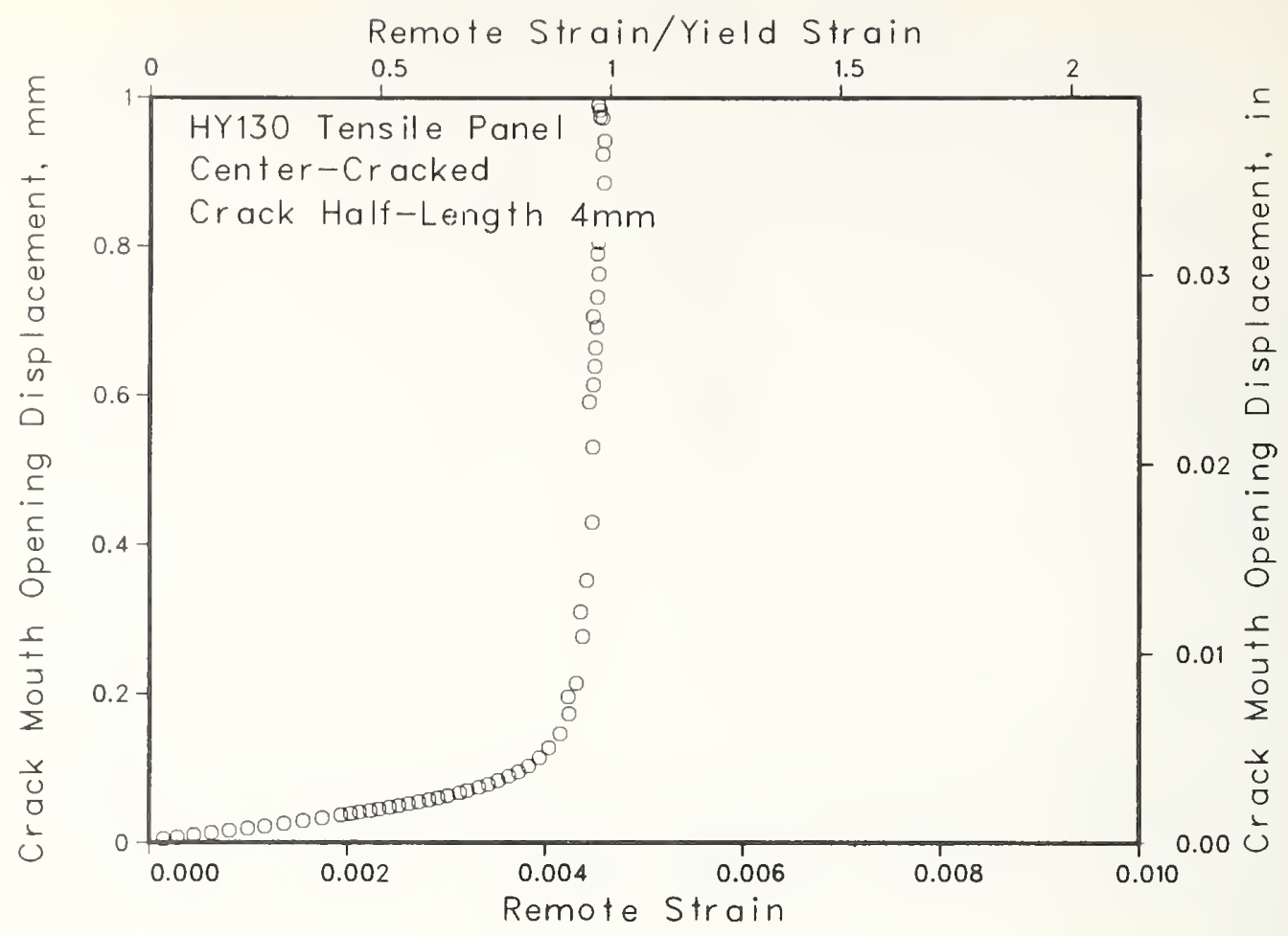

Figure 29i. Crack mouth opening displacement plotted against remote strain for center-cracked tensile panel with crack half-length $4 \mathrm{~mm}$.

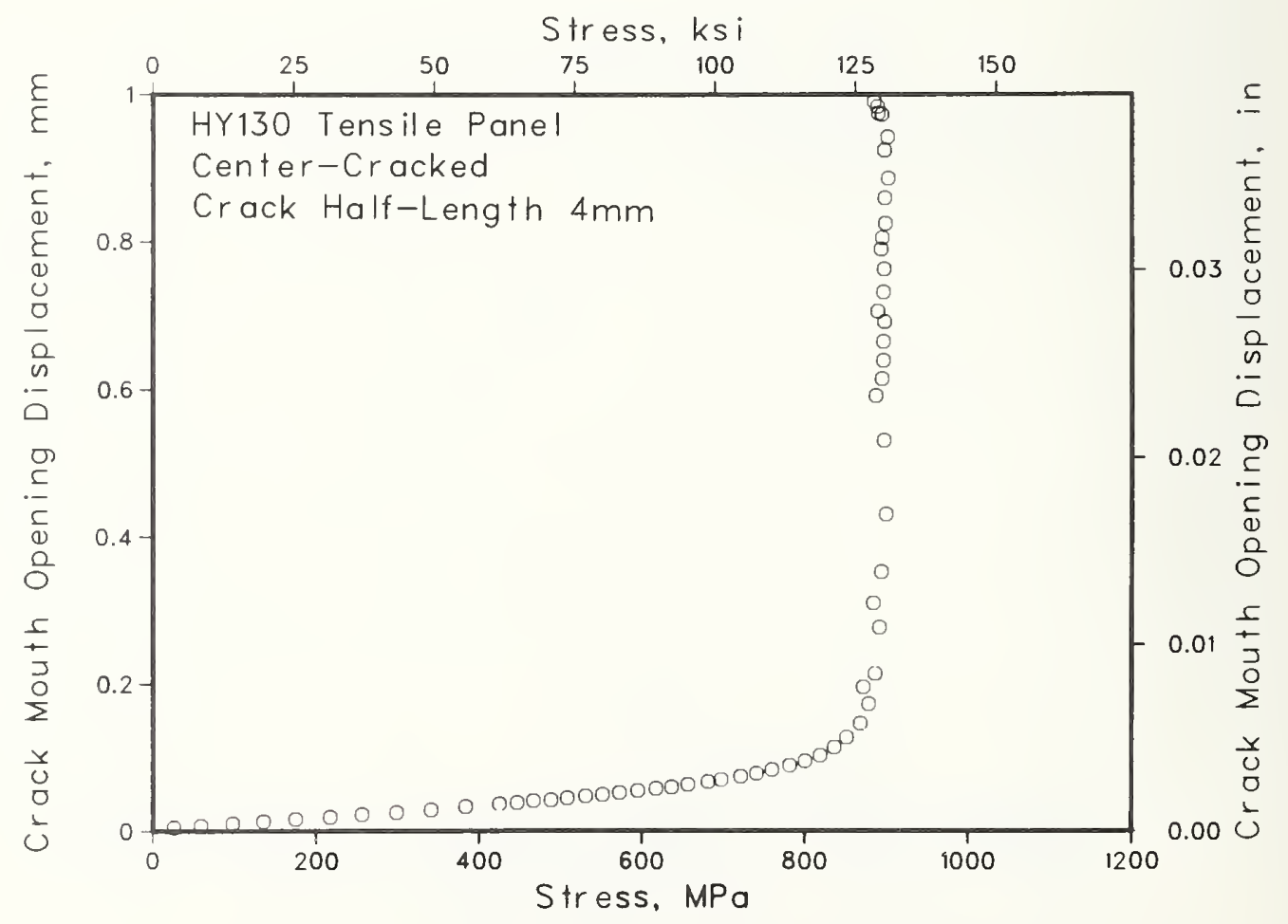

Figure 29j. Crack mouth opening displacement plotted against stress for center cracked tensile panel with crack half-length $4 \mathrm{~mm}$. 


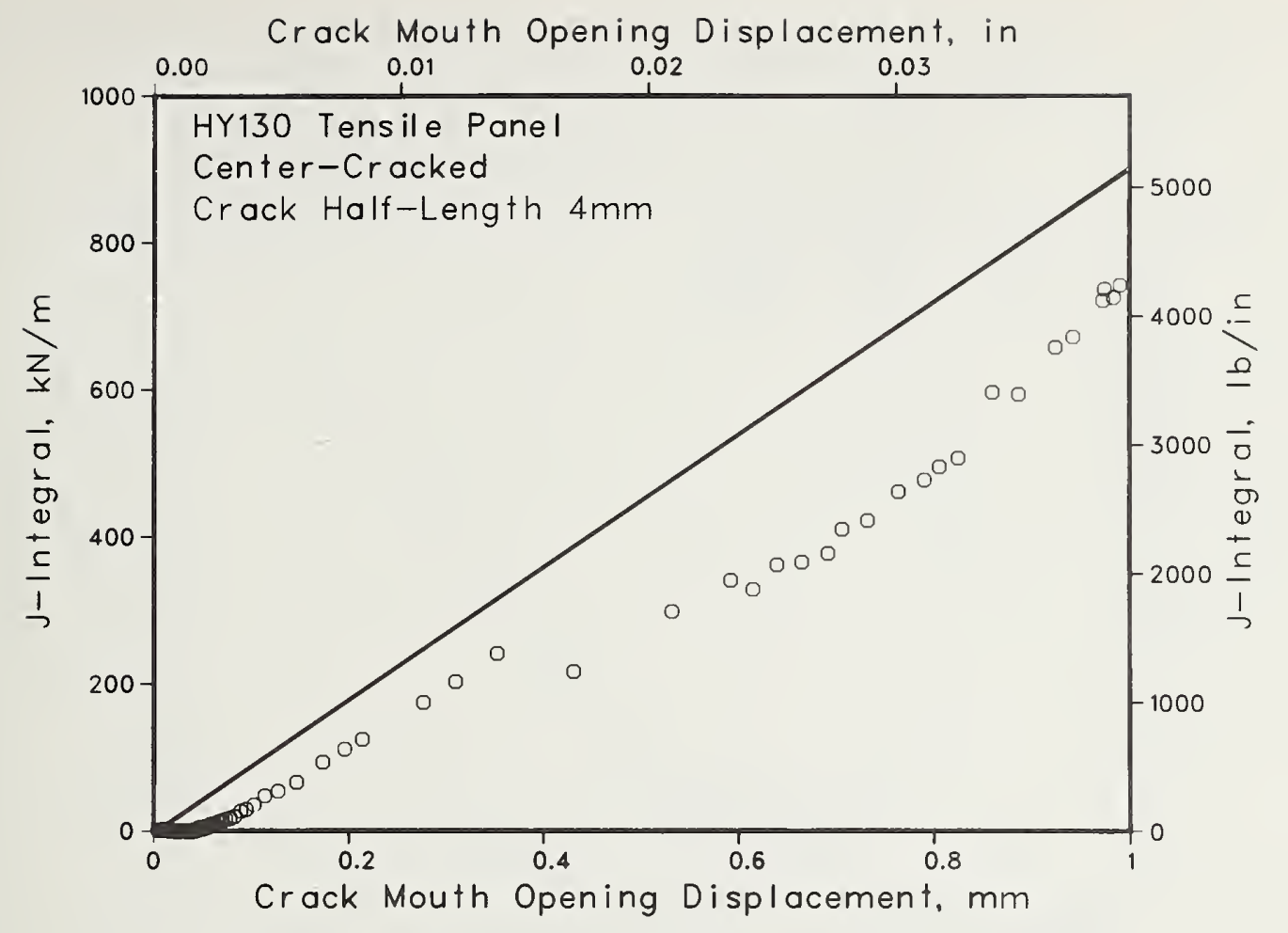

Figure 29k. J-integral plotted against crack mouth opening displacement for center-cracked tensile panel with crack half-length $4 \mathrm{~mm}$. 
Figure 30a-30k. Dependence of J-integral, stress, and crack mouth opening displacement on strain for single-edge-cracked tensile panel with crack length $4 \mathrm{~mm}$.

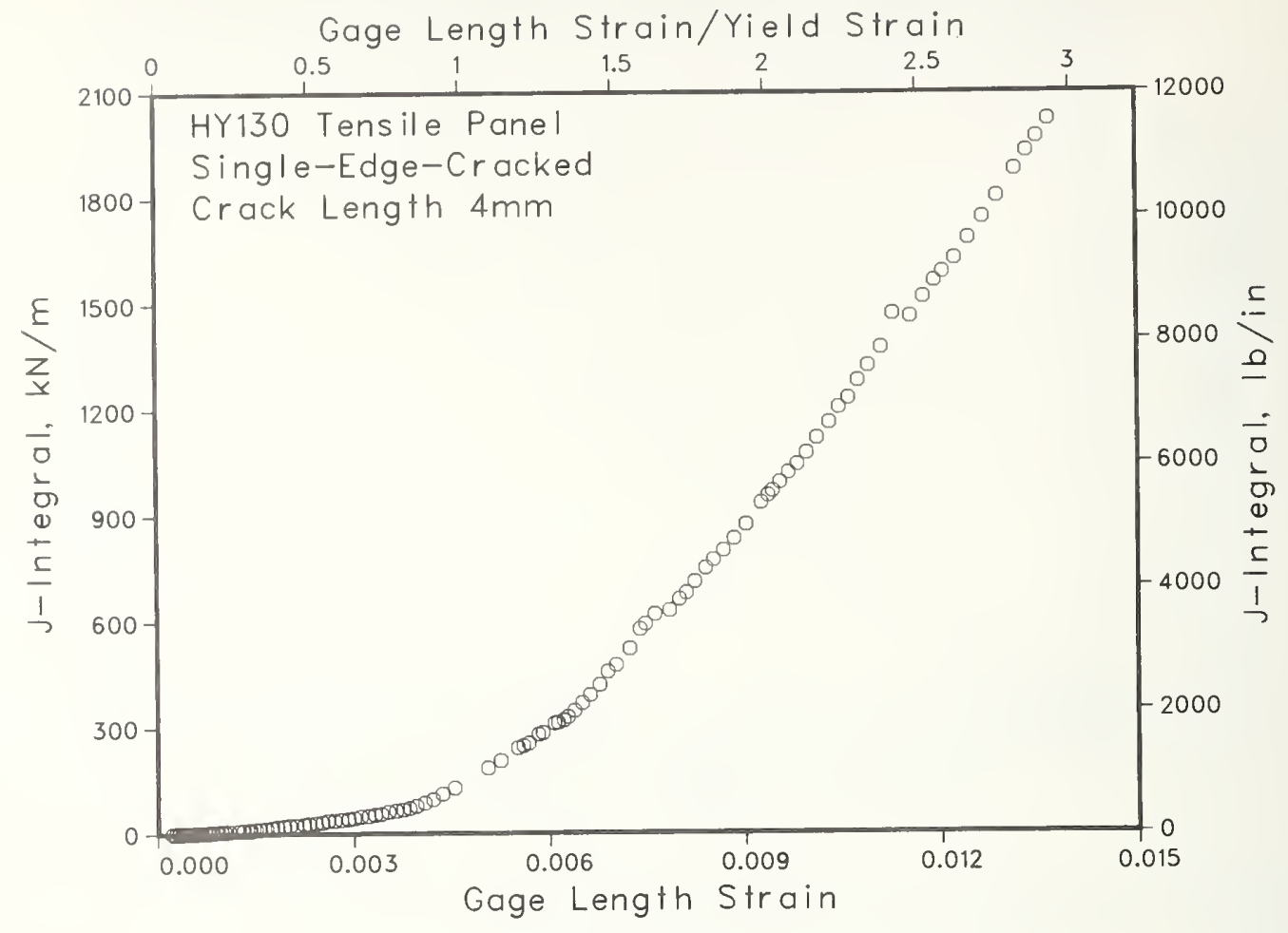

Figure $30 a$.

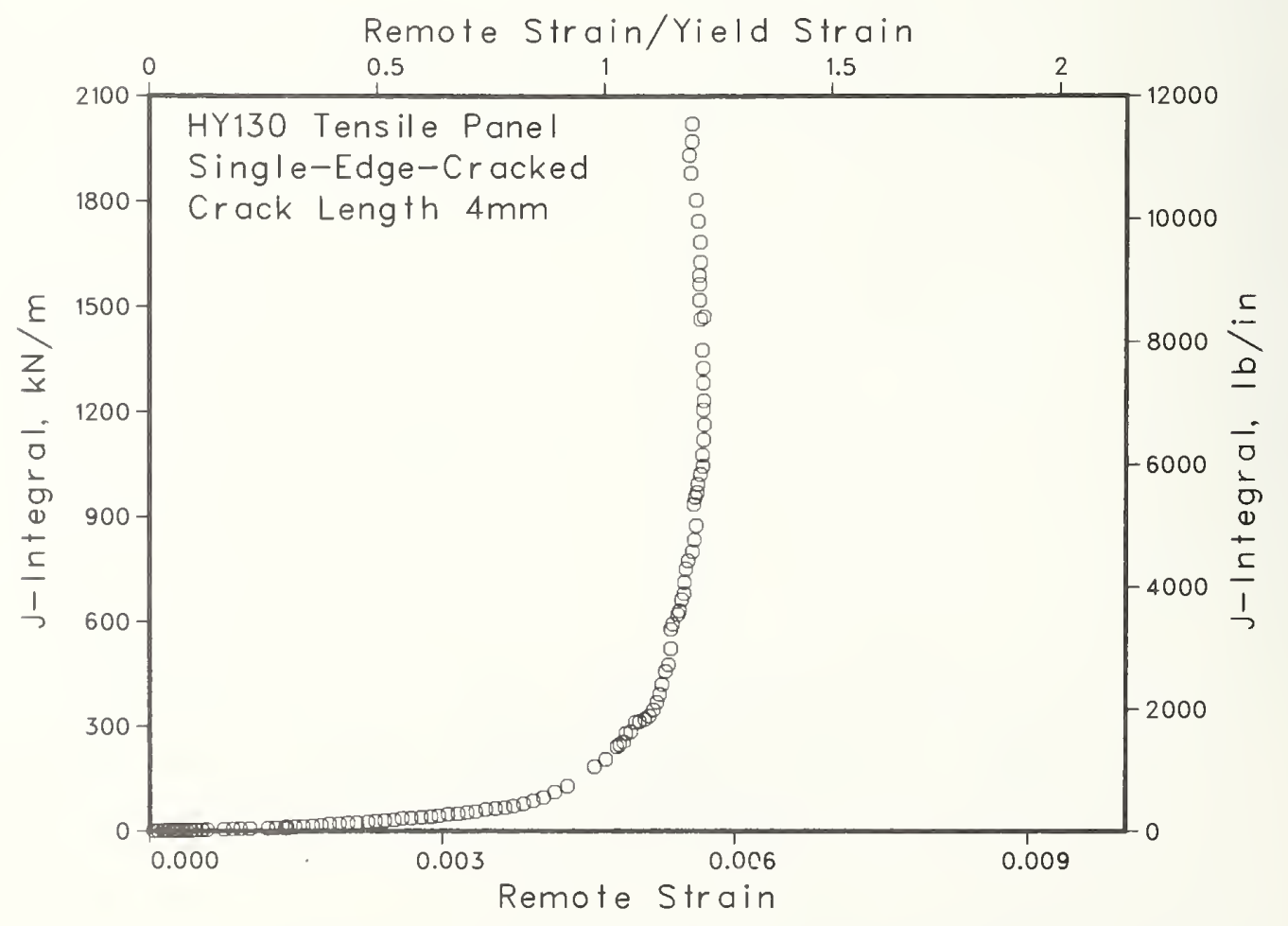

Figure 30b. 


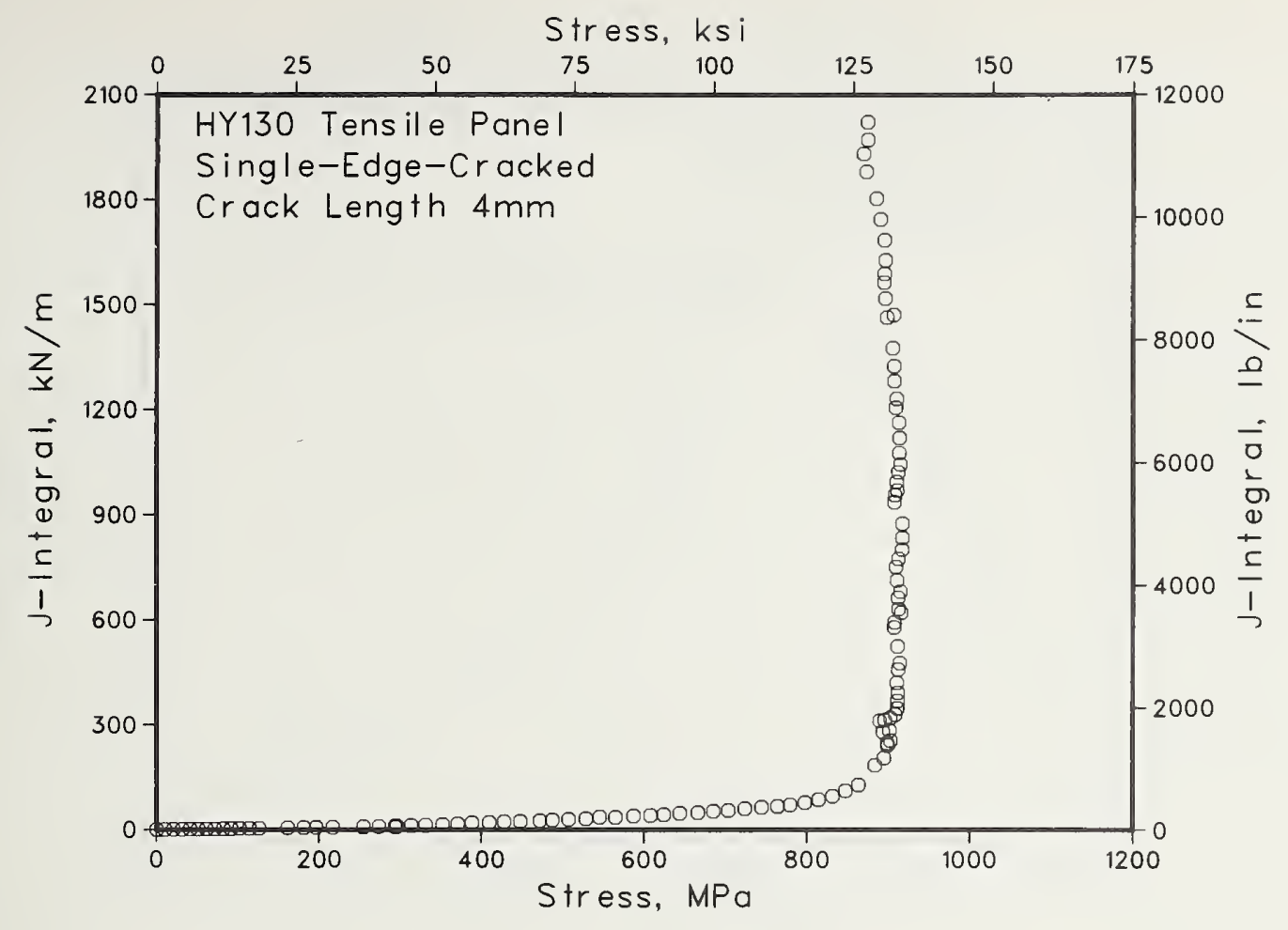

Figure 30c.

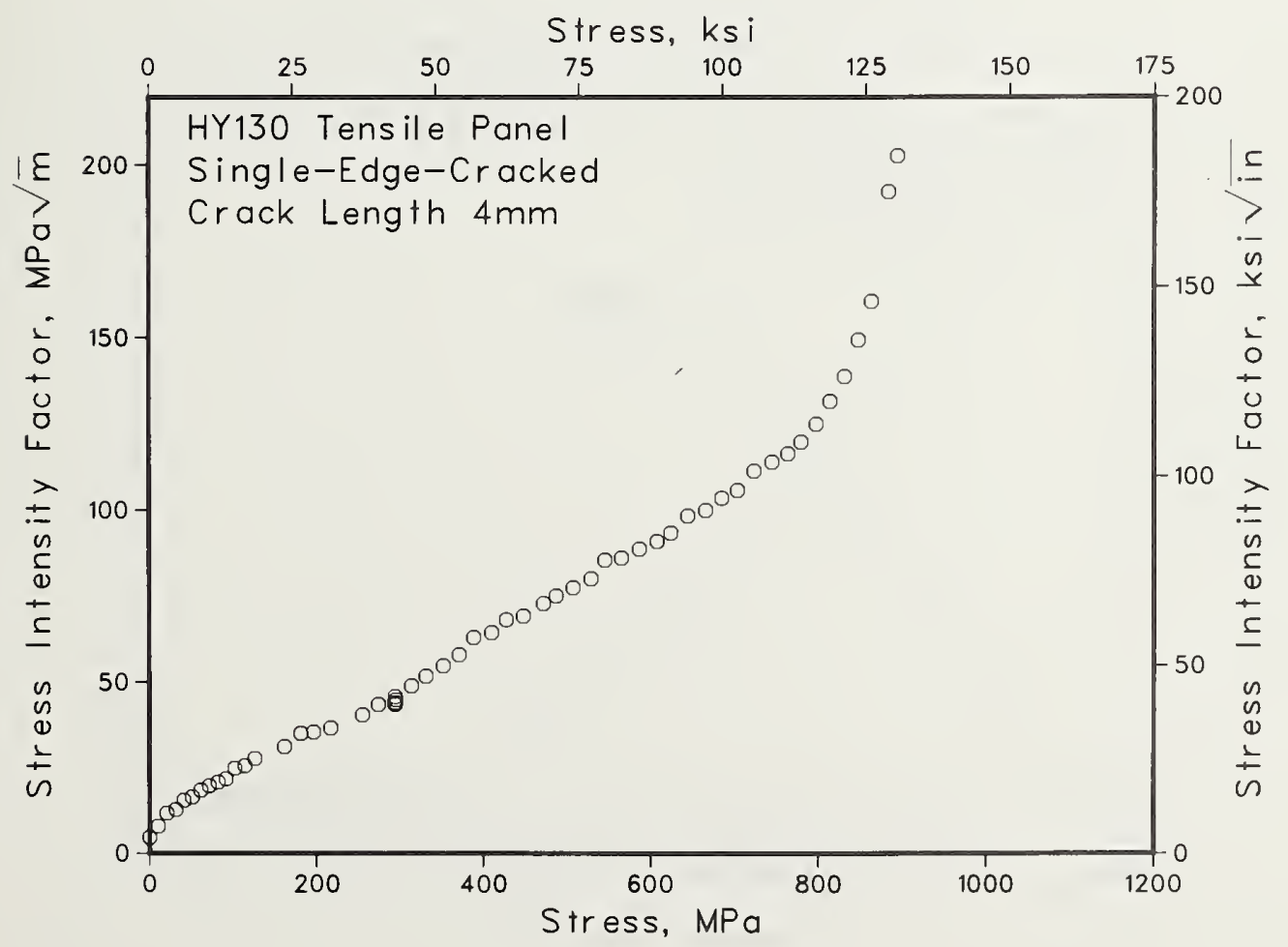

Figure 30d. 


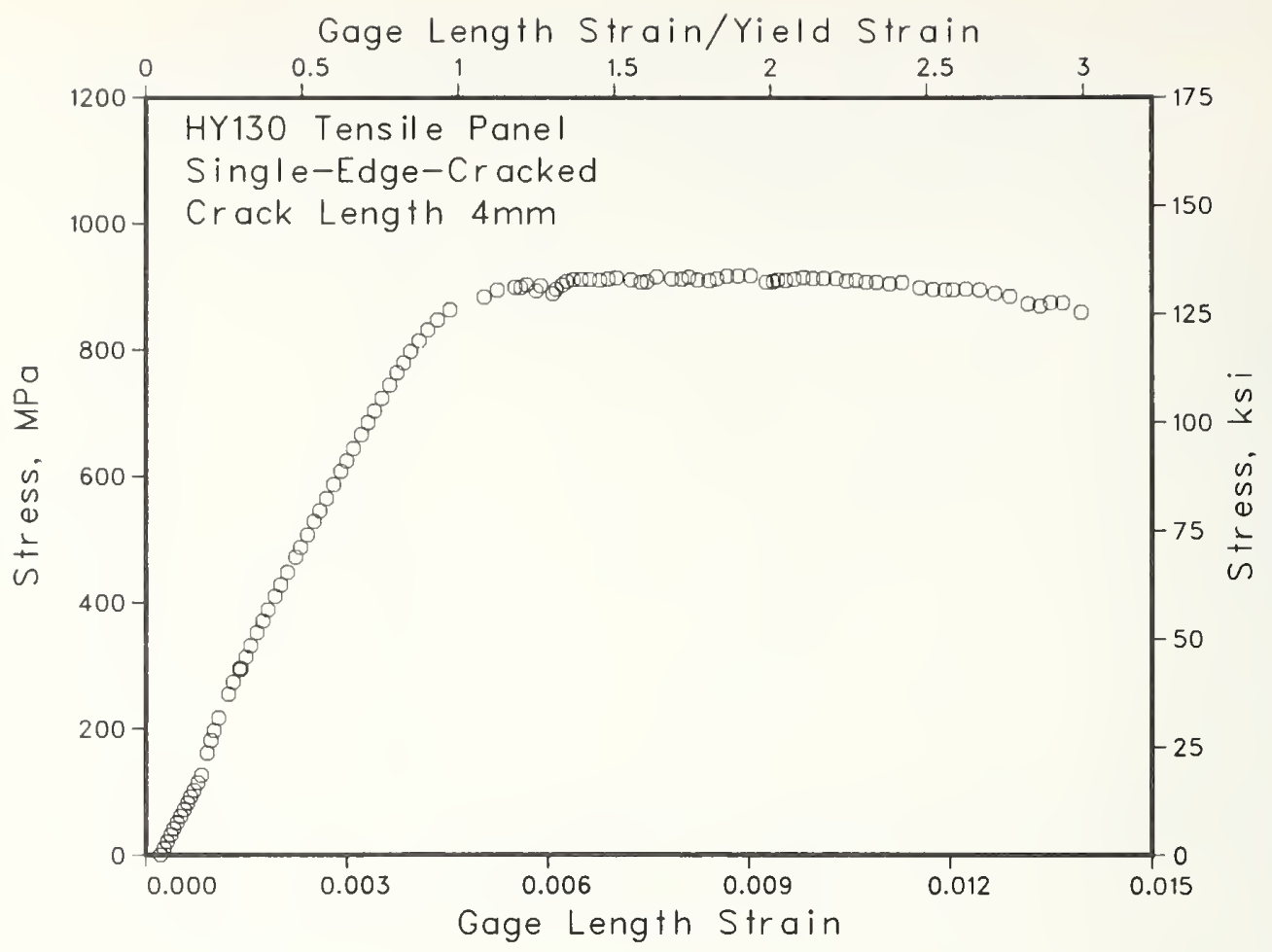

Figure 30 e.

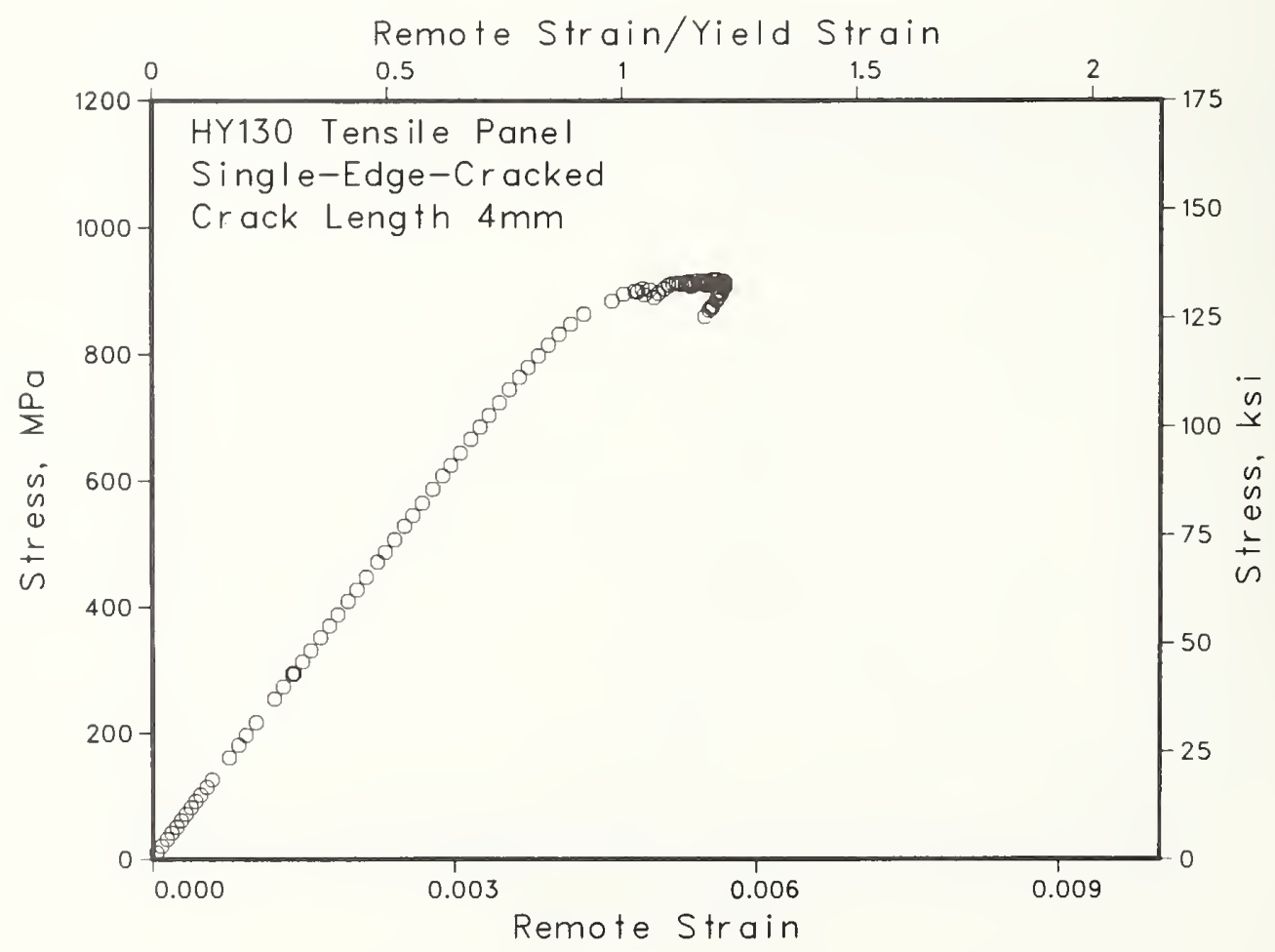

Figure $30 f$. 


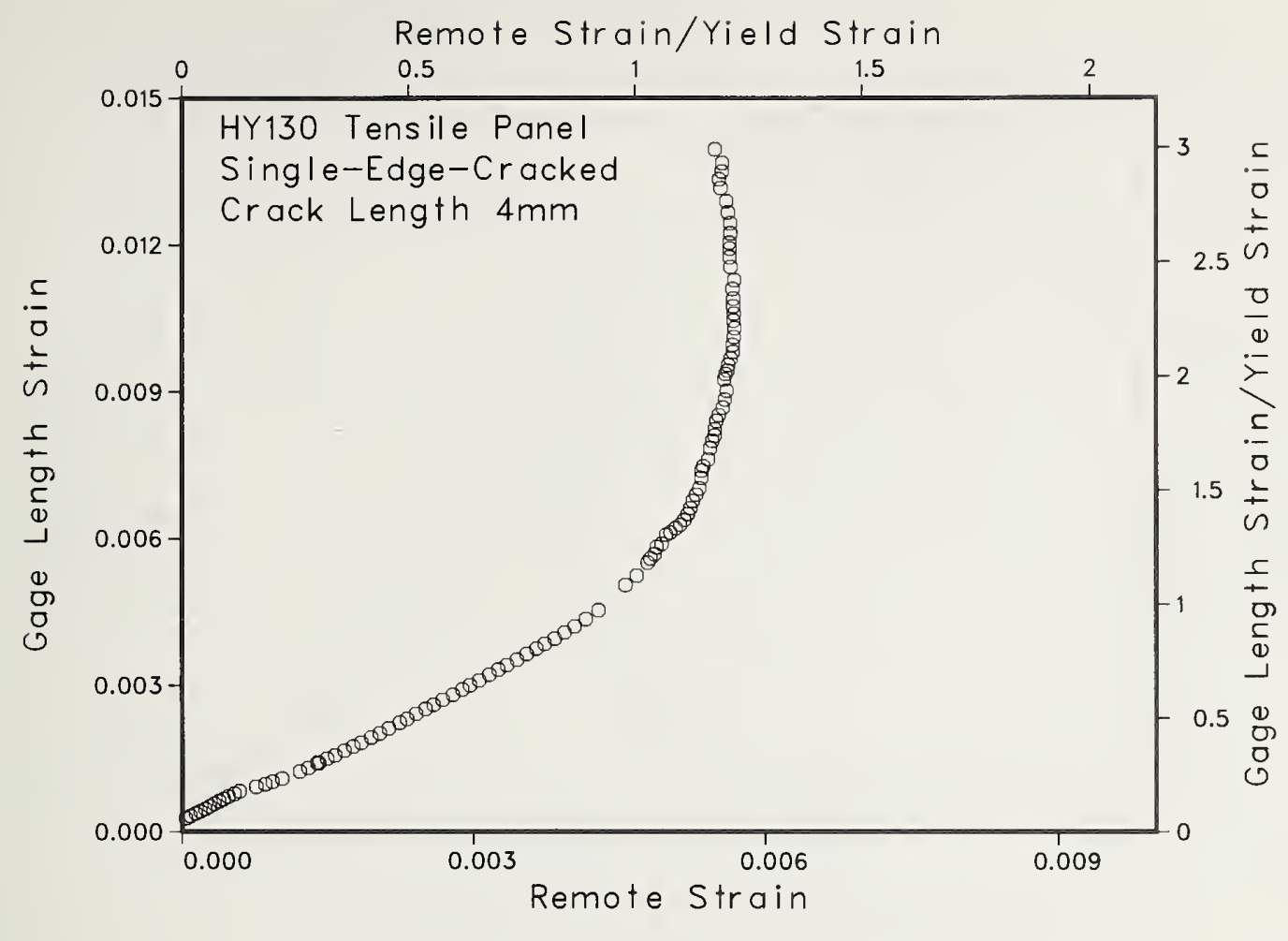

Figure $30 \mathrm{~g}$.

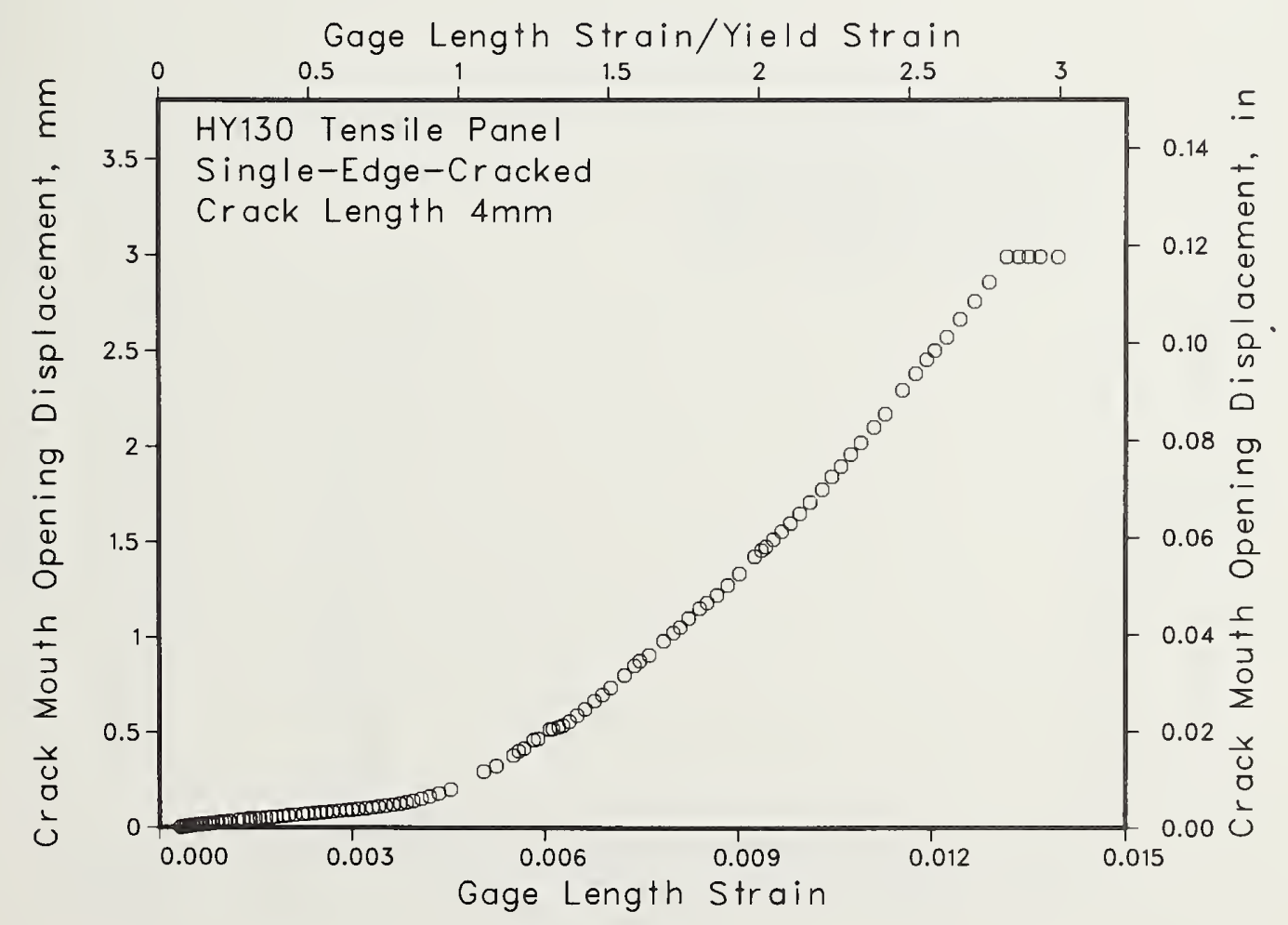

Figure $30 \mathrm{~h}$. 


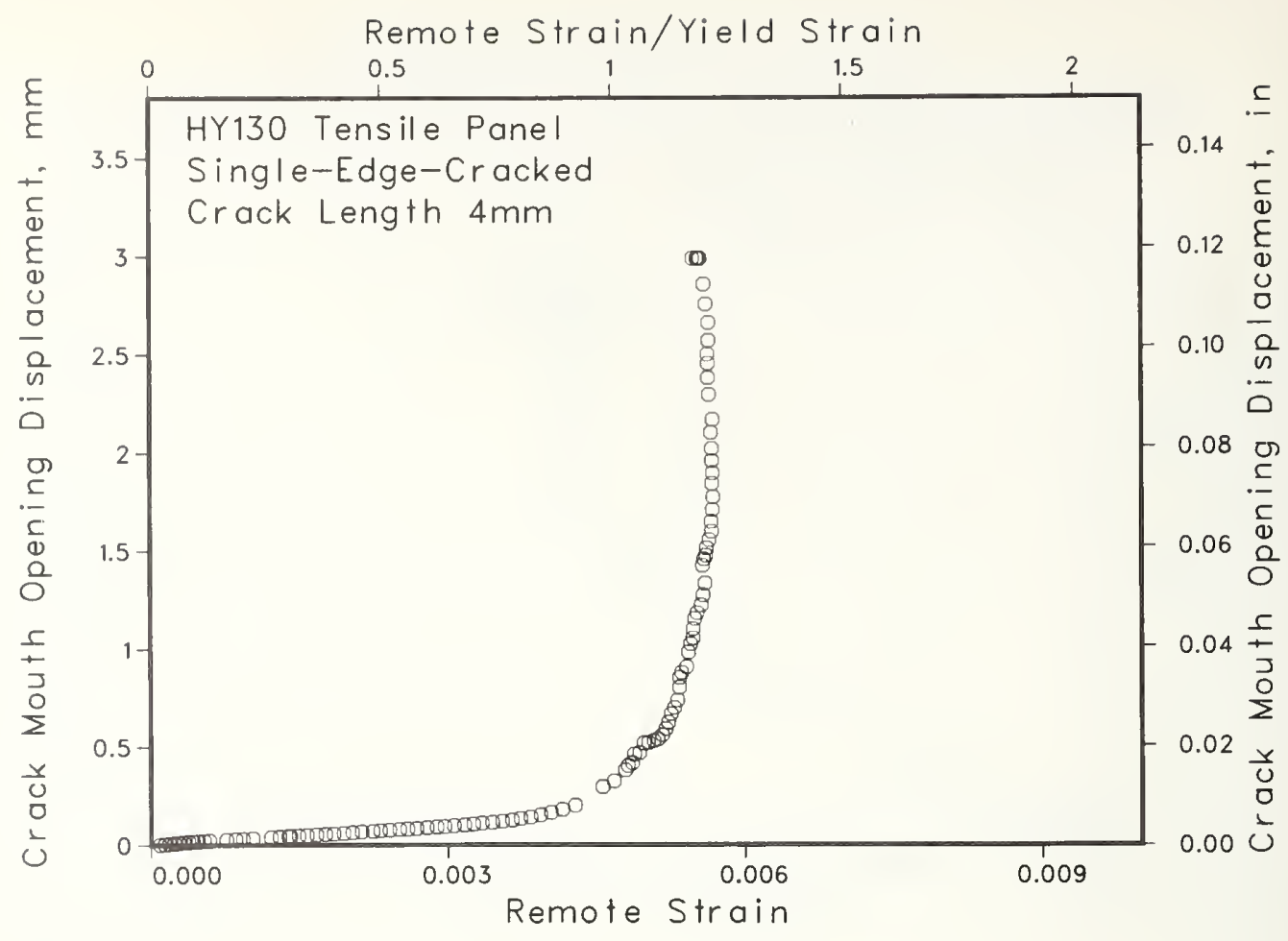

Figure $30 i$.

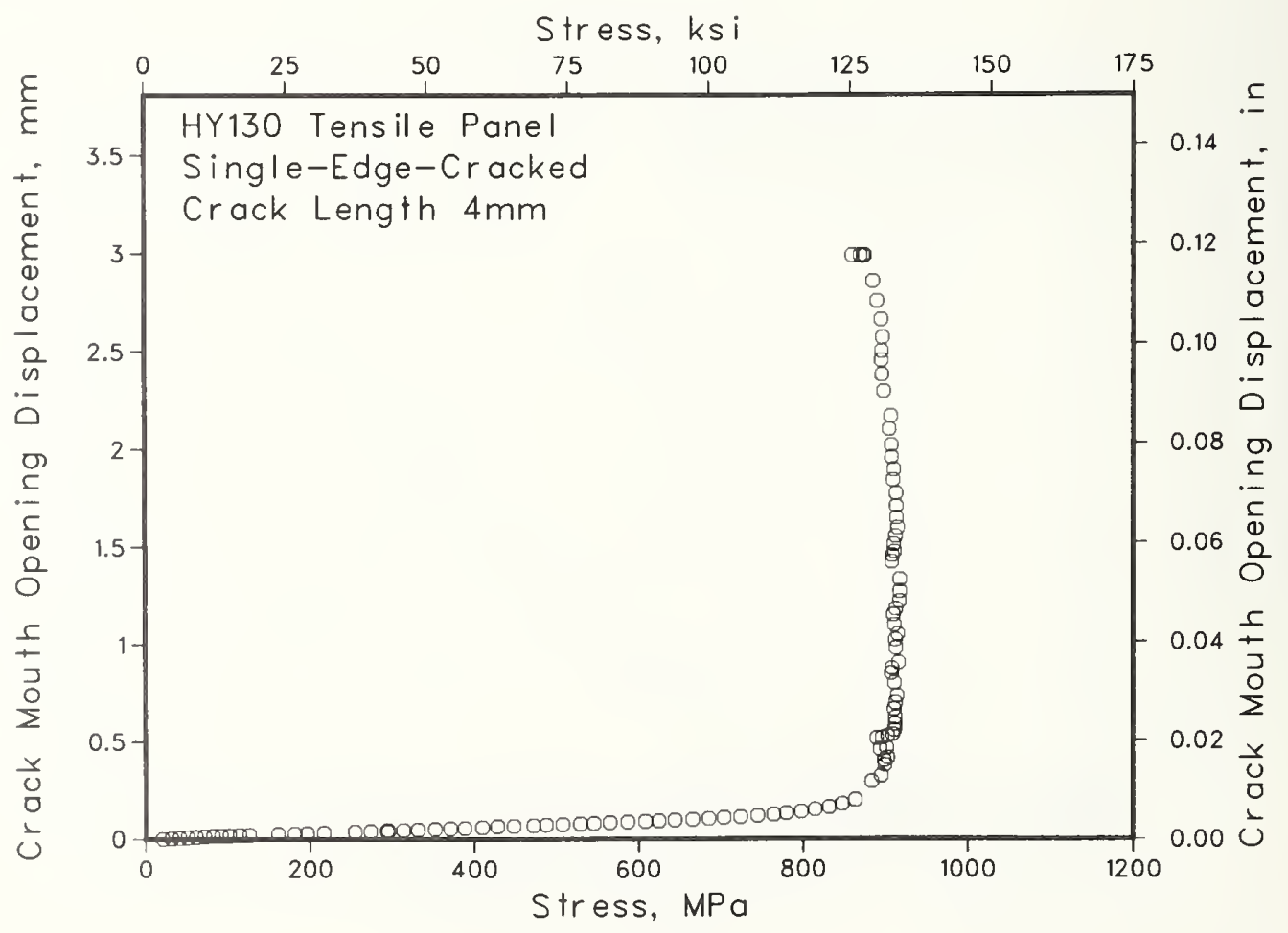

Figure $30 j$. 


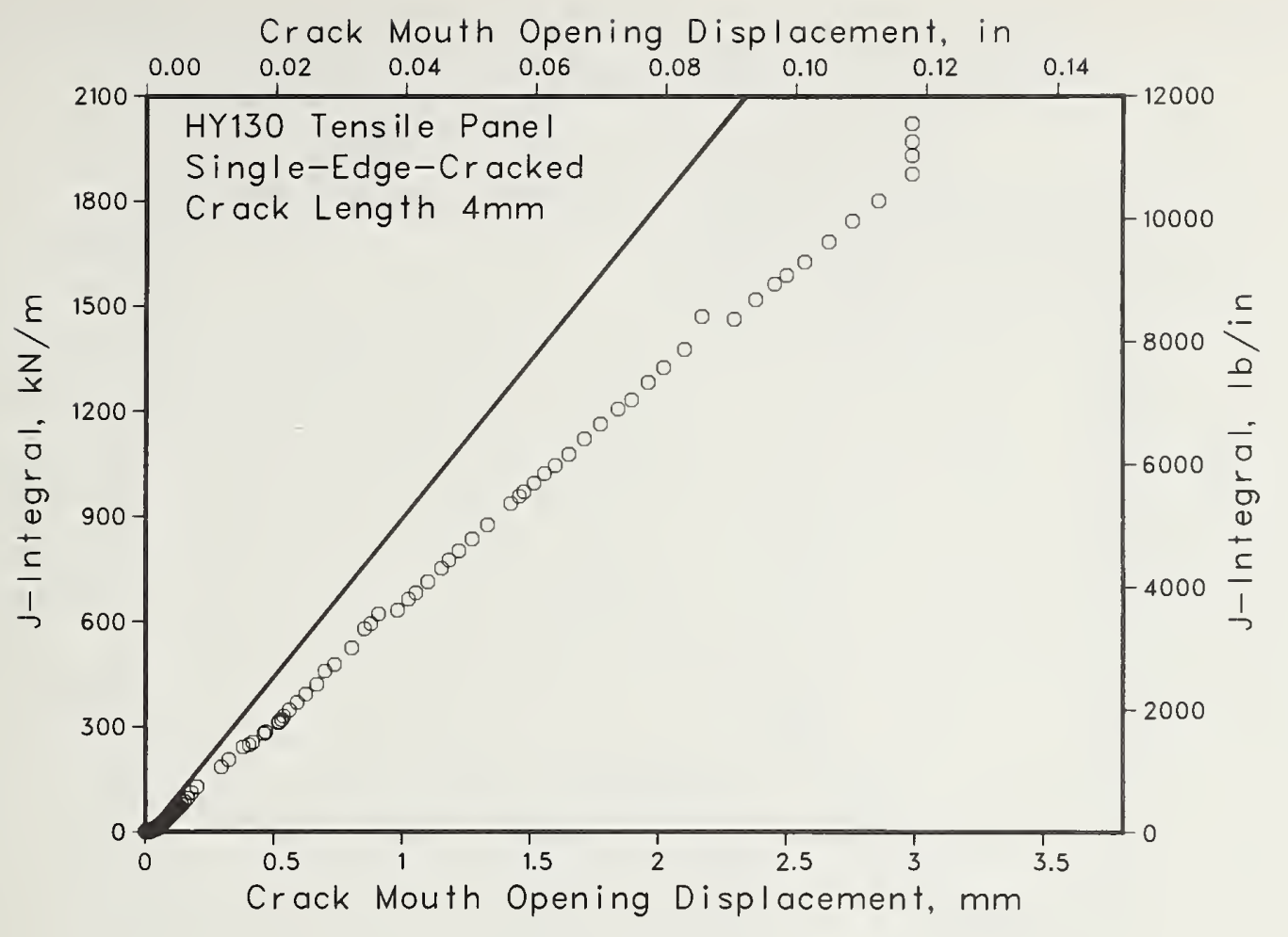

Figure $30 \mathrm{k}$. 
Fiqure 31a-31k. Dependence of J-integràl. stress, and crack mouth opening displacement on strain for double-edge-cracked tensile panel with crack lengths 2 mm.

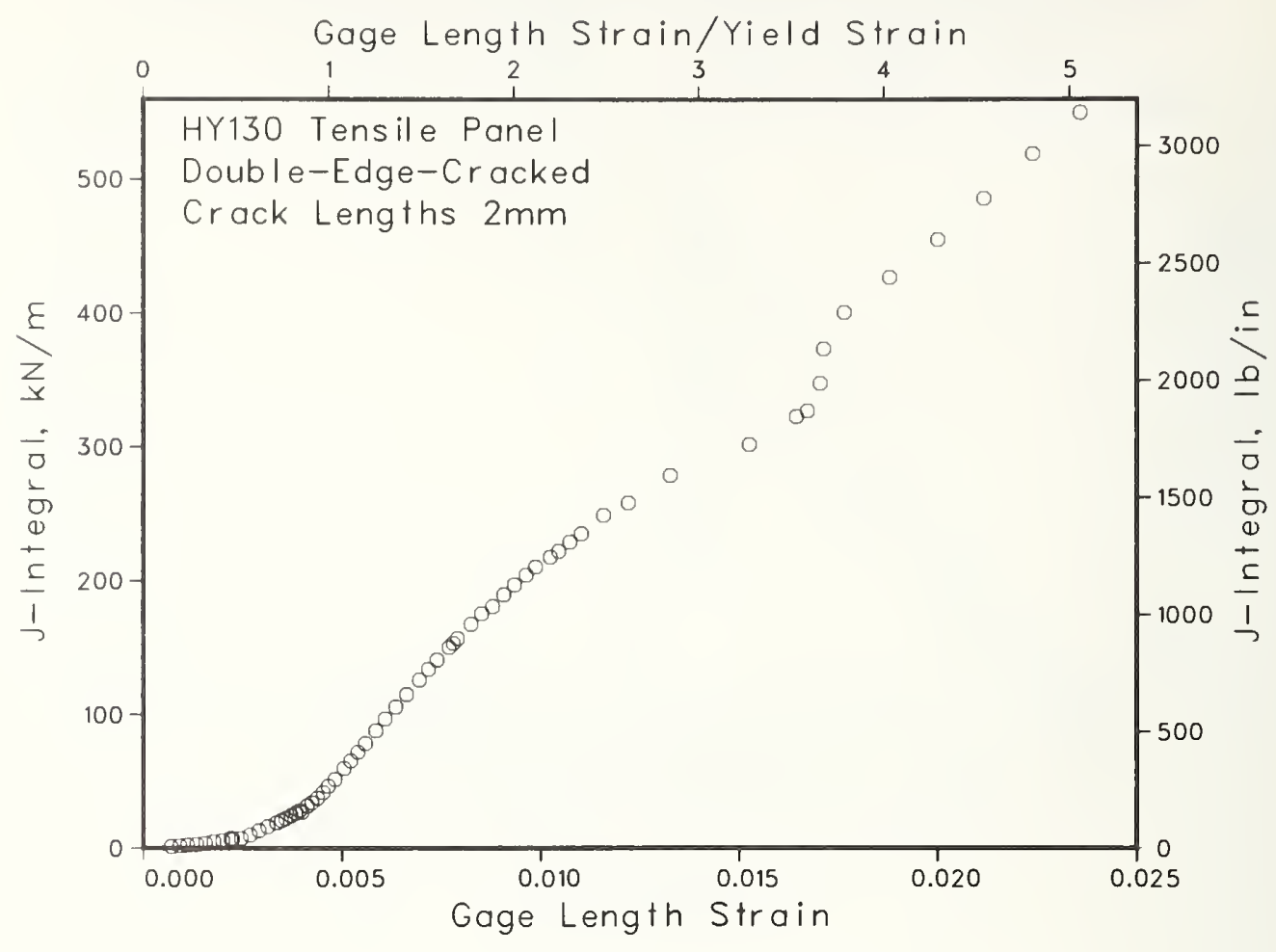

Figure 31a.

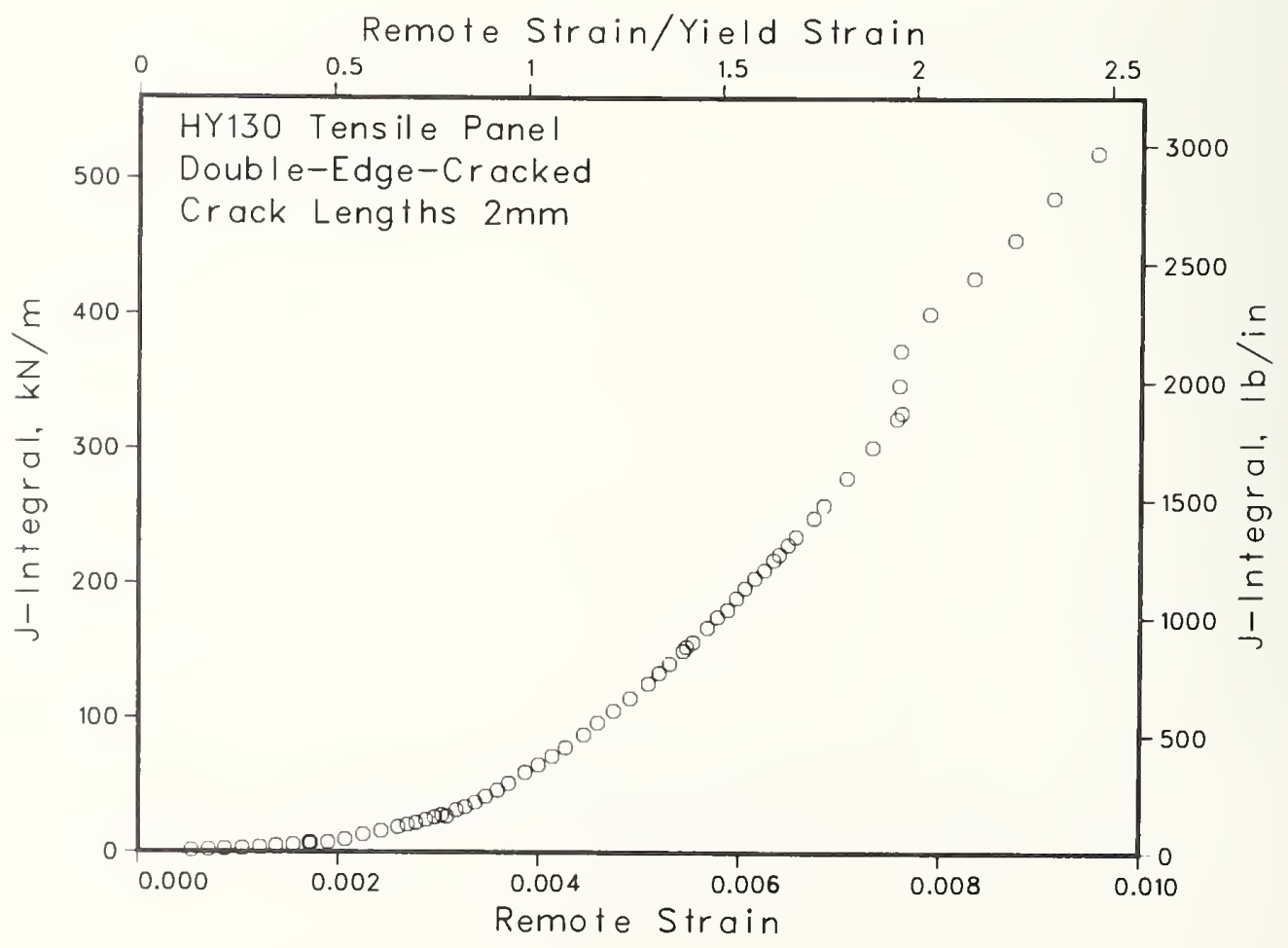

Figure $31 b$. 


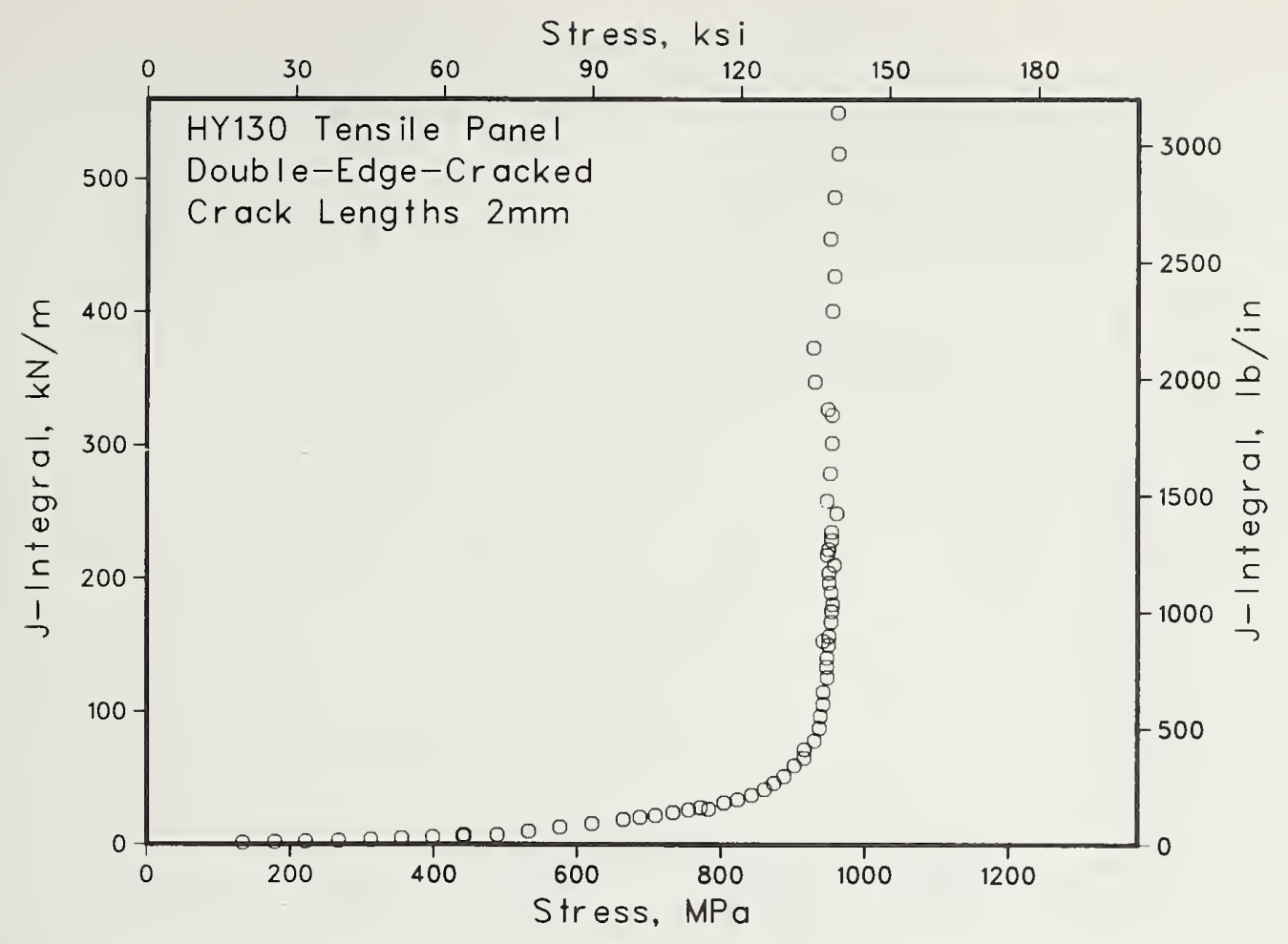

Figure 31c.

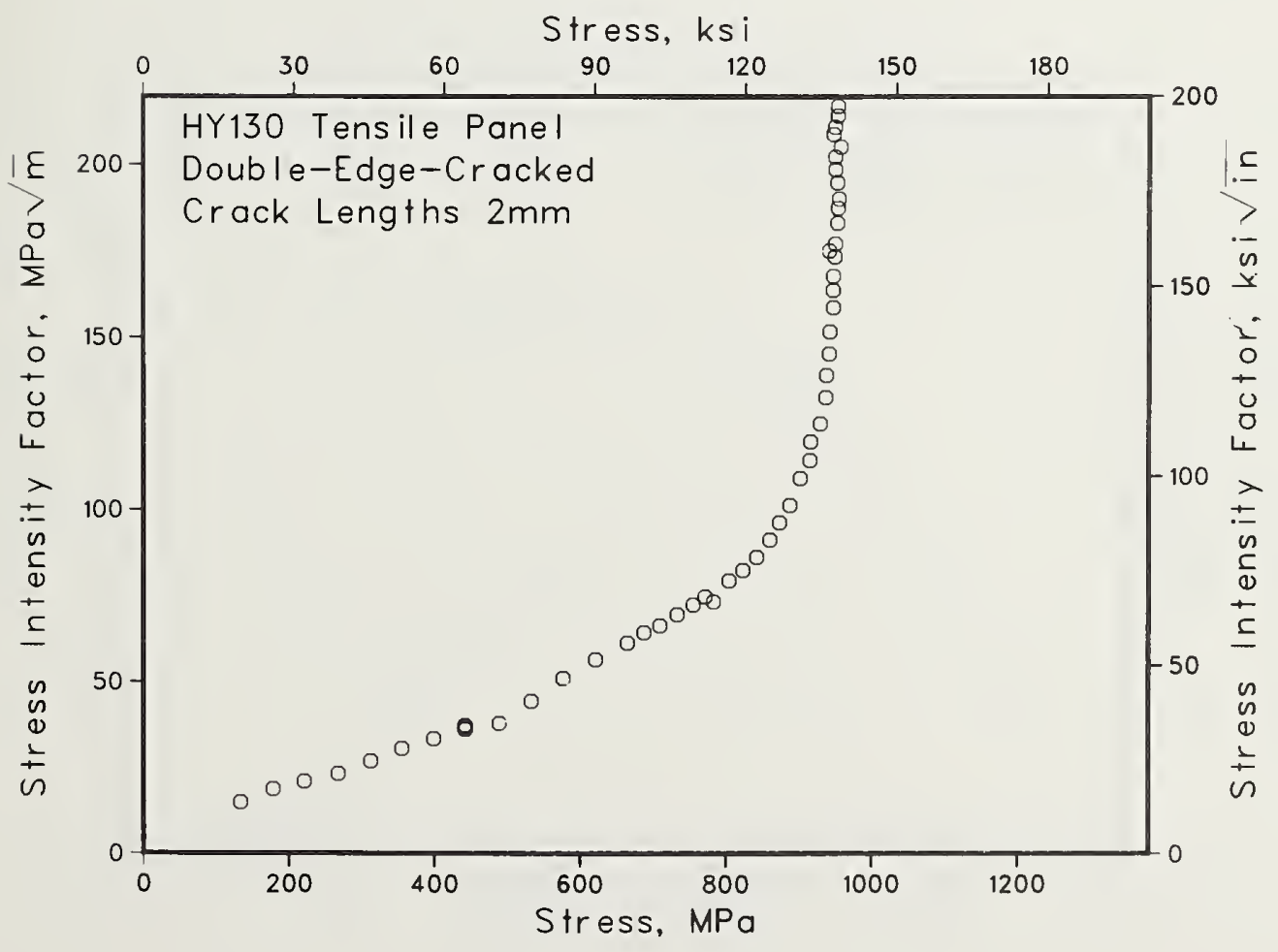

Figure 31d. 


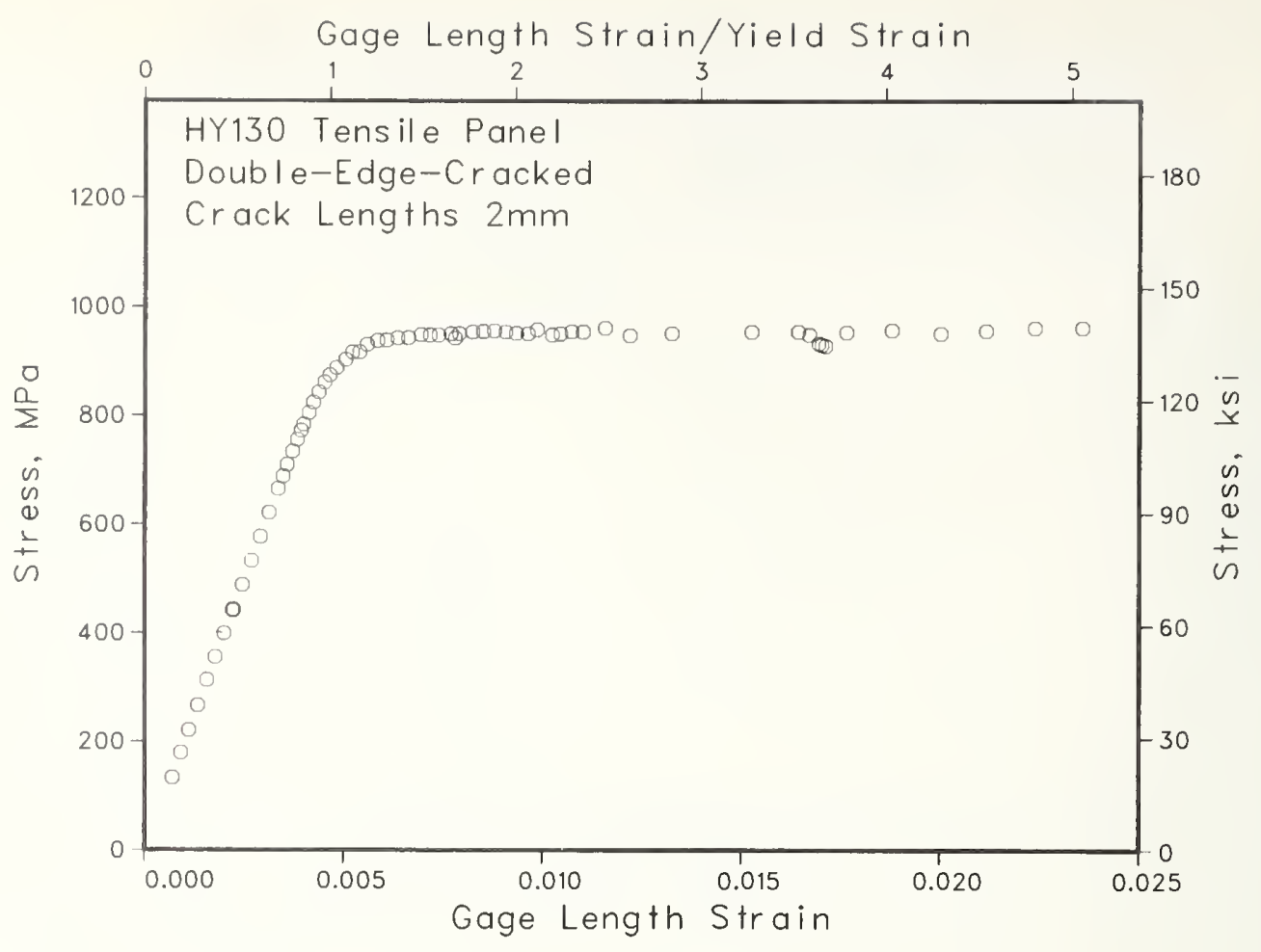

Figure 31 e.

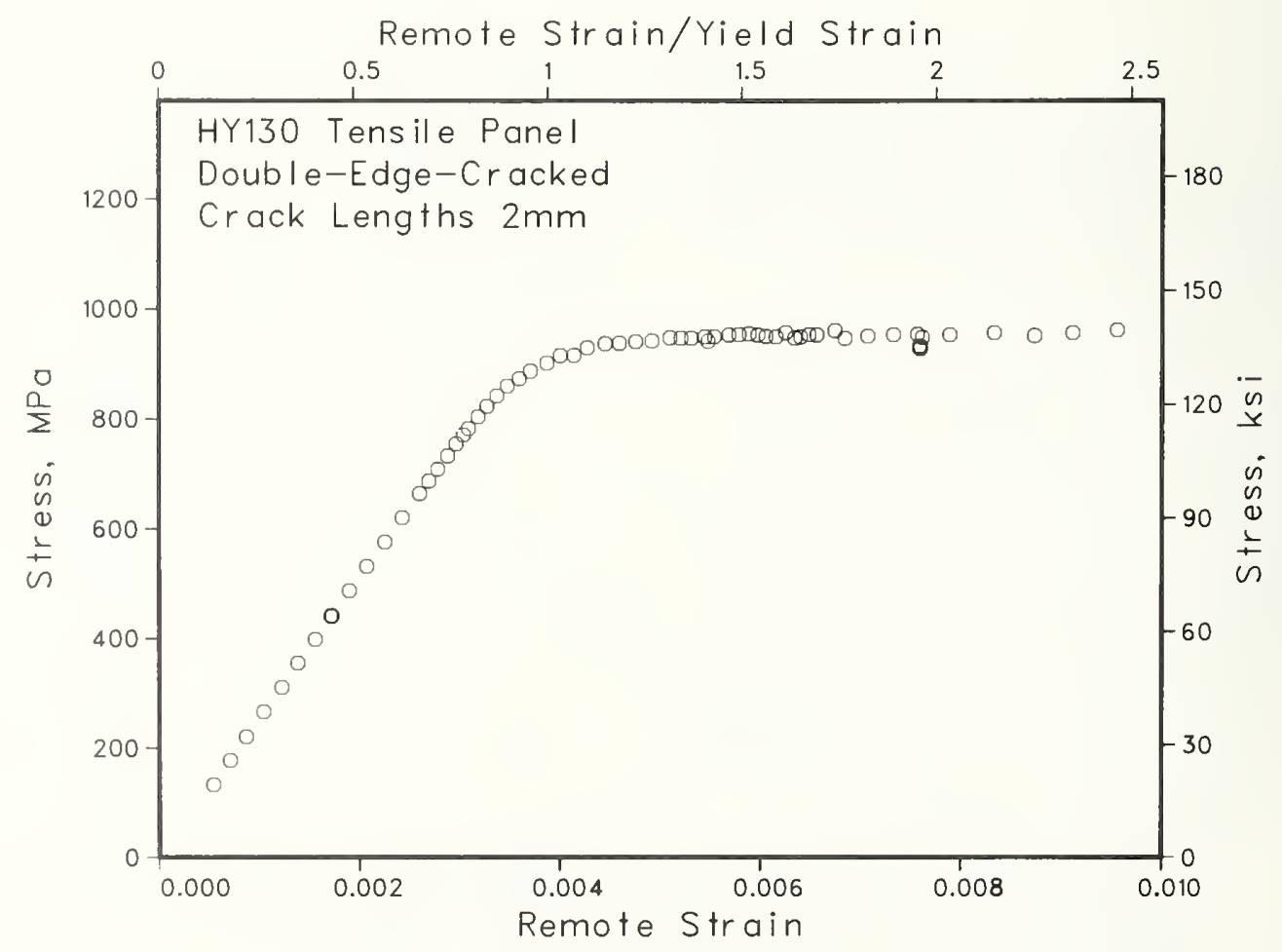

Figure $31 \mathrm{f}$. 


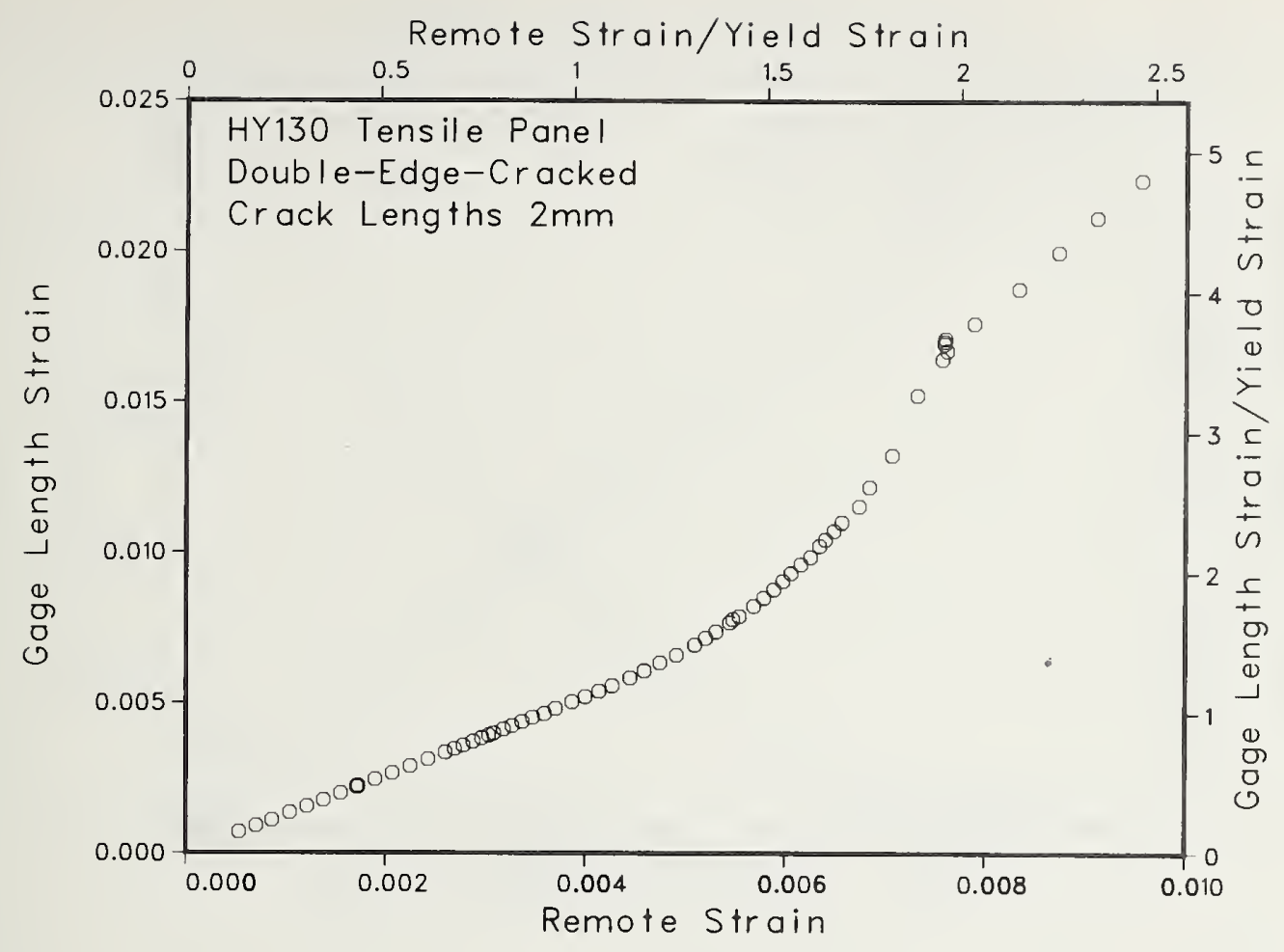

Figure $31 \mathrm{~g}$.

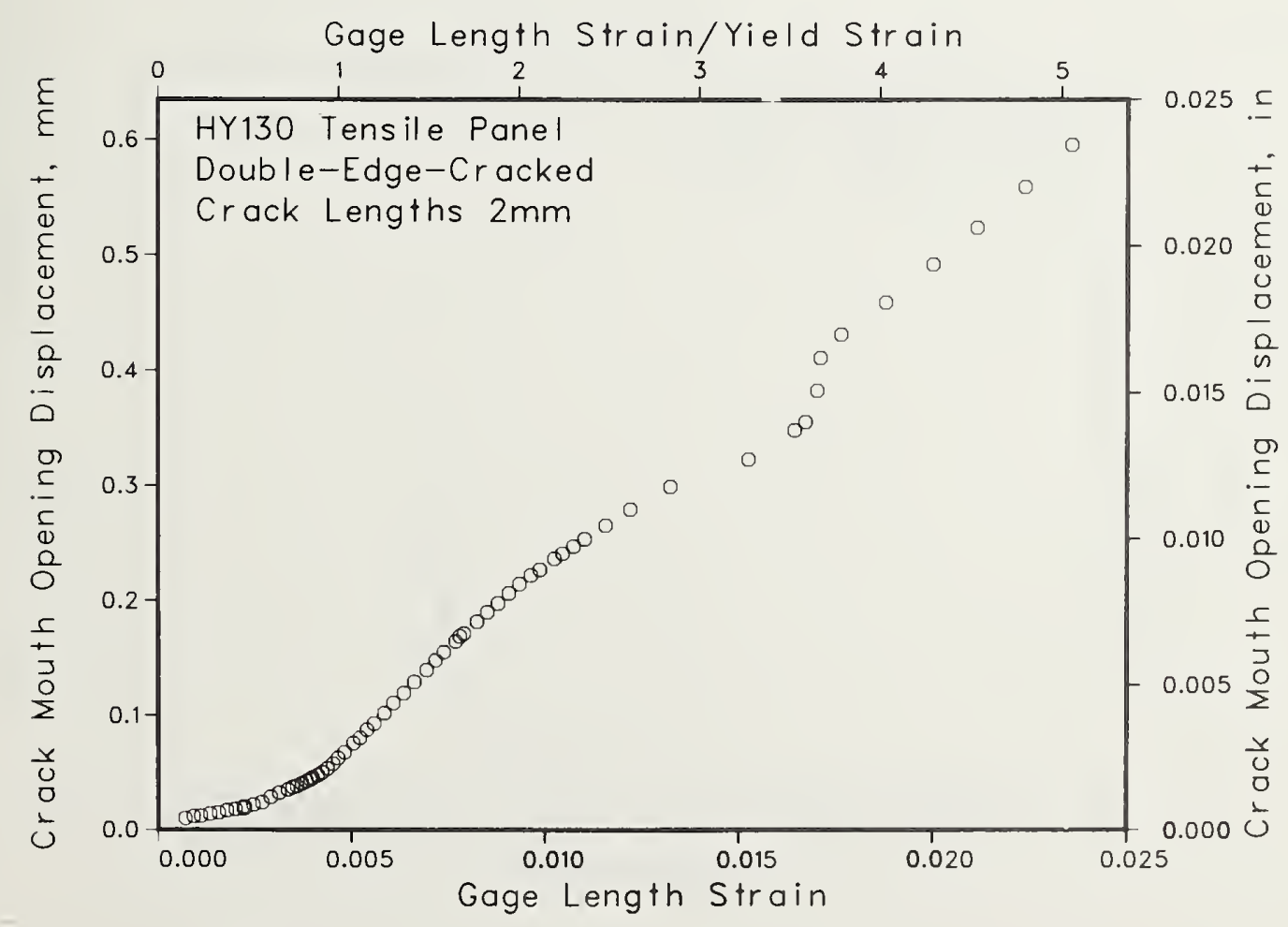

Figure $31 \mathrm{~h}$. 


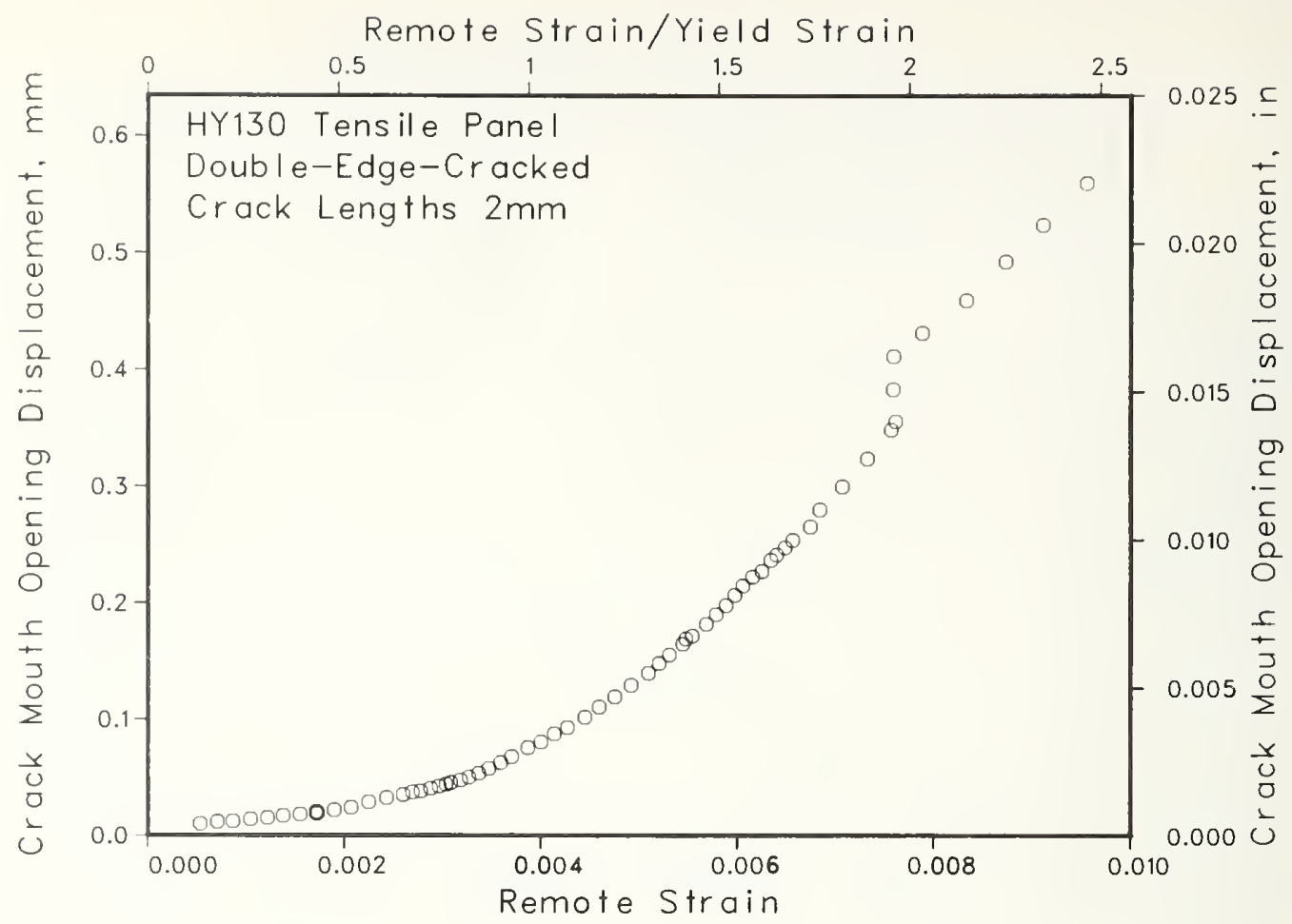

Figure $31 i$.

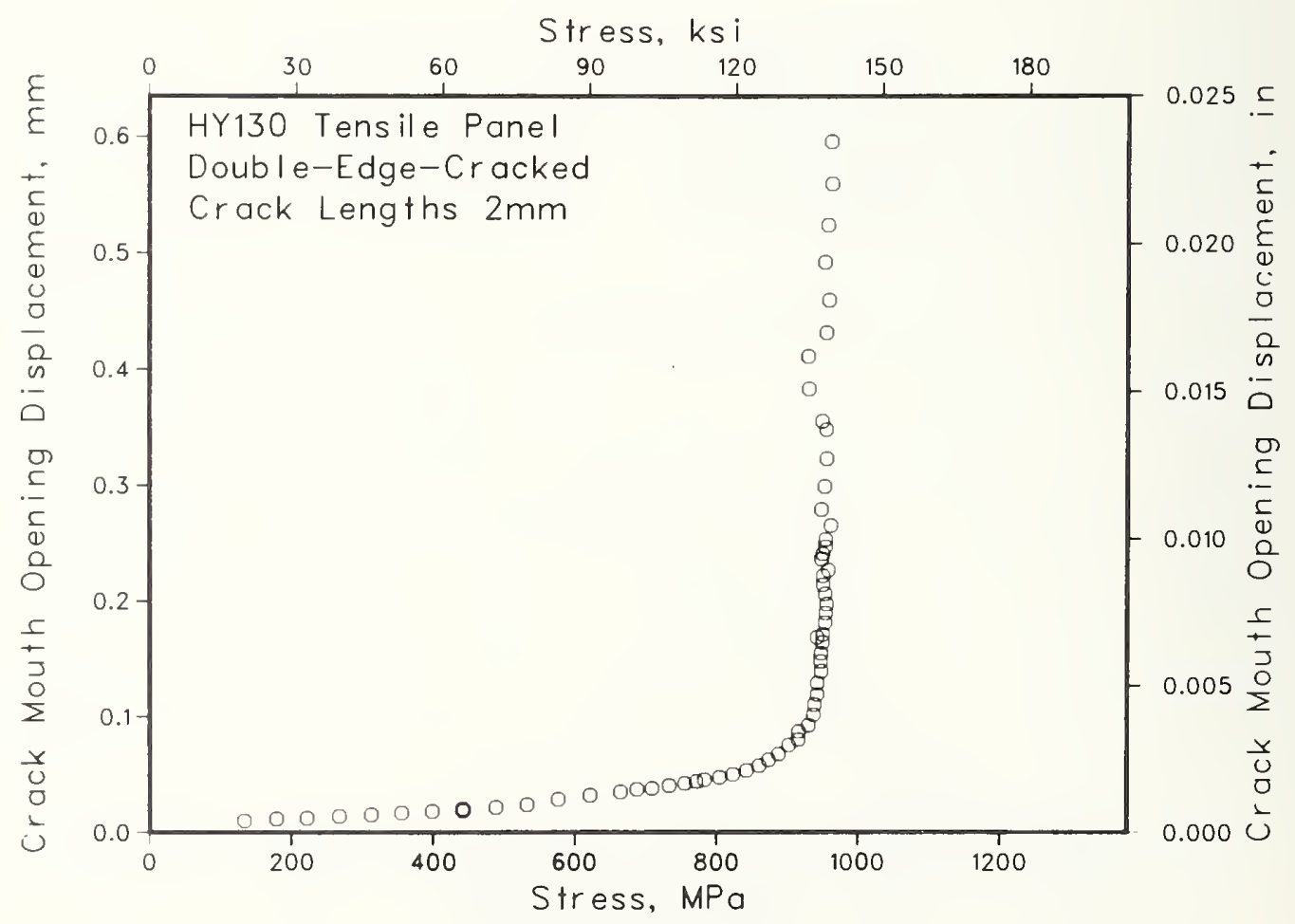

Figure $31 \mathrm{j}$. 


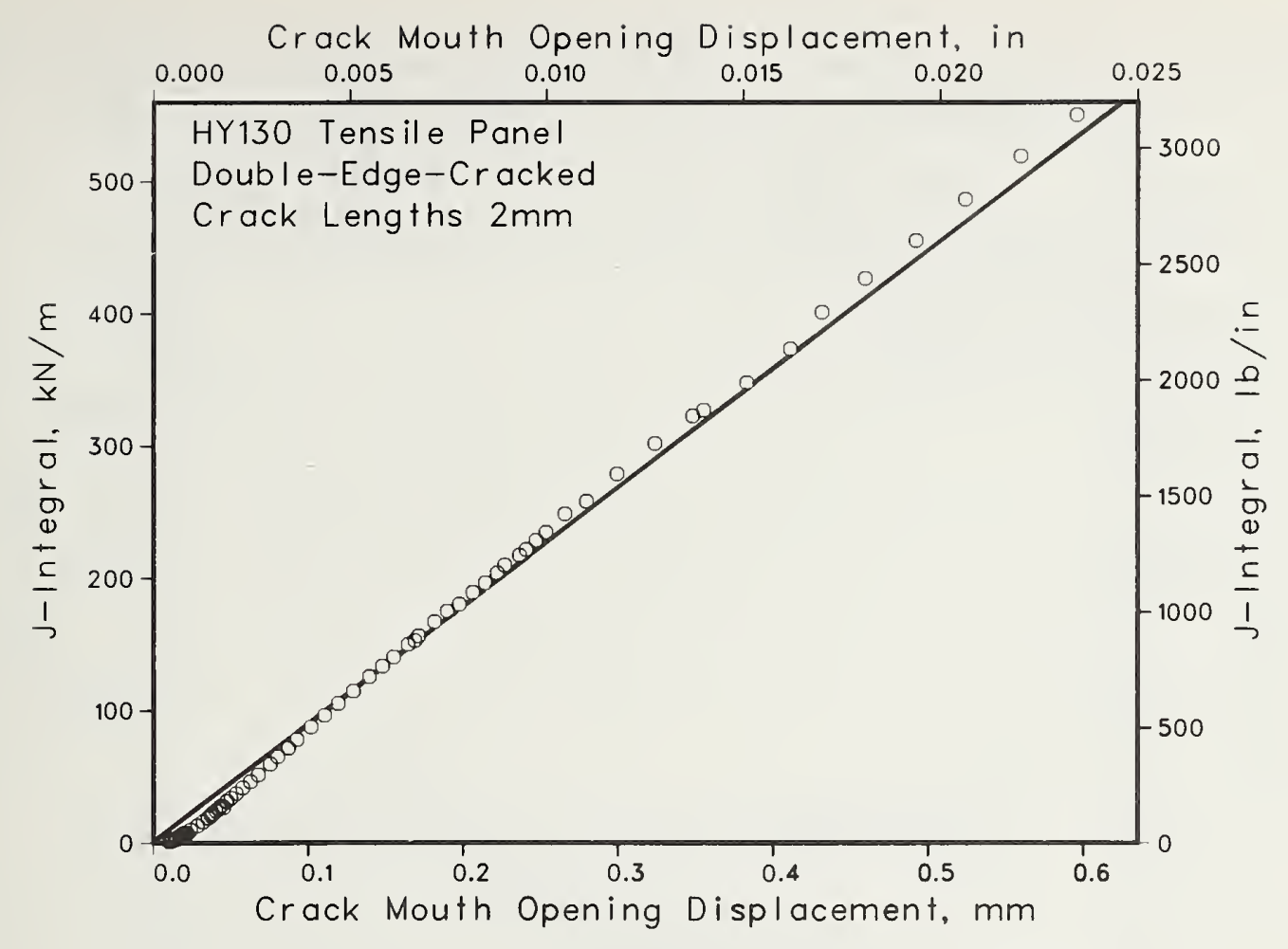

Figure 31k. 
Figure 32a-32k. Dependence of J-integral, stress, and crack mouth opening displacement on strain for face-cracked tensile panel with crack depth $2 \mathrm{~mm}$.

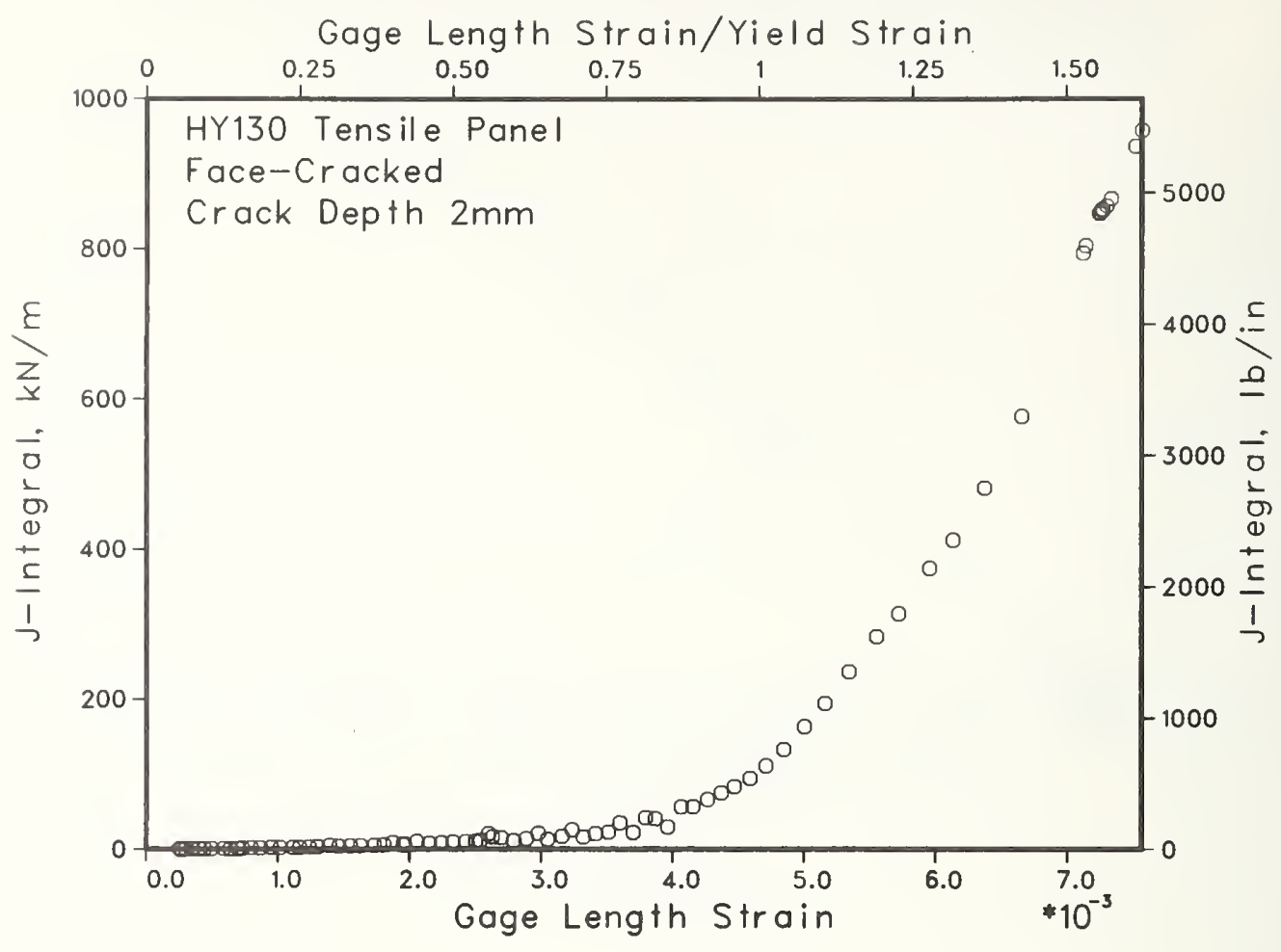

Figure 32a.

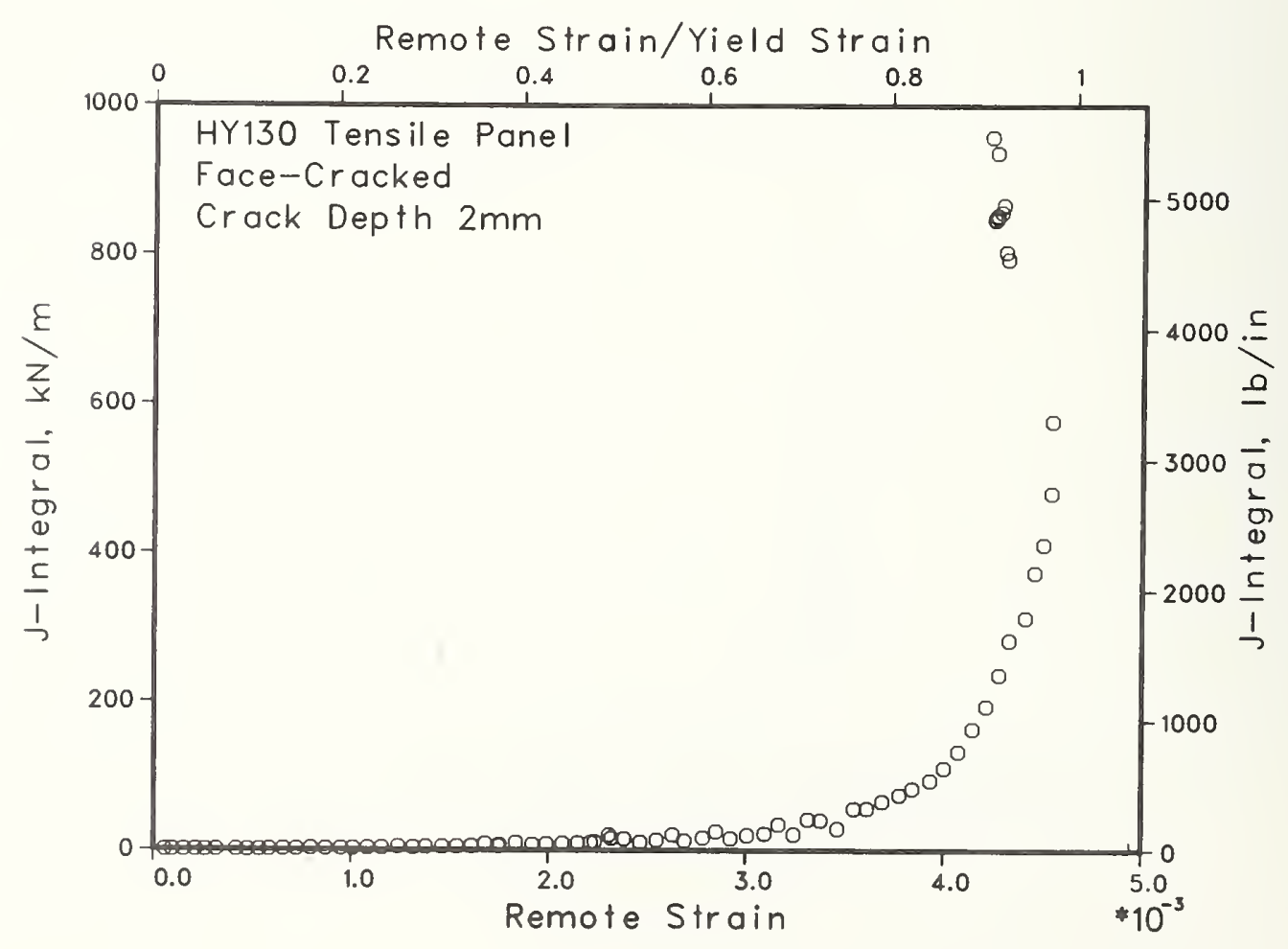

Figure 32b. 


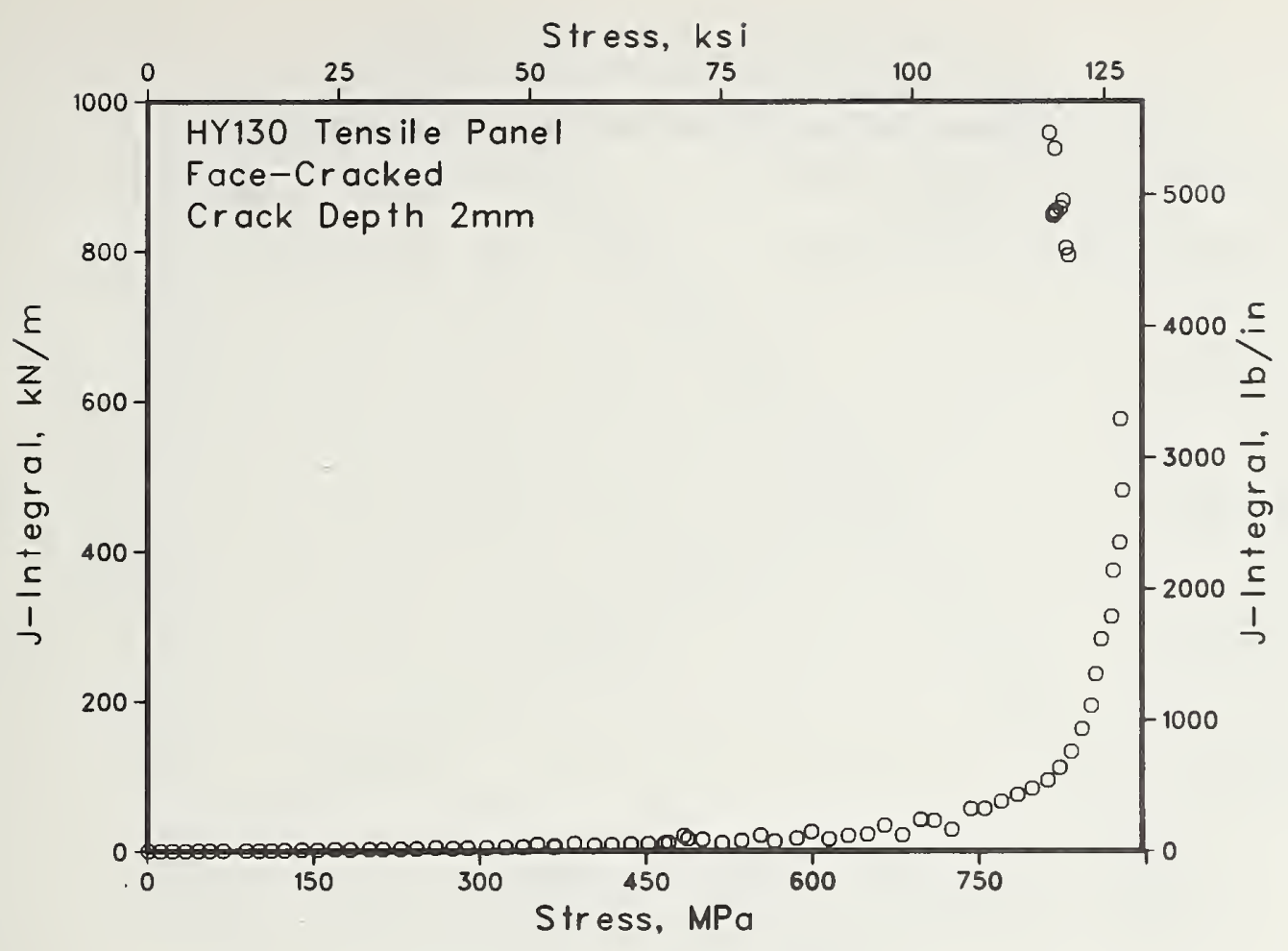

Figure 32c.

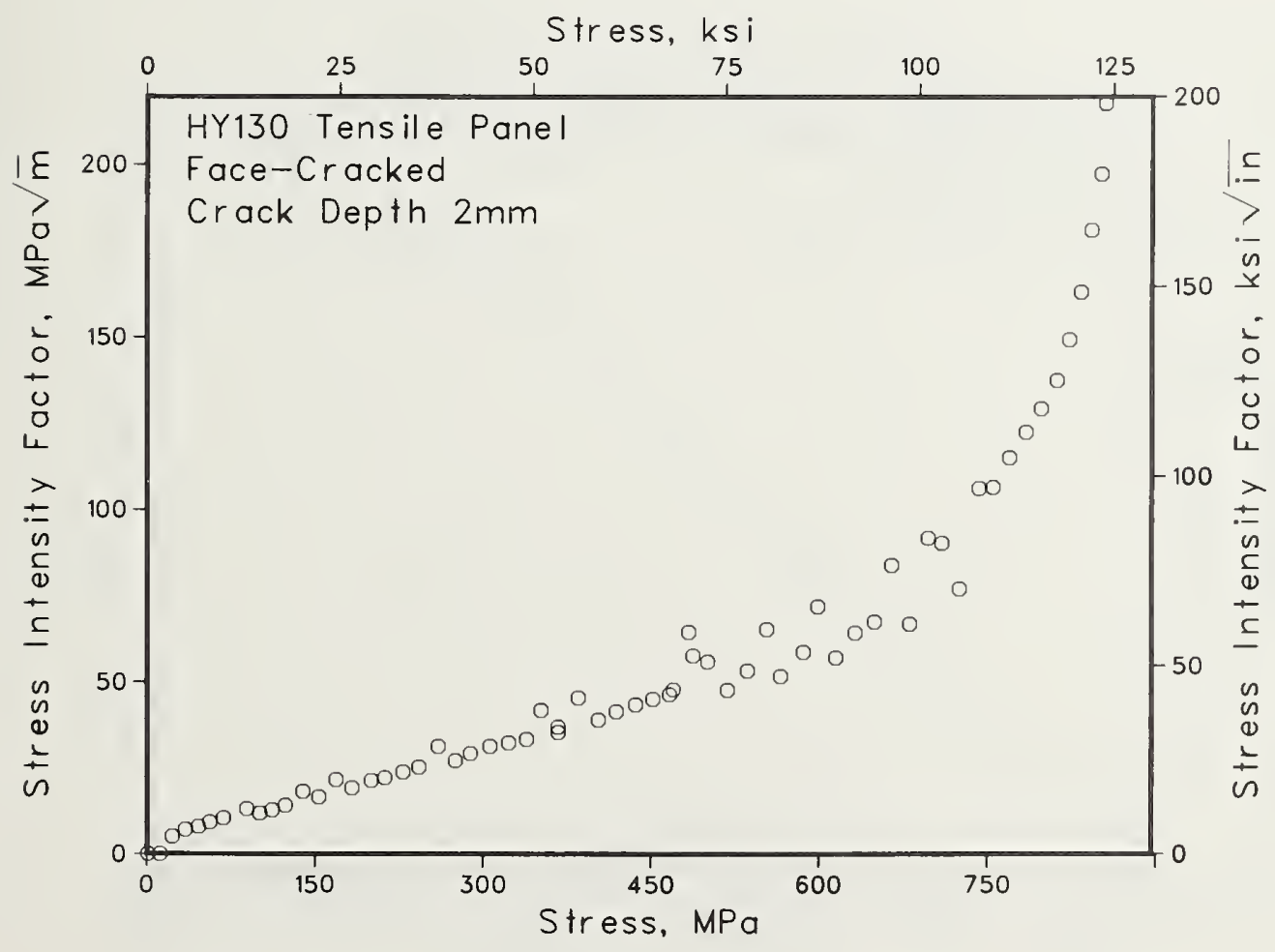

Figure $32 d$. 


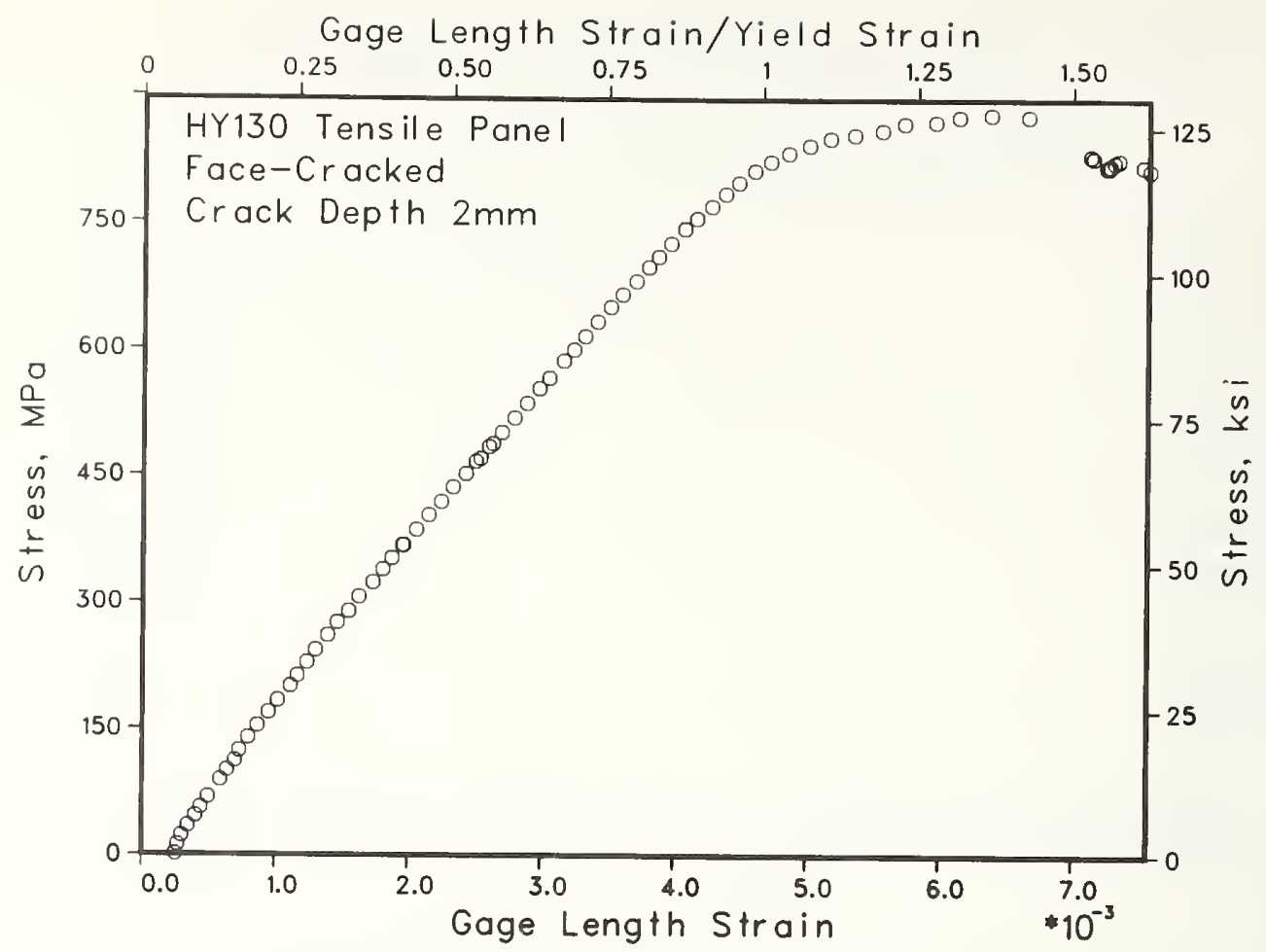

Figure $32 \mathrm{e}$.

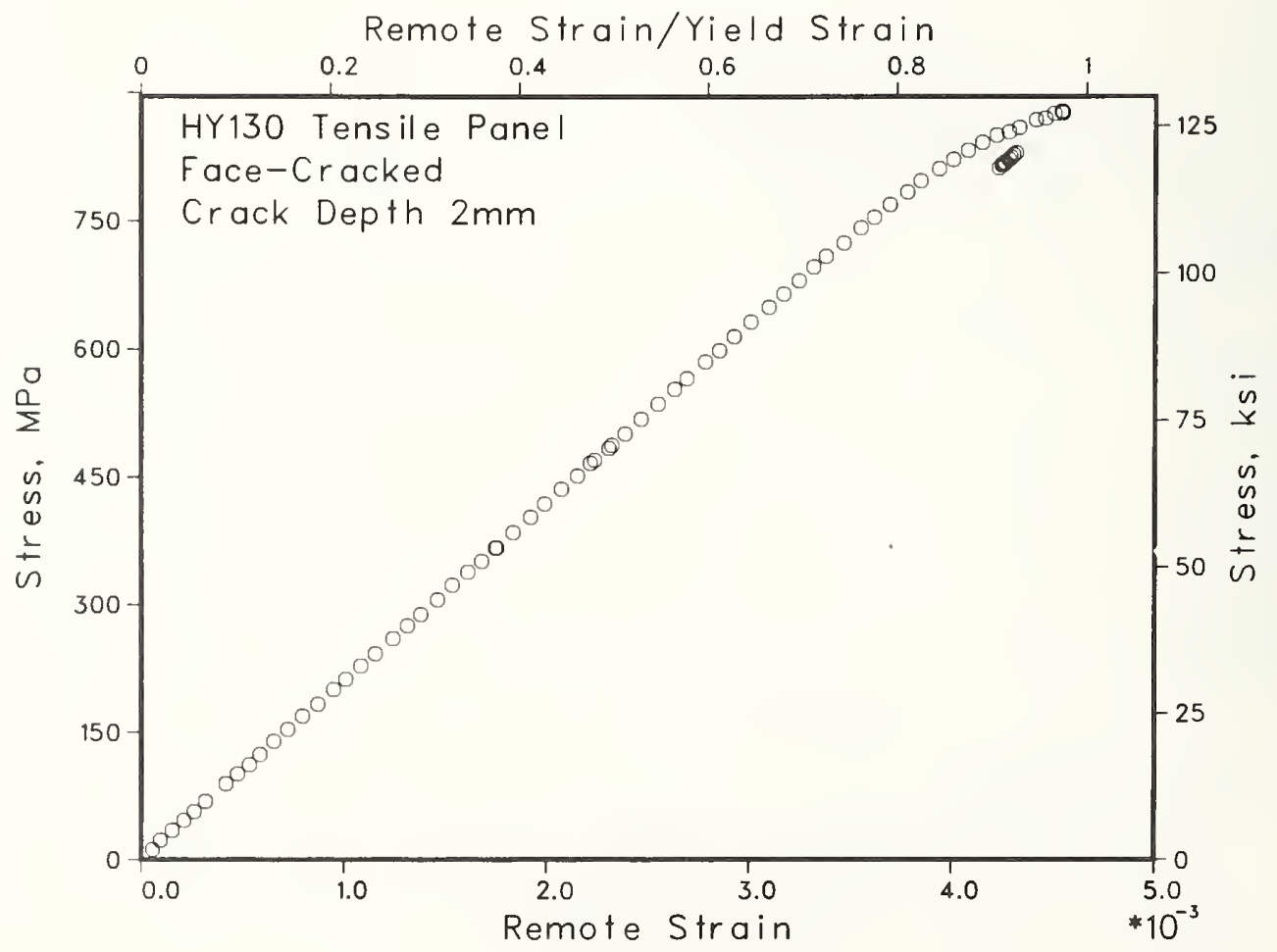

Figure $32 f$. 


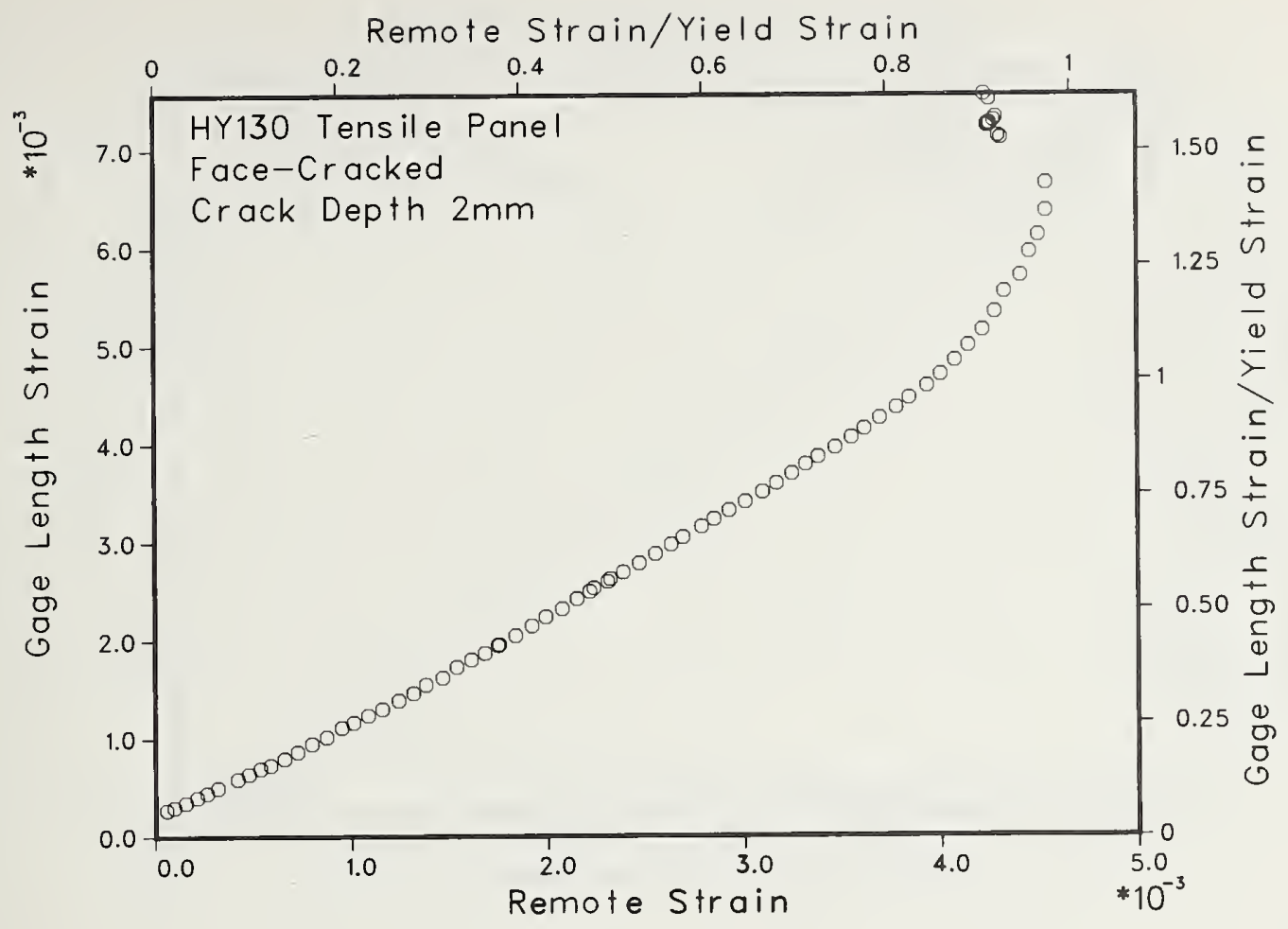

Figure $32 \mathrm{~g}$.

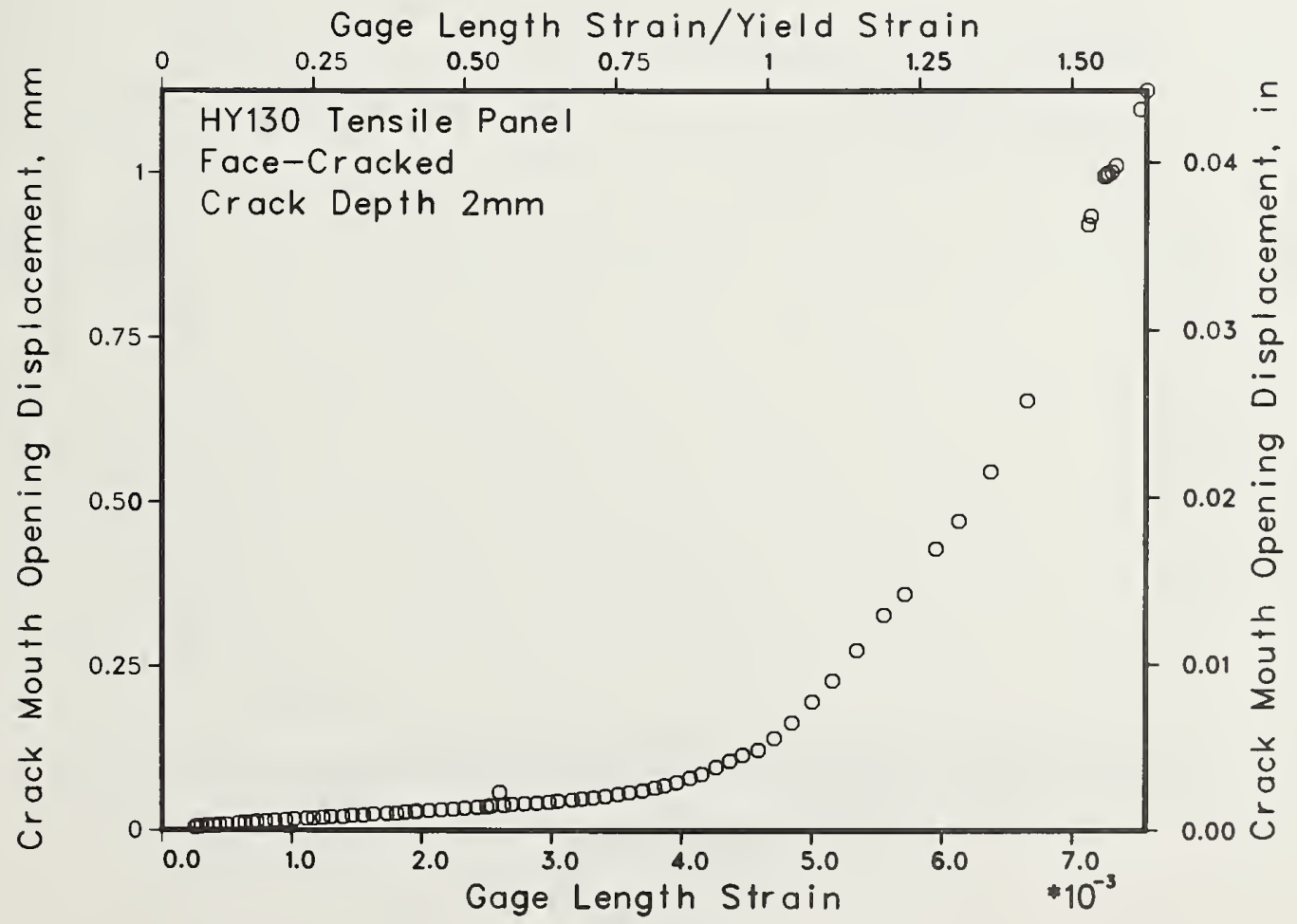

Figure $32 \mathrm{~h}$. 


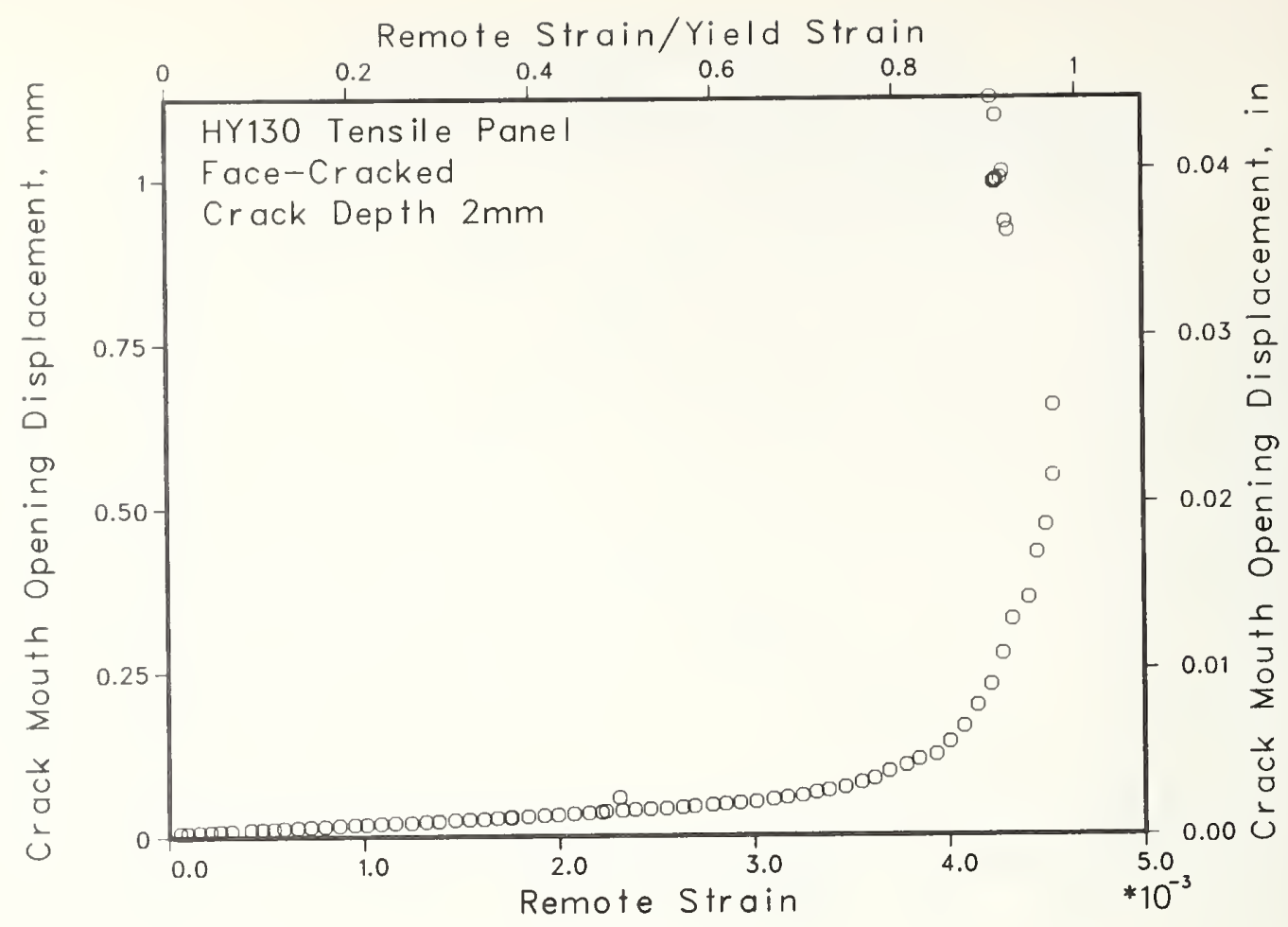

Figure $32 i$.

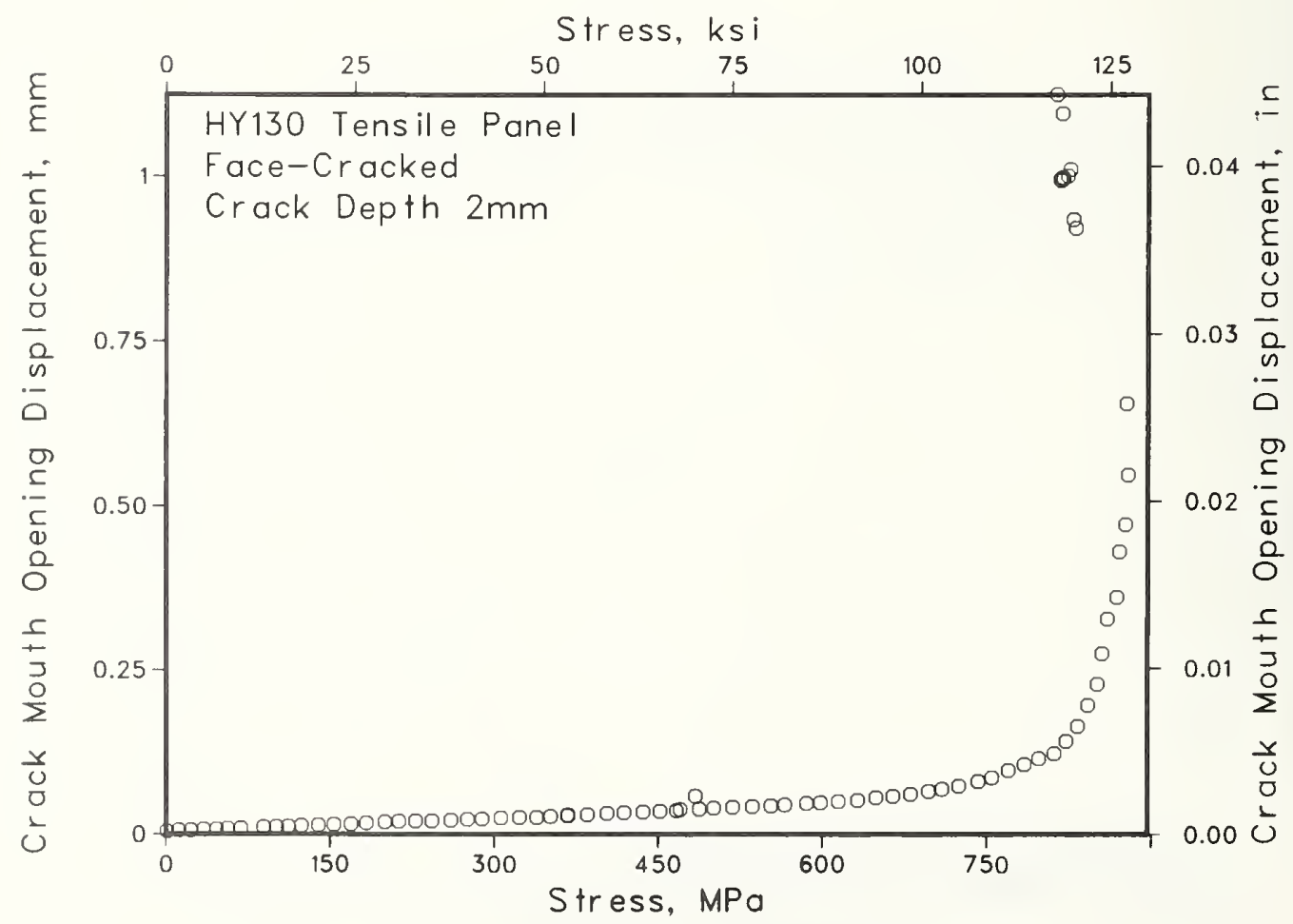

Figure $32 j$. 


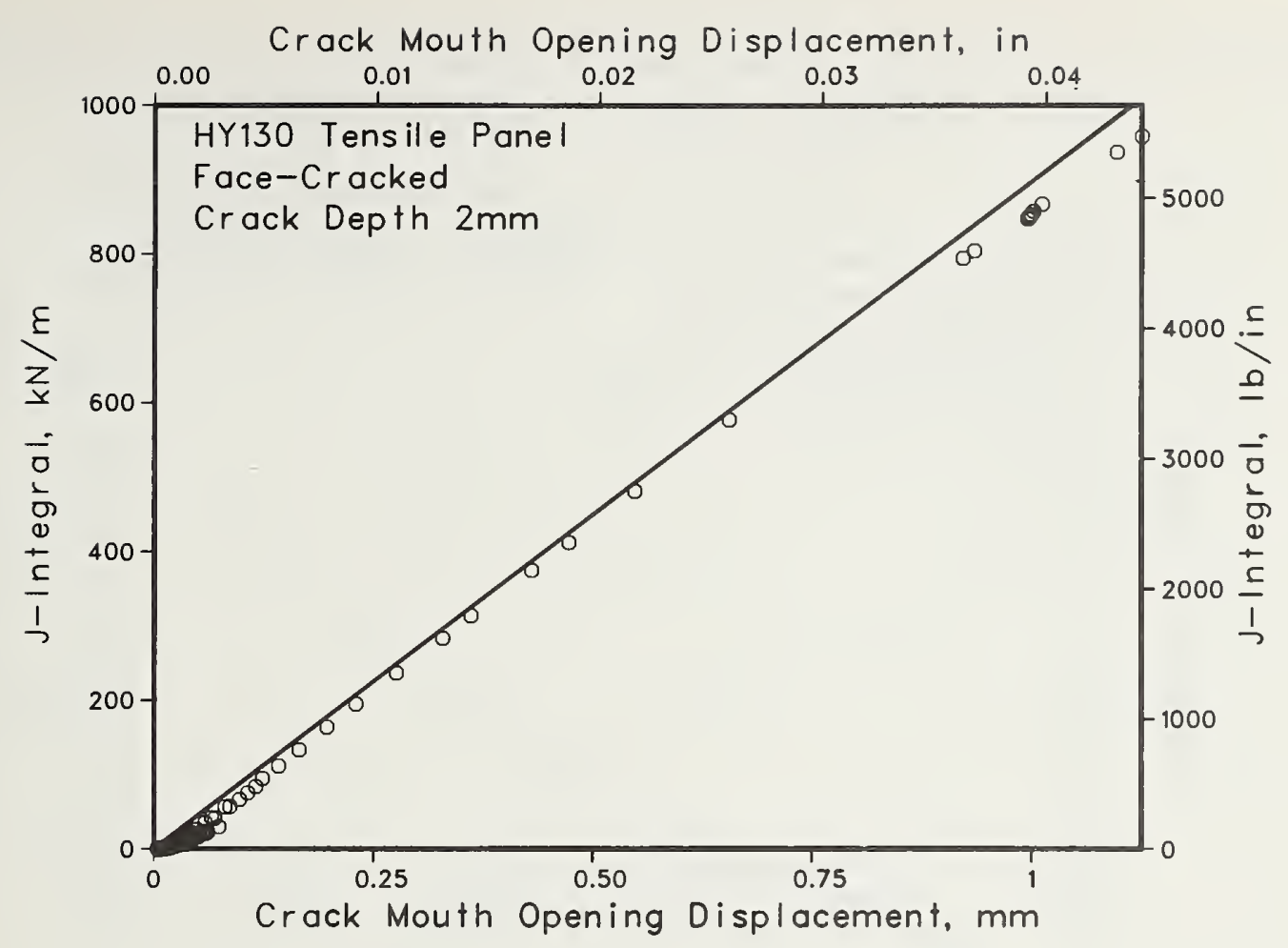

Figure $32 k$. 
Figure $33 \mathrm{a}-33 \mathrm{~g}$. Dependence of $\mathrm{J}$-integral, stress, and crack mouth opening displacement on strain for edoe-hole-cracked tensile panel with crack length $2 \mathrm{~mm}$.

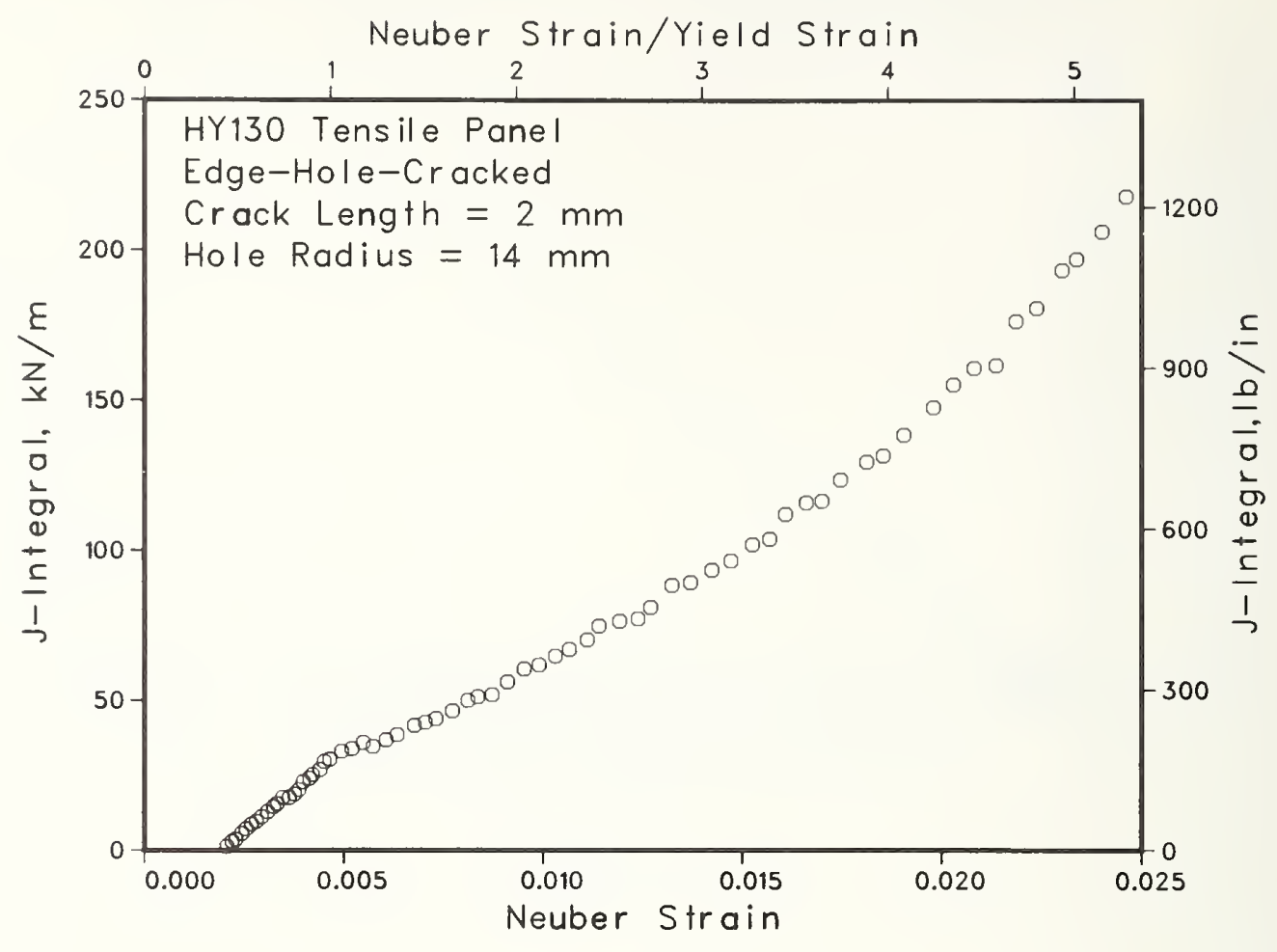

Figure $33 a$.

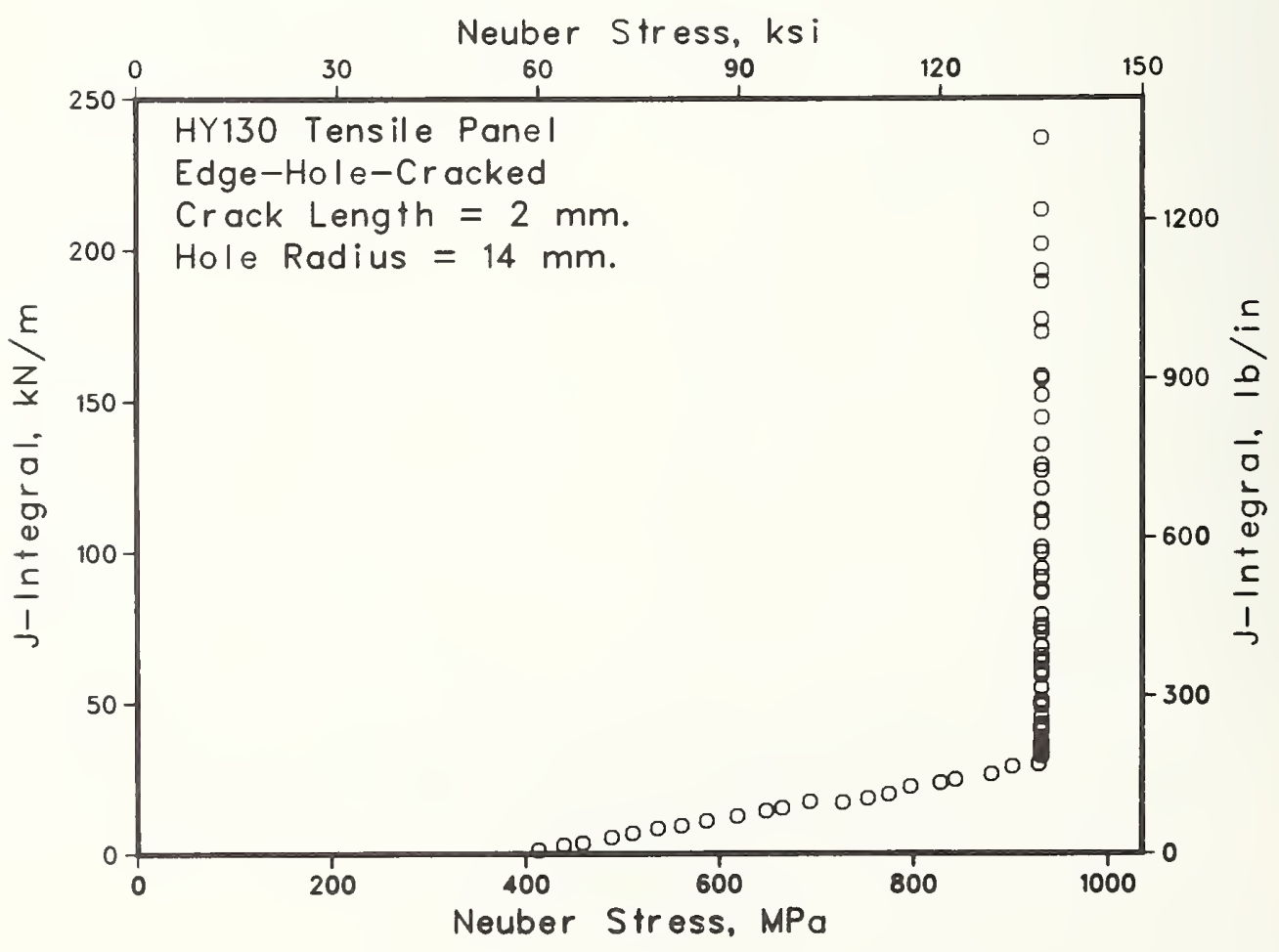

Figure 33b. 


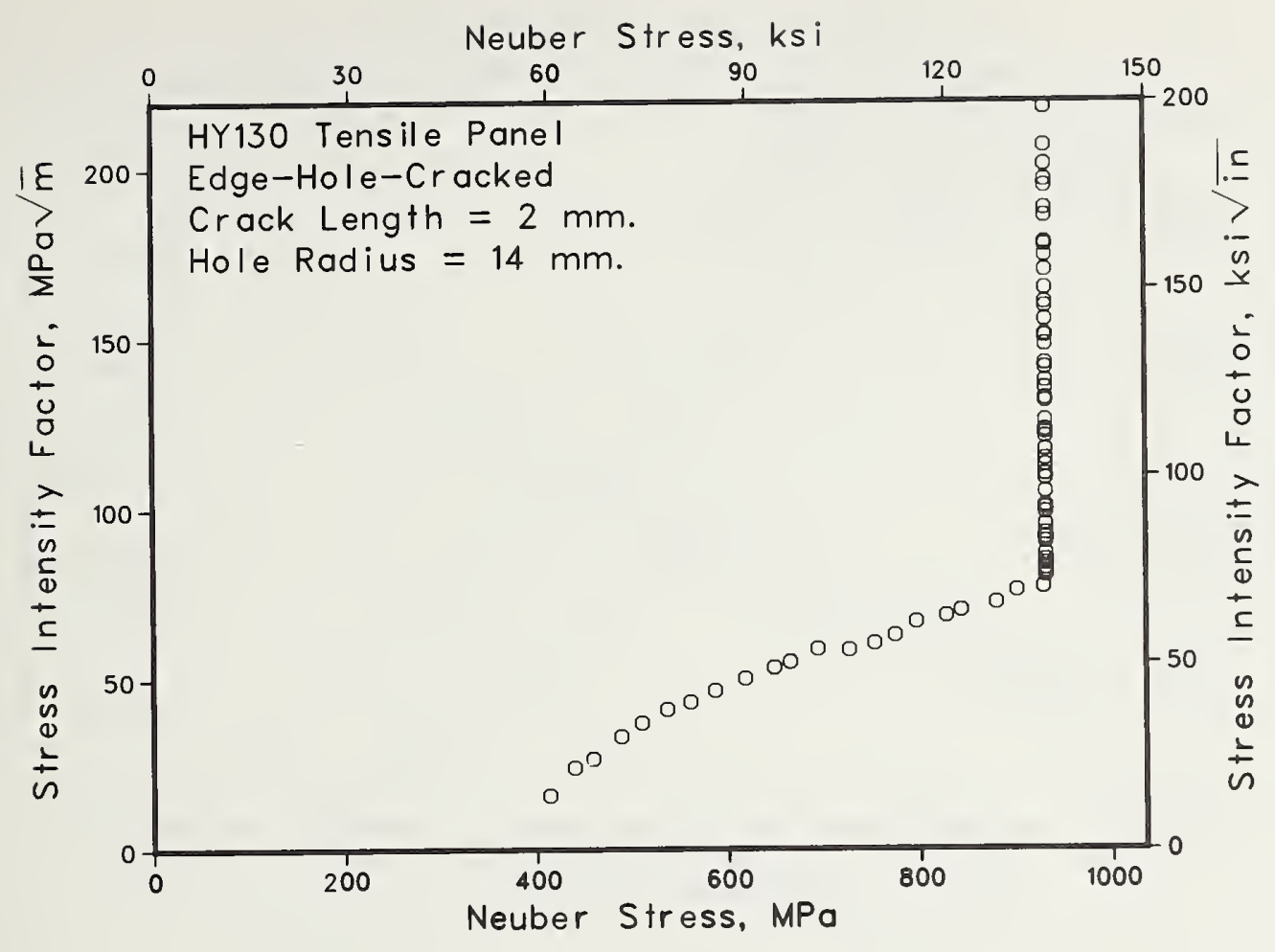

Figure $33 c$.

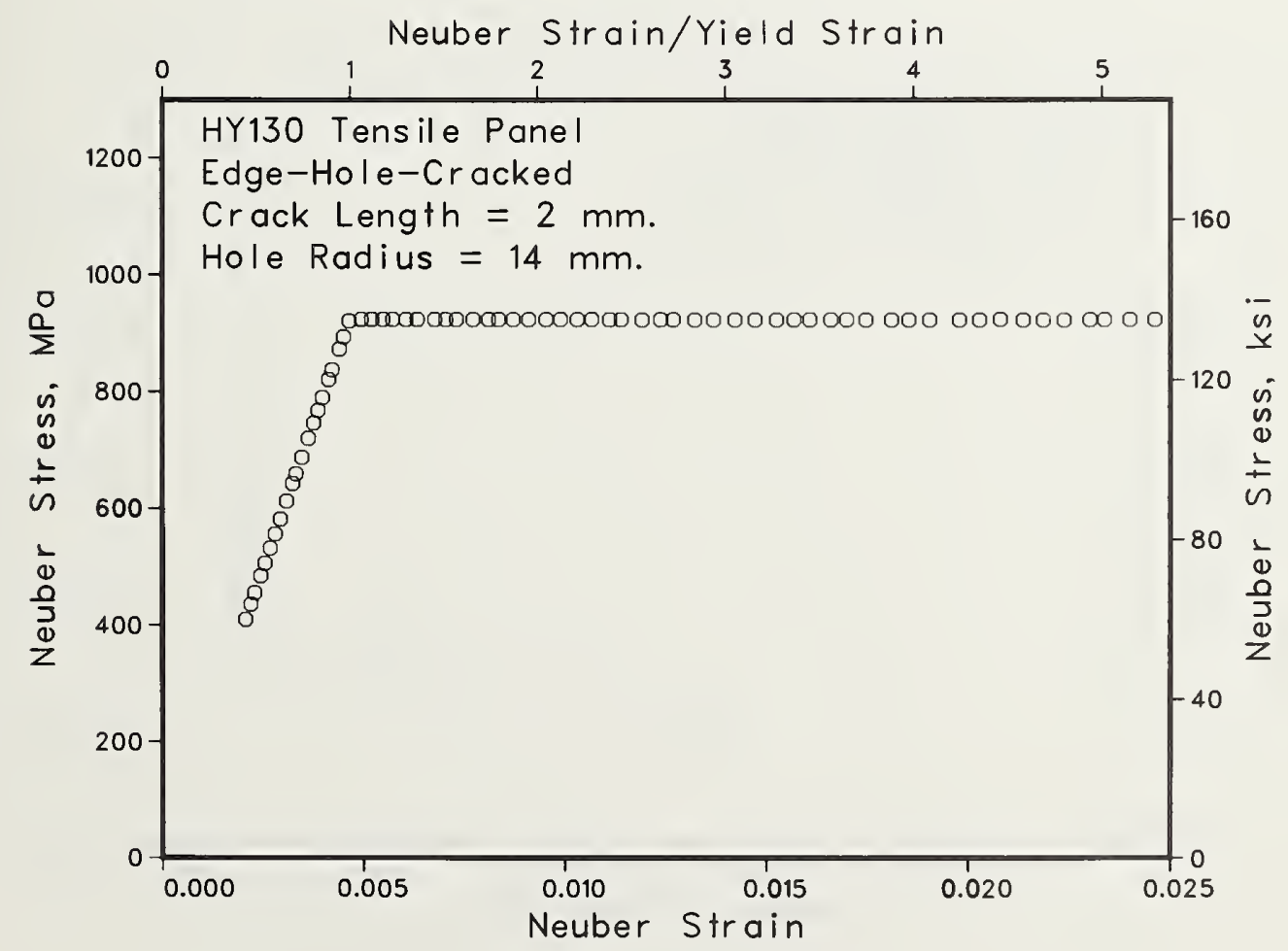

Figure 33d. 


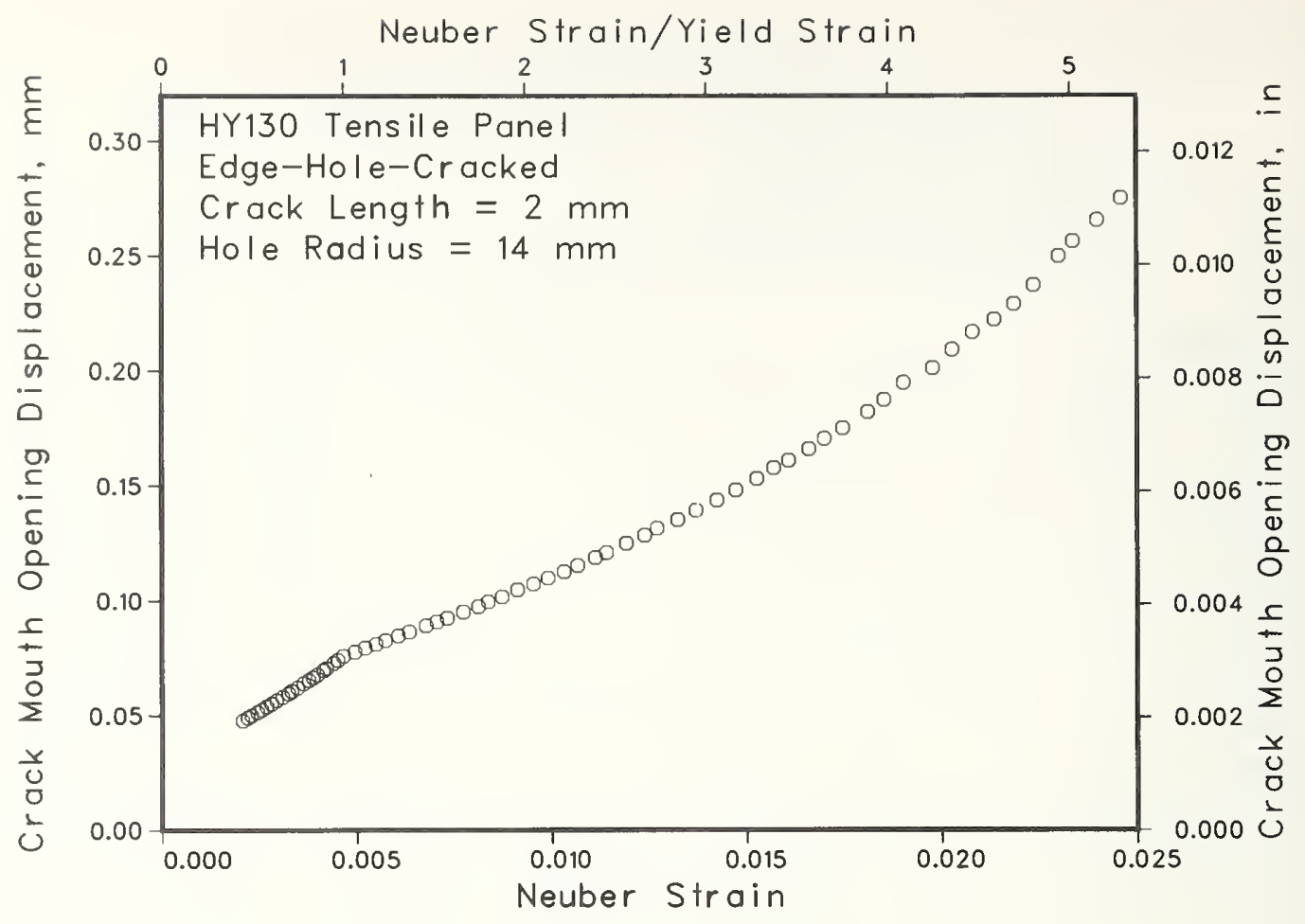

Figure 33e.

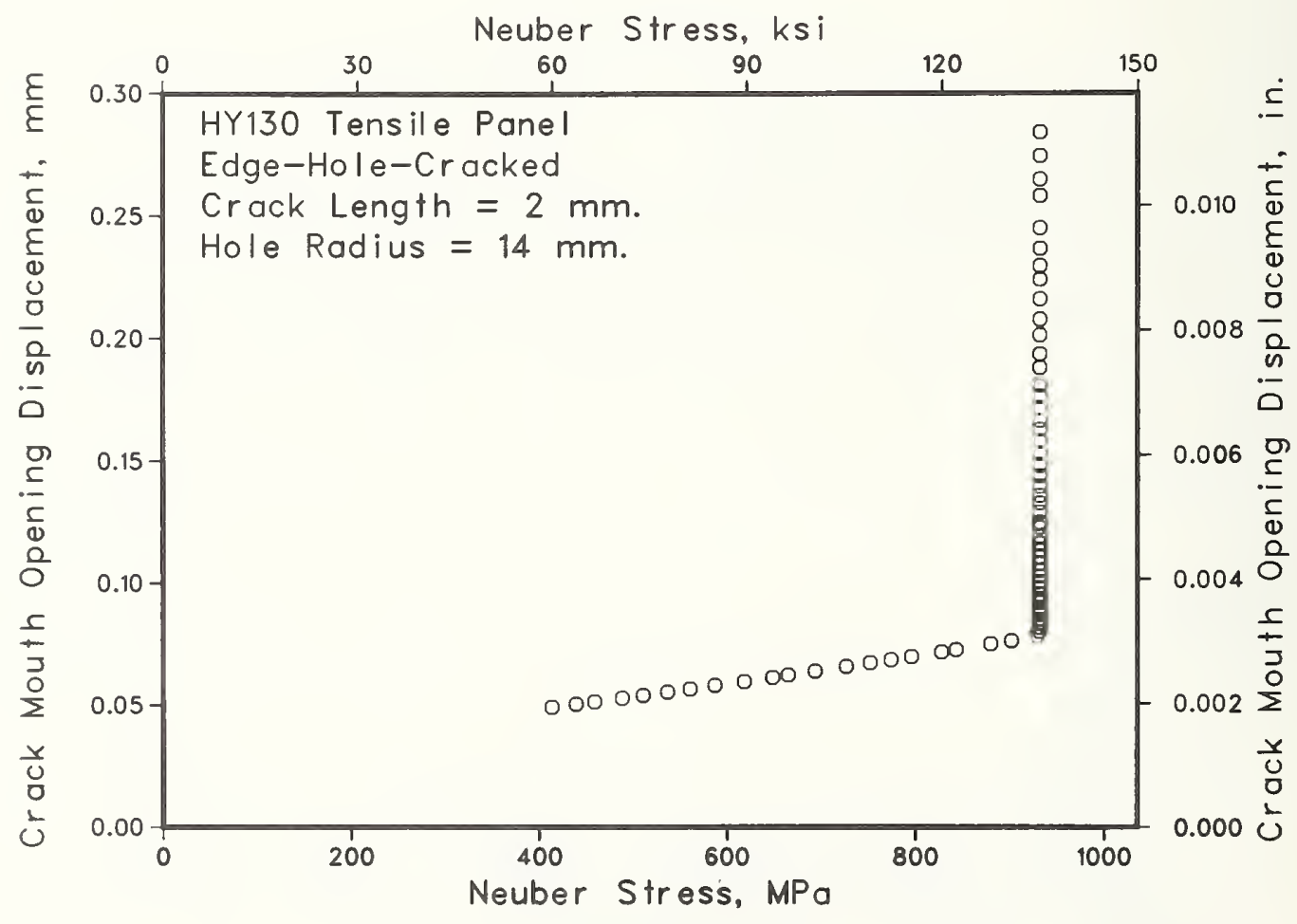

Figure $33 f$. 


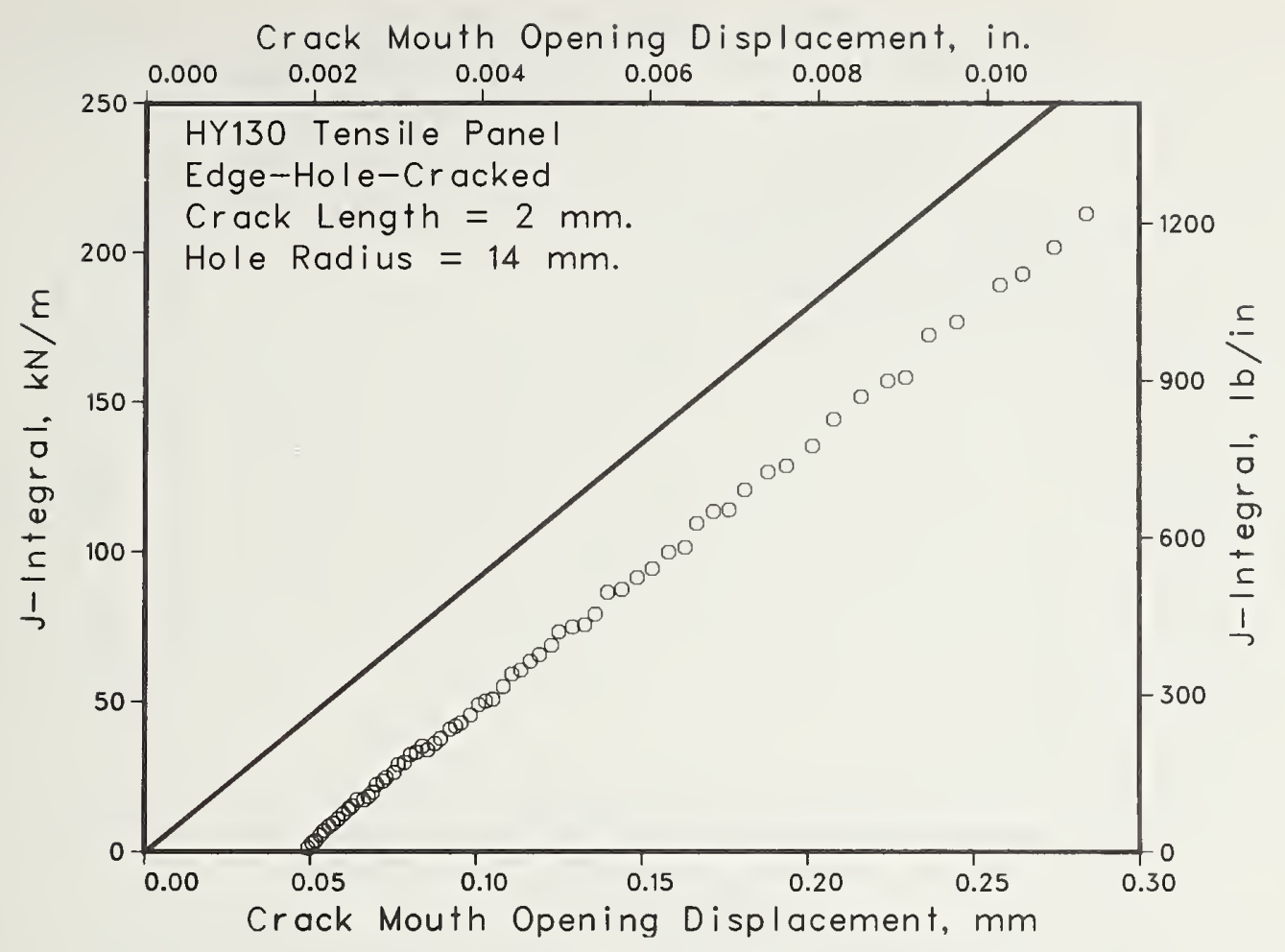

Figure 33g. 
Figure 34a-34k. Dependence of J-integral, stress, and crack mouth opening displacement on strain for center-cracked tensile panel with width $560 \mathrm{~mm}$ and crack half-length $16 \mathrm{~mm}$.

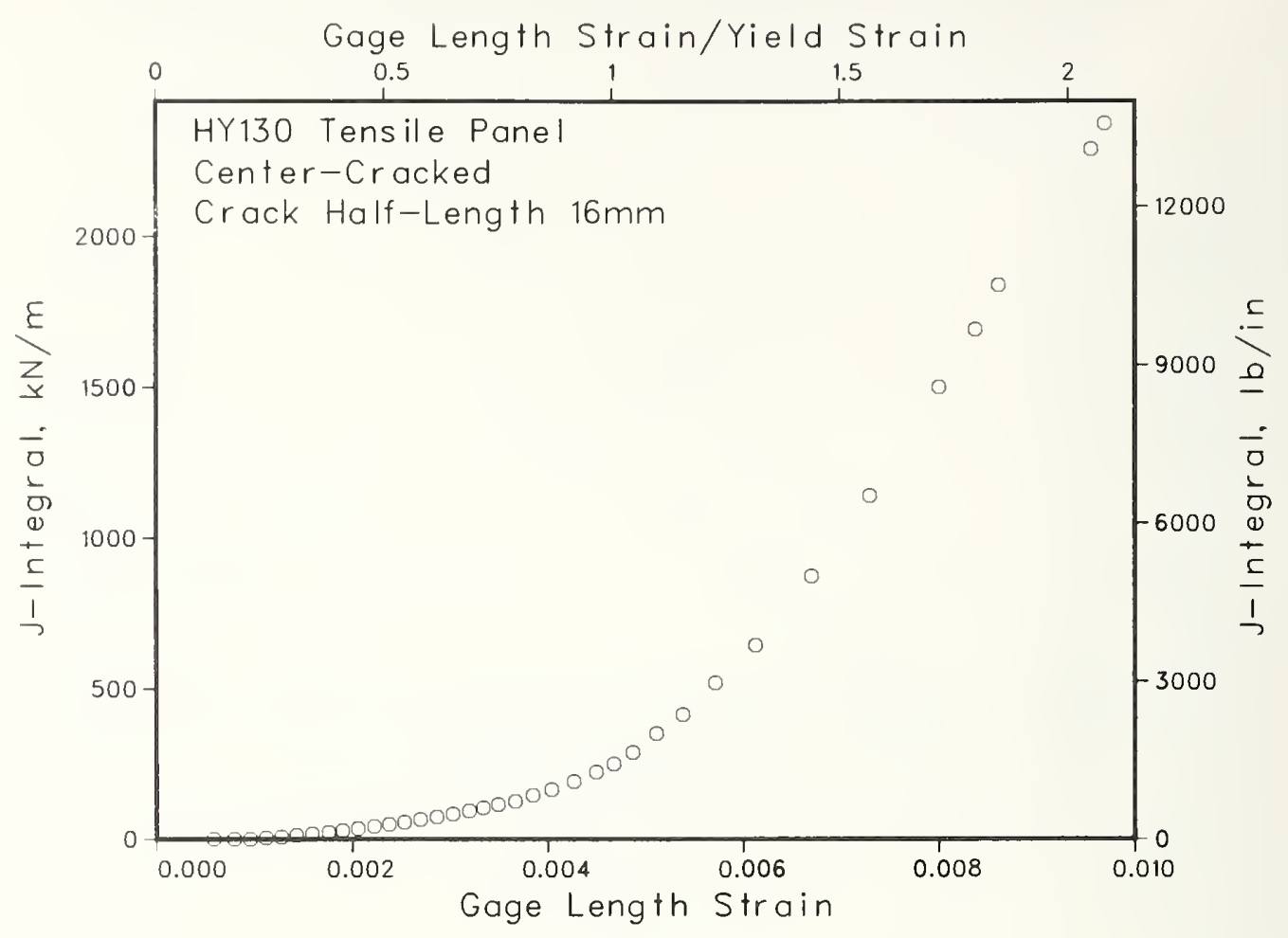

Figure $34 a$.

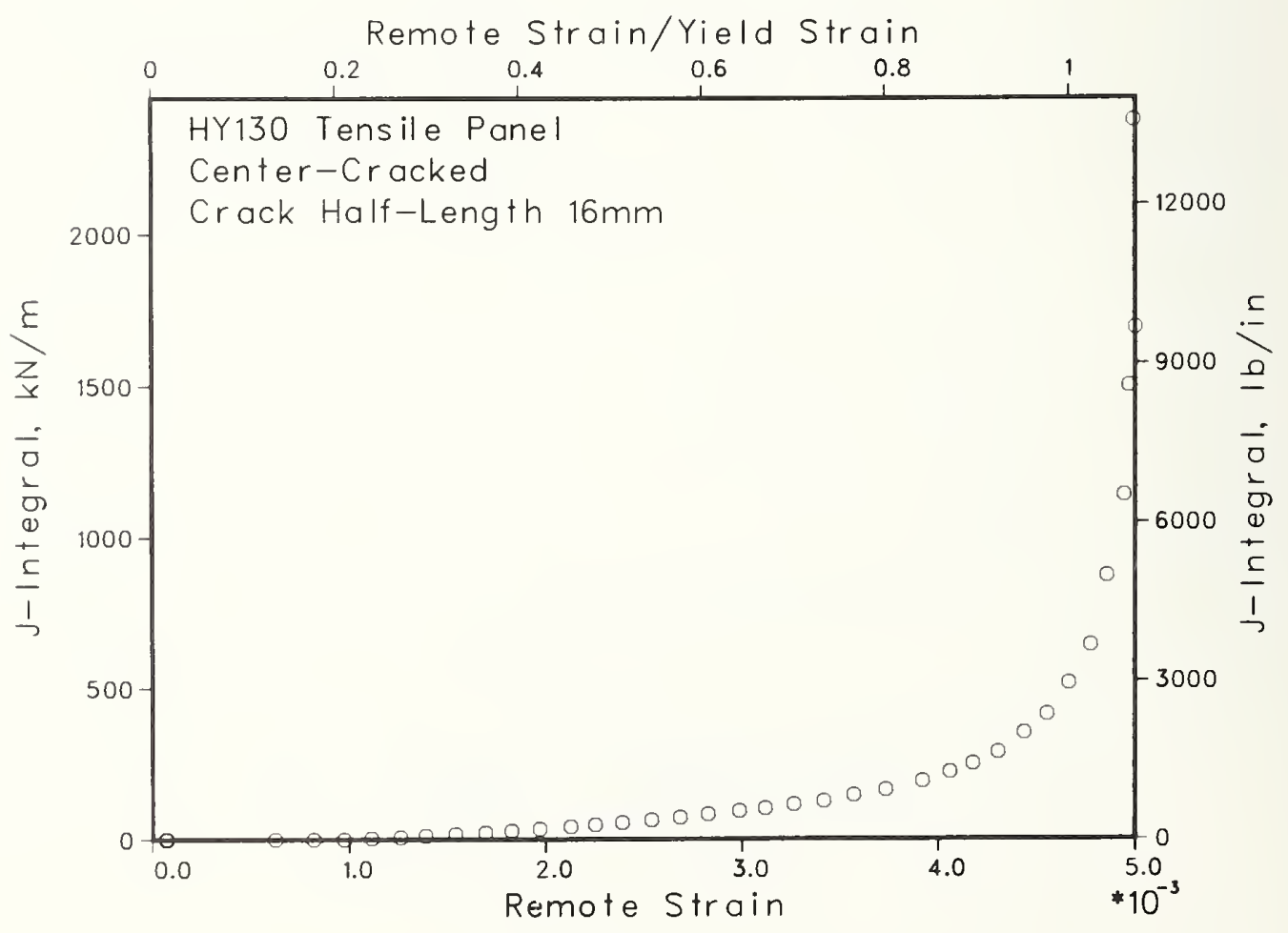

Figure 34b. 


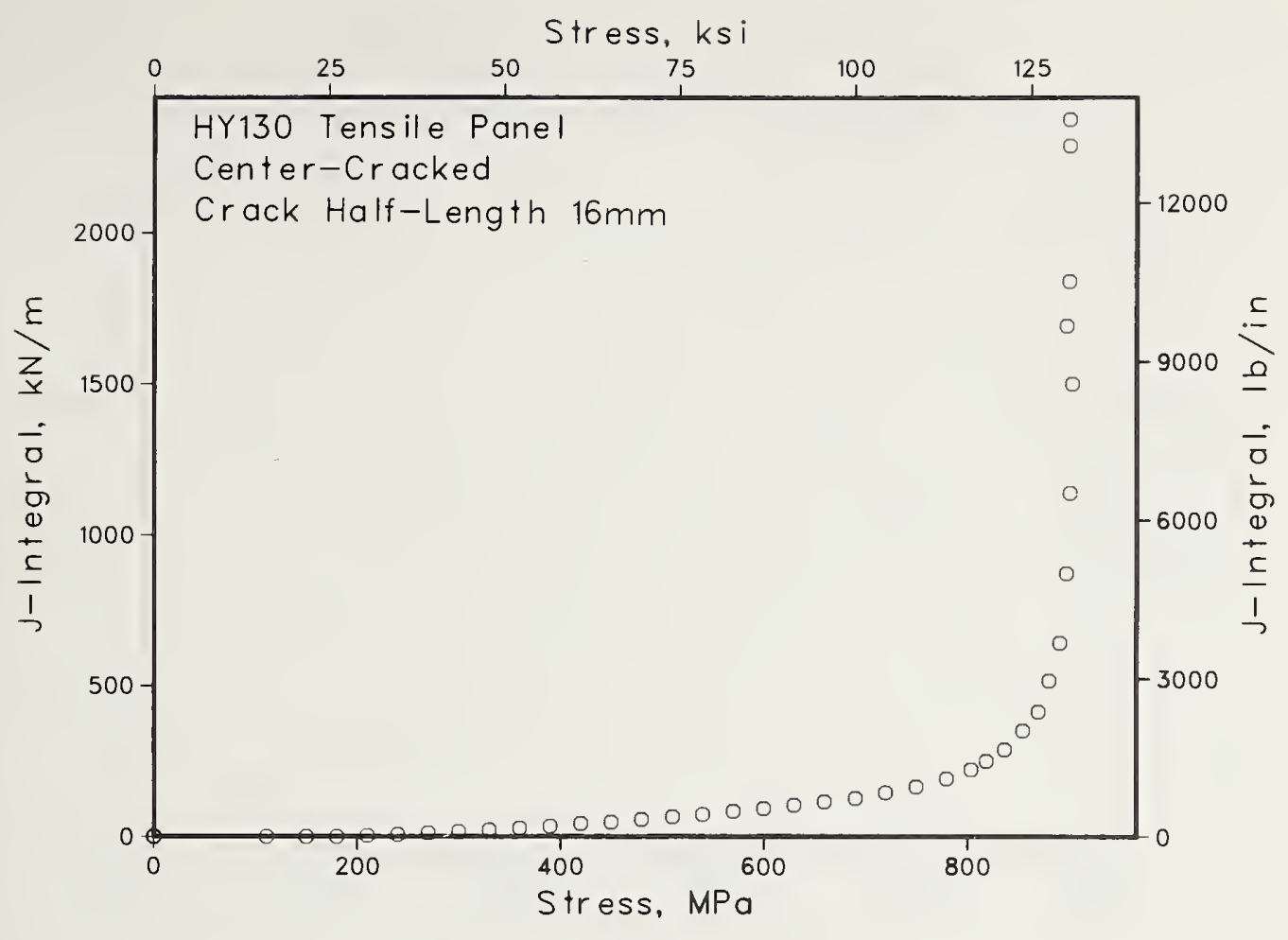

Figure $34 c$.

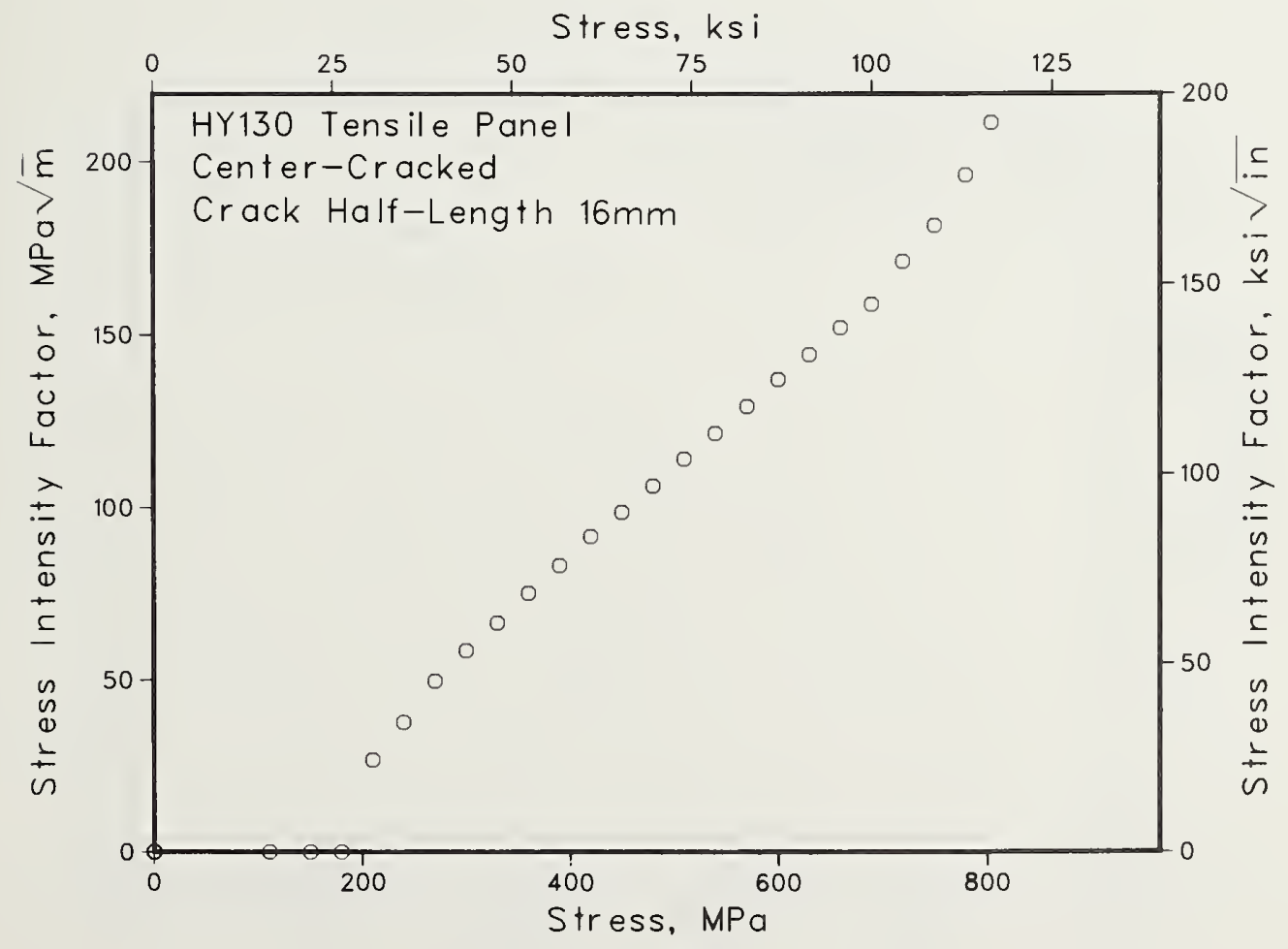

Figure $34 d$. 


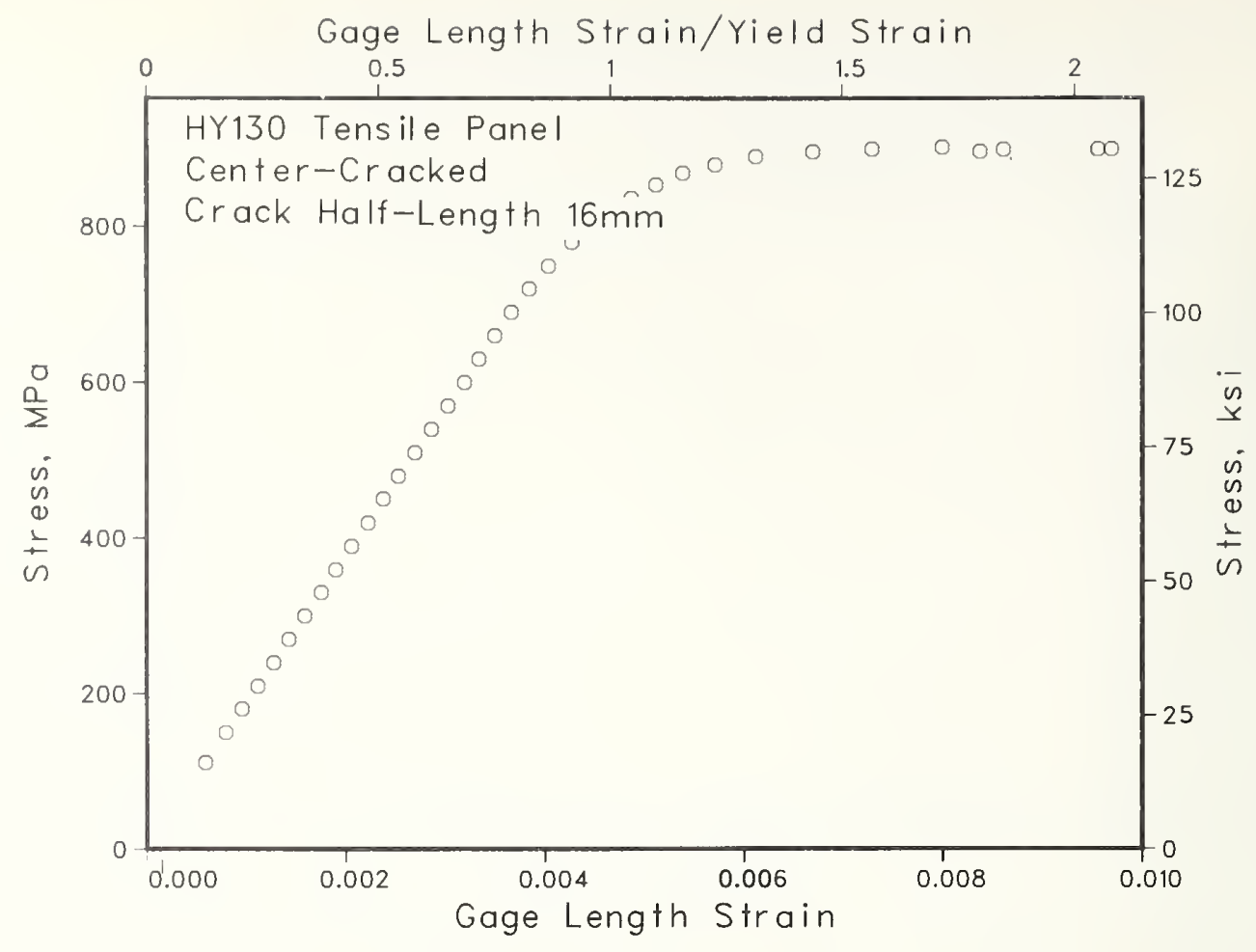

Figure $34 \mathrm{e}$.

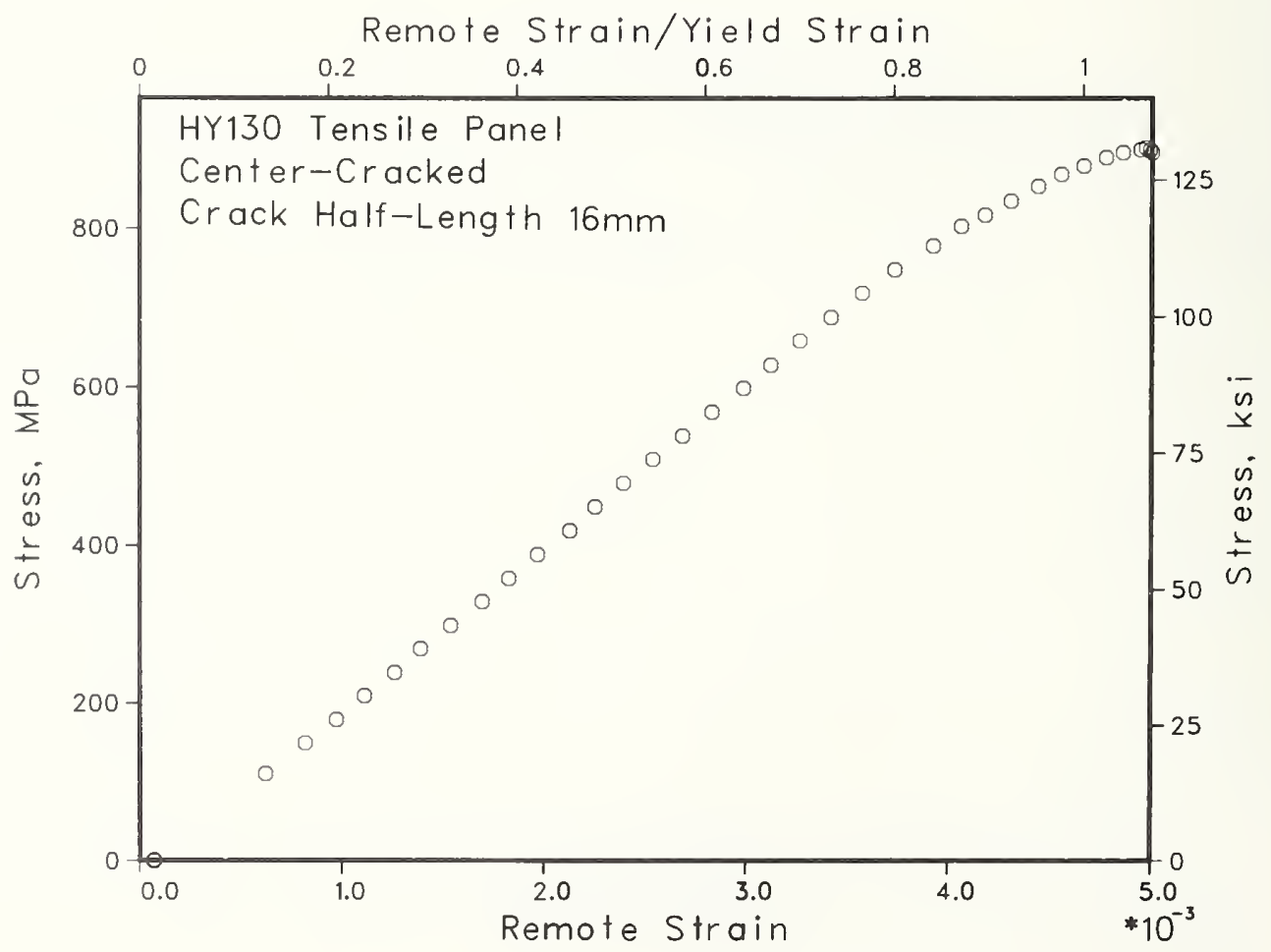

Figure $34 f$. 


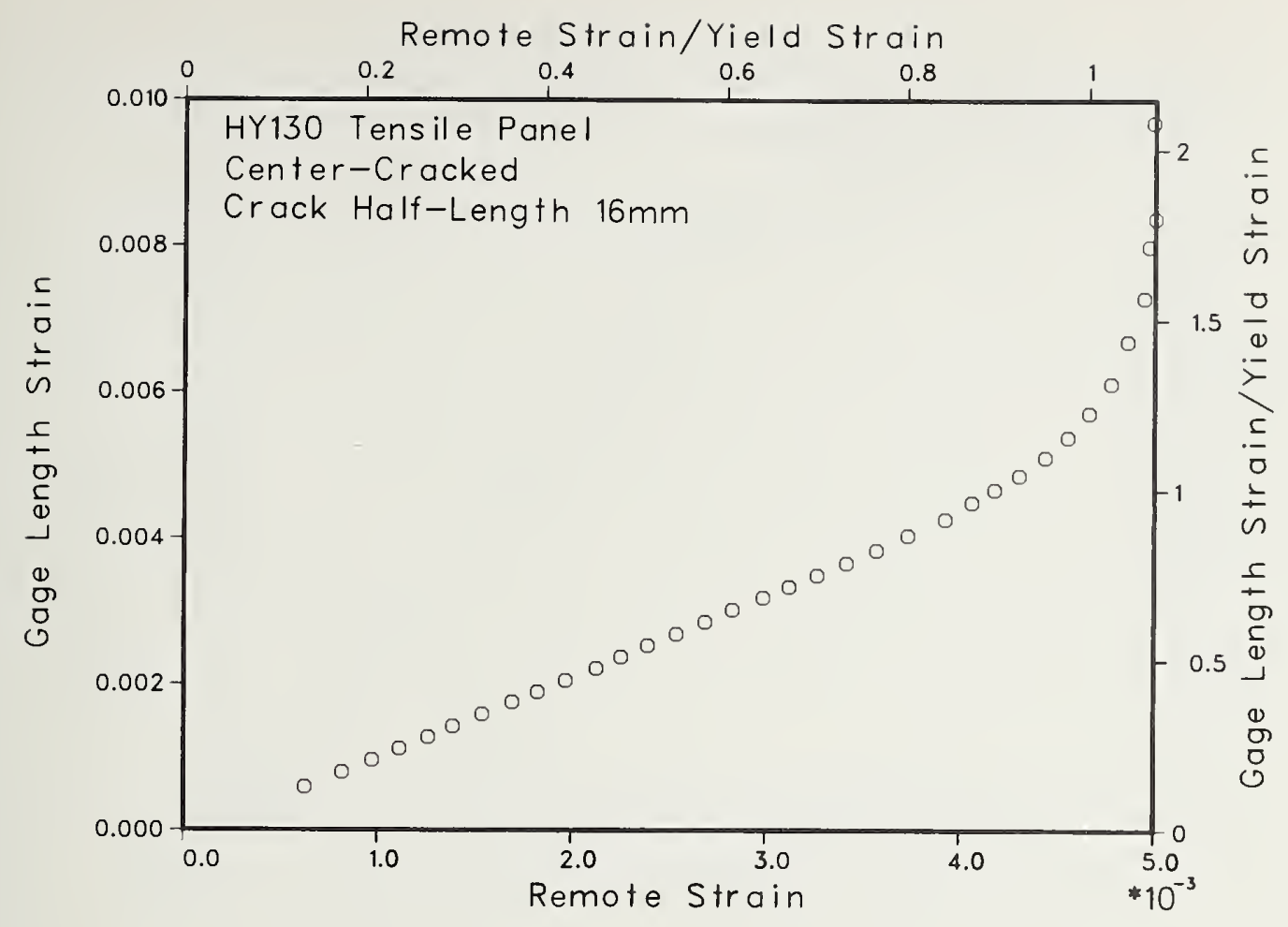

Figure $34 \mathrm{~g}$.

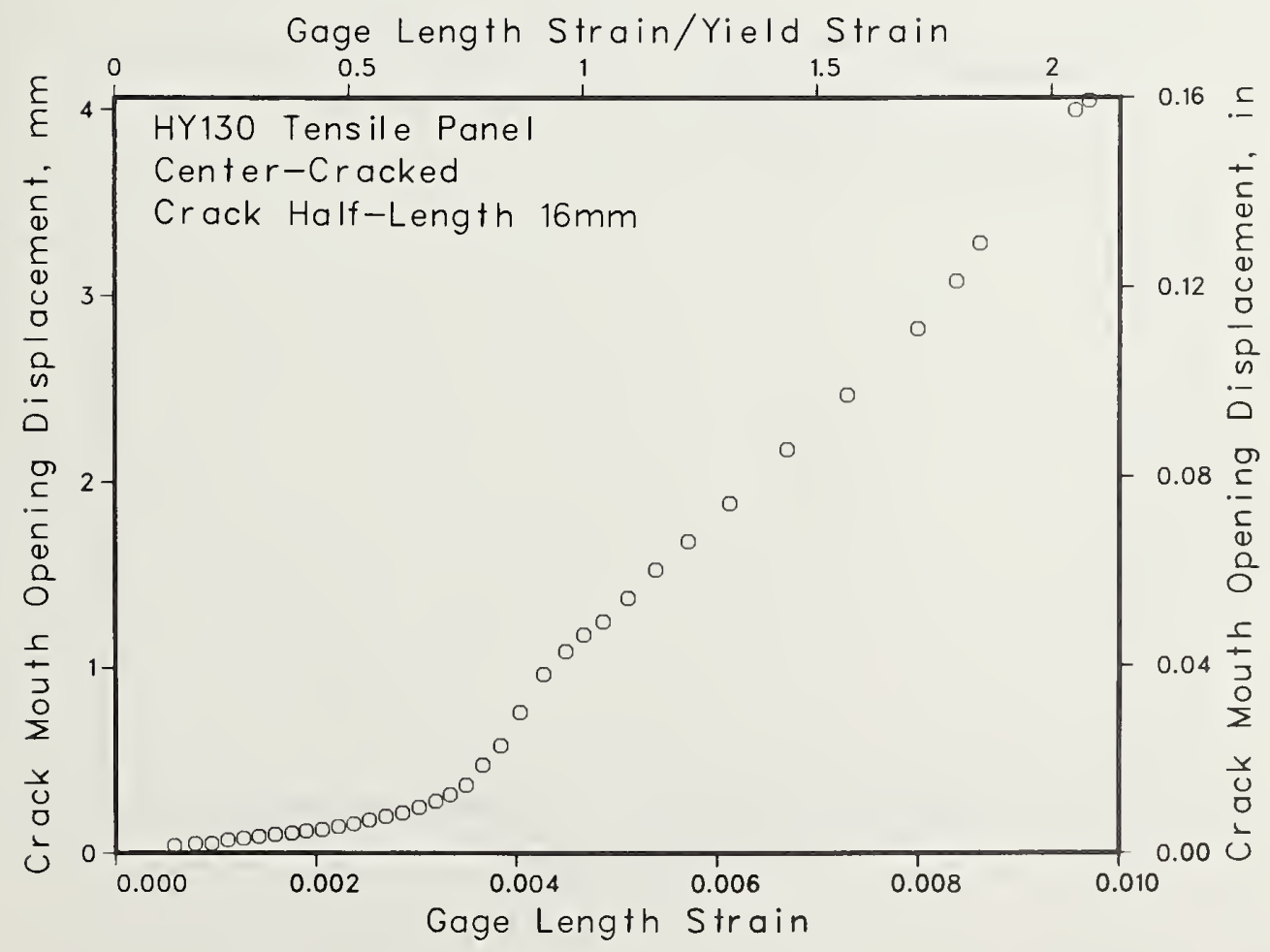

Figure $34 \mathrm{~h}$. 


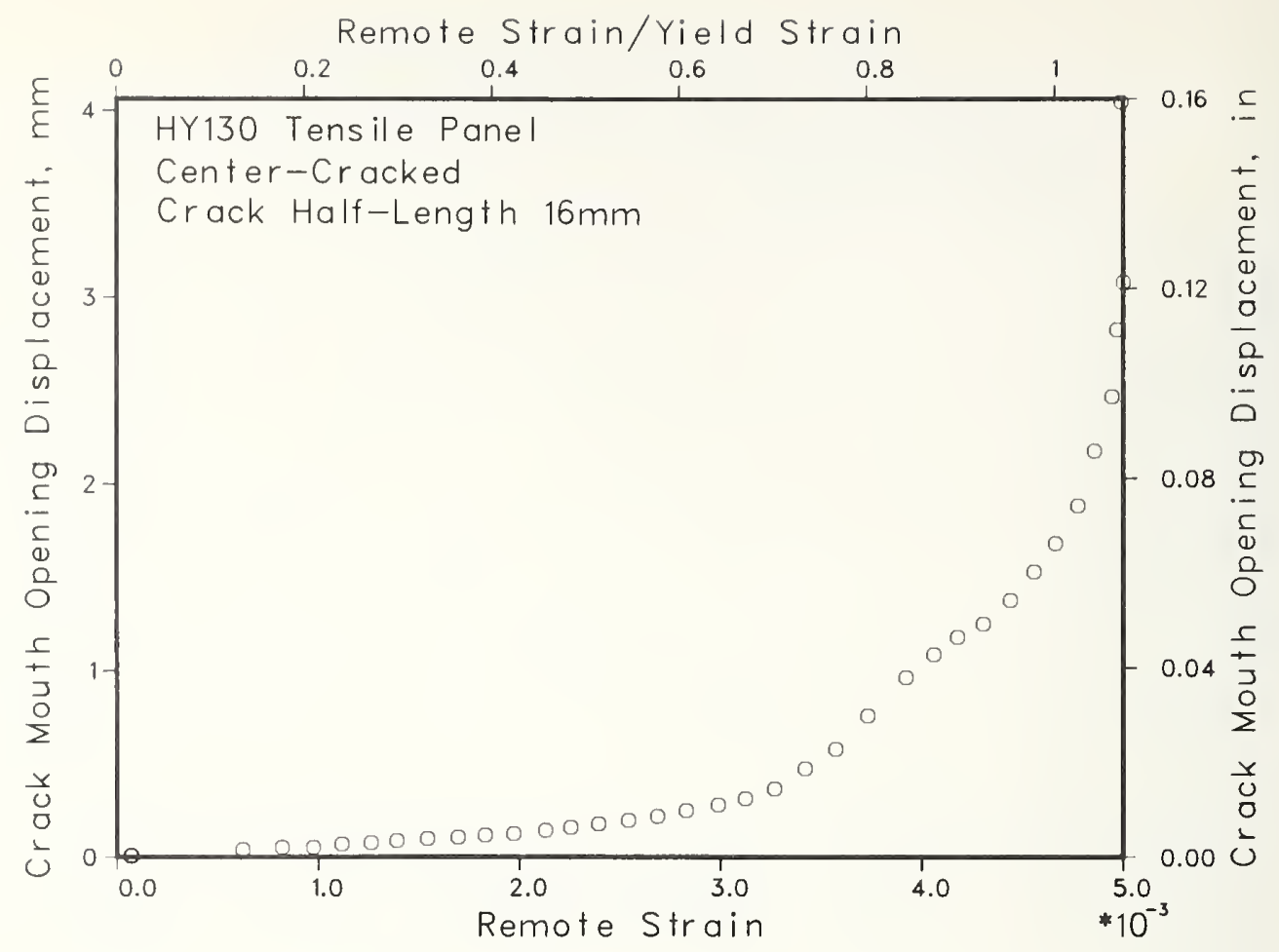

Figure $34 i$.

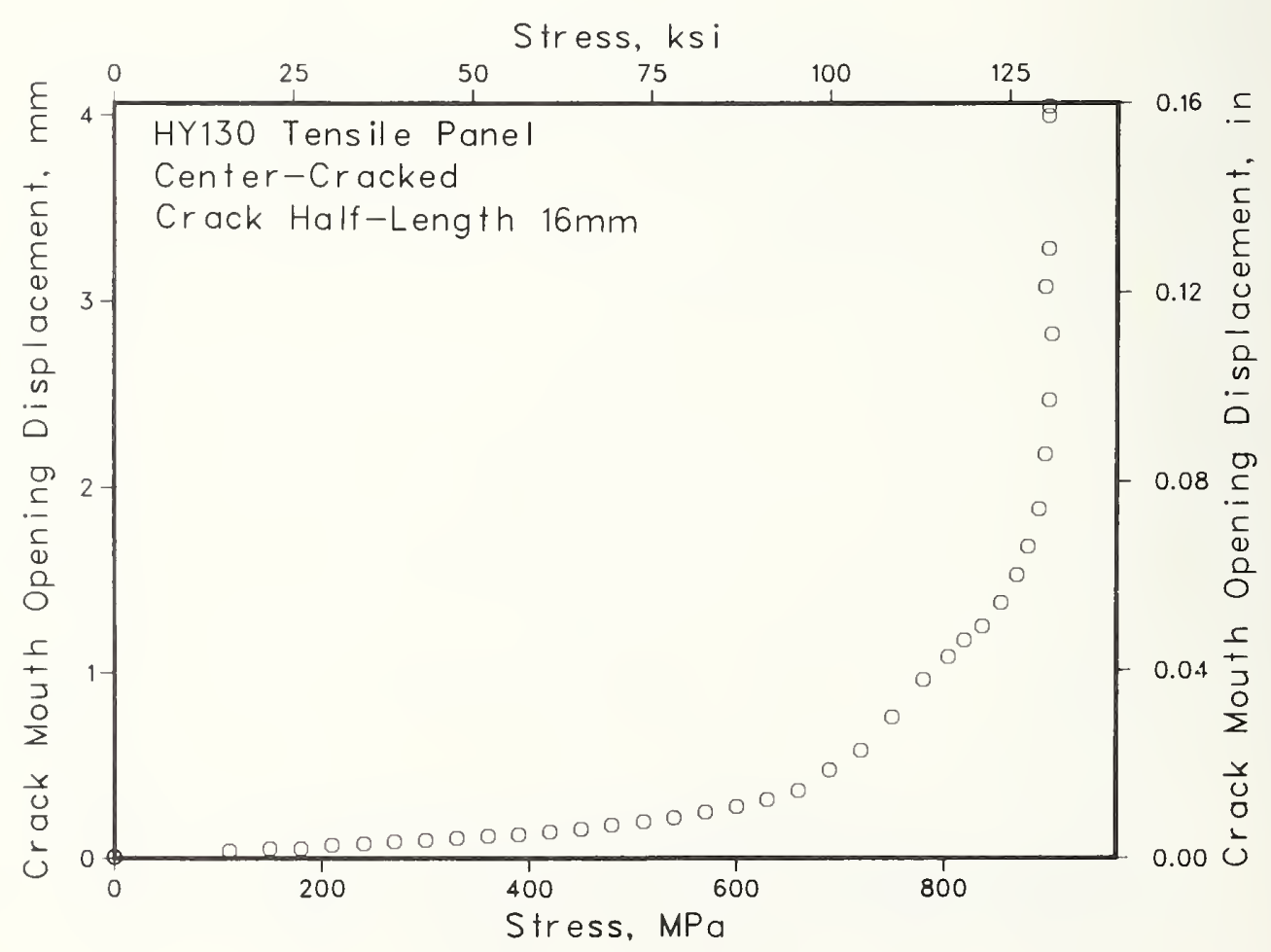

Figure $34 j$. 


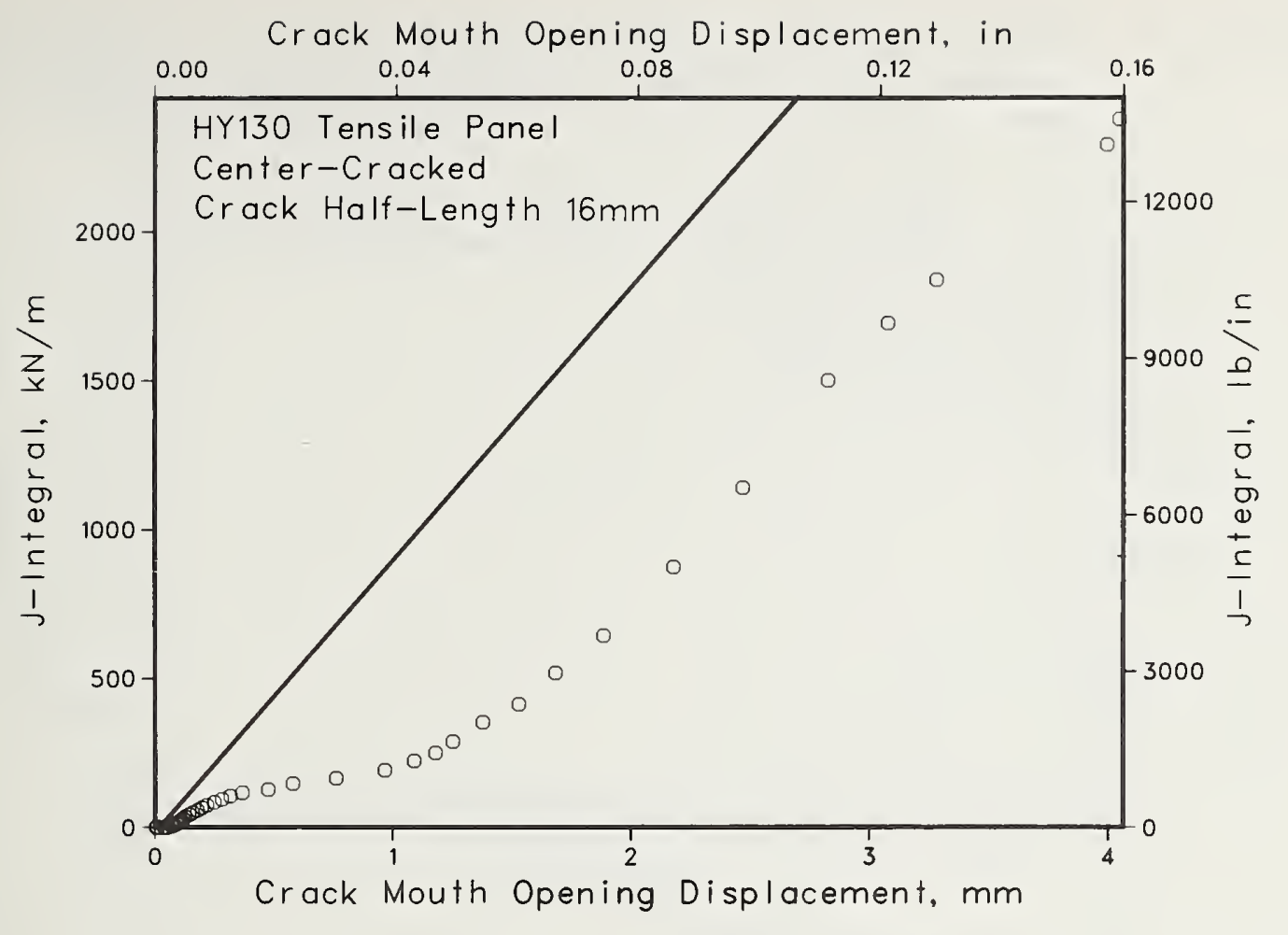

Figure $34 k$. 
Figure 35a-35k. Dependence of J-integral, stress, and crack mouth opening displacement on strain for surface-cracked tensile panel with crack depth $6 \mathrm{~mm}$ and crack length $25 \mathrm{~mm}$.

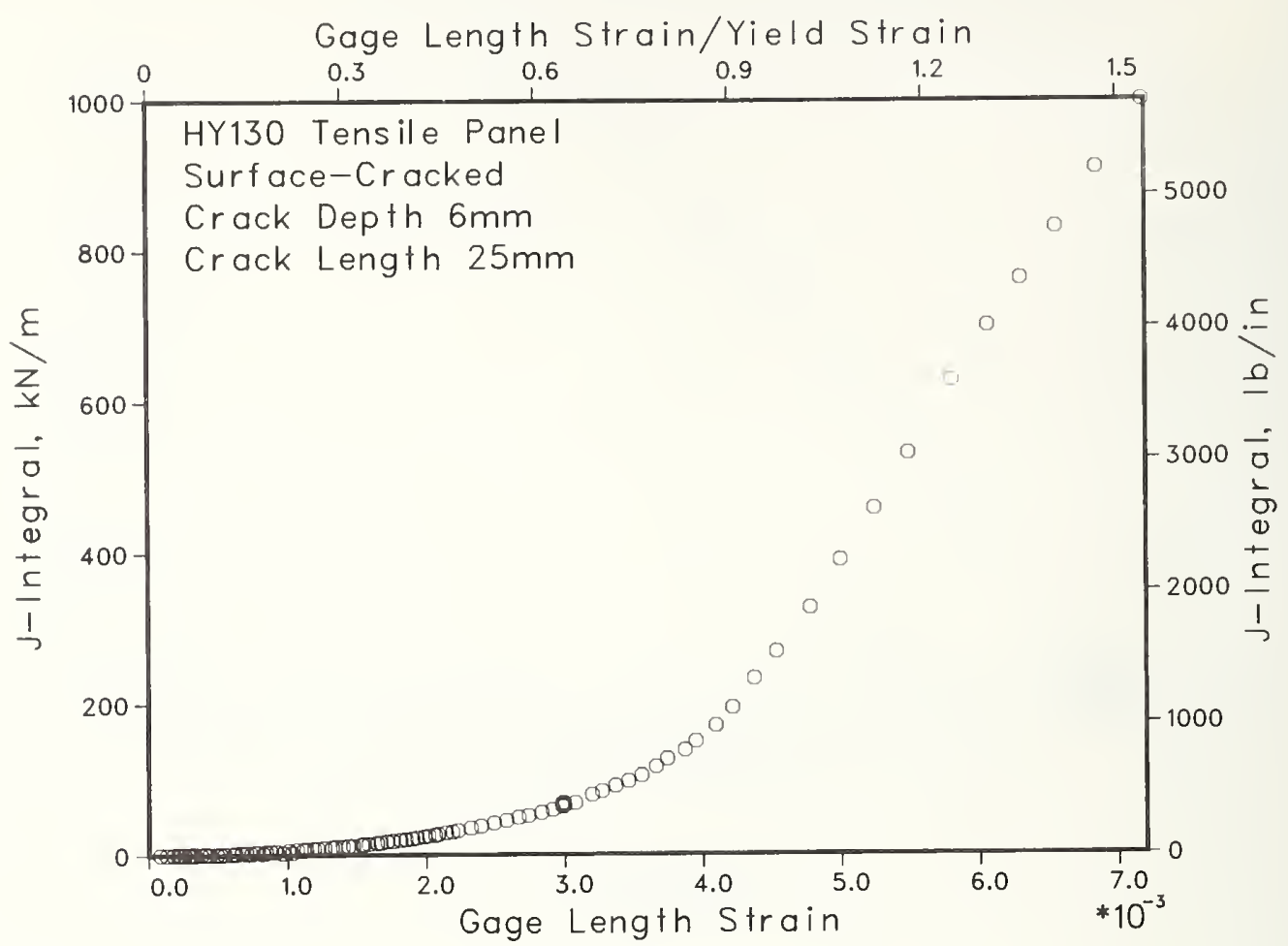

Figure $35 a$.

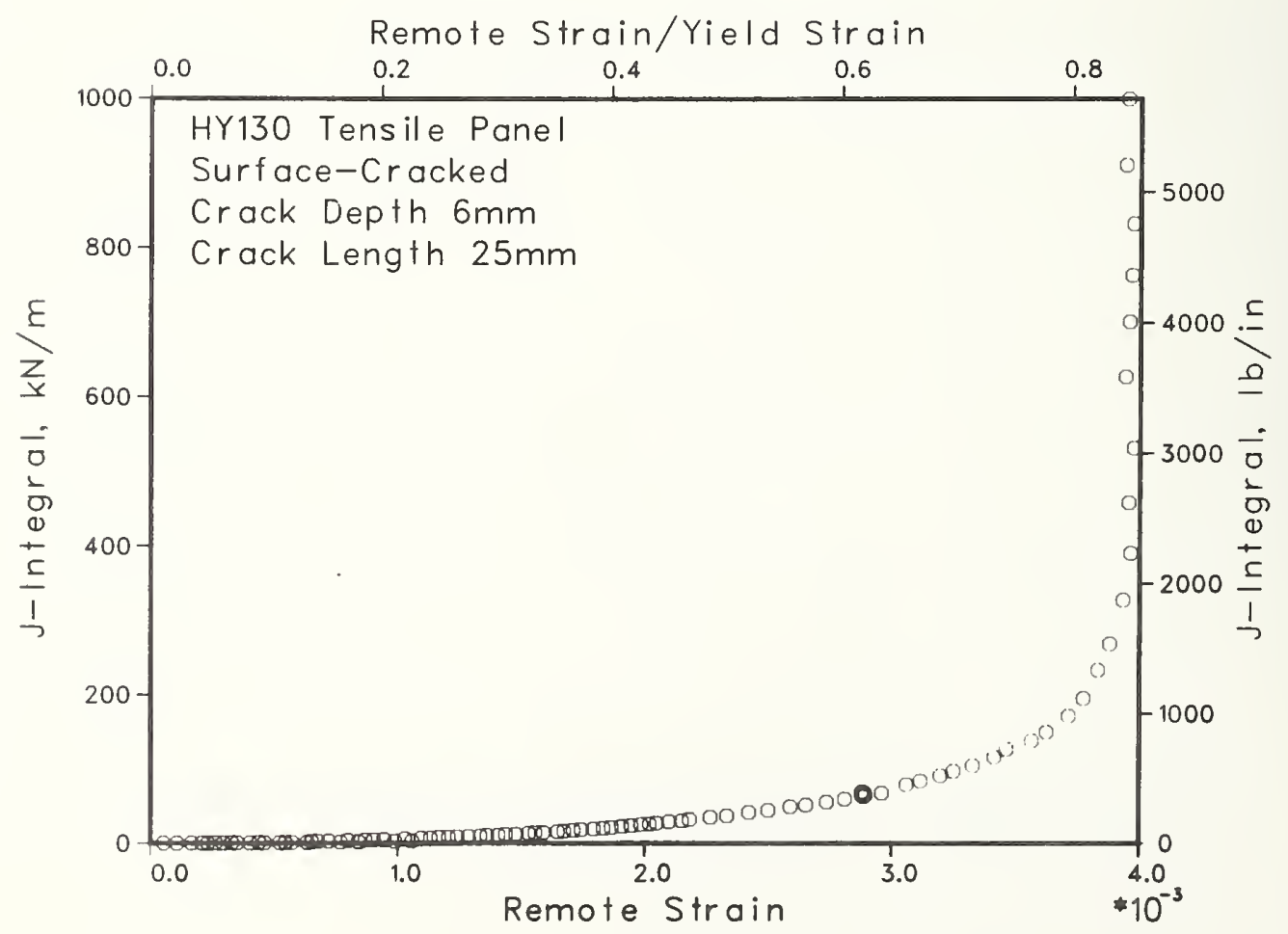

Figure 35b. 


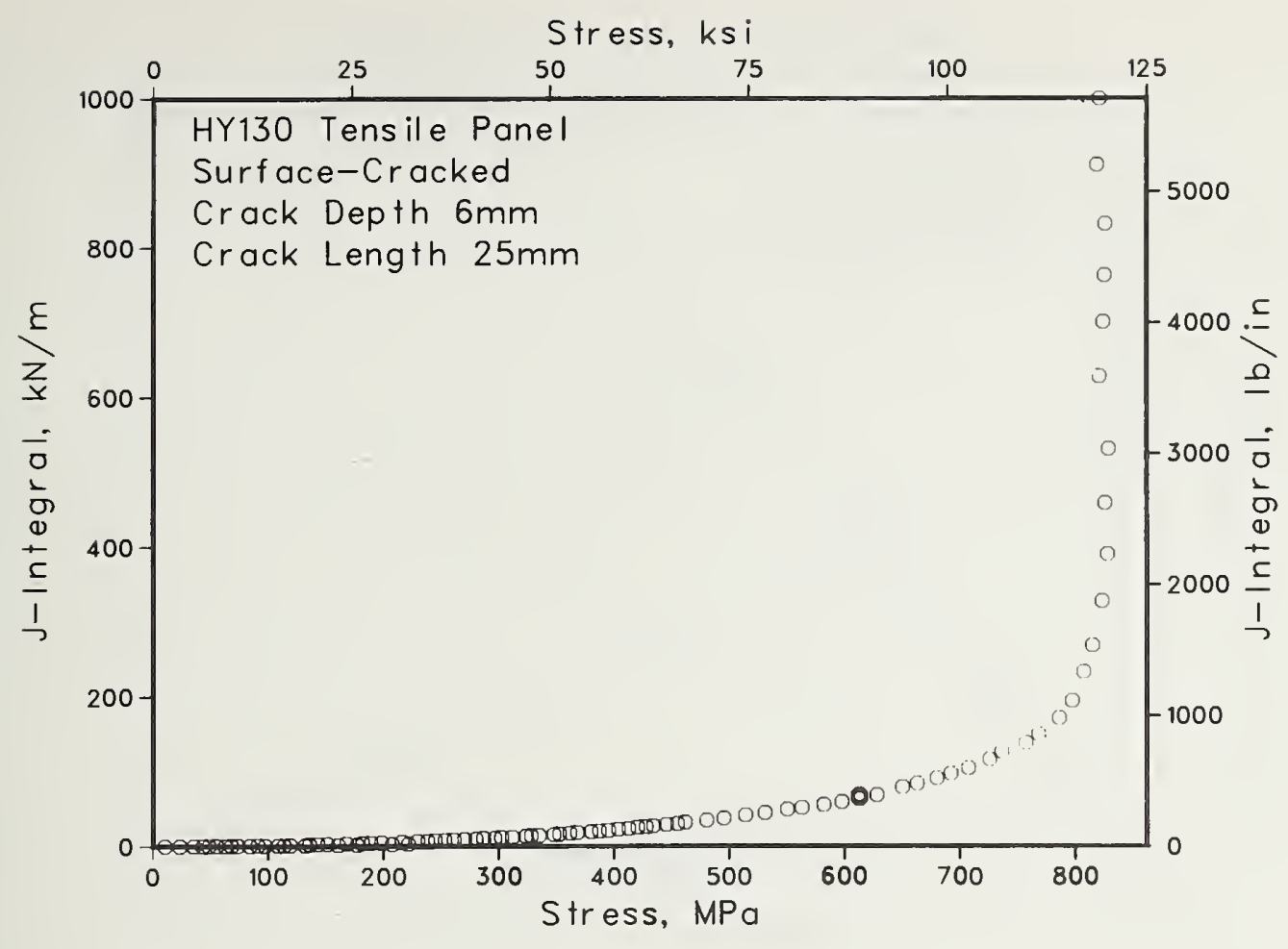

Figure $35 c$.

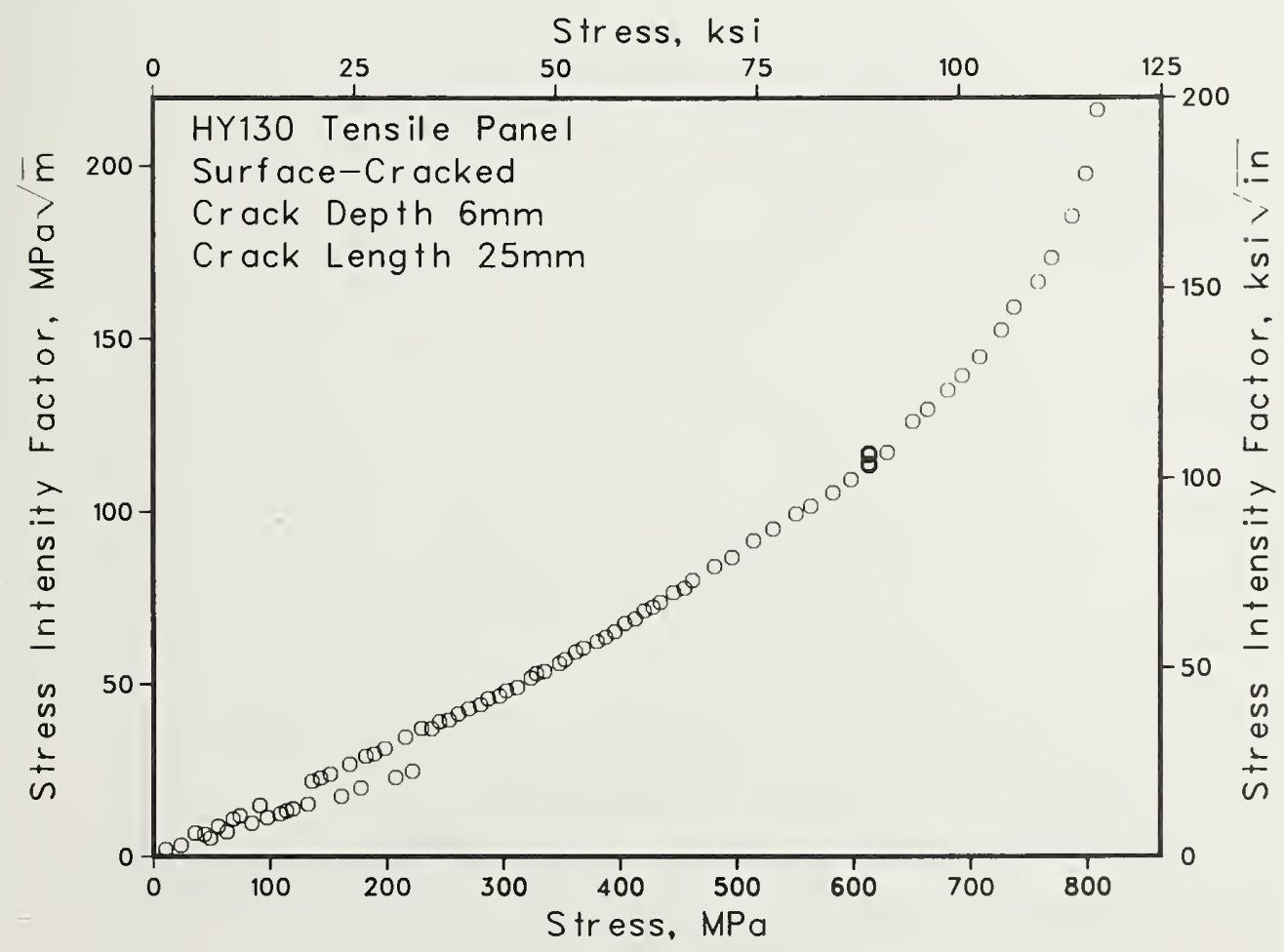

Figure 35d. 


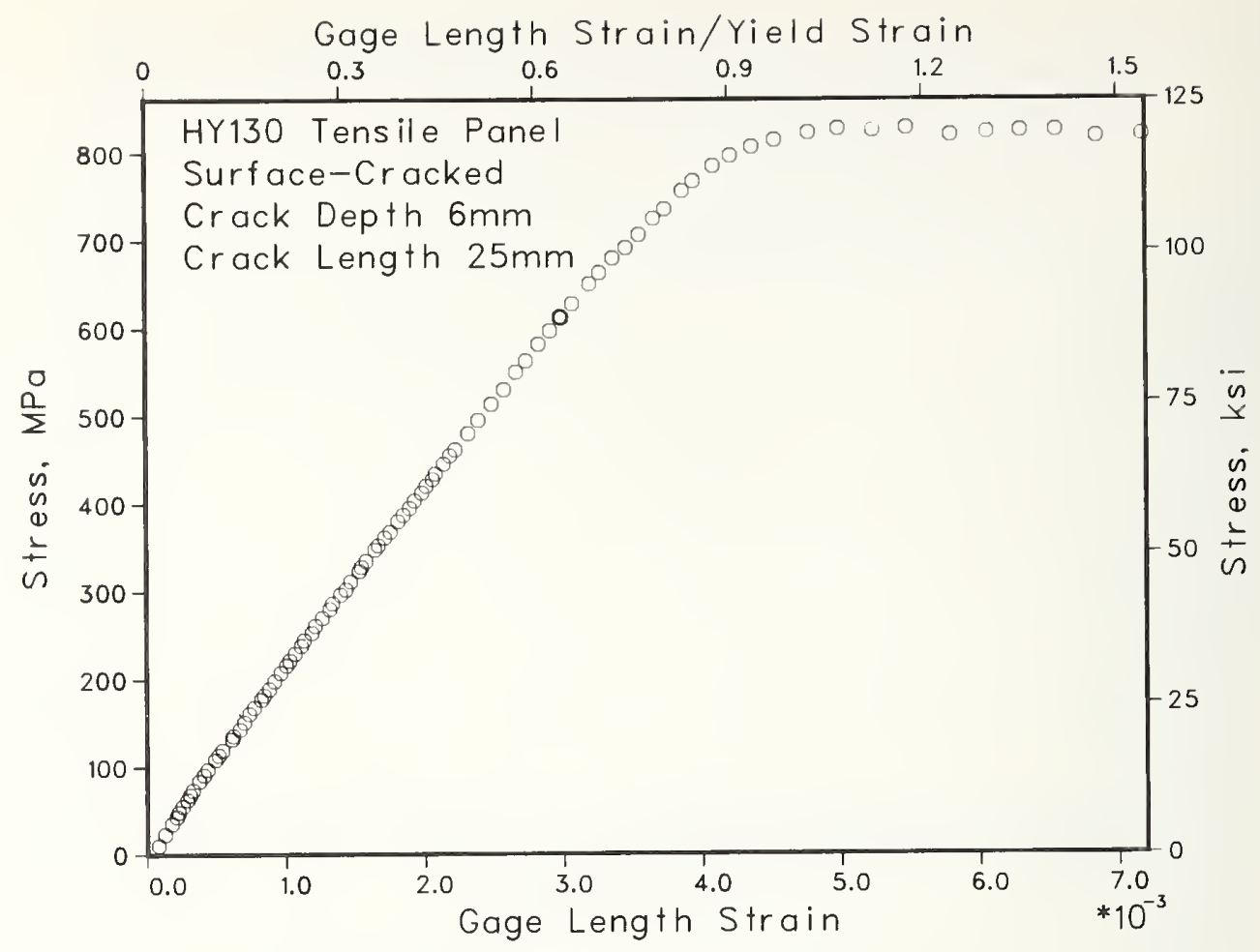

Figure $35 \mathrm{e}$.

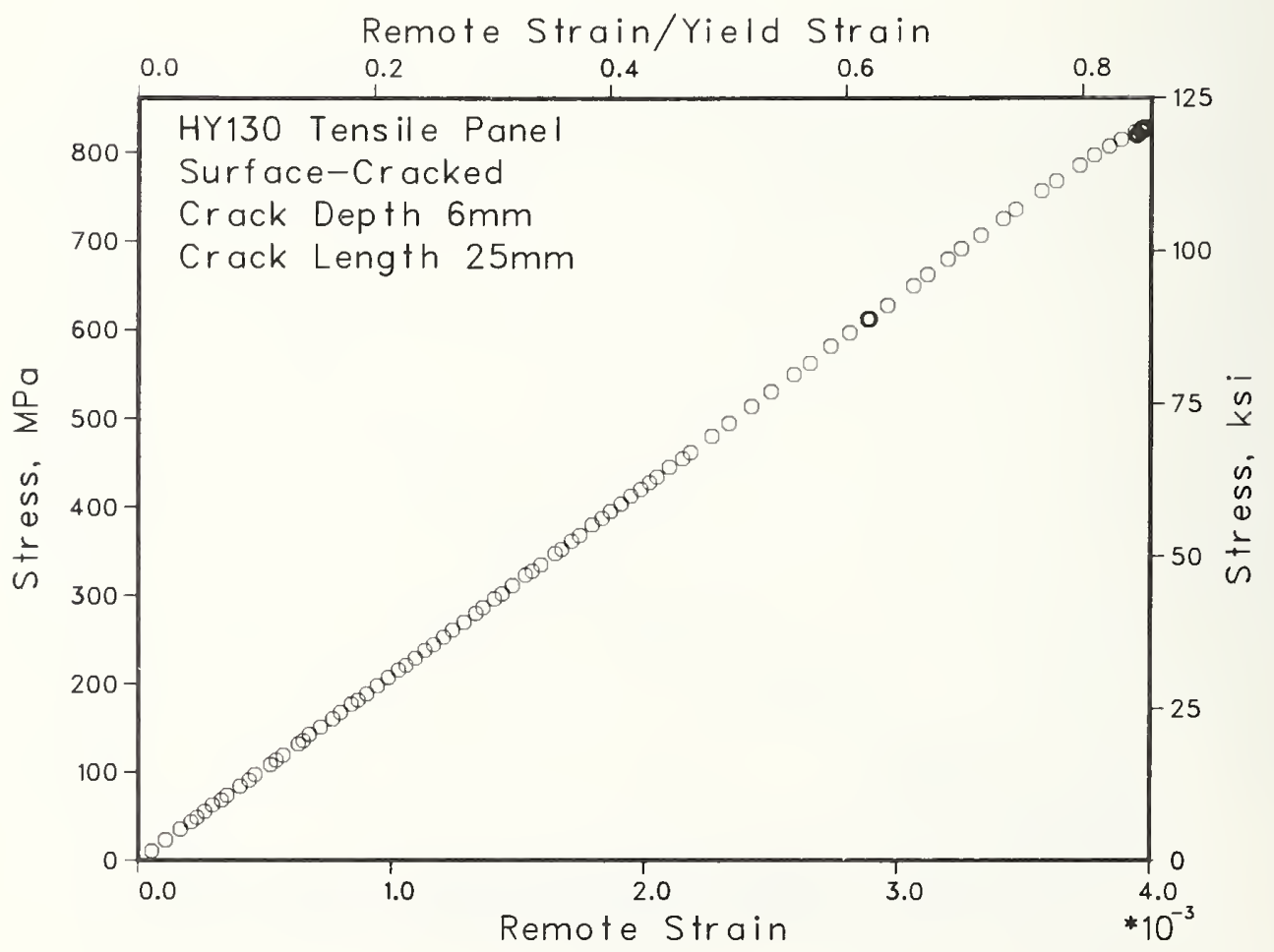

Figure $35 f$. 


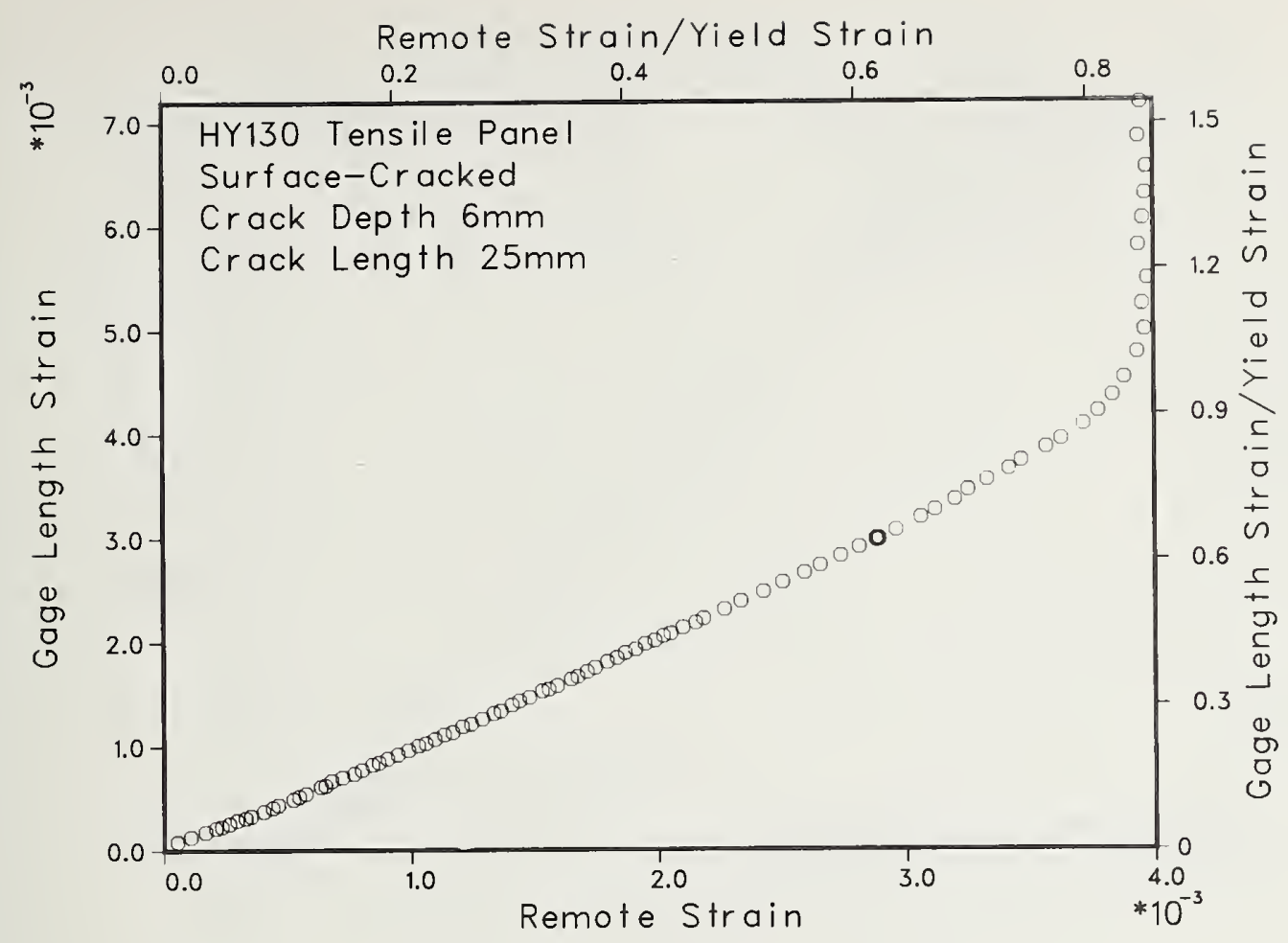

Figure $35 \mathrm{~g}$.

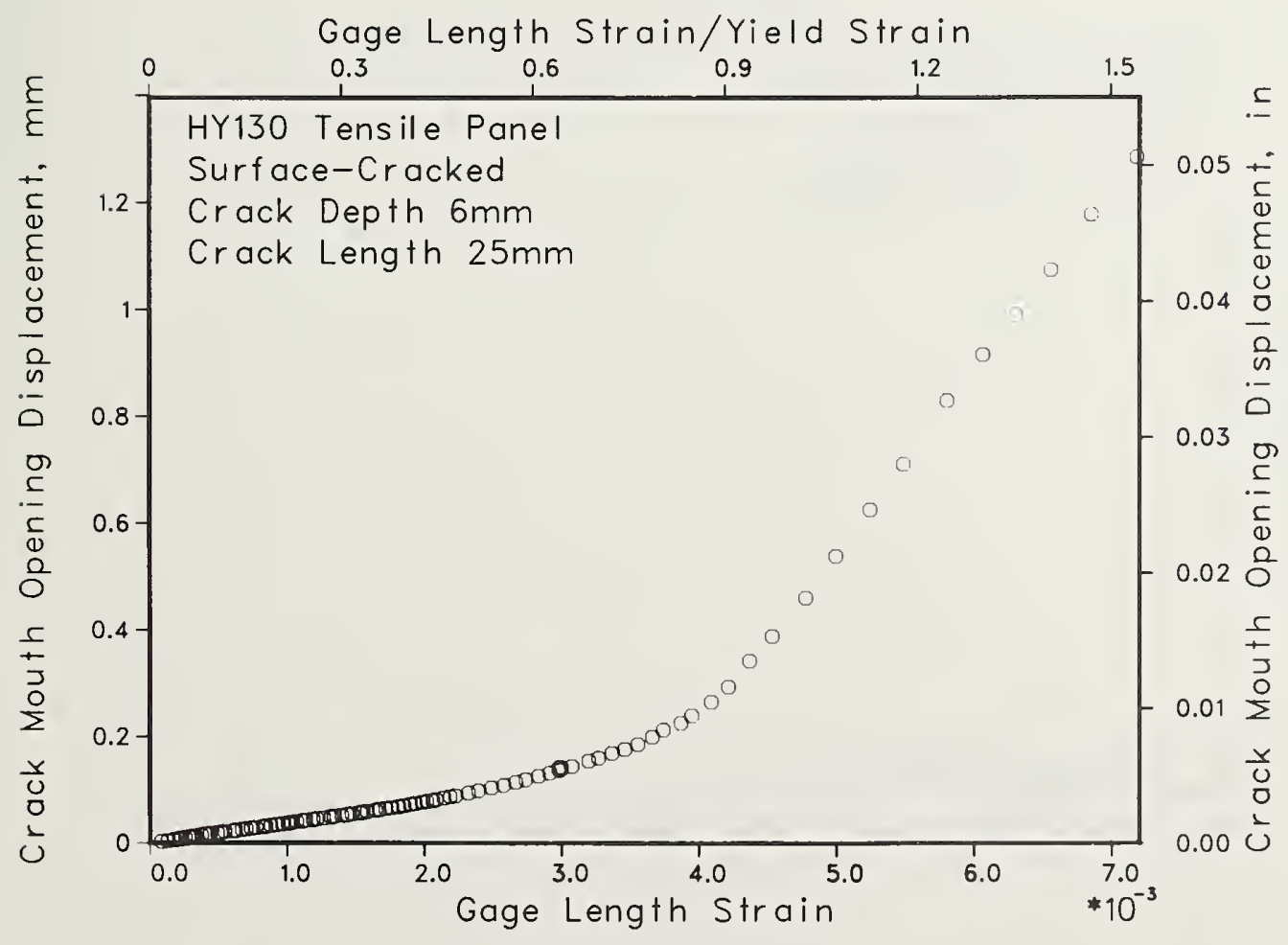

Figure $35 \mathrm{~h}$. 


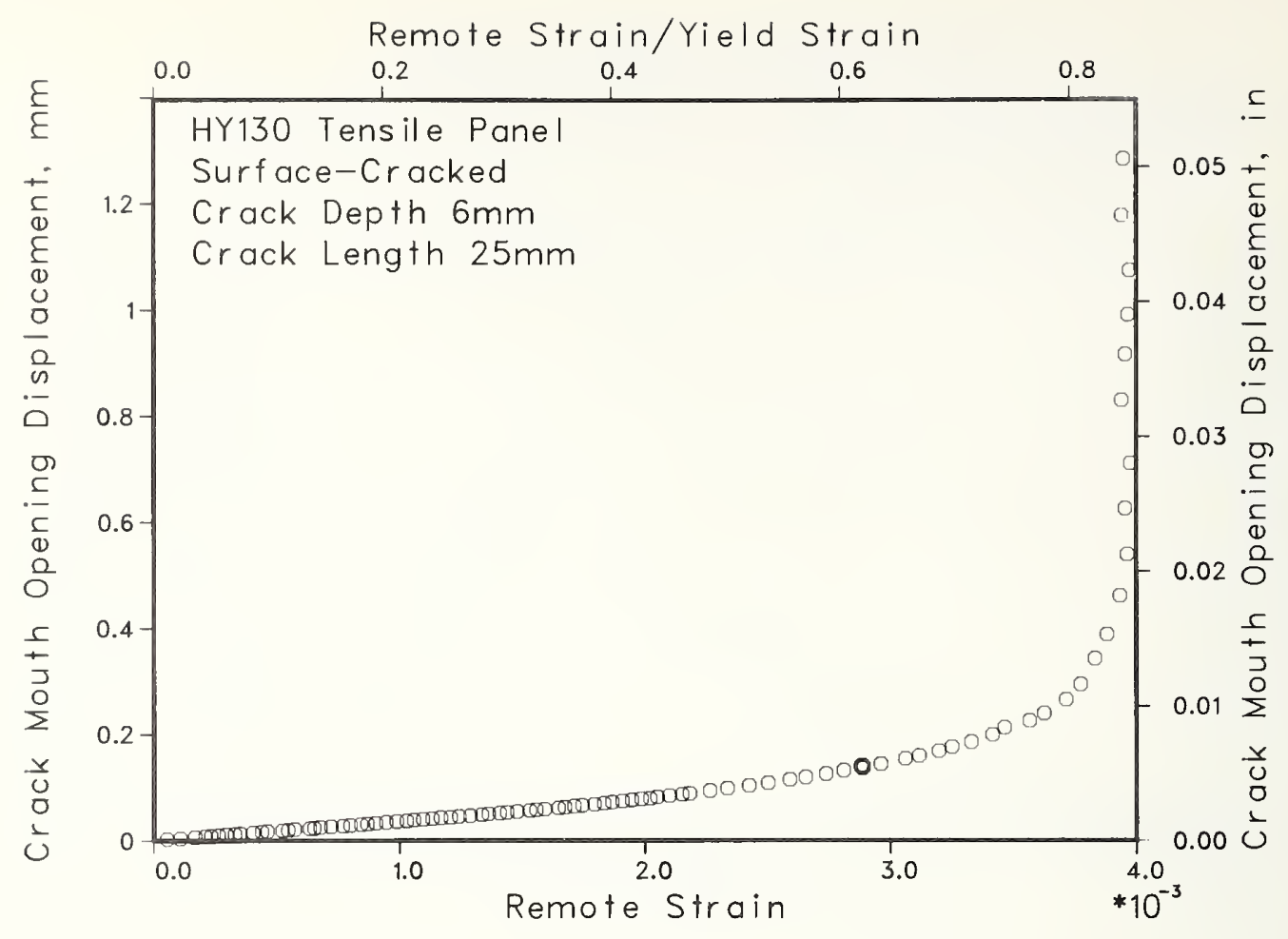

Figure $35 i$.

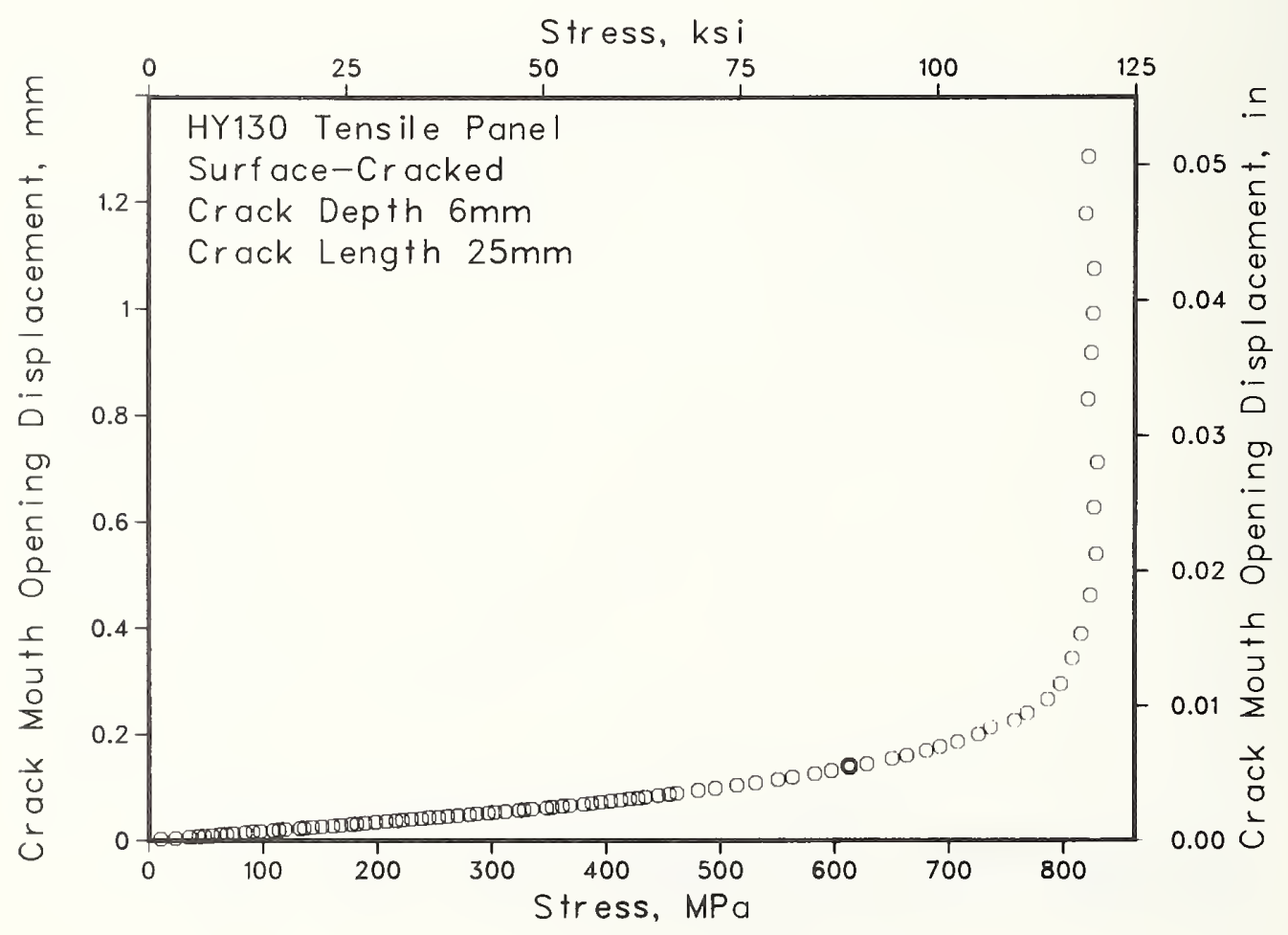

Figure $35 j$ 


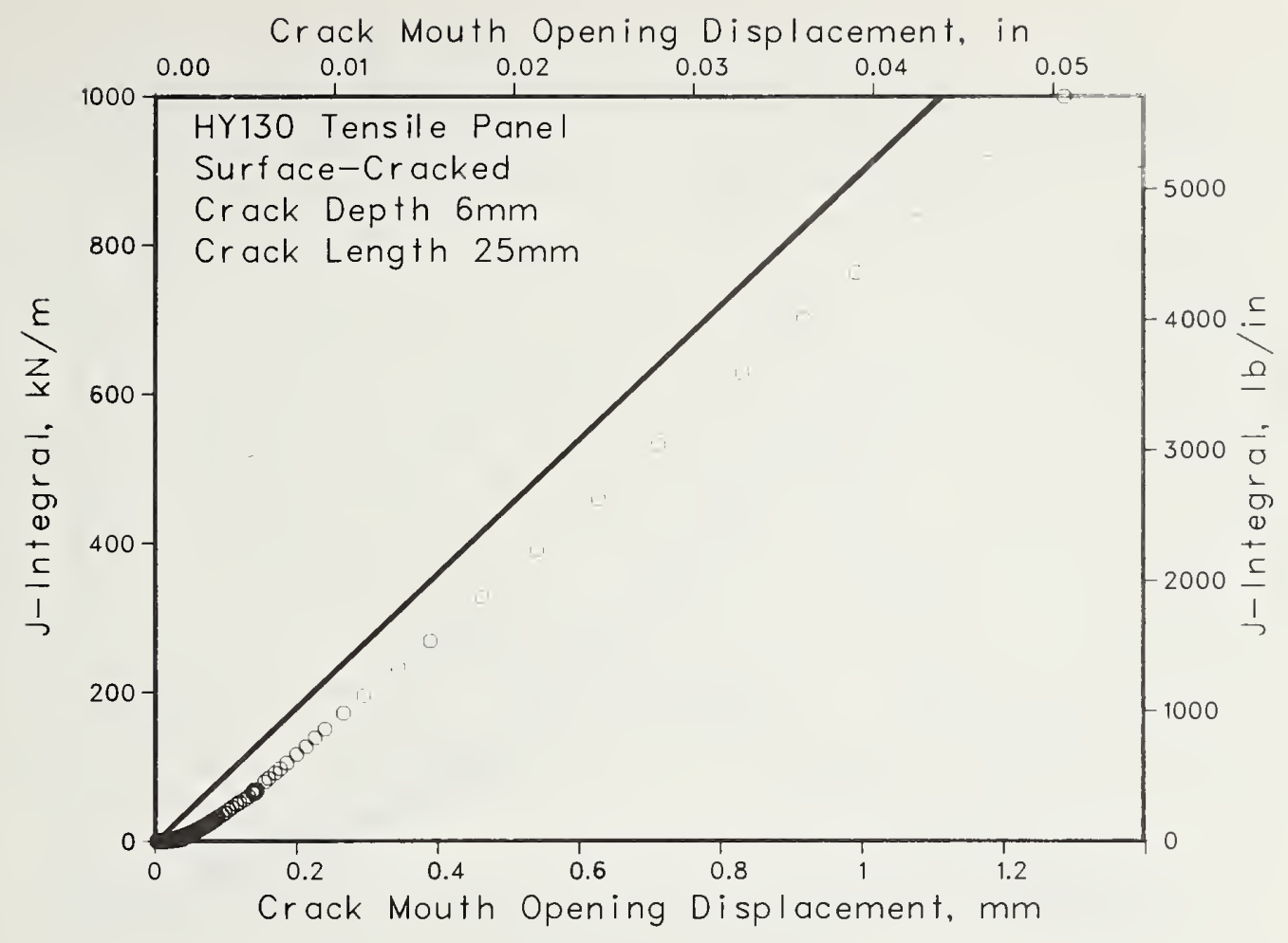

Figure $35 \mathrm{k}$. 


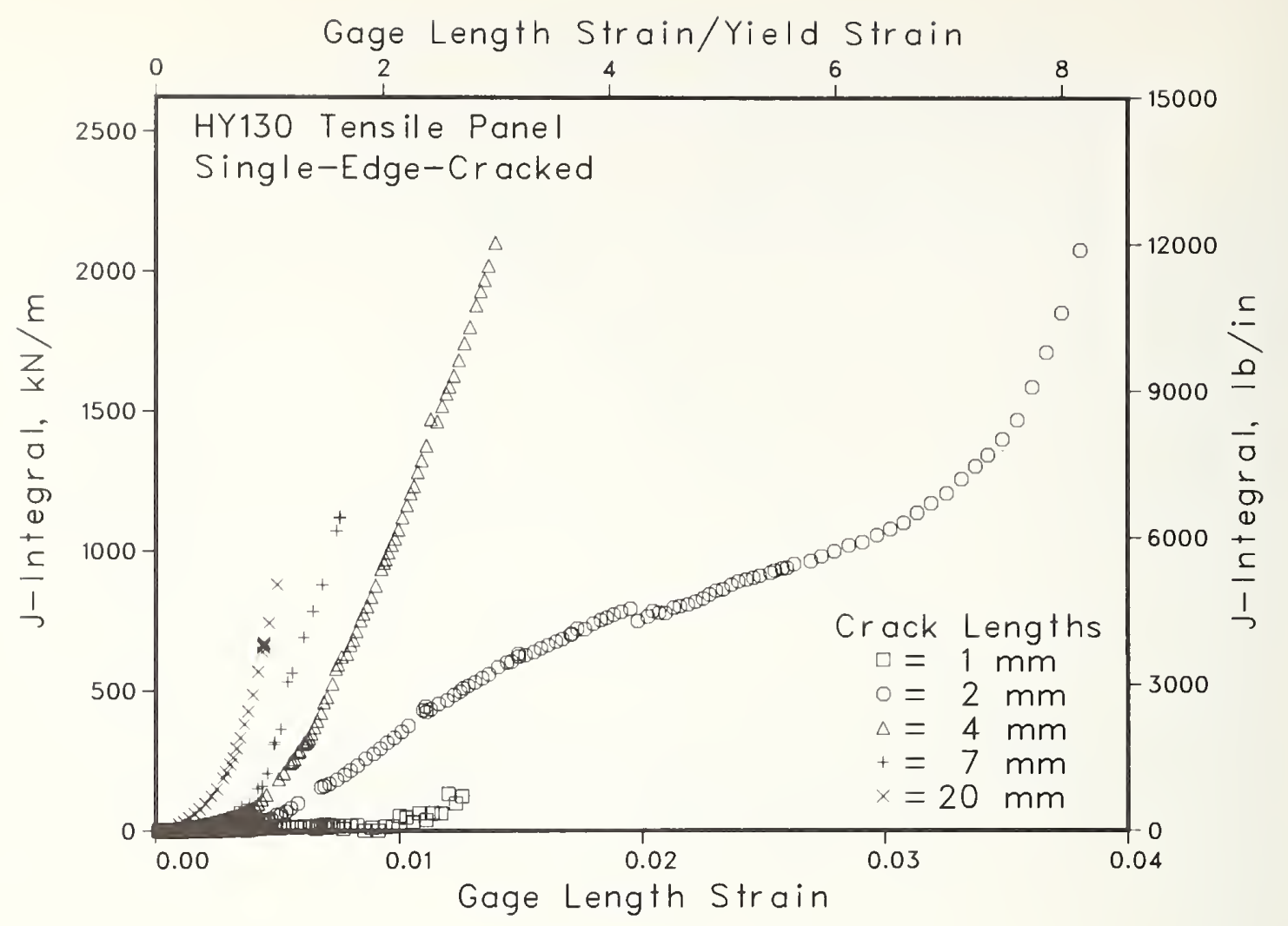

Fiqure 36. $\quad i^{3}$-integral plotted against gage length strain for five single-edge-cracked specimens.

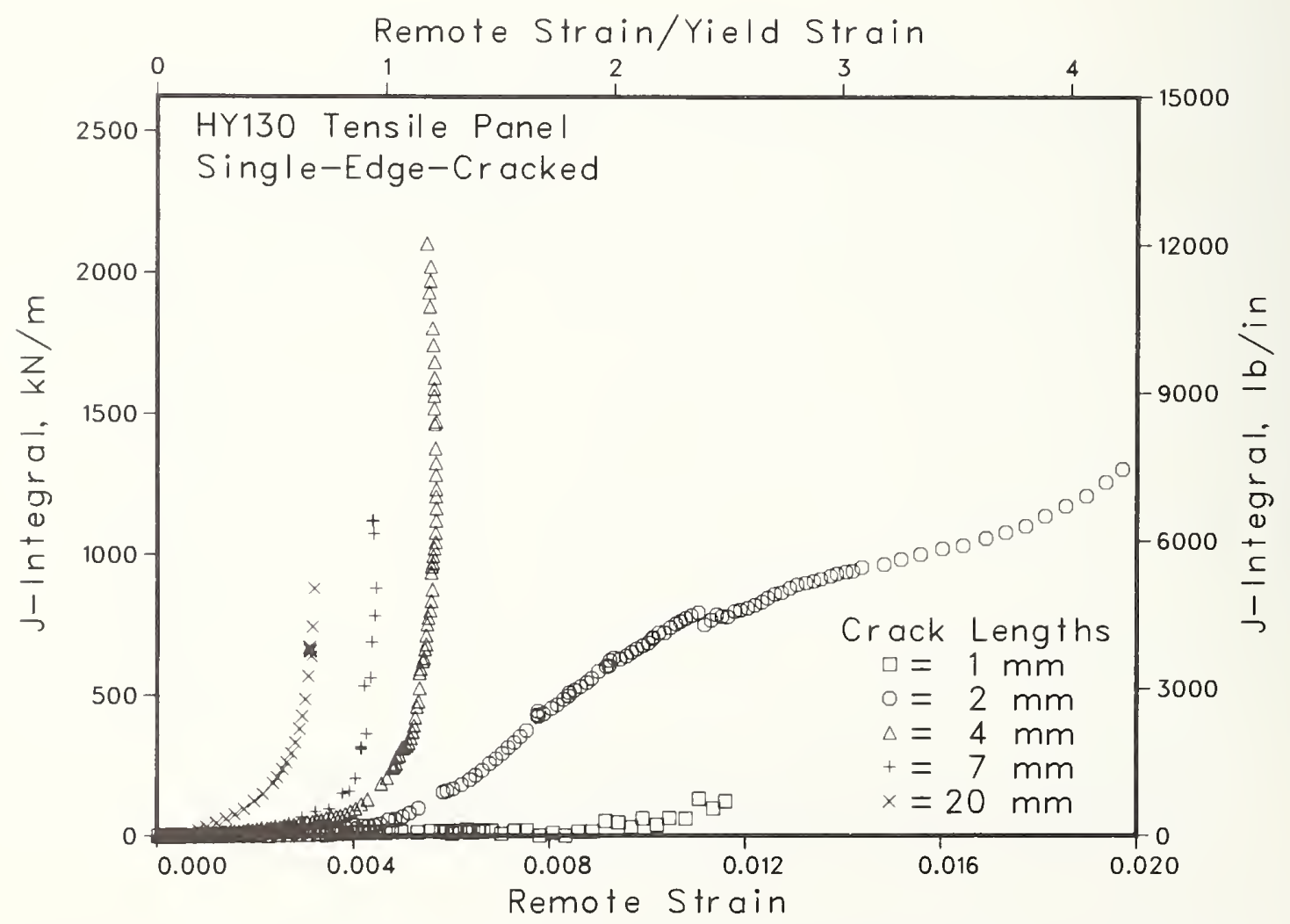

Figure 37. J-integral plotted against remote strain for five single-edge-cracked specimens. 


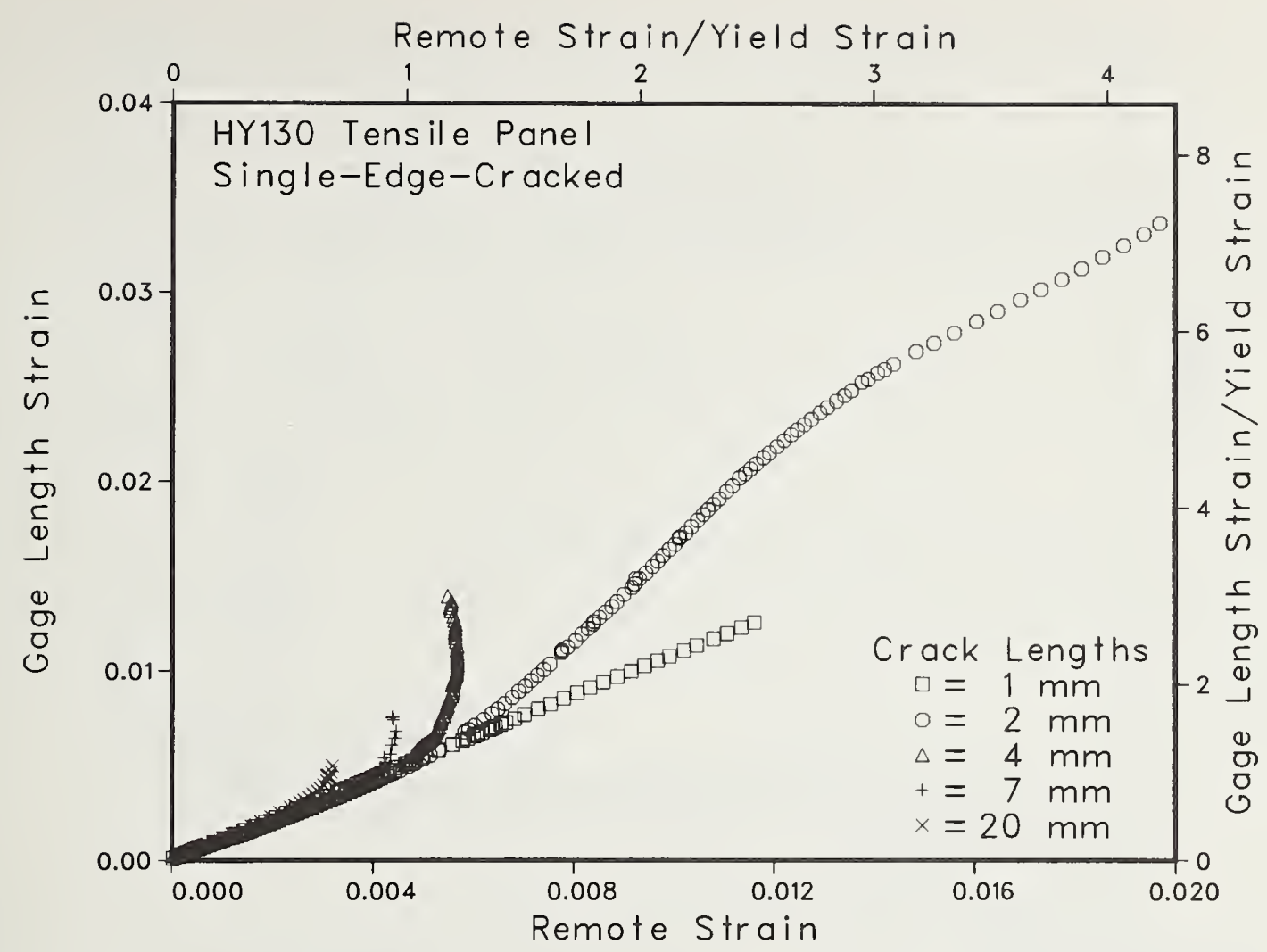

Figure 38. Gage length strain plotted against remote strain for five single-edge-cracked specimens.

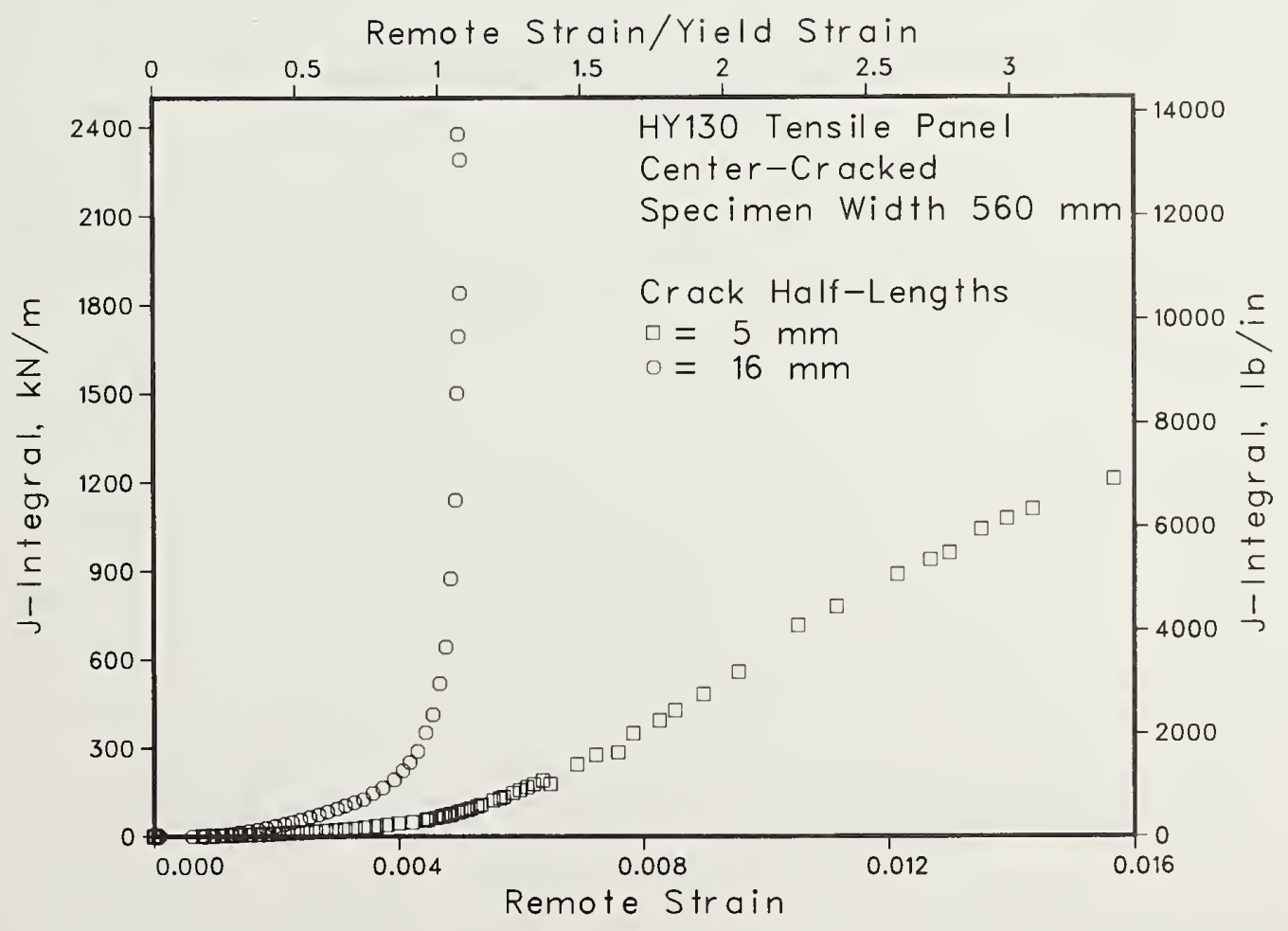

Figure 39. J-integral plotted against remote strain for two wide center-cracked panels. 


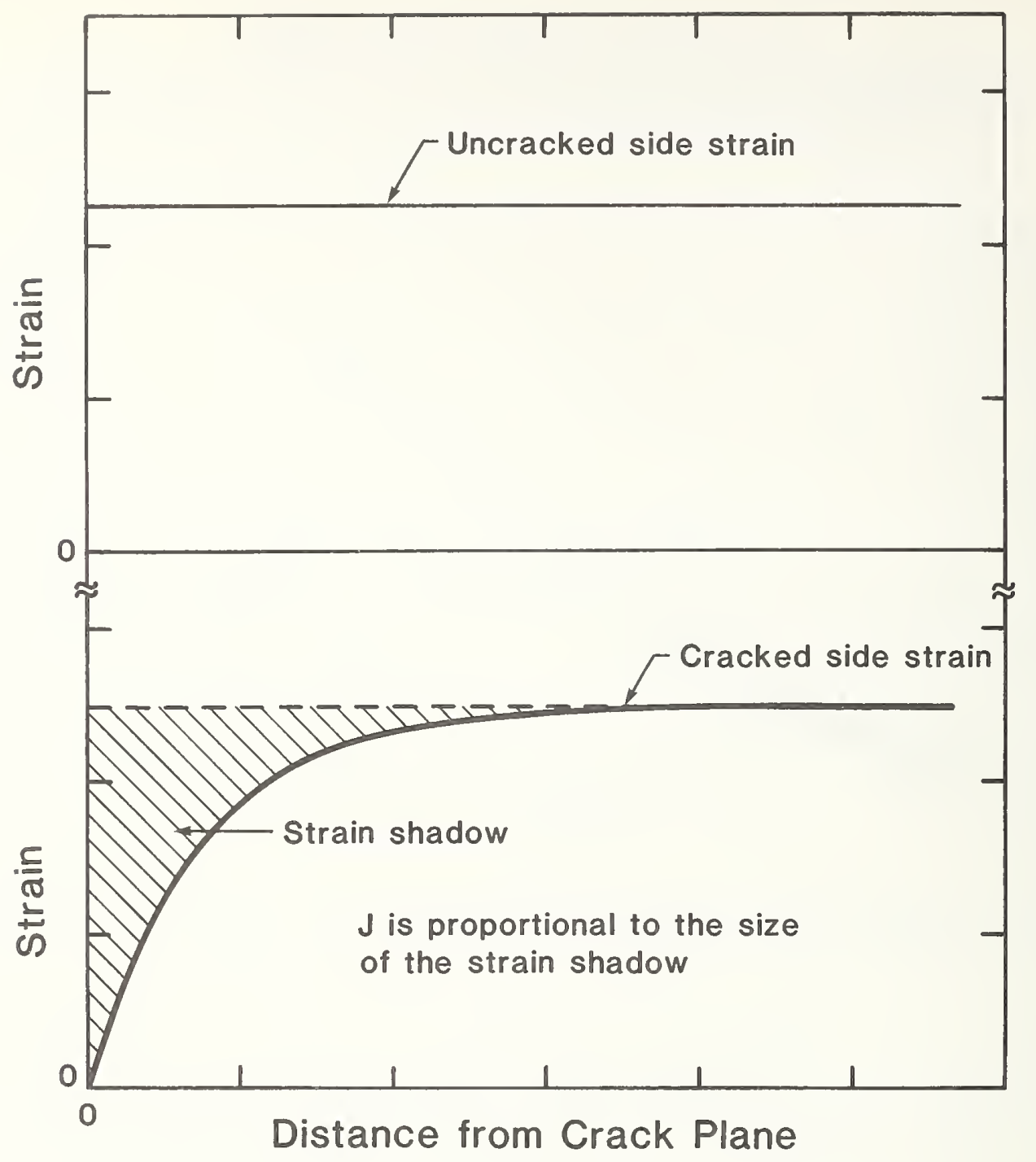

Figure 40. Schematic plot of behavior of strain along direction of tensile axis plotted against distance from crack plane showing strain shadow. 


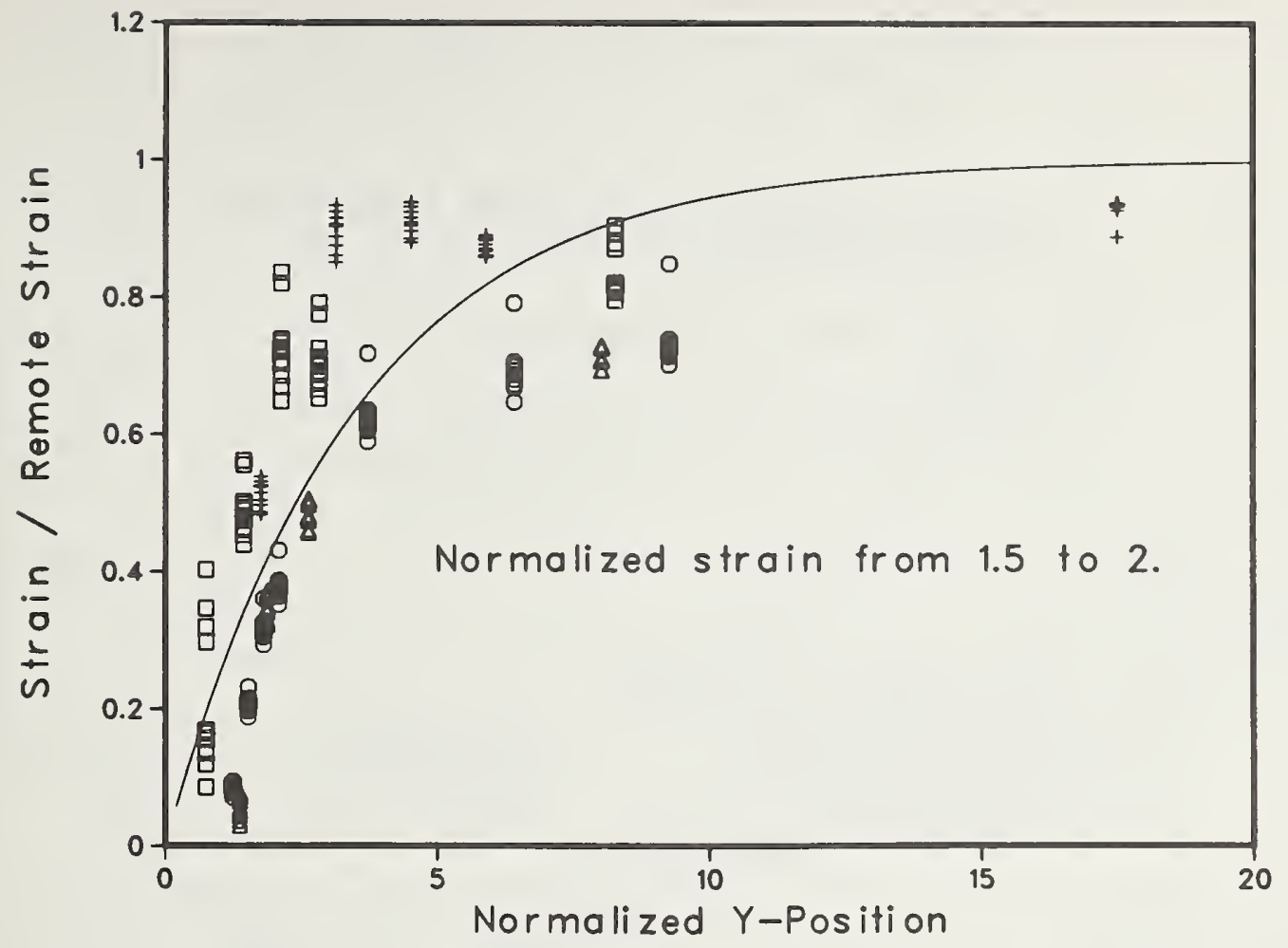

Figure 41. Plot of strain divided by remote strain against distance from crack plane divided by crack length for normalized remote strain 1.5 to 2 for the 4 specimens with gross section yielding and the fitting function of Eq. 12. For this data the fitted value of $g$ was 0.29 .

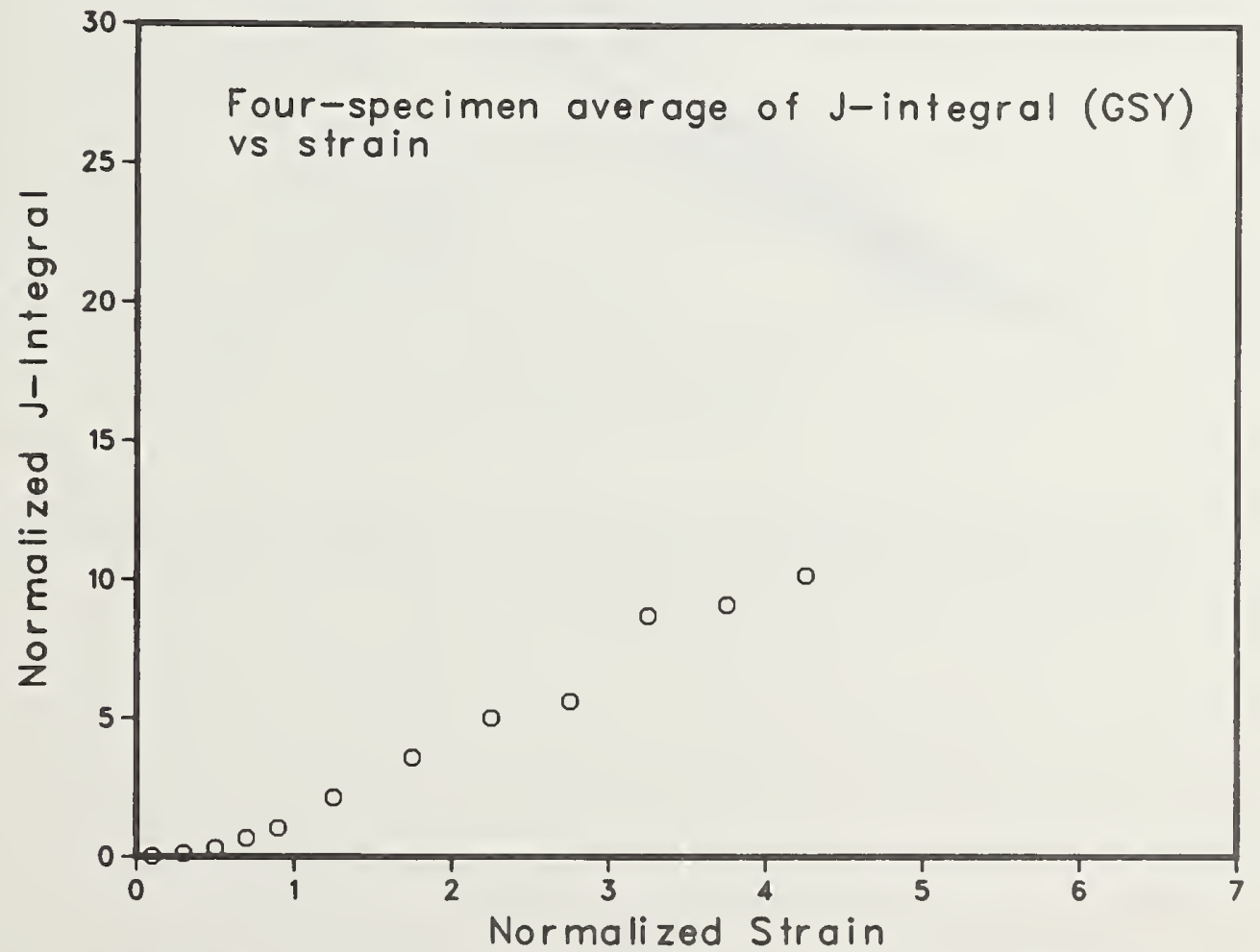

Figure 42. Normalized J-integral from gross section yielding plotted against normalized strain for the same specimens used for Fig. 39. 
HY130 Tensile Panels with Through Cracks

Gross and Net Section Yielding

$\square=$ Double-Edge - Cracked, $a=2 \mathrm{~mm}, 2 \mathrm{~W}=90 \mathrm{~mm}$

0 = Center-Cracked, $a=5 \mathrm{~mm}, 2 \mathrm{~W}=560 \mathrm{~mm}$

$\Delta=$ Single-Edge-Cracked, $a=2 \mathrm{~mm}, W=90 \mathrm{~mm}$

Gross Section Yielding

$+=$ Single $-E d g e-C$ r acked, $a=1 \mathrm{~mm}, W=90 \mathrm{~mm}$

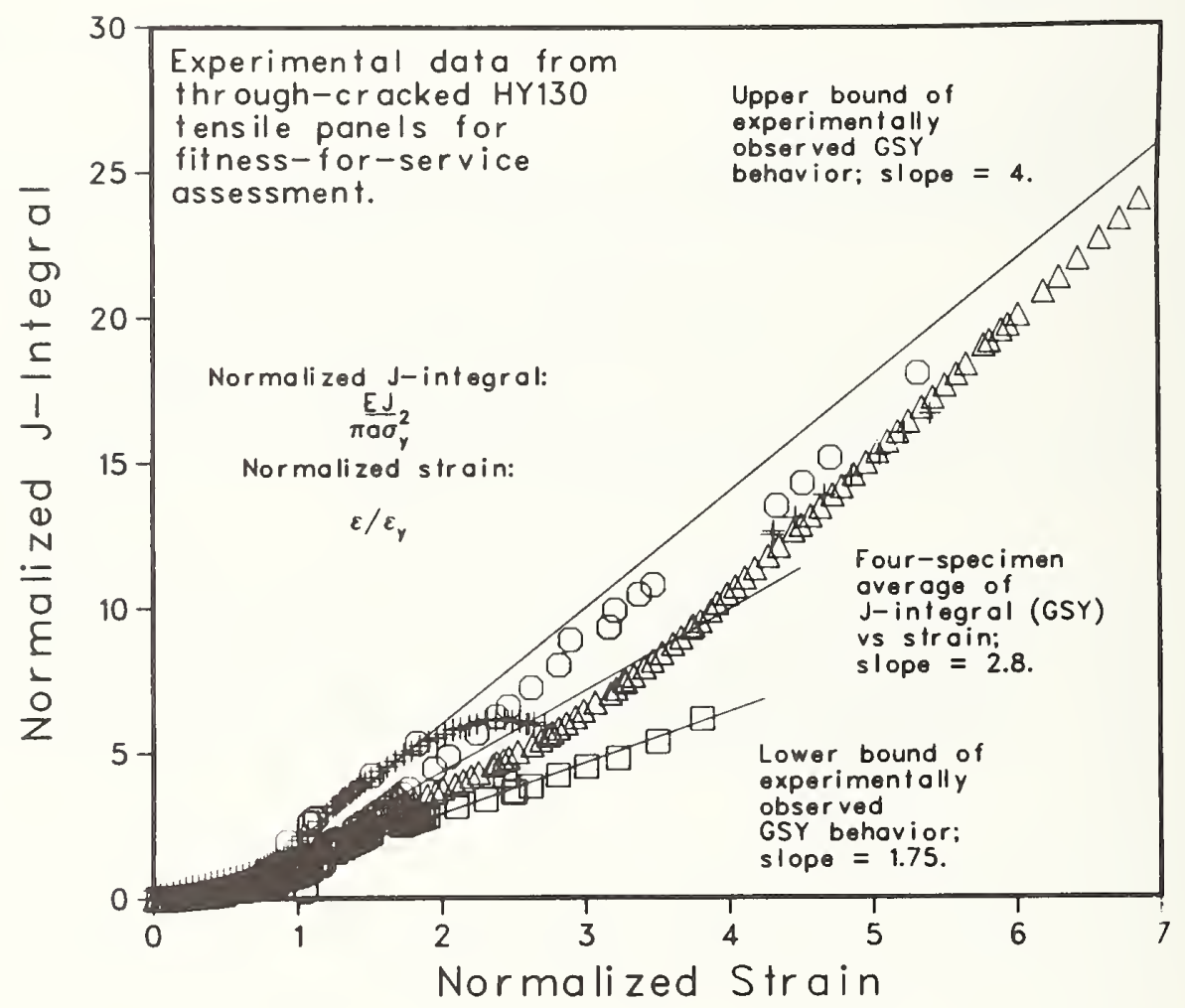

Figure 43. Plot of normalized J-integral from gross section yielding for individual specimens showing bounds and four-specimen average. 


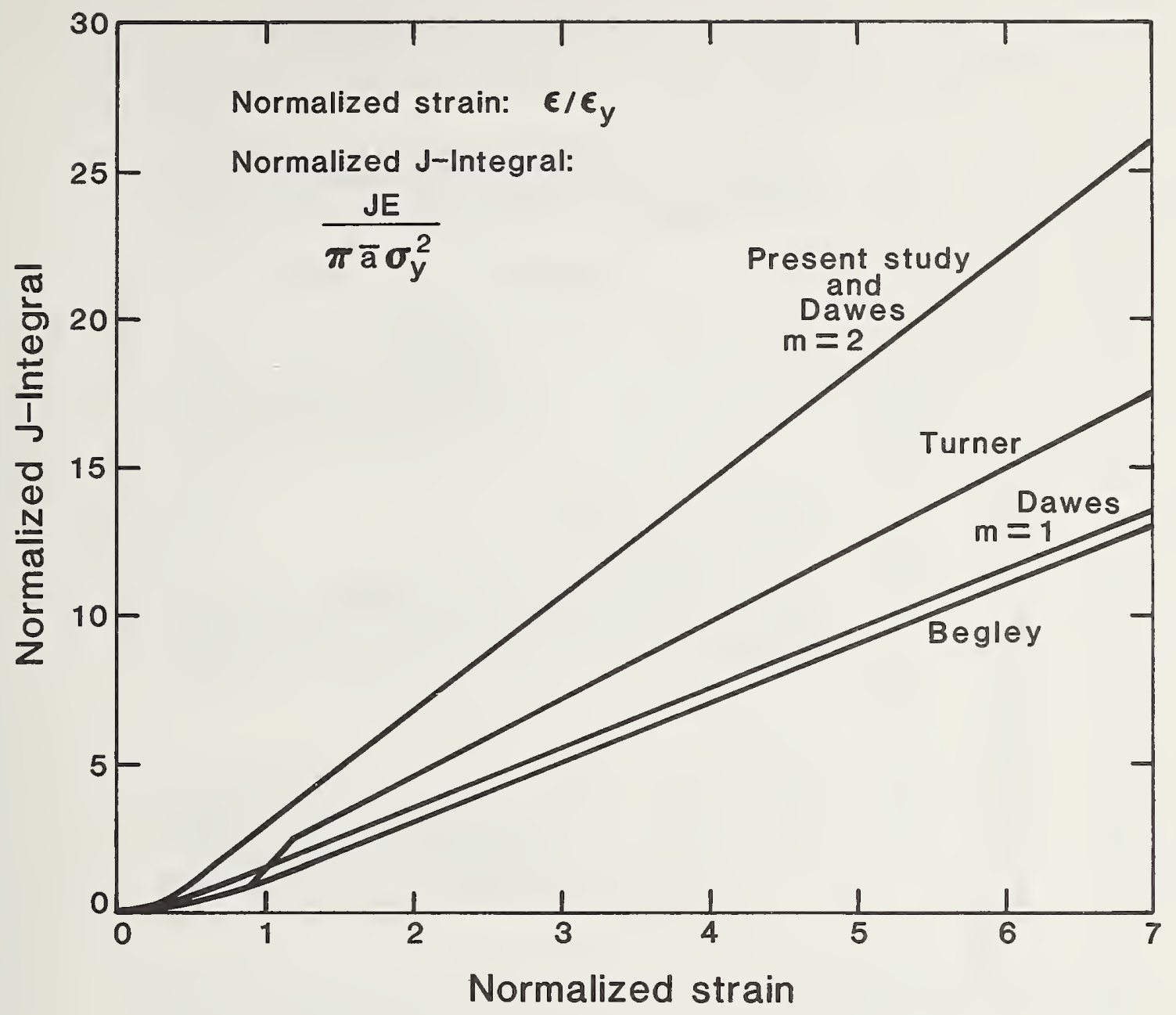

Figure 44. Previous J-integral estimation curves. 


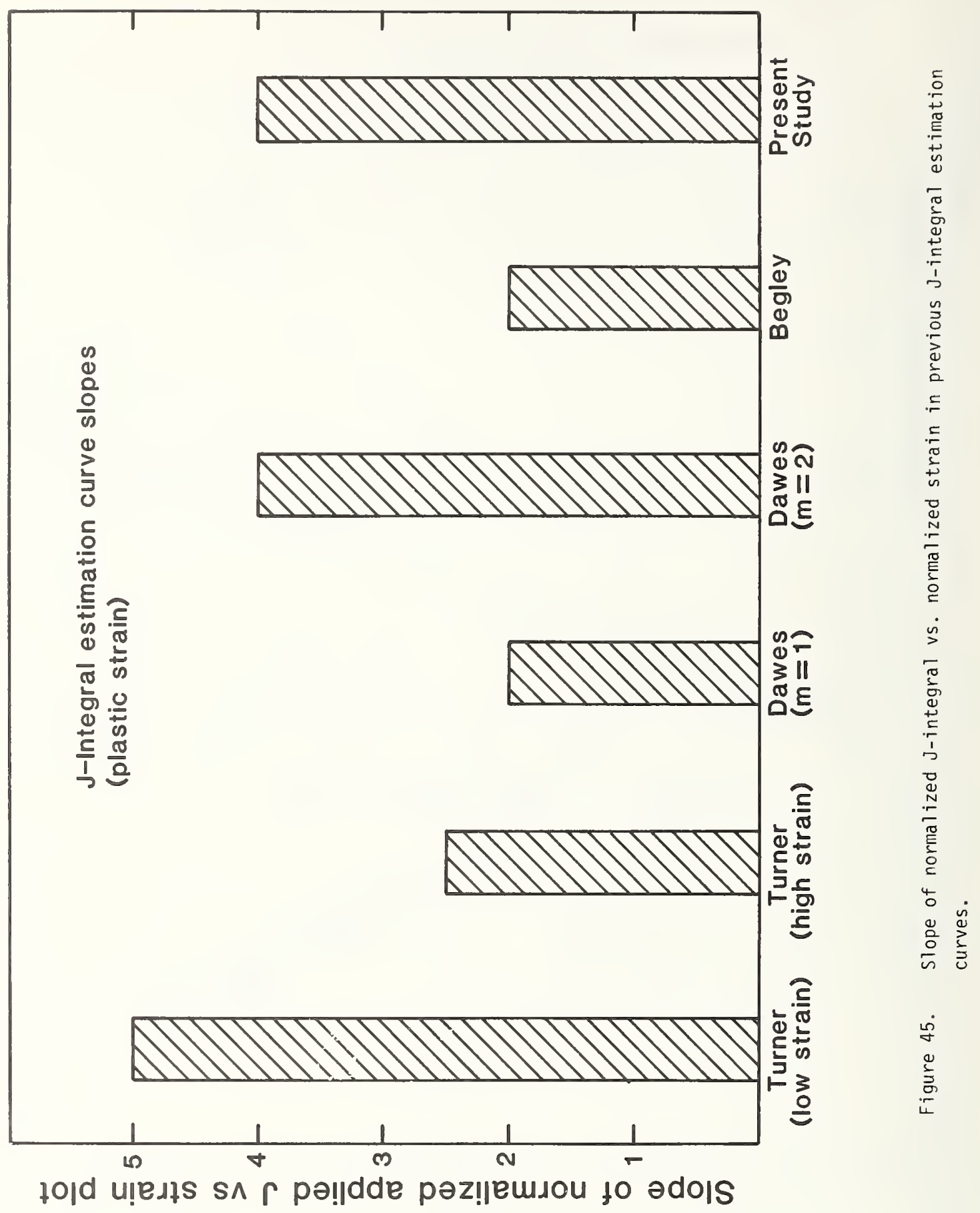


J-Integral Estimation Curve

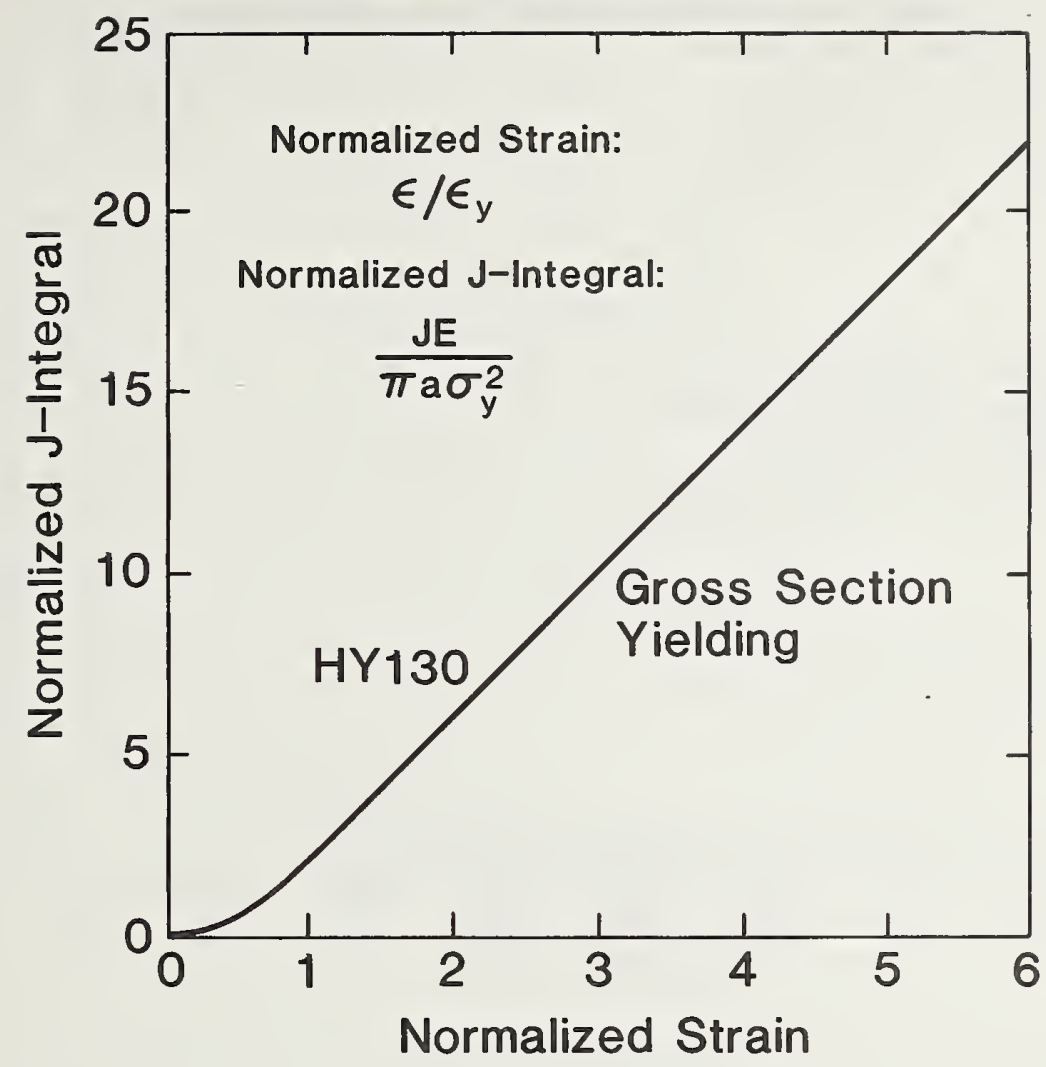

Figure 46. Experimentally derived J-integral estimation curve for contained yielding and gross section yielding in HY130 in tension. 


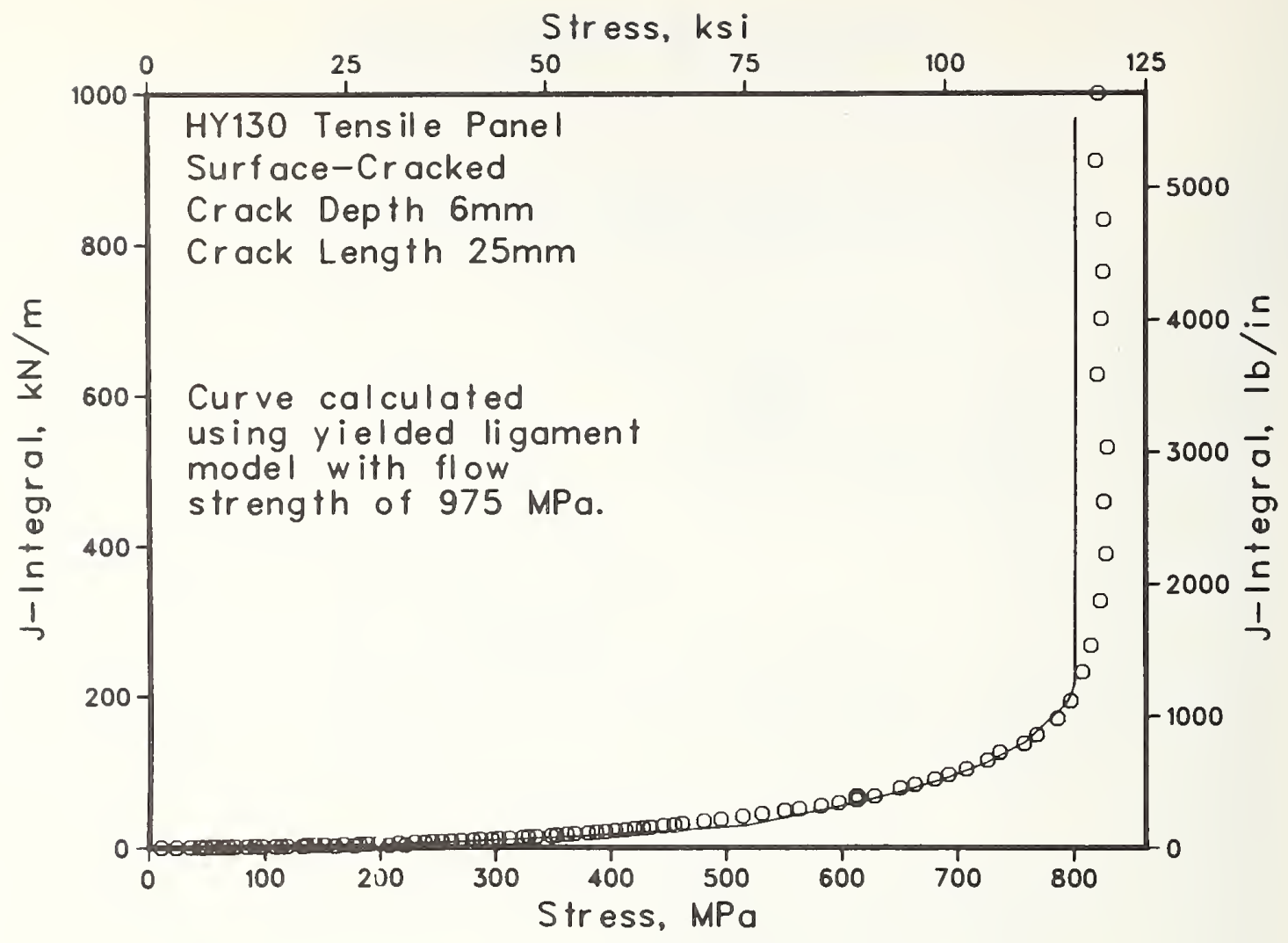

Figure 47. Dependence of applied J-integral on stress for a surface-cracked tensile panel with crack depth $5 \mathrm{~mm}$ and crack length $25 \mathrm{~mm}$. The curve gives values calculated using the simiplified line spring model with flow strength taken as $975 \mathrm{MPa}$ (141 ksi). 


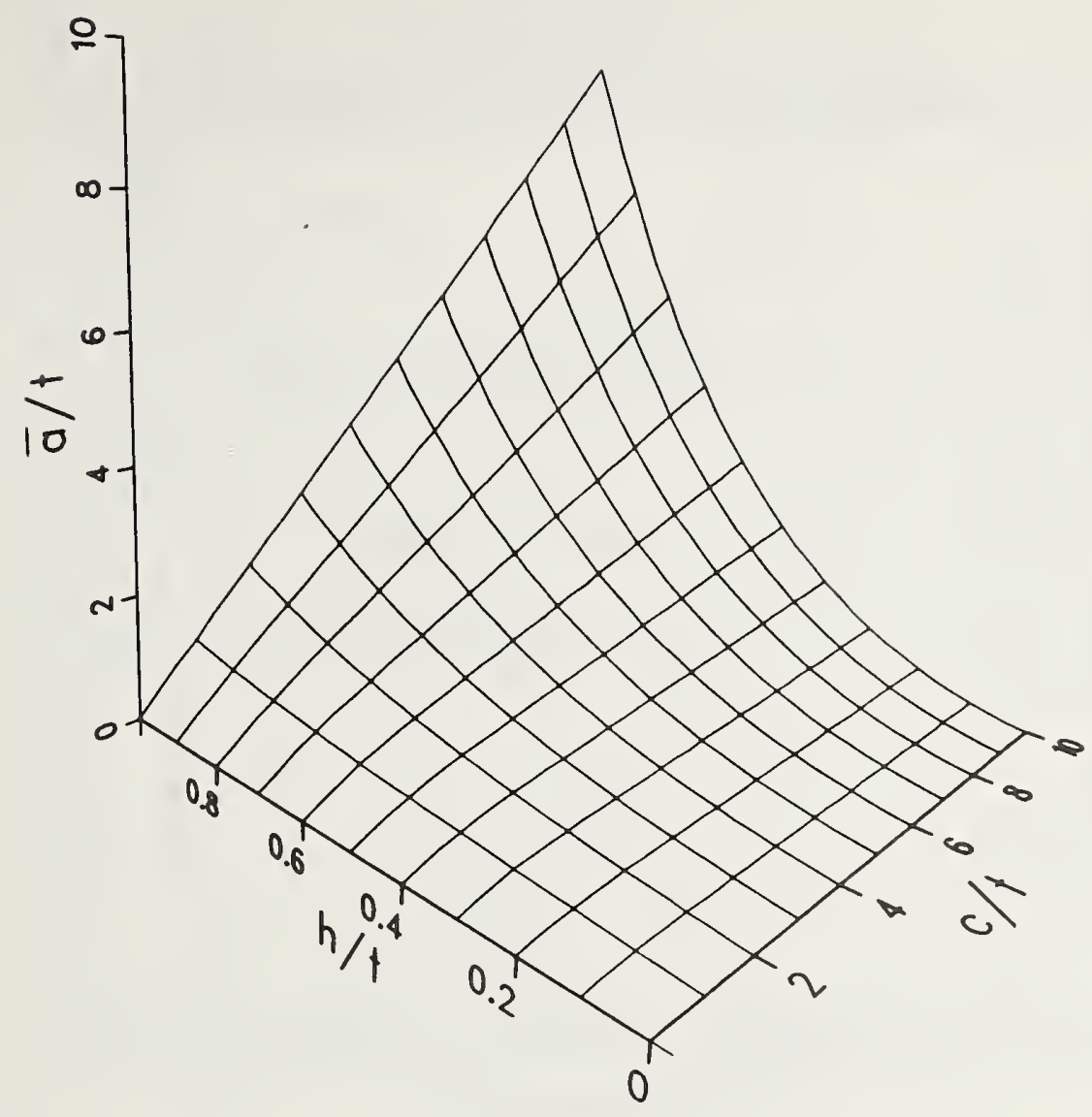

Figure 48. Form of the dependence of effective crack size $\bar{a}$ on crack depth to thickness ratio $\mathrm{h} / \mathrm{t}$ and half-length to thickness ratio $\mathrm{c} / \mathrm{t}$. 


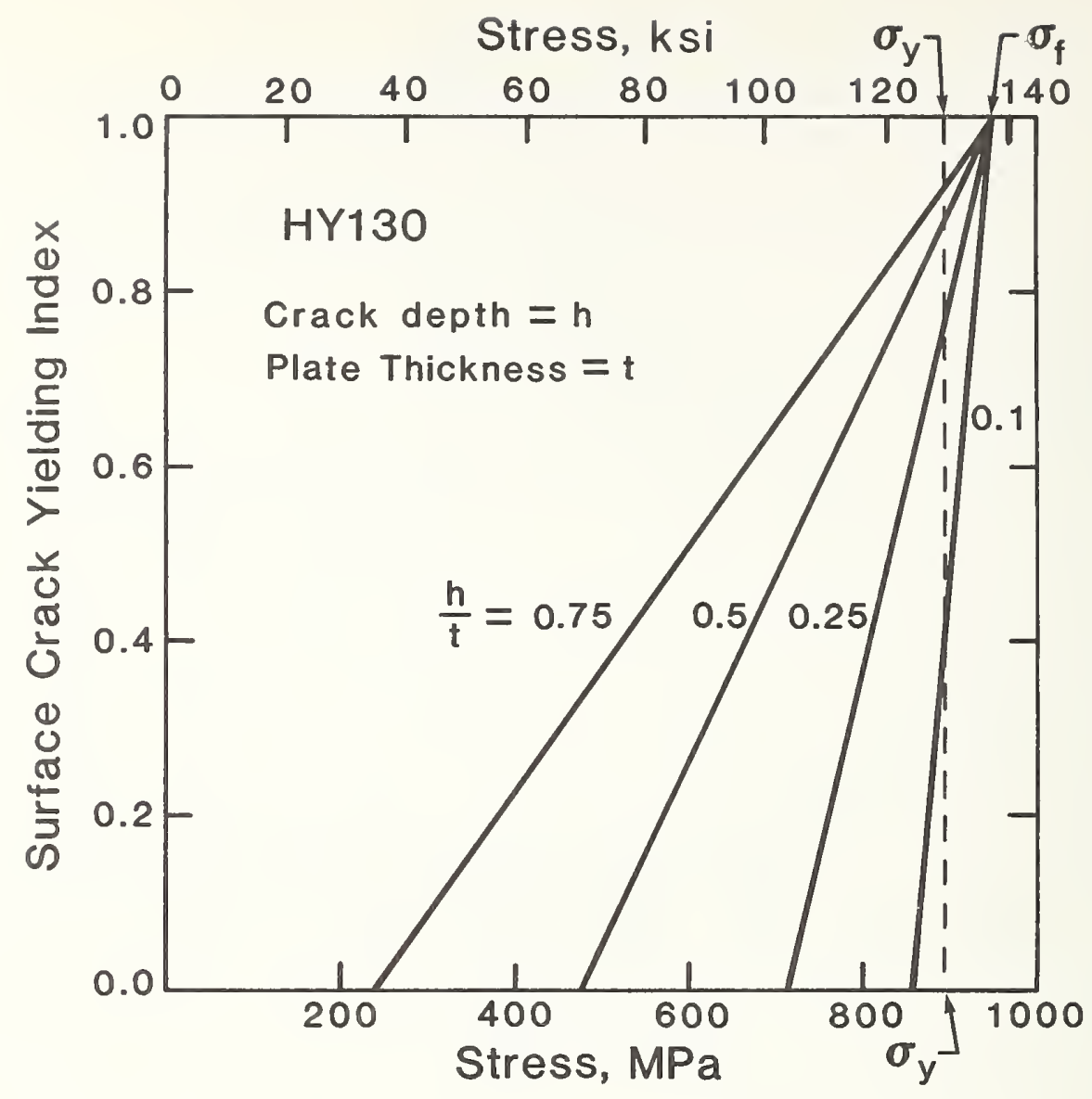

Figure 49. Surface crack yielding index for HY130 plotted against applied stress for several relative crack depths. 
Stress, ksi

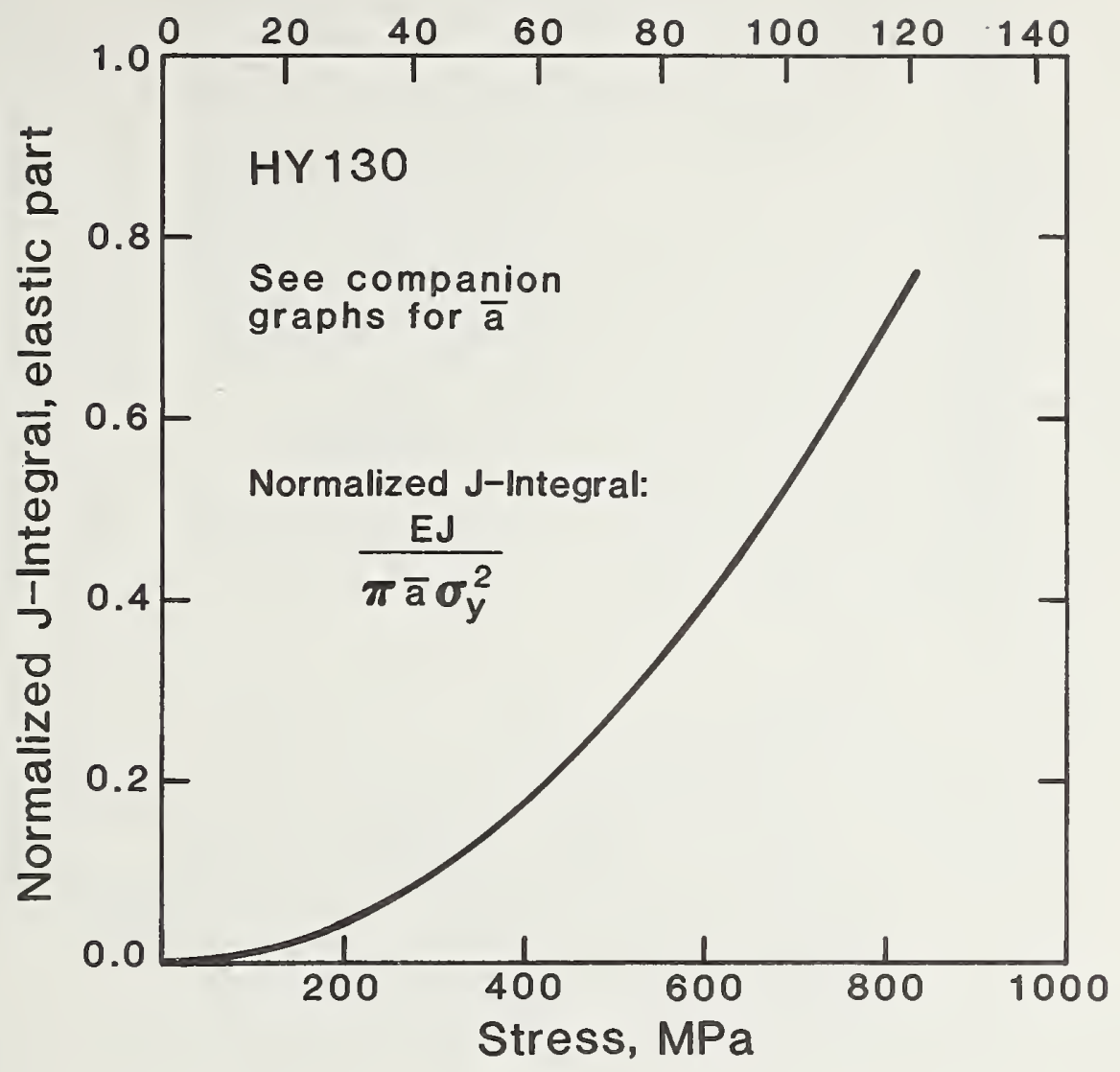

Figure 50. Dependence of normalized applied J-integral for HY130 on stress for contained plasticity for surface flaws. 

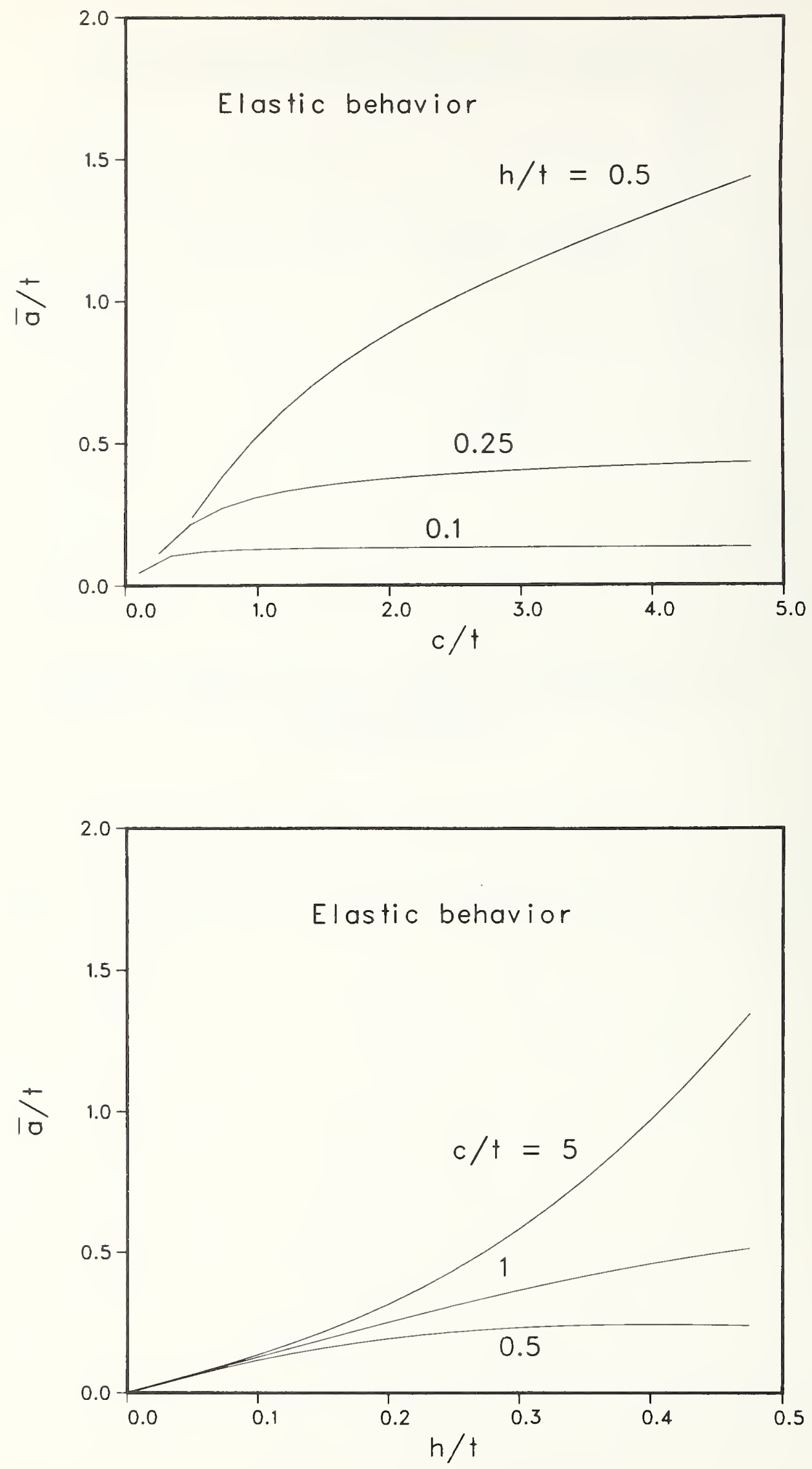

Figure 51. Effective crack size curves for surface cracks for containeci piasticity. 


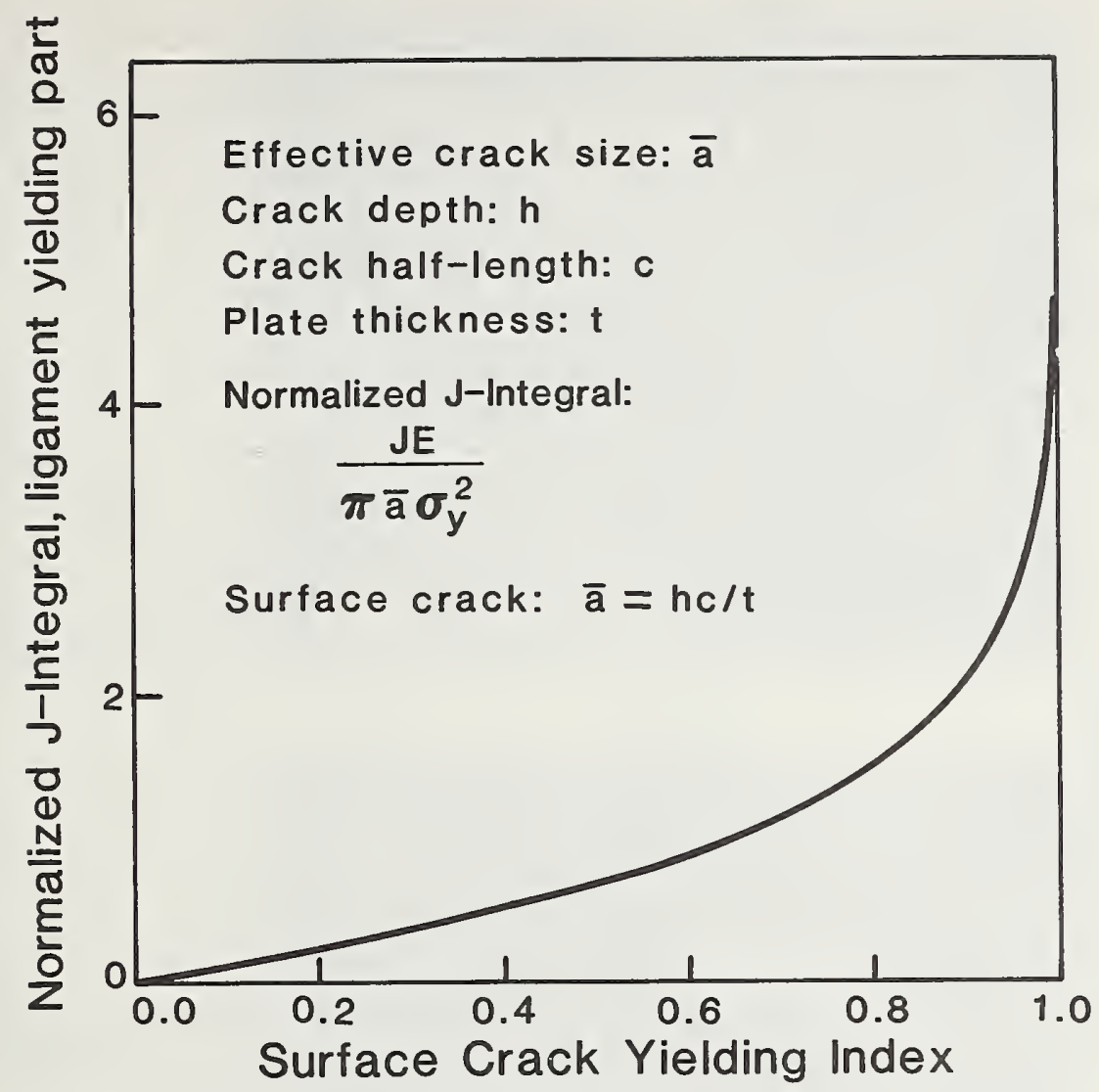

Figure 52. Normalized J-integral for ligament yielding plotted against surface crack yieldirc index.

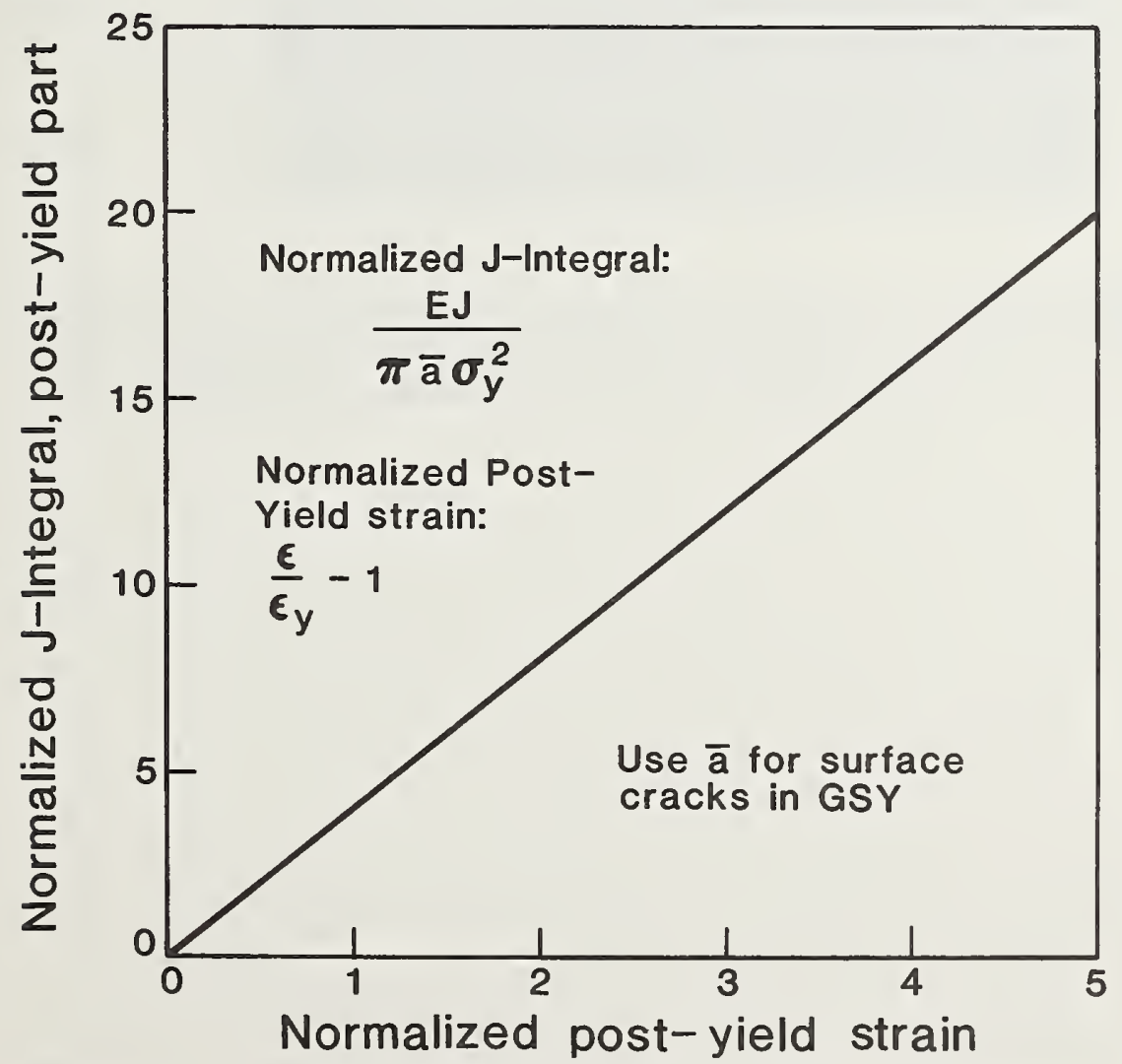

Figure 53. Dependence of normalized J-integral for surface cracks for gross section yielding on normalized applied strain. 


\section{Surface Cracks}

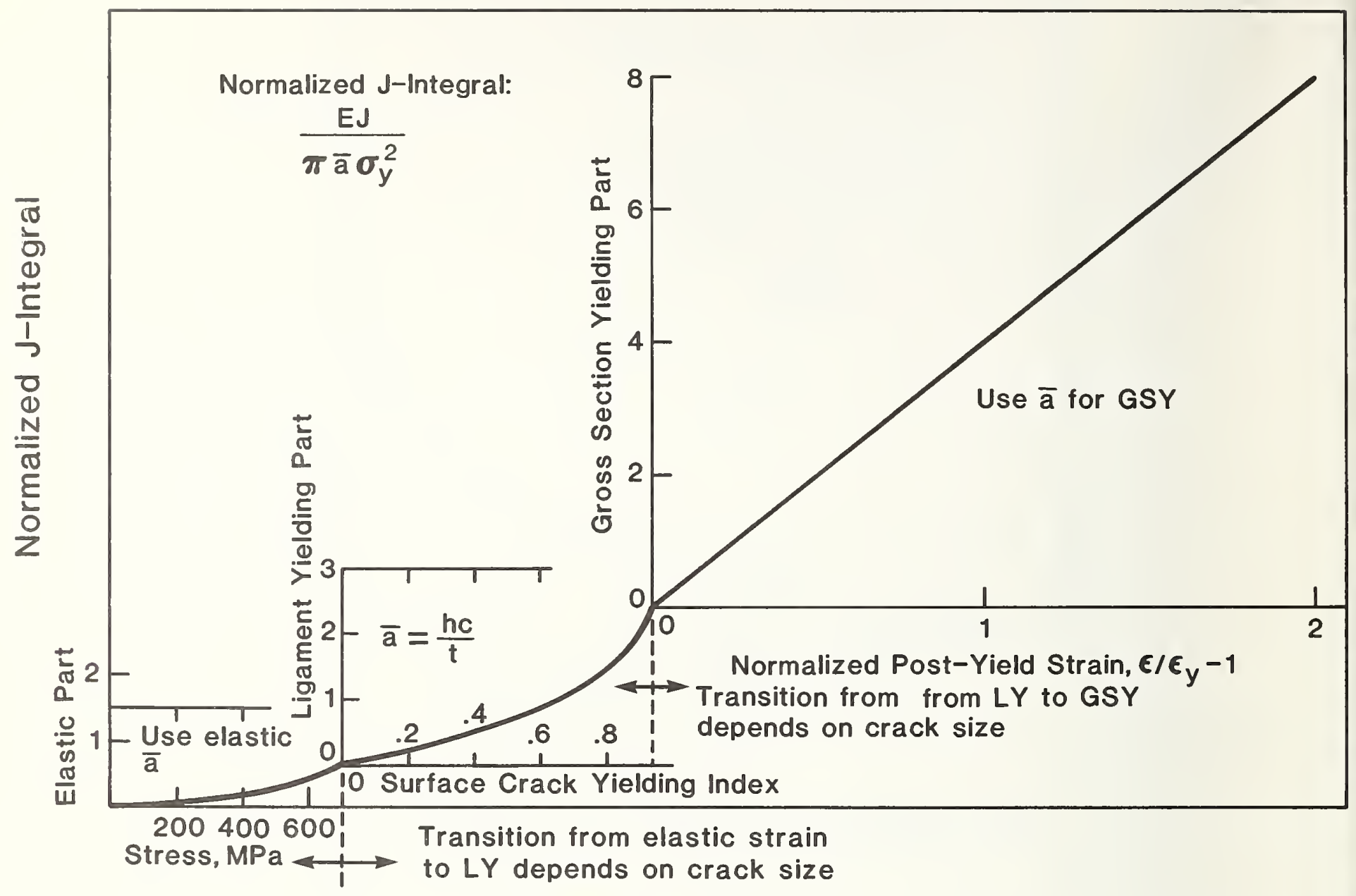

Figure 54. Schematic composite J-integral estimation curve for surface cracks showing contained yielding, ligament yielding, and gross section yielding behaviors. 

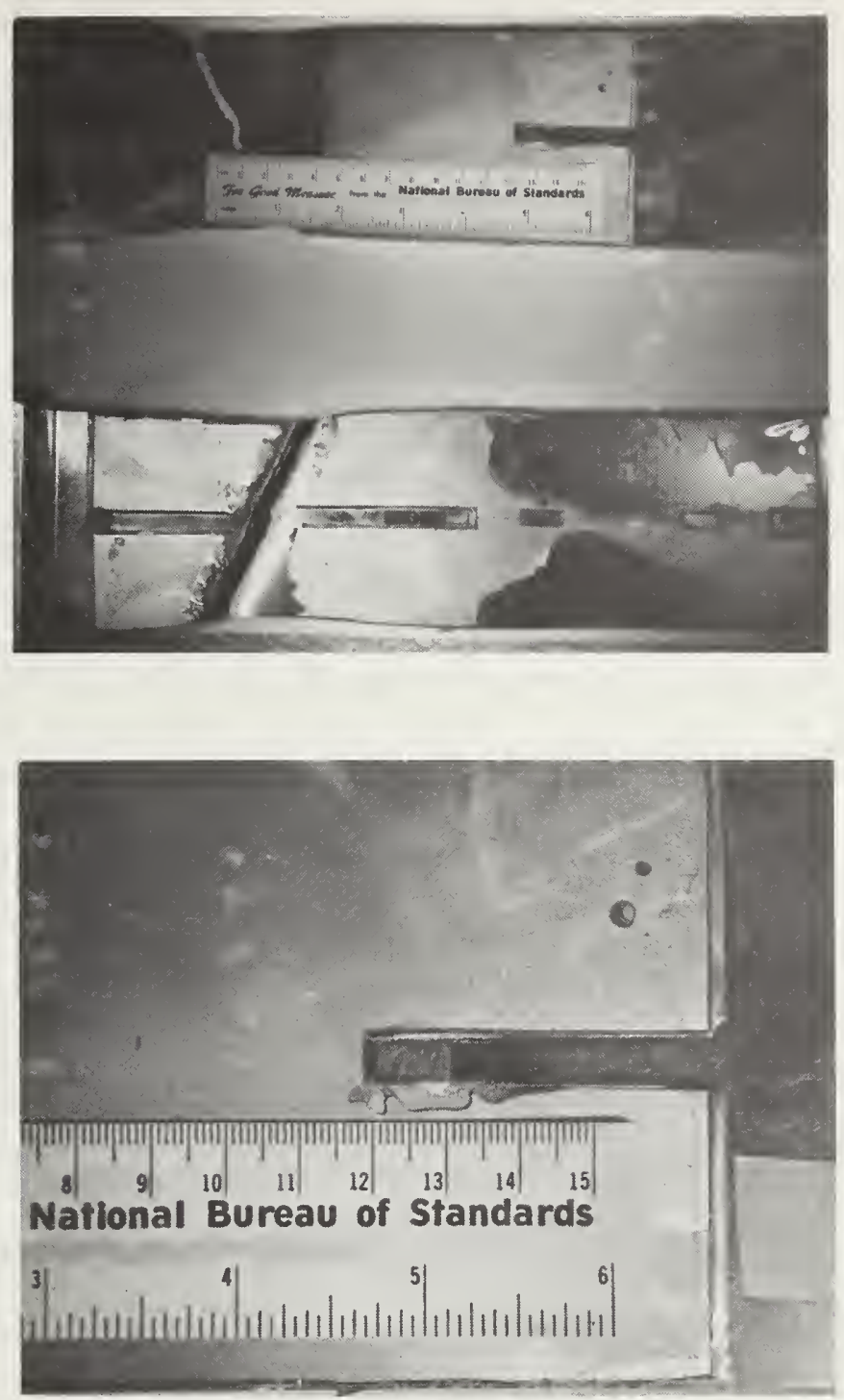

Figure 55. Photograph showing fractured welded and base metal HYl30 specimens containing small surface cracks. Note that the fractures occurred away from the cracks. 
APPENDIX

APPLIED J-INTEGRAL VALUES IN TENSILE PANELS

\author{
D. T. Read \\ Fracture and Deformation Division \\ National Bureau of Standards \\ Boulder, Colorado 80303
}

Key Words: fitness-for-service; fracture mechanics; fracture toughness; J-integral; nickel steel; yielding.

Contribution of NBS. Not subject to copyright.

This report was prepared as part of the Fracture Control Technology program under the sponsorship of Dr. H. H. Vanderveldt, Naval Sea Systems Command (SEA 05R15). The effort was directed by Mr. John P. Gudas, David Taylor Naval Ship R\&D Center, under Program Element 62761N, Task Area SF-61-544-504.

Published in Proceedings of the Second International Symposium on Elastic Plastic Fracture Mechanics, sponsored by the American Society for Testing and Materials, Philadelphia, PA, October 6-9, 1981. 


\section{ABSTRACT}

The $J$ contour integral has been applied widely in characterizing the fracture toughness of metals. In addition, the applied J-integral can be used to characterize the driving force for fracture in structures. This use of the $\mathrm{J}$-integral requires knowledge of the dependences of the applied $J$ integral on stress, strain, and crack size. Results from an experimental study of the applied $J$-integral as a function of strain in tensile panels are discussed in this paper. Variables controiling the applied $J$ integral are associated with the three observed deformation patterns: stress controls $\mathrm{J}$ for 1 inear elastic strains and contained yielding, displacement controls $\mathrm{J}$ for net section yielding, and strain controls $\mathrm{J}$ for gross section yielding. Experimental results of this study show that the applied J-integral value for a given strain level is much higher for net section yielding than for gross section yielding. The yielding pattern obtained was found to depend on the ratio of crack length to specimen width. The transition from gross to net section yielding in the material tested used occurred as the ratio of crack length to specimen width was raised from about 1 to about 5 percent. The significance of this transition is twofold; first, a strong increase in applied $J$ values is produced by a small increase in crack size; second, this effect occurs at crack sizes that are small compared with specimen width. The present experimental results resolve ambiguities in the literature regarding the applicability of different estimation formulae for $\mathrm{J}$ and allow approximate calculation of the applied $\mathrm{J}$-integral for any crack size or stress level. 
The $\mathrm{J}$ contour integral [1] has been applied widely in characterizing the fracture toughness of metals [2-4], but its application to evaluation of the durability of structures containing cracks has been delayed because dependences of the applied J-integral on stress, strain, and crack size have not been generally well established. In response to this need, a technique for measuremert of the applied J-integral in tensile panels of $\mathrm{HY}-130$ steel as a function of applied stress, displacement, and strain has been applied to the elastic-plastic strain range [5]. This technique is applicable to short, as well as long, cracks, unlike the J-integral evaluation techniques commonly used in material toughness testing. In this paper, experimental results on the behavior of the applied J-integral are discussed, and conclusions are drawn about the factors that control the applied J-integral. Two concepts central to the development of the arguments in this paper, controlling variables for $J$ and deformation patterns, are now introduced:

The use of $\mathrm{J}$ as a fracture-characterizing parameter requires that $\mathrm{J}$ be related to structural loading. To formulate such relationships, the structural loading must be appropriately characterized. Some variables that might be used to characterize structural loading are remote stress, remote strain, strain over some gage length, and applied displacement. This choice of a characterizing parameter is not necessary in linear elastic fracture mechanics (LEFM) because the laws of linear elasticity enforce consistent relationships among the variables. For example, the stress and strain, are related through the material elastic constants. The LEFM stress intensity factor is related unambiguously to either remote stress or strain. Widespread yielding invalidates the laws of 
linear elasticity and also the fixed relationships among the loading variables. Therefore, one may not simply assume that some variable, for example stress, is the appropriate controlling variable for $\mathrm{J}$ in yielding fracture mechanics; the appropriate controlling variable must be identified. For some materials power-law hardening occurs over the entire strain range of interest, and so the various loading parameters may scale with one another [6]. In HY130, however, the stress-strain behavior is nearly elastic-perfectly plastic, so that deformations above yield can occur at essentially constant stress. This behavior prevents reliable scaling of deformations against applied stresses. The criterion for a proper J-controlling variable characteristic of the deformation state is that the J-integral must be a single-valued function of the controlling variable. Variables that change while the J-integral remains constant or that remain constant while the J-integral changes must obviously be rejected. A major argument herein is that different variables control J at different stress and strain levels and crack lengths for HY130 and possibly for many other materials.

A convenient classification of stress levels and crack lengths is by deformation patterns $[7,8]$. Figure 1 depicts deformation patterns characteristic of different deformation levels in a cracked specimen: linear elastic, contained yielding, net section yielding, and gross section yielding. Each of these patterns was observed in the present study and was important for interpreting the results. In this paper the appropriate controlling variables for the applied J-integral for the different deformation patterns are identified and formulas for estimating $\mathrm{J}$ for each region are discussed. 
EXPERIMENTAL TECHNIQUE

The experimental technique used for measurement of the J-contour integral for elastic-plastic conditions was described in detail in a previous paper [5]. The materials tested was HY-130 steel, a 5-Ni, 0.4-Cr, 0.5-Mo steel with a yield strength of $933 \mathrm{MPa}$, an ultimate strength of $964 \mathrm{MPa}$, and very low strain hardening. Briefly, contours enclosing crack tips in single-edge-cracked, center-cracked, and surfacecracked specimens of HY-130 steel were instrumented with strain gages and Tinear-variable-displacement transducers (LVDTs) to measure the integrand terms of the J-integral. The integral was then evaluated numerically. Pin-loaded specimens with a gage section of $300 \mathrm{~mm} \times 90$ $\mathrm{mm} \times 10 \mathrm{~mm}$ were used. Cracks were simulated by saw-cut notches of 1-, 2-, 4-, 7-, and 20-mm lengths. Some notches were sharpened by fatigue. Load was measured using the built-in load cell of the 1 MN servohydraulic test apparatus. Displacement over the gage length was obtained from the LVDT outputs. Remote strain was obtained from the strain gages near the end of the gage section. The experimental uncertainty in the J-integral in the plastic range was estimated at $\pm 10 \%$.

\section{RESULTS AND DISCUSSION}

Measured values of the $J$-integral are plotted against gage length strain in Fig. 2. Gage length strain is defined as the change in the length of the gage section divided by its length. For most crack lengths, the $J$ values assume a parabolic dependence on strain for low strain values and a linear dependence at higher strains. For a given strain level, $J$ increases with crack length. In short, the general trends of the data in this figure are in accord with prior observations $[9,10]$. 
Appropriate controlling variables for $\mathrm{J}$ for the different deformation patterns are now considered.

Linear Elastic Strains and Contained Yielding

First, consider loads well below the nominal yield load of the cracked specimens. For such loads, the plastic zone at the crack tip is small compared with the length, width, and thickness of the specimen, so a linear elastic treatment is appropriate. For this situation, the elastic strain (given by $\sigma / E$ where $\sigma$ is the nominal remote stress and $E$ is Young's modulus), the gage length strain, and the remote strain are a11 approximately the same except near the crack tip because linear elasticity holds throughout the specimen. Nominal stress is commonly used as the independent variable in linear elastic fracture mechanics [11]. In the linear elastic region it is clearly most convenient to regard nominal stress as the controlling parameter. Experimentally derived values of the applied stress intensity factor, $K$, are plotted against nominal stress in Fig. 3. The stress intensity factor data in this figure were calculated using measured J-integral values and the equation

$$
K=\sqrt{(J E)}
$$

The experimental data of Fig. 3 support the existence of the linear elastic regime; the stress intensity is proportional to the stress up to about $700 \mathrm{MPa}$, which is about $75 \%$ of the material yield strength. The experimentally measured $K$ values are in agreement with predicted values from linear elastic fracture mechanics within the experimental uncertainty. For the elastic strain region, linear elastic relationships between applied stress $\sigma$, and stress intensity factor, $K$, for several crack configurations may be used. These are conveniently collected in Ref. [11]. 
As the load is further increased, the plastic zone expands rapidly outward from the crack tip. As long as the plastic zone remains sufficiently small, nominal stress remains the appropriate J-controlling parameter [12]. This situation is termed contained yielding. Net Section Yielding

The HY-130 material used in the present study has very little strain hardening, so a definite limit load is reached when the remaining ligament adjacent to the crack yields. The plastic zone penetrates to a free boundary forming a deformation band (Fig. 1). Upon further imposed displacement, the load no longer increases but the J-integral continues to increase because the crack continues to open. A plot of experimentally measured J-integral values vs. stress, Fig. 4, illustrates this behavior. After yield, nominal stress is no longer the J-controlling variable because $J$ increases while stress remains constant. For relatively deep cracks, the remote strain becomes constant along with the nominal stress, because all the imposed deformation is transmitted to the deformation bands while the specimen ends move apart as rigid bodies. Therefore remote strain is also ineligible for consideration as the controlling parameter for $\mathrm{J}$ for this case. The gage length strain, that is, imposed displacement divided by some qacie lenath, increases with the J-intearal, but it depends on the gage lengich and so is not unique. The displacement, that is, the change of the gage length from its original value, increases along the width $\mathrm{J}$ and does not depend strongly on the choice of gage length, so it is a possible J-controlling variable for deep cracks. This choice is supported by relationships given by Rice, Paris, and Merk1e [13] for the J-integral in specimens with deep cracks; in these relationships, $J$ is proportional to the imposed displacement in tensile specimens: 


$$
J=-\frac{1}{B} \cdot \int_{0}^{V} d P / d a d V .
$$

where $V$ is imposed displacement at the load point, $P$ is the load, and a is crack length. This relationship applies for both elastic and plastic deformation. In plasticity, $P$ becomes the limit load. For the case of single-edge-cracked specimens pin-loaded in plane stress, the limit load is [14]

$$
P=\sigma_{f} W B\left\{\left[(1-a / W)^{2}+(a / W)^{2}\right]^{1 / 2}-a / W\right\}
$$

Here $\sigma_{f}$ is the flow stress and $W$ the specimen width. Applying (2), assuming no strain hardening, the plastic part of $\mathrm{J}$ is found:

$$
\left.J_{p}=\sigma_{f}\left\{\frac{1-2 a / W}{\left[(1-a / W)^{2}\right.}+(a / W)^{2}\right]^{1 / 2}+1\right\} v_{p},
$$

where $J_{p}$ is the part of $J$ associated with plastic deformation and $V_{p}$ is the total displacement less the elastic part. Using (4), the normalized rate of change of $J$ with imposed displacement, $M$, given by $M=\Delta J / \sigma_{y} \Delta V$, is

$$
M=\frac{1-2 a / W}{\left[(1-a / W)^{2}+(a / W)^{2}\right]^{1 / 2}}+1,
$$

This $M$ value is applicable for plastic strains. The flow stress for the limit load expression may be taken as the average of yield and ultimate strengths. This value is accurately known for HY-130 because its yield and ultimate strengths are nearly the same. Experimental data are shown in Fig. 5. In this figure, experimentally determined values of the quantity $M$ are plotted against normalized crack length. The net section yield theory prediction (5) is shown as a broken 1 ine. 
The noteworthy feature of this comparison is that the experimental data fall away from the theoretical predictions of a/W at values less than about 0.1. Similar behavior was previously observed for a C-Mn ship steel [9]. Equation 2 with conventional limit load expressions usually gives finite $J$ values at $a=0$. But a nonzero $J$ value is nonsensical in the abscence of a crack. Therefore, at some crack iength, J must deviate from the conventional predictions and approach zero as crack length approaches zero. The data fall approximately on a straight line through the origin, although the actual behavior is probably more complex. Using the slope of this line, $g$, dependence of $J$ on displacement in this short-crack net-section-yielding region, $\mathrm{J}_{\mathrm{sn}}$, can be described approximately by

$$
\Delta J_{s n}=g \quad a \quad \sigma_{f} \Delta V / W
$$

The full value of $J$ in this region is given by

$$
J=J e+g a \sigma_{f}\left(V^{\prime}-V_{e}\right) / W
$$

where $J_{e}$ and $v_{e}$ are the J-integral and displacement values at yield. From the data of Fig. 5, the constant g was evaluated to be about 15 .

An extension of the simple theory of Eq. 2, in which a term accounting for crack tip region constraint (CTRC) was added to the usual expression for applied load, was used previously to obtain a closer fit to the data in Fig. 5 [5].

In summary, in net section yielding for both long and short cracks, imposed displacement controls the applied J value. 


\section{Gross Section Yielding}

For very small crack lengths, the plastic strain is no longer concentrated by the crack tip in the remaining 1 igament but instead spreads throughout the whole specimen. The corresponding deformation pattern is gross section yielding. Strain is the controlling variable for the gross yielding region [15-17]. The transition from net section yielding to gross section yielding is illustrated in Fig. 6. This figure presents a plot of displacement contributed by strains associated with the crack (abbreviated crack-related displacement) against remote strain. The crack-related displacement is the total imposed displacement less the product of remote strain times gage length. Figure 6 shows that for the deeper cracks the remote strain remained constant as the crack-related displacement increased, as would be expected for net section yielding. But for the 1-mm crack the remote strain continued to increase and the crack-related displacement showed no steep rise at yield as in the net section yielding case, indicating that the entire specimen was yielding, behavior characteristic of gross section yielding. From this figure, it can be seen that the boundary between net section yielding and gross section yielding for the HY-130 material used in this study is located somewhere between the 1-mm crack and the 2-mm crack. It will be rounded off to $a / W=0.01$ for purposes of the next section. Figure 2 shows that the measured J-integral values for the 1- and 2-mm cracks were much less than for the longer cracks. This illustrates the fact that $\mathrm{J}$ for the net section yielding is much higher that for gross section yielding. Relationships between $J$ and strain for gross section yielding have been proposed previously [15-17]. These are in general agreement with one another but have not been critically evaluated in this study. 
It has been shown that the proper controlling parameters for $\mathrm{J}$ are stress, imposed displacement, and remote strain, and that each rules in a specific region of applied stress or strain and crack size; a behavior map depicting the location of these regions is shown as Fig. 7. Its ordinate is a logarithmic scale for normalized crack size, a/W. Its abcissa is normalized stress, $\sigma / \sigma_{y}$, up to $\sigma / \sigma_{y}=1$, and then it divides into separate scales for long and short cracks. For long cracks, the second part of the abcissa is displacement, and for short cracks, it is normalized remote strain, $\varepsilon_{\mathrm{rem}} / \varepsilon_{\mathrm{y}}$. For low nominal stresses, the deformation is linear elastic for all crack sizes. With increasing stress, specimens with long cracks yield first, and eventually as $\sigma / \sigma_{y} \rightarrow 1$ all specimens yield. The curve extending from the upper left corner of the graph down to $\sigma / \sigma_{y}=1, a / W \simeq 0$ is the boundary between linear elastic behavior and contained yielding. The nearly parallel curve forms the boundary between contained yielding and extensive yielding. Extensive yielding is divided by a horizontal line into gross section and net section yielding. Here this line has been placed at $a / W=0.01$. High strain hardening or yield elevation by constraint might raise this line. For small crack lengths (the gross section yielding region) the controlling parameter for $J$, namely, remote strain, is given on the lower abcissa. For larger cracks (net section yielding), the controlling parameter for $J$, namely displacement, is given on the upper abcissa. Within the net section yielding region, the short crack region is separated from the remainder by another horizontal line. Displacement is still the controlling 
parameter for this region, but the crack-size dependence is different. Deformation maps like this could be used to depict the effect of material, part geometry, or deformation type (for example, residual vs applied stress) on the formation of the different deformation patterns.

The large behavior difference observed between gross and net section yielding explains why one set of J-vs-displacement formulae, of the type given by Ref. [13], have been used in material toughness tests of deeply notched specimens, whereas an entirely different family of relationships between $J$ and strain has been proposed for application to structures [15-17]. Structures usually have small cracks, which produce gross section yielding, whereas test specimens are deeply cracked, producing net section yielding.

Further Research

The present results are, of course, not adequate for general, reliable application to decisions about cracks in real structures. The most needed experimental extension of the present work is to geometries that produce yield elevation by constraint and materials with different stress-strain behaviors; such work is in progress. The two most important outstanding issues are: (1) the location of the transition from net section yielding to gross section yielding, and, (2) the dependence of $\mathrm{J}$ on remote strain and crack length for gross section yielding. Analytical methods, such as finite element analysis, also need to be developed to allow explanation and, eventually, prediction of the occurence of the various deformation patterns and their effects on applied J-integral values [18]. 
The question of the applicability of conventionally measured fracture toughness values to the variety of deformation patterns described here is an interesting problem that arises once net and gross section yielding behaviors have been clearly differentiated. CONCLUSION

In this study, the variables controlling the applied J-integral in the linear elastic, contained yielding, net section yielding, and gross section yielding regions have been identified as stress, displacement, and remote strain, respectively. Experimental evidence in favor of the validity of existing relationships between $J$ and stress, $J$ and displacement, and $J$ and strain in their appropriate regions has been presented, and a new relationship between $J$ and displacement for the short crack net section yielding region has been derived from experimental results.

\section{ACKNOWLEDGMENT}

This report was prepared as part of the Fracture Control Technology Program under the sponsorship of Dr. H. H. Vanderveldt, Naval Sea Systems Command (SEA 05R15). The effort was directed by Mr. John P. Gudas, David Taylor Naval Ship R\&D Center, Under Program Element 62761N, Task Area SF-61-544-504.

Technical assistance by J. D. McColskey and helpful discussions with H. I. McHenry, R. B. King, and R. H. Dodds, Jr. are gratefully acknowledged. 


\section{REFERENCES}

1. J. R. Rice, "A Path Independent Integral and the Approximate Analysis of Strain Concentration by Notches and Cracks," Journal of Applied Mechanics 35, 1979, pp. 379-386.

2. J. A. Begley and J. D. Landes, "The J Integral as a Fracture Criterion," Fracture Toughness, ASTM STP 514, American Society for Testing and Materials, Philadelphia, 1972, pp. 1-20.

3. J. D. Landes and J. A. Begley, "The Effect of Specimen Geometry on JIC" "Fracture Toughness, ASTM STP 514, American Society for Testing and Materials, 1972, pp. 24-39.

4. W. A. Logsdon, "Elastic Plastic $\left(J_{I C}\right)$ Fracture Toughness Values: Their Experimental Determination and Comparison with Conventional Linear Elastic $\left(\mathrm{K}_{\mathrm{Ic}}\right.$ ) Fracture Toughness Values for Five Materials," Mechanics of Crack Growth, ASTM STP 560, American Society for Testing and Materials, 1976, pp. 43-60.

5. D. T. Read, "Direct Experimental Evaluation of the J Contour Integral," forthcoming.

6. V. Kumar, M. D. German, and C. F. Shih, "Estimation Technique for the Prediction of Elastic-Plastic Fracture of Structural Components of Nuclear Systems," General Electric Report SRD-80-094, 1980.

7. C. E. Turner, "Methods for Post-Yield Fracture Safety Assessment," Post-Yield Fracture Mechanics, edited by D. G. H. Latzko, Applied Science Publishers, London, 1979, pp. 23-210.

8. W. Soete and R. Denys, "Full and General Yield Behavior of Homogeneous Plates with Cracks," Proceedings of the International Institute of Welding Conference at Bratislava, Doc. X-927-79, 1979. 
9. D. T. Read and H. I. McHenry, "Strain Dependence of the J-Contour Integral in Tensile Panels," Advances in Fracture Research, edited by D. Francois, Pergamon, New York, 1981, pp. 1715-1722.

10. R. J. Bucci, P. C. Paris, J. D. Landes, and J. R. Rice, "J Integral Estimation Procedures," Fracture Toughness, ASTM STP 514, American Society for Testing and Materials, Philadelphia, 1972, pp. 40-69.

11. H. Tada, P. C. Paris, and G. R. Irwin, "The Stress Analysis of Cracks Handbook," Del Research Corporation, Hellertown, Pennsylvania, 1973.

12. G. R. Irwin and P. C. Paris, "Fundamental Aspects of Crack Growth and Fracture," in Fracture, An Advanced Treatise, Vol. III, edited by H. Liebowitz, Academic Press, New York, 1971, pp. 1-46.

13. J. R. Rice, P. C. Paris, and J. G. Merkle, "Some Further Results of J-Integral Analysis and Estimates," Progress in Flaw Growth and Fracture Toughness Testing, ASTM STP 536, American Society for Testing and Materials, Philadelphia, 1973, pp. 231-245.

14. G. G. Chel1, "Elastic-Plastic Fracture Mechanics," in Developments in Fracture Mechanics-1, edited by G. G. Che11, Applied Science, London, 1979, p. 76.

15. M. G. Dawes, "The COD Design Curve," in Advances in Elasto-Plastic Fracture Mechanics, edited by L. H. Larsson, Applied Science Publishers, 1980, London, pp. 279-300.

16. J. A. Begley, J. D. Landes, and W. K. Wilson, "An Estimation Model for the Application of the J-Integral," Fracture Analysis ASTM STP 560, American Society for Testing and Materials, Philadelphia, 1974, pp. 155-169. 
17. C. E. Turner, "Elastic-Plastic aspects of fracture stress analysis: methods for other than standardized test conditions," in Fracture Mechanics in Design and Service, Phi1. Trans. R. Soc. Lond. A299, 1981, pp. 73-92.

18. R. H. Dodds, Jr., D. T. Read, and G. W. Wellman, "Finite Elment and Experimental Evaluation of the J-Integral for Short Cracks," to be published in Proceedings of the 14th National Symposium on Fracture, Los Angeles, 1981, sponsored by the American Society for Testing and Materials. 


\section{YIELDING PATTERNS (no bending)}

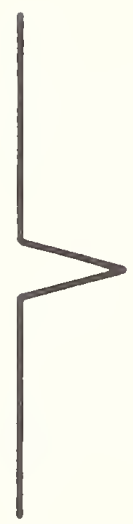

Elastic Strains Everywhere

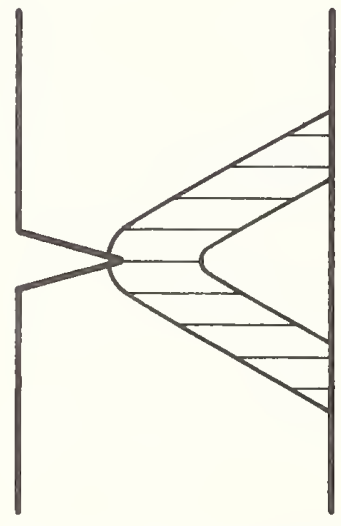

Net Section Yielding

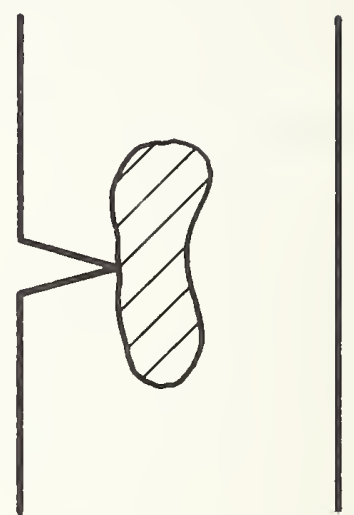

Yielding Confined to Crack Tip Region

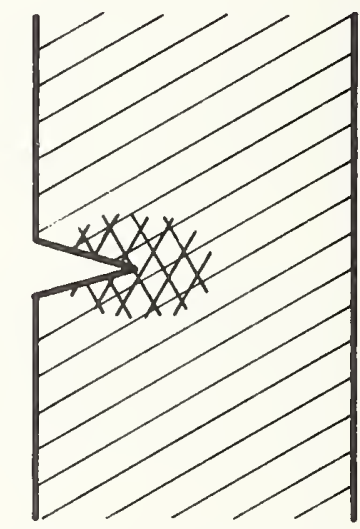

Gross Section Yielding

Figure 1. Deformation patterns. 


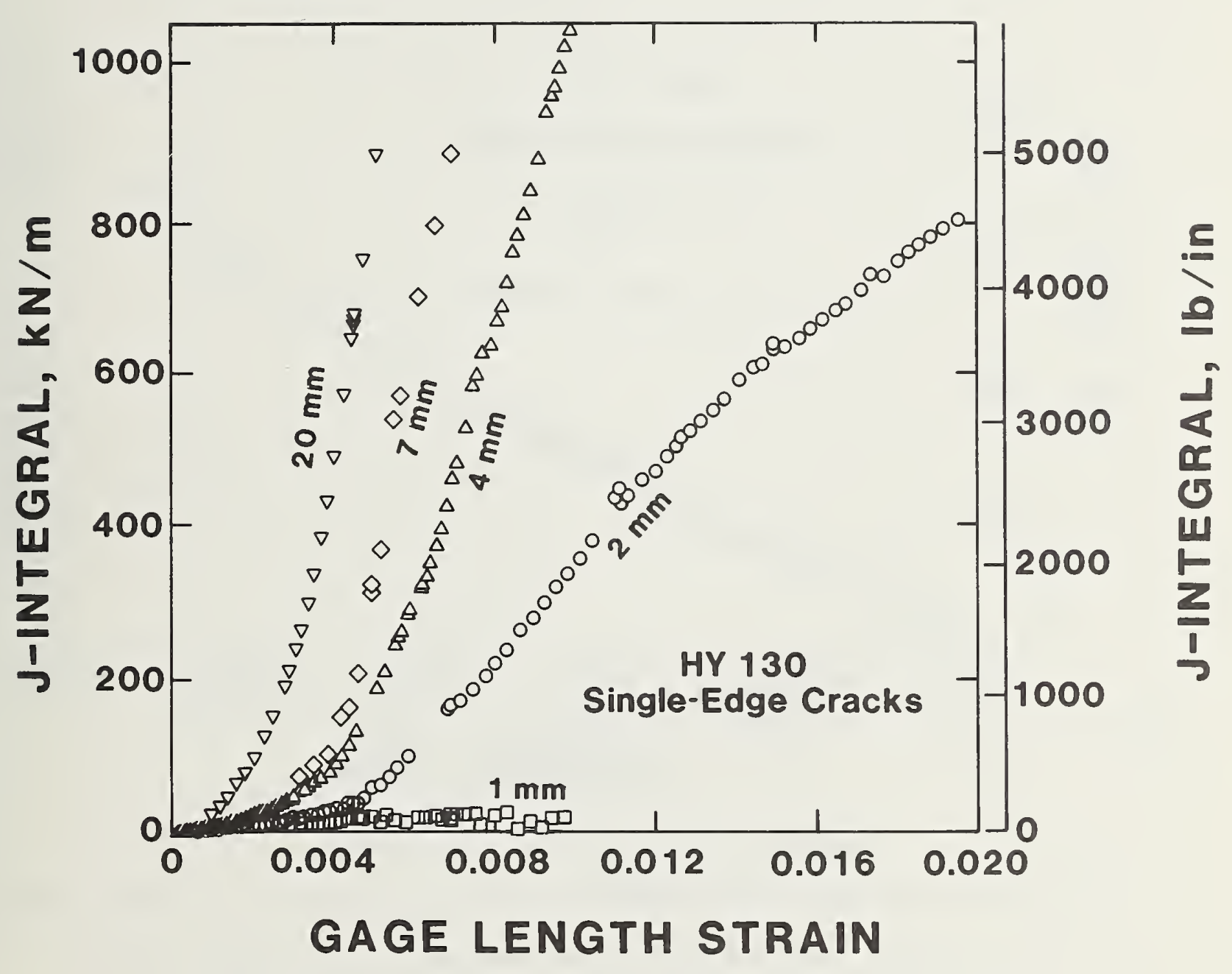

Figure 2. J-integral plotted against gage length strain for several crack lengths. 


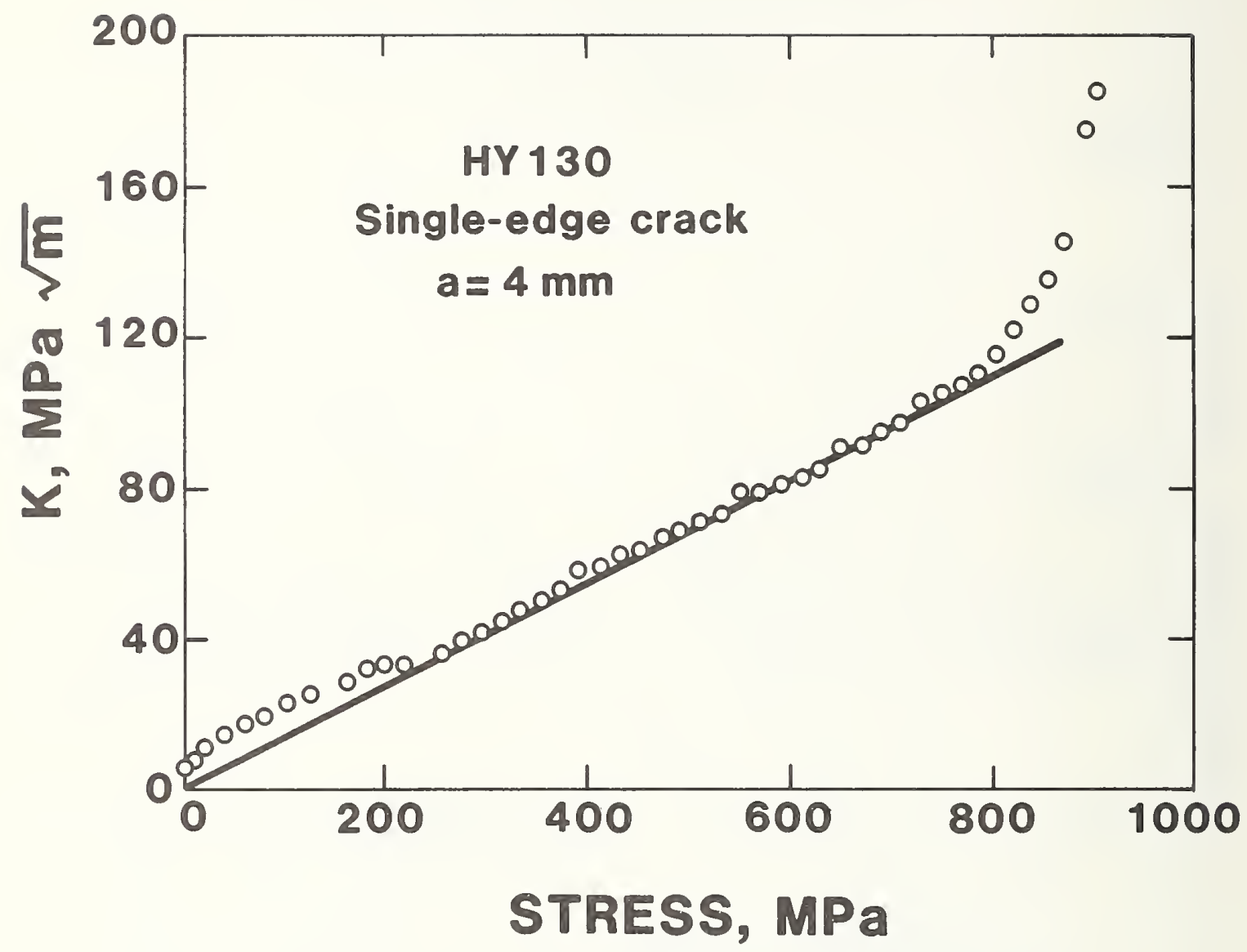

Figure 3. Measured stress intensity factor plotted against remote stress for a single-edge-cracked specimen with a 4-mm crack. 


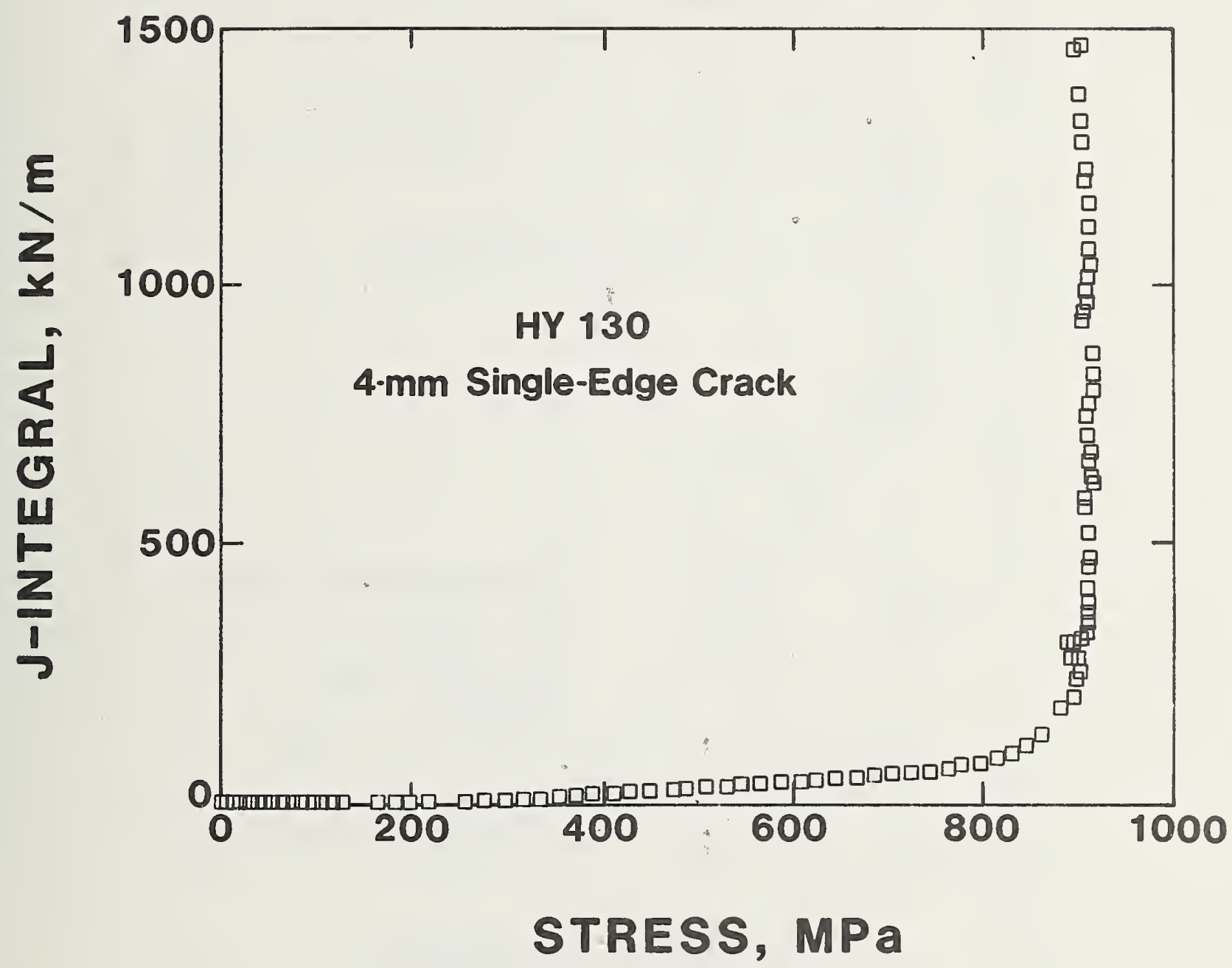

Figure 4. Measured J-integral plotted against remote stress for a single-edge-cracked specimen with a 4-mm crack. 


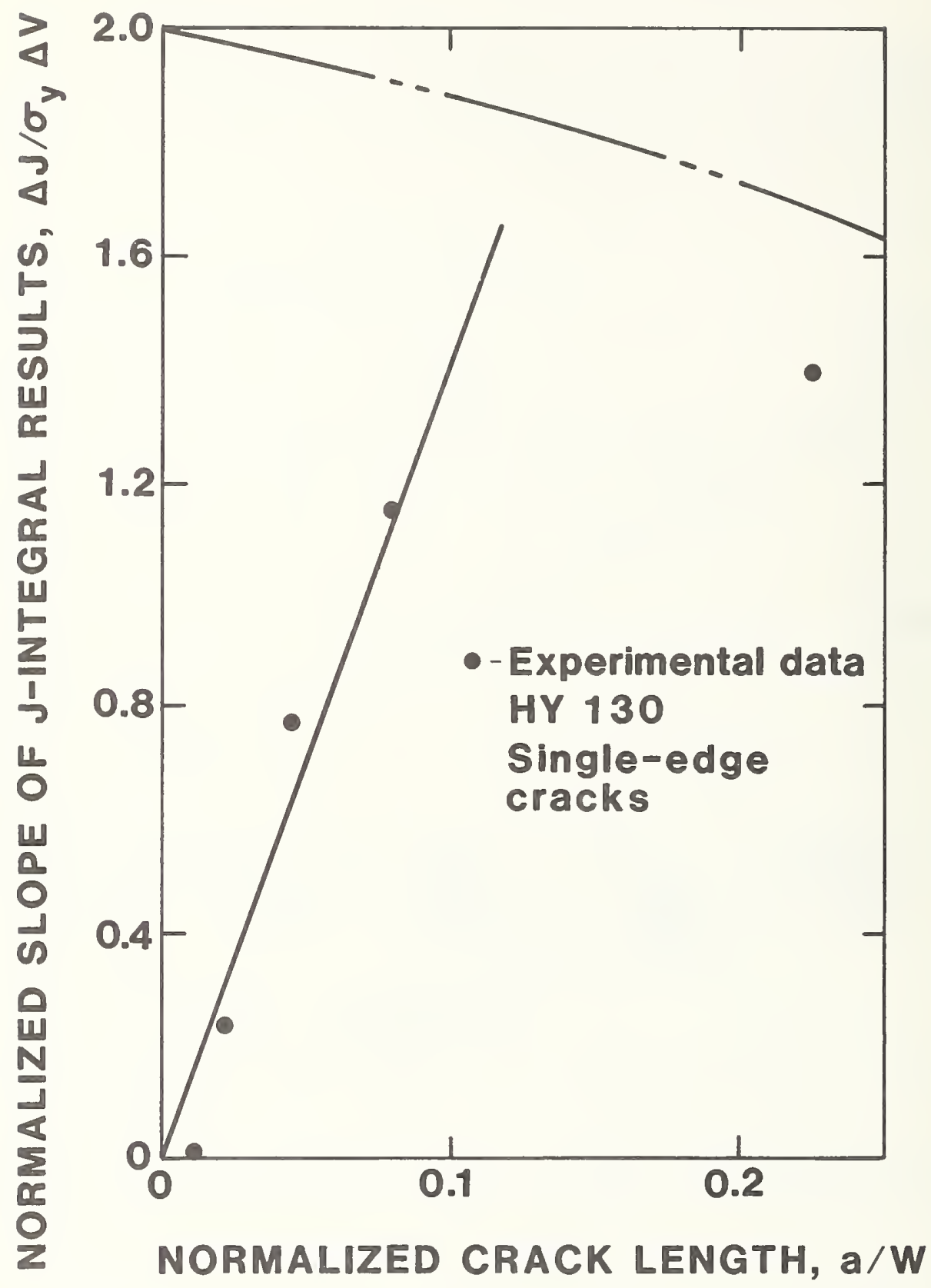

Figure 5. Net section yielding, theory and experiment. Normalized slopes of J-integral-vs.-displacement lines and experimental data. 


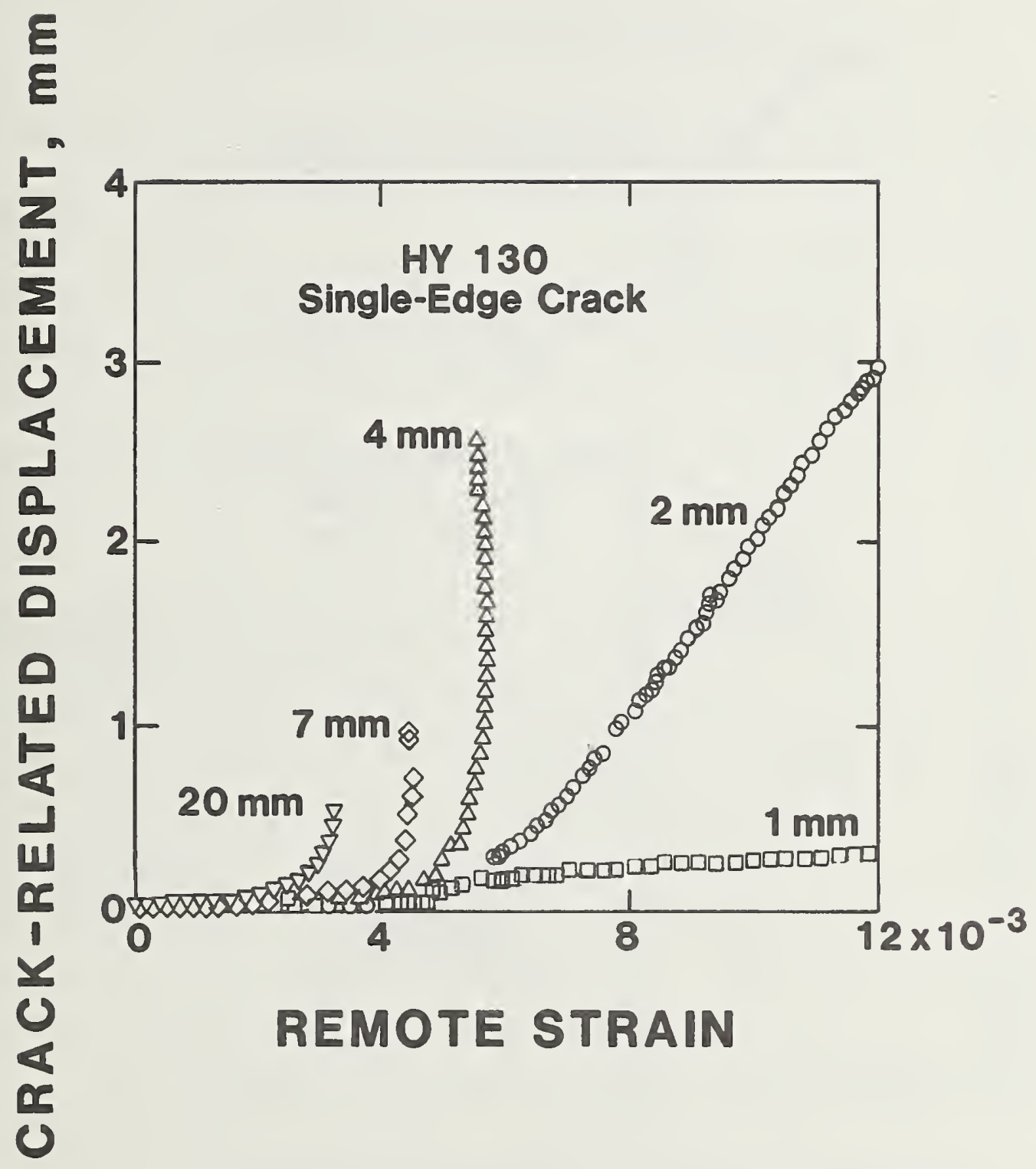

Figure 6. Displacement contributed by the strain field of the crack (crack-related displacement) plotted against remote strain. 


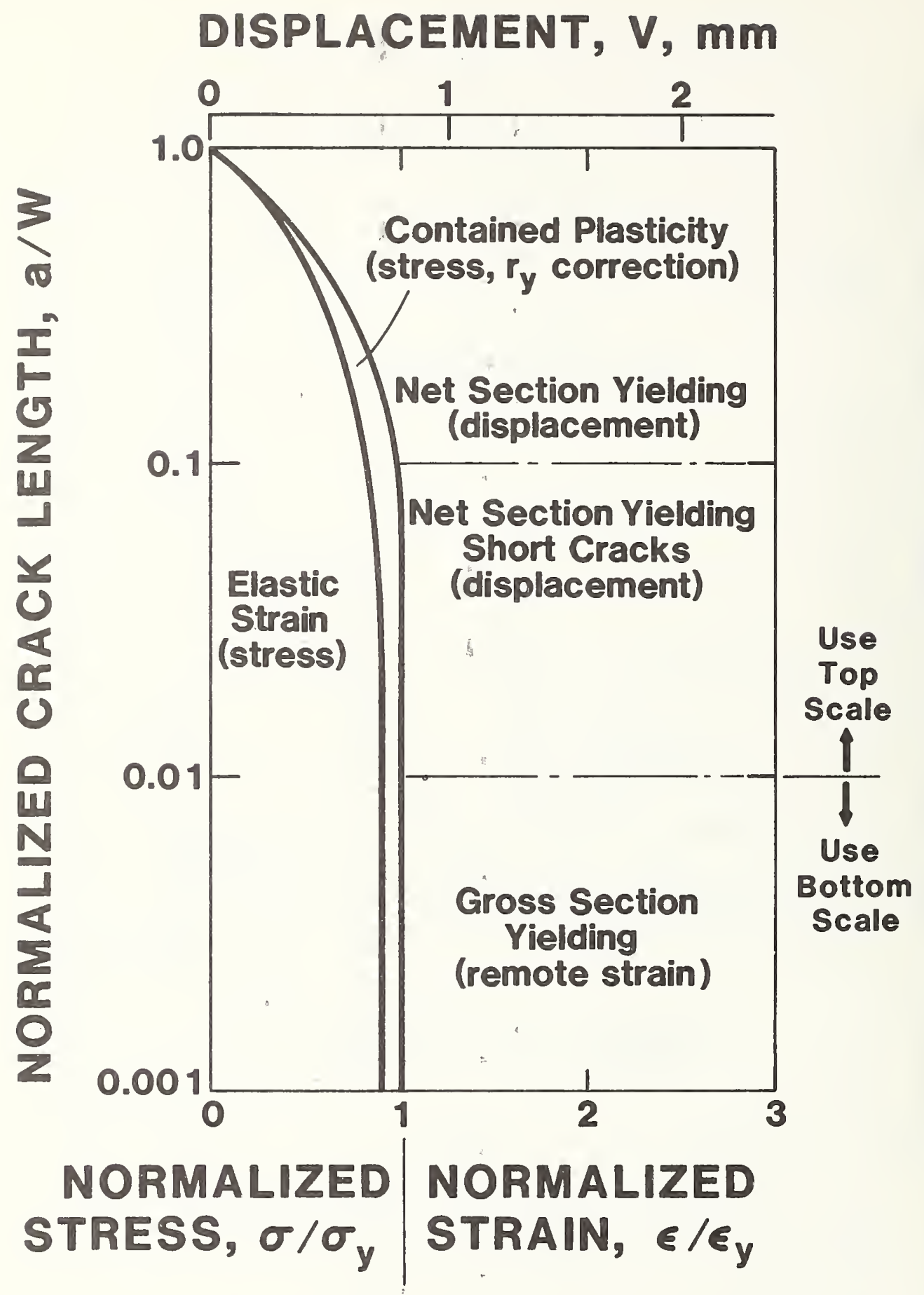

Figure 7. Deformation behavior map for tensile panels of HYl30 with cracks. 
NBS-114A (REV. 2-8C)

U.S. DEPT. OF COMM.

BIBLIOGRAPHIC DATA

SHEET (See instructions) 1. PUBLICATION OR
REPORT NO.

NBSIR 82-1670

August 1982

4. TITLE AND SUBTITLE

APPLIED J-INTEGRAL IN HY130 TENSILE PANELS AND IMPLICATIONS FOR FITNESS FOR SERVICE ASSESSMENT

5. AUTHOR(S)

D. T. Read

6. PERFORMING ORGANIZATION (If joint or other than NBS, see instructions)

7. ContracUGrant No.

NATIONAL BUREAU OF STANDARDS

DEPARTMENT OF COMMERCE

WASHINGTON, D.C. 20234

8. Type of Report \& Period Covered

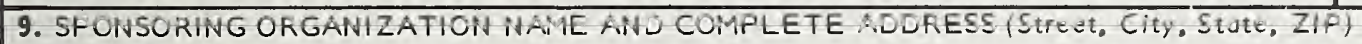

Naval Sea Systems Command

John P. Gudas, Project Monitor

Code DTNSRDC 2814

David Taylor Naval Ship R\&D Center

10. SUPPLEMENTARY NOTES

[D Document describes a computer program; SF-185, FIPS Software Summary, is attached.

11. ABSTRACT (A 200-word or less factual summary of most significant information. If document includes a significant bibliography or literature survey. mention it here)

An experimental technique for direct evaluation of the $\mathrm{J}$ contour integral is described. Results are reported and discussed. Some fifteen cracked HY130 tensile panels were tested, including center-cracked, single-edge-cracked, double-edgecracked, face-cracked, and part-through-cracked configurations. As crack size increased, the post-yield deformation pattern changed from gross section yielding, for very small cracks, to net section yielding, for larger cracks. Net section yielding was associated with much larger J-integral values than gross section yielding. The product of crack mouth opening displacement and yield strength was approximately equal to the J-integral for all cases in the tensile panel geometry used here. The implications of these results for fitness-for-service assessment of practical components and structures containing crack-like defects are discussed. Net section yielding behavior is intolerable in high-performance applications. Gross section yielding behavior can be treated using a J-integral estimation curve derived from the present experimental results. The scatter in the normalized gross section yielding contribution to $\mathrm{J}$ was high, approximately a factor of 2 . This scatter was attributed to specimen imperfections and experimental problems. The experimentally derived J-integral estimation curve of the present study fell at the top of the range of previously reported curves. Applications of this estimation curve to cases of residual stresses, stress concentrations, and surface cracks are briefly described.

12. KEY WORDS (Six to twelve entries; alphabetical order; capitalize only proper names; and separate key words by semicolons) crack; defect; fitness-for-service; fracture mechanics; gross section yielding; J-integral; net section yielding; surface crack; through crack.

13. AVAILABILITY

$[X]$ Unlimited

For Official Distribution. Do Not Release to NTIS

Order From Superintendent of Documents, U.S. Government Printing Office, Washington, D.C. 20402.

X] Order From National Technical Information Service (NTIS), Springfield, VA. 2216I
14. NO. OF

PRINTED PAGES

130

15. Price

$\$ 13.50$ 


\section{INSTRUCTIONS}

FORM NBS-114A: BIBLIOGRAPHIC DATA SHEET. This bibliographic data sheet meets the standards adopted for use by all U.S. Government agencies. It is needed for NTIS processing and must accompany all NBS papers, those appearing in nongovernmental media as well as those in NBS series, since all reports of NBS technical work are normally entered in to the NTIS system. For all GPO publications, it becomes an integral part of the document and is widely used by librarians and abstractors.

Items 1, 2 - Complete if information is available; otherwise Publications Office will complete Iater. If non-NBS publication, state "see item 10" (Enter other agency sponsor's report number if requested to do so, and enter NBSIR number under item 2).

Item 3 - Complete if known; otherwise Publications Office will complete.

Items 4,5 - Complete as shown on manuscript. When NBS-I /4A is resubmitted along with NBS-266, following publication of non-NBS media papers, these items must agree with published paper.

Item 6 - If not NBS, blank out and enter Grantee/Contractor name and address, o- if performed jointly, show both.

Item 7 - Complete when applicable.

Item 8 - Enter "Interim," "Final," or period covered.

Item 9 - Enter all sponsors' names and addresses. Include NBS if also a sponsor.

Item 10 - Enter other relevant information, i.e., related or superseded documents. Also used by Publications Office for Library of Congress catalog number, and entry of non-NBS media citation upon receipt of Form NBS-266 from author. Check block if appropriate and attach SFI85.

Item 11, 12 - Prepare abstract and key words with special care. These are published separately by NBS, NTIS, and other bibliographic services, and are vital elements in guiding readers to your paper. The key words will be used as entries in a subject index. See NBS Communications Manual for additional guidance.

Item 13 - Indicate "Unlimited" - for open-literature documents cleared under NBS editorial procedures, or "For official distribution. Do not release to NTIS" - for limited, restricted, or need-toknow material (See Communications Manual). Publications Office will mark appropriate "order" box and complete Stock Number when known.

Items 14, 15 -Leave blank. To be completed by Publications Office or call Printing and Duplicating for NBSIR's. 

